\author{
UNIVERSIDADE DE SÃO PAULO - USP \\ Escola De EngENHARIA De SÃo CARLOS - EESC \\ DePARTAMENTO De ENGENHARIA ElÉTRICA E DE COMPUTAÇÃO \\ Programa De PÓS-GRAdUAÇÃo EM ENGENHARIA ELÉTRICA
}

Ricardo de Oliveira Camargo Scarcelli

\title{
Afluências Agregadas na Programação Dinâmica Estocástica Aplicada ao Planejamento da Operação Energética
}



RICARDO DE OLIVEIRA CAMARGO SCARCELLI

\section{Afluências Agregadas na Programação Dinâmica Estocástica Aplicada ao Planejamento da Operação Energética}

Tese de doutorado apresentada ao Programa de Engenharia Elétrica da Escola de Engenharia de São Carlos, da Universidade de São Paulo, como parte dos requisitos para obtenção do título de Doutor em Ciências.

Área de Concentração: Sistemas Elétricos de Potência.

Orientador: Prof. Dr. Adriano Alber de França Mendes Carneiro.

São Carlos

2016 
AUTORIZO A REPRODUÇÃO E DIVULGAÇÃO TOTAL OU PARCIAL DESTE TRABALHO, POR QUALQUER MEIO CONVENCIONAL OU ELETRÔNICO, PARA FINS DE ESTUDO E PESQUISA, DESDE QUE CITADA A FONTE.

Ficha catalográfica preparada pela Seção de Tratamento da Informação do Serviço de Biblioteca - EESC/USP

\begin{tabular}{|c|c|}
\hline & Scarcelli, Ricardo de Oliveira Camargo \\
\hline \multirow[t]{3}{*}{$\mathrm{S} 285 \mathrm{a}$} & $\begin{array}{l}\text { Afluências Agregadas na Programação Dinâmica } \\
\text { Estocástica Aplicada ao Planejamento da Operação } \\
\text { Energética / Ricardo de Oliveira Camargo Scarcelli; } \\
\text { orientador Adriano Alber de França Mendes Carneiro. São } \\
\text { Carlos, 2016. }\end{array}$ \\
\hline & $\begin{array}{l}\text { Tese - doutorado (Programa de Pós-Graduação em Ciências } \\
\text { em Engenharia Elétrica e Área de Concentraço em Sistemas } \\
\text { Elétricos de Potência)-- Escola de Engenharia de São Carlos } \\
\text { da Universidade de São Paulo, } 2016 \text {. }\end{array}$ \\
\hline & $\begin{array}{l}\text { 1. Sistemas Hidrotérmicos. 2. Programação Dinâmica } \\
\text { Estocástica. 3. Afluências Agregadas. 4. Planejamento } \\
\text { Energético de Médio Prazo. I. Título. }\end{array}$ \\
\hline
\end{tabular}


Candidato: Engenheiro RICARDO DE OLIVEIRA CAMARGO SCARCELLI.

Título da tese: "Afluências agregadas na programação dinâmica estocástica aplicada ao planejamento da operação energética".

Data da defesa: 22/08/2016

Comissão Julgadora:

Resultado:

Prof. Associado Adriano Alber de França Mendes Carneiro (Orientador)

(Escola de Engenharia de São Carlos/EESC)

Prof. Dr. José Carlos de Melo Vieira Junior

APROVADO

(Escola de Engenharia de São Carlos/EESC)

Profa. Dra. Maíra Martins da Silva

APROVADO

(Escola de Engenharia de São Carlos/EESC)

Dr. André Luiz Diniz Souto Lima

APROVADO

(Centro de Pesquisas de Energia Elétrica/CEPEL)

Prof. Dr. Ruben Augusto Romero Lázaro

(Universidade Estadual Paulista "Júlio de Mesquita Filho"/UNESP - Ilha Solteira)

Coordenador do Programa de Pós-Graduação em Engenharia Elétrica: Prof. Associado Luis Fernando Costa Alberto

Presidente da Comissão de Pós-Graduação:

Prof. Associado Luis Fernando Costa Alberto 



\section{Dedicatória}

Aos meus familiares por todo o apoio. 



\section{Agradecimentos}

Em primeiro lugar agradeço a Deus por me ajudar na conclusão deste trabalho;

Agradeço aos meus familiares, pelo apoio incondicional durante todos os anos de minha vida, mesmo estando distantes. A minha esposa, Tatiana, por todo o carinho e amor;

Aos colegas de laboratório, de pós-graduação, e aos grandes amigos que fiz em São Carlos, em especial ao Daniel Motter, Thaís Kempner, Renato Monaro, Rafael Marsola e Rui Bertho, por todo o aprendizado, por toda a amizade, momentos de descontração e pelos cafezinhos do laboratório;

Aos colaboradores dessa tese, Prof. Dr. Secundino Soares Filho e Dra. Mônica de Souza Zambelli, por idealizar, orientar e corrigir este trabalho desde o início, sempre com dedicação, paciência, excelência e valiosas contribuições técnicas. Agradeço também por toda acessibilidade em relação a dúvidas e conversas, pelos conselhos e por toda amizade;

Ao meu orientador, Prof. Dr. Adriano Alber de França Mendes Carneiro, pelas oportunidades oferecidas e por me receber de braços abertos como seu orientado de doutorado;

Ao Laboratório de Sistemas de Energia Elétrica, ao Departamento de Engenharia Elétrica e de Computação, à Escola de Engenharia de São Carlos e à Universidade de São Paulo, por toda a infraestrutura a mim disponibilizada;

Aos funcionários do Departamento de Engenharia Elétrica e de Computação e da Escola de Engenharia de São Carlos, por toda a disponibilidade e pronto atendimento;

Por fim, agradeço ao Instituto Federal de São Paulo, campus São João da Boa Vista (IFSP/SBV) pela liberação parcial para a conclusão deste trabalho. 

"Descobrir consiste em olhar para o que todo mundo está vendo e pensar uma coisa diferente..."

Roger Von Oech. 



\section{Resumo}

\section{SCARCELli, R. O. C. Afluências Agregadas na Programação Dinâmica Estocástica}

Aplicada ao Planejamento da Operação Energética. 150 p. Tese de Doutorado - Escola de Engenharia de São Carlos, Universidade de São Paulo, São Carlos, 2016.

O planejamento da operação energética em sistemas hidrotérmicos de potência com um único reservatório tem como objetivo determinar a participação de usinas hidrelétricas e térmicas de forma a garantir o suprimento de energia demandada ao menor custo operacional possível, dentro de restrições físicas e técnicas do modelo. Alguns fatores tornam a solução deste problema bastante complexa destacando a não linearidade e a não separabilidade temporal aditiva. O objetivo deste trabalho é apresentar uma nova abordagem com tratamento agregado das afluências, descrevendo uma nova caracterização das distribuições de probabilidades e um novo modelo para a programação dinâmica estocástica markoviana. Nesse novo modelo da programação dinâmica estocástica markoviana, agregações plurimensais de vazões são utilizadas como entrada em um modelo de programação dinâmica estocástica markoviana modificado para discretizações temporais plurimensais. A nova abordagem proposta foi simulada em diferentes usinas hidrelétricas brasileiras localizadas em diferentes regiões geográficas e sob diferentes regimes hidrológicos. Os resultados das simulações feitas com a utilização deste novo modelo são apresentados e comparados ao modelo de programação dinâmica estocástica markoviana mensal, atualmente utilizado no setor elétrico brasileiro, com economia de custos relativas superiores a $10 \%$ em alguns casos.

Palavras-chave: Programação Dinâmica Estocástica, Afluências Agregadas, Usina Hidrelétrica e Usina Térmica. 



\begin{abstract}
SCARCELLI, R. O. C. Agregated Inflows for Stochastic Dynamic Programming applied to Energetic Operation Planning. 2014. 150 p. Dissertation (Master Degree) - São Carlos School of Engineering, University of São Paulo, São Carlos, 2014.

The energetic operation planning on hydrothermal power systems with a single reservoir aims to determine the participation of hydroelectric power plants and thermal power plants to guaranty supply of energy demanded with the smallest possible cost, under physical and technical model boundaries. Some points became the solution of this problem complex, highlighting the non linearity and the additive non time separability. The objective of this paper is show the new approach with aggregated inflows, describing a new probability distributions featuring and a new model for the markovian stochastic dynamic programming. On this new model of markovian stochastic dynamic programming, multi monthly inflow aggregations are used as input in a model of markovian stochastic dynamic programming modified for multi months discretizations. The new approach proposed was simulated on differents Brazilian hydroelectric power plants located on different regions and under different hydrologic regime. The results of simulations using this new model are presented and compared to the model of monthly markovian dynamic programming, nowadays used on the Brazilian electrical sector,ith relatives economic savings up to $10 \%$ in some cases.
\end{abstract}

Keywords: Stochastic Dynamic Programming, Aggregated Inflows, Hydroelectric Power Plant and Thermal Power Plant. 



\section{Lista de Figuras}

Figura 1 - Curvas normais de densidades de probabilidades de afluências, médias e desvios padrão para agregações de um mês (a), dois meses (b), três meses (c), quatro meses (d), seis

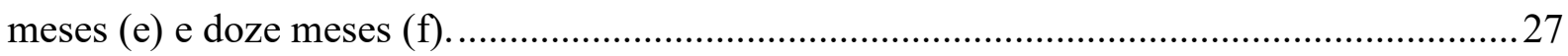

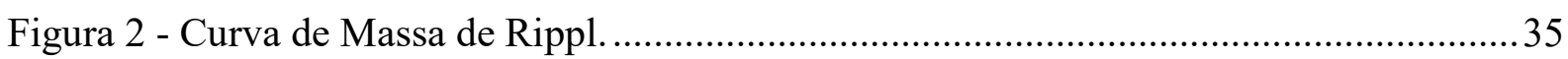

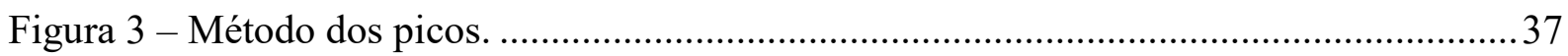

Figura 4 - Consequências das decisões do uso do reservatório sob possíveis afluências........39

Figura 5 - Função de custos presente, futuro e total para o Planejamento Energético. ............40

Figura 6 - Capacidade Instalada e custo de geração por usina térmica brasileira em 2013 [63].

Figura 7 - Custos de geração térmica reais e aproximados.................................................42

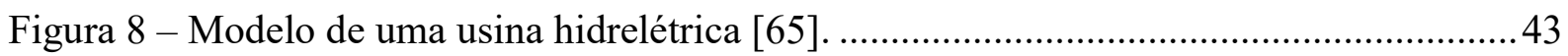

Figura 9 - Esquema de decisões da programação dinâmica com perfeita previsão.................49

Figura 10 - Fluxograma completo da Programação Dinâmica ...............................................50

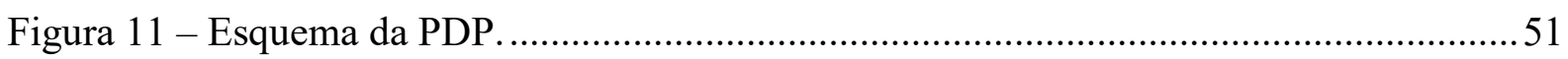

Figura 12 - Tabelas De Decisões da Programação Dinâmica do exemplo de PDP.................57

Figura 13 - Trajetórias ótimas de geração hidráulica e térmica e demanda requisitada..........58

Figura 14 - Trajetórias ótimas de volumes e afluências ocorridas..........................................58

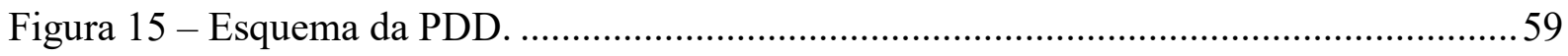

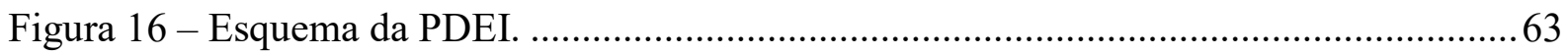

Figura 17 - Dados históricos de afluências, valores discretizados e estatísticas obtidas com a distribuição normal para a usina hidrelétrica de Furnas no mês de janeiro para a PDEI. 66

Figura 18 - Tabelas de decisões da programação dinâmica em forma gráfica para a usina de Serra da Mesa para o mês de dezembro. ........................................................................... 70

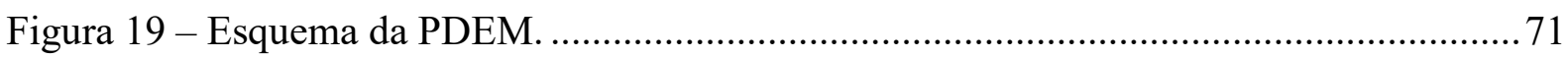

Figura 20 - Dados históricos de afluências, valores discretizados e estatísticas obtidas com a distribuição normal para a usina hidrelétrica de Furnas no mês de Janeiro para a PDEM. .....73 Figura 21 - Tabelas de decisões da PDEM em forma gráfica para a usina de Furnas para o mês de janeiro. 
Figura 22 - Densidades de probabilidades log-normal mensal independente (a), agregada anual independente (b), agregada anual dependente com base em Janeiro (c) e agregada anual dependente com base em Julho (d) para a usina hidrelétrica de Furnas.

Figura 23 - Correlações cruzadas com base nos 12 meses do ano e média em agregações mensais $(\mathrm{k} 1)$, bimestrais $(\mathrm{k} 2)$, trimestrais $(\mathrm{k} 3)$, quadrimestrais $(\mathrm{k} 4)$, semestrais $(\mathrm{k} 6)$ e anuais (k12) para as afluências da usina hidrelétrica de Furnas. 79

Figura 24 - Esquema do tratamento das vazões afluentes entre a PDEM mensal e a PDEM-k2.

Figura 25 - Coeficientes de variação com base nos 12 meses do ano e média em agregações mensais (k1), bimestrais $(\mathrm{k} 2)$, trimestrais $(\mathrm{k} 3)$, quadrimestrais $(\mathrm{k} 4)$, semestrais $(\mathrm{k} 6)$ e anuais (k12) para as afluências da usina hidrelétrica de Furnas. 82

Figura 26 - Fluxograma completo do modelo proposto (PDEM-k)........................................ 85

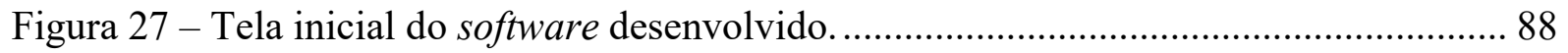

Figura 28 - Densidades de probabilidades log-normais para a usina hidrelétrica de Furnas com base no mês de Janeiro mensal (a), bimestral (b), trimestral (c), quadrimestral (d), semestral (e) e anual (f) e no mês de 91

Figura 29 - Tabelas de decisões de turbinagens para a usina hidrelétrica de Furnas para no mês de Janeiro mensal (a), bimestral (b), trimestral (c), quadrimestral (d), semestral (e) e anual (f) e para o mês de. 93

Figura 30 - Erros quadráticos médios percentuais a MLT das previsões com o modelo PAR-1 para os meses de Janeiro (a) e Julho (b) na usina hidrelétrica de Furnas. 95 Figura 31 - Volumes mensais armazenados na usina hidrelétrica de Furnas com as técnicas clássicas. 96

Figura 32 - Volumes mensais armazenados na usina hidrelétrica de Furnas com as técnicas propostas. 97

Figura 33 - Volumes armazenados médios mensais da usina hidrelétrica de Furnas. ............ 98

Figura 34 - Volumes médios mensais vertidos na usina hidrelétrica de Furnas. 99

Figura 35 - Gerações hidrelétricas médias para a usina hidrelétrica de Furnas. 100 Figura 36 - Curvas de permanência e de diferenças entre PDEM e PDEM-k12M da usina de Furnas. 101

Figura 37 - Curvas de permanência e de diferenças entre PDEM e PDEM-k12M das usinas hidrelétricas de Foz do Areia (a), Serra da Mesa (b) e Sobradinho (c). 103 Figura 38 - Volumes médios anuais armazenados na usina hidrelétrica de Furnas para os 5 anos de hidrologias menos favoráveis e para os 5 anos com hidrologias mais favoráveis. 105 
Figura 39 - Densidades de probabilidades log-normais para a usina hidrelétrica de Foz do Areia com base no mês de Janeiro mensal (a), bimestral (b), trimestral (c), quadrimestral (d), semestral (e) e anual (f) e no mês Julho mensal (g), bimestral (h), trimestral (i), quadrimestral (j), semestral (k) e anual (l). 128

Figura 40 - Densidades de probabilidades log-normais para a usina hidrelétrica de Serra da Mesa com base no mês de Janeiro mensal (a), bimestral (b), trimestral (c), quadrimestral (d), semestral (e) e anual (f) e no mês de Julho mensal (g), bimestral (h), trimestral (i), quadrimestral (j), semestral (k) e anual (l).

Figura 41 - Densidades de probabilidades log-normais para a usina hidrelétrica de Sobradinho com base no mês de Janeiro mensal (a), bimestral (b), trimestral (c), quadrimestral (d), semestral (e) e anual (f) e no mês de Julho mensal (g), bimestral (h), trimestral (i), quadrimestral (j), semestral (k) e anual (l).

Figura 42 - Tabelas de decisões de turbinagens para a usina hidrelétrica de Foz do Areia para no mês de Janeiro mensal (a), bimestral (b), trimestral (c), quadrimestral (d), semestral (e) e anual (f) e para o mês de Julho mensal (g), bimestral (h), trimestral (i), quadrimestral (j), semestral (k) e anual (l).

Figura 43 - Tabelas de decisões de turbinagens para a usina hidrelétrica de Serra da Mesa para no mês de Janeiro mensal (a), bimestral (b), trimestral (c), quadrimestral (d), semestral (e) e anual (f) e para o mês de Julho mensal (g), bimestral (h), trimestral (i), quadrimestral (j), semestral (k) e anual (l).

Figura 44 - Tabelas de decisões de turbinagens para a usina hidrelétrica de Sobradinho para no mês de Janeiro mensal (a), bimestral (b), trimestral (c), quadrimestral (d), semestral (e) e anual (f) e para o mês de Julho mensal (g), bimestral (h), trimestral (i), quadrimestral (j), semestral (k) e anual (1).

Figura 45 - Erros quadráticos médios percentuais a MLT das previsões com o modelo PAR-1 para os meses de Janeiro (a) e Julho (b) na usina hidrelétrica de Foz do Areia. 134 Figura 46 - Erros quadráticos médios percentuais a MLT das previsões com o modelo PAR-1 para os meses de Janeiro (a) e Julho (b) na usina hidrelétrica de Serra da Mesa. 135 Figura 47 - Erros quadráticos médios percentuais a MLT das previsões com o modelo PAR-1 para os meses de Janeiro (a) e Julho (b) na usina hidrelétrica de Sobradinho. Figura 48 - Volumes mensais armazenados na usina hidrelétrica de Foz do Areia com as técnicas clássicas (a) e com as técnicas propostas (b). Figura 49 - Volumes armazenados médios mensais da usina hidrelétrica de Foz do Areia... 138 
Figura 50 - Volumes mensais armazenados na usina hidrelétrica de Serra da Mesa com as técnicas clássicas (a) e com as técnicas propostas (b).

Figura 51 - Volumes armazenados médios mensais da usina hidrelétrica de Serra da Mesa. 140 Figura 52 - Volumes mensais armazenados na usina hidrelétrica de Sobradinho com as técnicas clássicas (a) e com as técnicas propostas (b). 141

Figura 53 - Volumes armazenados médios mensais da usina hidrelétrica de Sobradinho. ... 142 Figura 54 - Volumes médios mensais vertidos na usina hidrelétrica de Foz do Areia (a), Serra da Mesa (b) e Sobradinho (c) 143

Figura 55 - Gerações hidrelétricas médias na usina hidrelétrica de Foz do Areia (a), Serra da Mesa (b) e Sobradinho (c). 


\section{Lista de Tabelas}

Tabela 1 - Tabela de Programação Dinâmica para o mês 9 do exemplo de PDP.

Tabela 2 - Tabela de Decisões da Programação Dinâmica para o mês 9 do exemplo de PDP.

Tabela 3 - Tabela de Programação Dinâmica para o mês 8 do exemplo de PDP.

Tabela 4 - Tabela de Decisões da Programação Dinâmica para o mês 8 do exemplo de PDP.55

Tabela 5 - Tabela de Programação Dinâmica para o mês 1 do exemplo de PDP.

Tabela 6 - Tabela de Decisões da Programação Dinâmica para o mês 1 do exemplo de PDP.56

Tabela 7 - Tabela de Programação Dinâmica para o mês T do exemplo de PDD.

Tabela 8 - Tabela de Decisões da Programação Dinâmica para o mês T do exemplo de PDD.

Tabela 9 - Tabelas convergidas de Decisões da Programação Dinâmica do exemplo de PDD.

Tabela 10 - Dados de entradas de afluências, probabilidades e demanda. 67

Tabela 11 - Tabela de Programação Dinâmica para o mês T do exemplo de PDEI.

Tabela 12 - Tabela de Decisões da Programação Dinâmica para o mês T do exemplo de PDEI. .68

Tabela 13 - Tabela de Programação Dinâmica para o mês T-1 do exemplo de PDEI. 68

Tabela 14 - Tabelas convergidas de Decisões da Programação Dinâmica do exemplo de PDEI.

Tabela 15 - Afluências e probabilidades para o exemplo da PDEM. .73

Tabela 16 - Tabela de Programação Dinâmica para o mês T do exemplo de PDEM. 74

Tabela 17 - Tabelas convergidas de Decisões da Programação Dinâmica do exemplo de PDEM.

Tabela 18 - Limites operativos das usinas hidrelétricas simuladas.

Tabela 19 - Coeficientes dos polinômios cota volume, $\phi\left(x_{t}^{\text {med }}\right)$, e cota jusante, $\theta\left(u_{t}\right)$

Tabela 20 - Resultados médios comparativos para a usina hidrelétrica de Furnas - utilização da água em estatísticas de eficiência e produtividade. 106 
Tabela 21 - Resultados comparativos para a usina hidrelétrica de Furnas - custos e geração hidrelétrica.

Tabela 22 - Resultados comparativos entre as usinas hidrelétricas de Furnas, Foz do Areia, Serra da Mesa e Sobradinho com relação ao uso da água.

Tabela 23 - Resultados comparativos entre as usinas hidrelétricas de Furnas, Foz do Areia, Serra da Mesa e Sobradinho com relação a energia elétrica gerada e aos custos.

Tabela 24 - Resultados comparativos entre as usinas hidrelétricas de Furnas, Foz do Areia, Serra da Mesa e Sobradinho com relação aos custos comparativos

Tabela 25 - Resultados médios comparativos para a usina hidrelétrica de Foz do Areia utilização da água em estatísticas de eficiência e produtividade.

Tabela 26 - Resultados comparativos para a usina hidrelétrica de Foz do Areia - custos e geração hidrelétrica.

Tabela 27 - Resultados médios comparativos para a usina hidrelétrica de Serra da Mesa utilização da água em estatísticas de eficiência e produtividade.

Tabela 28 - Resultados comparativos para a usina hidrelétrica de Serra da Mesa - custos e geração hidrelétrica.

Tabela 29 - Resultados médios comparativos para a usina hidrelétrica de Sobradinho utilização da água em estatísticas de eficiência e produtividade.

Tabela 30 - Resultados comparativos para a usina hidrelétrica de Sobradinho - custos e geração hidrelétrica. 


\section{Lista Siglas}

ANEEL Agência Nacional de Energia Elétrica

CCEE Câmara de Comercialização de Energia Elétrica

CEPEL Centro de Pesquisas de Energia Elétrica

CLIA Curva Limite Inferior de Armazenamento

EPE Empresa de Pesquisa Energética

MLT Média de Longo Termo

NEWAVE Modelo Estratégico de Geração Hidrotérmica a Subsistemas Equivalentes

ONS Operador Nacional do Sistema

PD Programação Dinâmica

PDD Programação Dinâmica Determinística

PDEE Plano Decenal de Expansão de Energia

PDE Programação Dinâmica Estocástica

PDED Programação Dinâmica Estocástica Dual

PDEI Programação Dinâmica Independente

PDEM Programação Dinâmica Dependente Markoviana

PDEM-k2 Estocástico Dependente Bimestral

PDEM-k3 Estocástico Dependente Trimestral

PDEM-k4 Estocástico Dependente Quadrimestral

PDEM-k6 Estocástico Dependente Semestral

PDEM-k12 Estocástico Dependente Anual

PDI Programação Dinâmica Incremental

PDISA Programação Dinâmica Incremental com Sucessivas Aproximações

PDP Programação Dinâmica Perfeita

PDSA Programação Dinâmica com Sucessivas Aproximações

POE Planejamento da Operação Energética

POESH Planejamento da Operação Elétrica de Sistemas Hidrotérmicos 



\section{Sumário}

INTRODUÇÃ

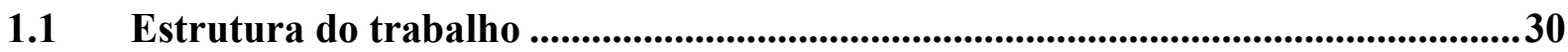

OPERAÇÃO DE RESERVATÓRIOS E SISTEMAS HIDROTÉRMICOS.....................33

2.1 Histórico da Utilização de Reservatórios ...............................................................33

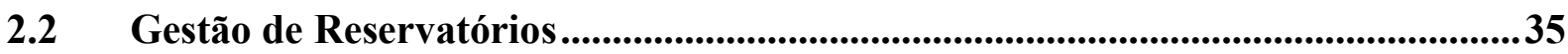

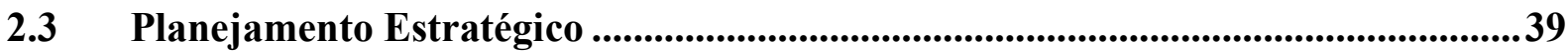

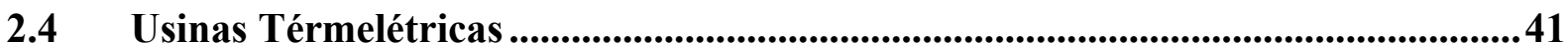

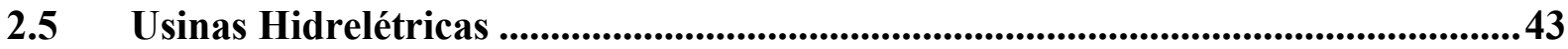

2.6 Modelagem do problema ….................................................................................................44

PROGRAMAÇÃO DINÂMICA E MODELO PROPOSTO ..........................................47

3.1 Programação Dinâmica - Definições.........................................................................47

3.2 Programação Dinâmica com Perfeita Previsão …...........................................................51

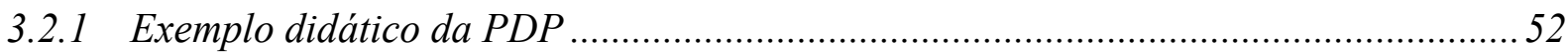

3.3 Programação Dinâmica Determinística ......................................................................58

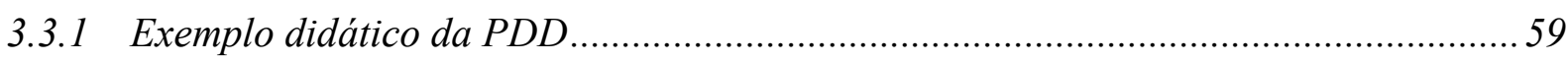

3.4 Programação Dinâmica Estocástica Independente ..............................................62

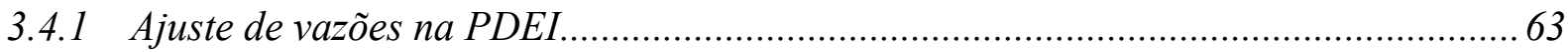

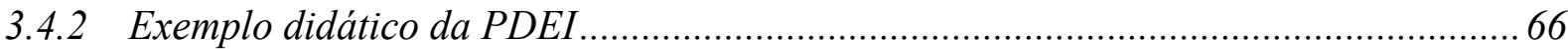


3.5 Programação Dinâmica Estocástica Dependente.................................................. 70

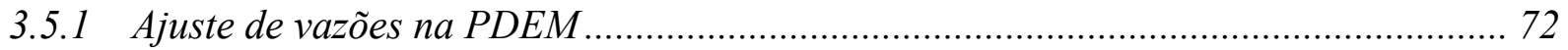

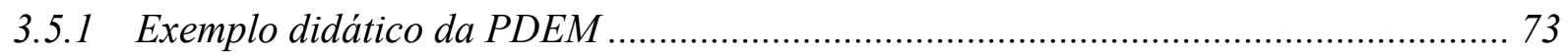

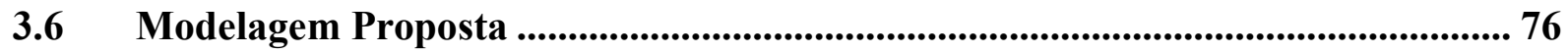

SIMULAÇÕES E COMPARAÇÃO DOS RESULTADOS ............................................. 87

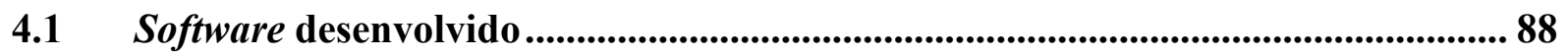

$4.2 \quad$ Dados operativos das usinas......................................................................................... 89

4.3 Curvas de distribuições de probabilidades ......................................................... 90

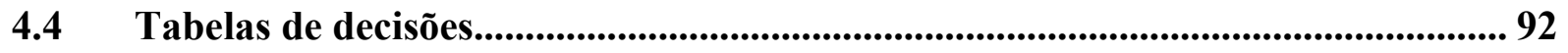

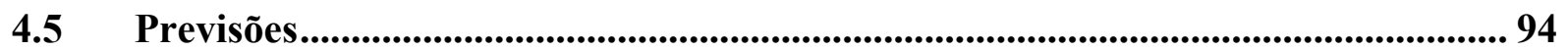

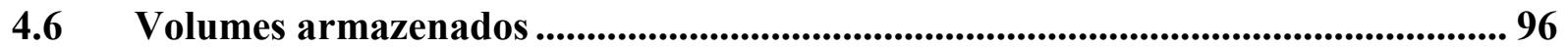

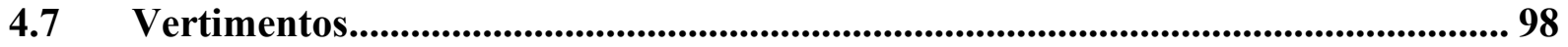

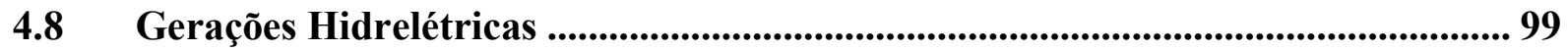

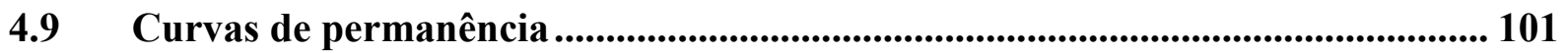

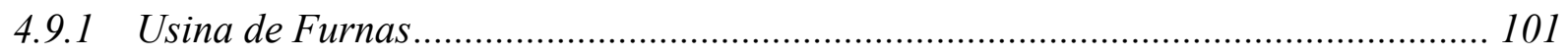

4.9.2 Usinas de Foz do Areia, Serra da Mesa e Sobradinho............................................... 103

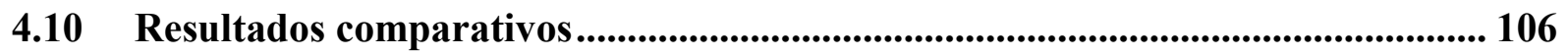

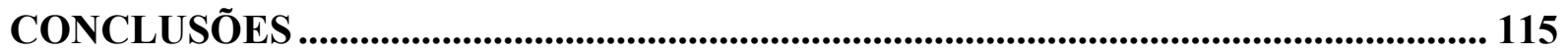

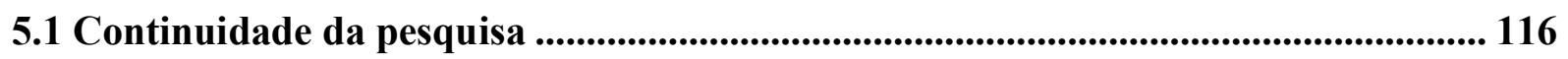

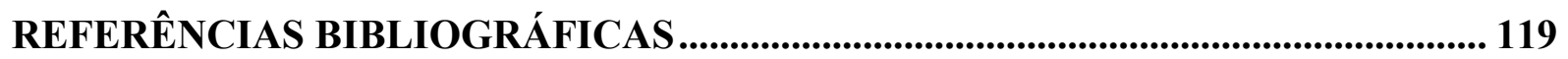

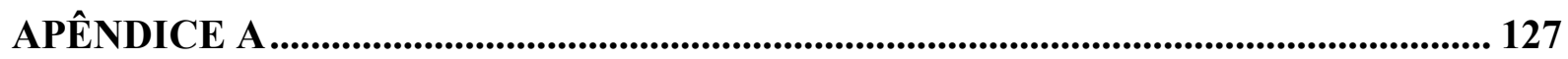




\section{Capítulo 1}

\section{Introdução}

O planejamento da operação energética (POE) é algo crucial para a definição de estratégias de desenvolvimento mundial. Esse planejamento deve considerar um fino e delicado ajuste de projeções econômicas e energéticas, levando em conta perspectivas de crescimento econômico, de geração e de consumo energético. Especificamente em termos elétricos, o POE define os patamares futuros de geração e consumo mais prováveis, tanto em horizontes de curtíssimo prazo quanto em horizontes de longo prazo.

No Brasil o documento que norteia decisões estratégicas de energia para os próximos anos é o Plano Decenal de Expansão de Energia (PDEE) [1], elaborado pela Empresa de Pesquisa Energética (EPE) [2], que reúne os principais dados referentes às estatísticas observadas e projeções de geração e de consumo de energia no Brasil para os próximos 10 anos.

Segundo o PDEE de 2014 o consumo final de energia elétrica no Brasil deverá saltar de aproximadamente 525,3 TWh em 2015 para mais de 790,9 TWh em 2024. A capacidade instalada de geração de energia elétrica por fontes hidráulicas passaria, segundo o PDEE de 2014, de $90 \mathrm{GW}$, em dezembro 2014, para $117 \mathrm{GW}$ em dezembro de 2024. Estes valores indicam uma projeção para 2024 de, aproximadamente, 56,7\% de geração de energia elétrica proveniente de fontes hidráulicas, sendo a parte complementar proveniente de outras fontes, sendo, aproximadamente, $16 \%$ de fontes termelétricas e $27,3 \%$ de outras fontes renováveis. Com isso pode-se definir a geração de energia elétrica no Brasil como sendo hidrotérmica, com participação majoritária de fontes hidrelétricas e complementação termelétrica. 
O planejamento da operação elétrica de sistemas hidrotérmicos (POESH) busca, assim como o POE, construir estratégias [3] [4]. Por se tratar de um sistema hidrotérmico, essas estratégias devem ser especificas para o suprimento de uma demanda elétrica específica em um sistema de geração de energia elétrica proveniente de fontes hidrelétricas e termelétricas. Estas estratégias devem, ainda, minimizar o custo esperado da geração de energia elétrica em um horizonte de até 5 anos.

Alguns fatores caracterizam o problema do POESH como complexo. Dentre eles podemos destacar a aleatoriedade das vazões afluentes nas usinas hidrelétricas, a aleatoriedade dos custos, relacionada ao combustível utilizado nas usinas termelétricas, as variações de demanda do mercado a ser atendido e a não-linearidade das funções de produção hidrelétrica $[5]$.

Outra dificuldade para a solução do POESH é o fato de que os reservatórios das usinas hidrelétricas têm limites de armazenamento. Com isso a decisão tomada em cada intervalo de tempo acarreta uma consequência no próximo intervalo de tempo tornando o problema não separável temporalmente.

O método da Programação Dinâmica Estocástica (PDE) é um método que consegue resolver o POESH considerando a estocasticidade presente. A PDE divide-se, basicamente, em variáveis temporais (estágios), variáveis de estado e variáveis de decisão. O problema é resolvido recursivamente, vindo de um estágio final com uma condição de estado prédeterminada, onde se define uma decisão ótima de cada estágio de acordo com o estado em que o sistema se encontra. O uso da PDE no POESH depende de algumas considerações. Dentre elas destaca-se a discretização das afluências por faixas, com probabilidades associadas para cada faixa.

O Princípio da Otimalidade garante que a otimalidade em cada estágio e para cada estado faz parte de um conjunto de decisões ótimas globais [6]. O principal entrave na execução da PDE para o POESH é a "maldição da dimensionalidade". O esforço computacional para soluções de POESH com a PDE aumenta exponencialmente a cada variável inserida no problema. Esse aumento no esforço computacional é significativo e torna a solução do problema inviável para mais de uma usina hidrelétrica com o uso dos atuais computadores comerciais disponíveis no mercado.

Deve-se notar que a PDE necessita, portanto, de três procedimentos para que possa encontrar a solução ótima do POESH: a discretização dos possíveis valores de armazenamento do reservatório (variáveis de estado), a discretização dos possíveis valores de turbinagem (variáveis de decisão) e os valores de afluências. Os valores das afluências, por serem incertos 
são modelados de forma estocástica e são dependentes da qualidade da estatística de tratamento destes dados.

No intuito de fazer uma avaliação mais detalhada destas afluências e de suas estatísticas associadas, alguns dados são mostrados abaixo.

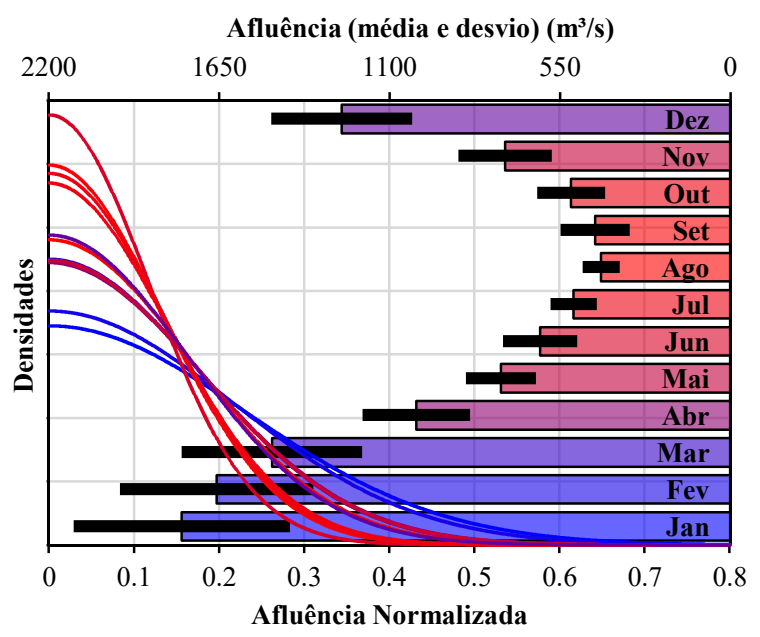

(a)

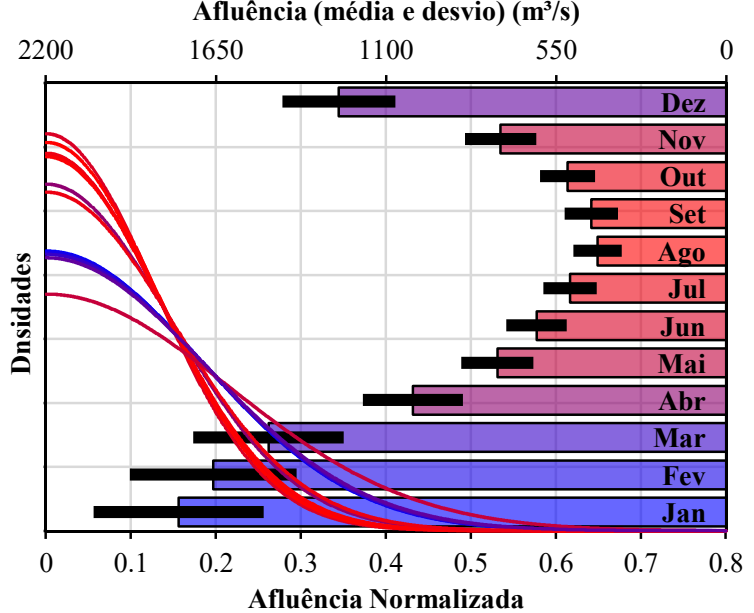

(c)

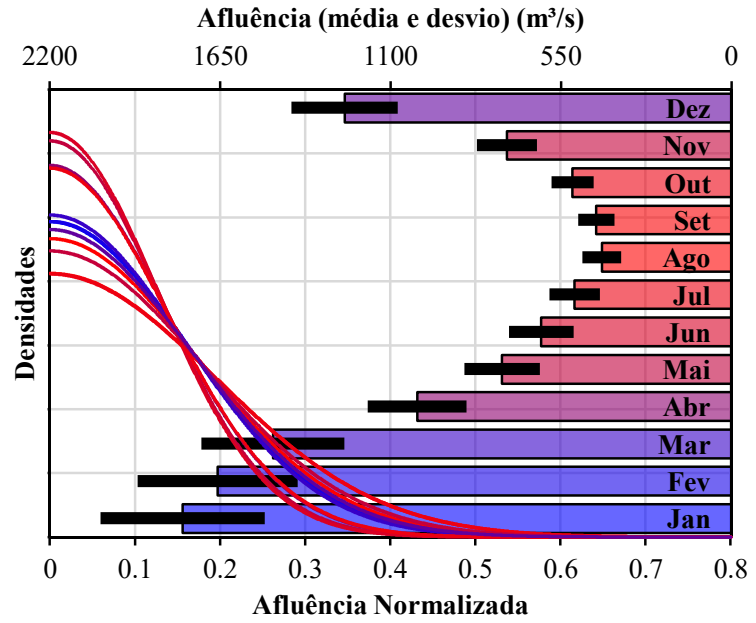

(e)

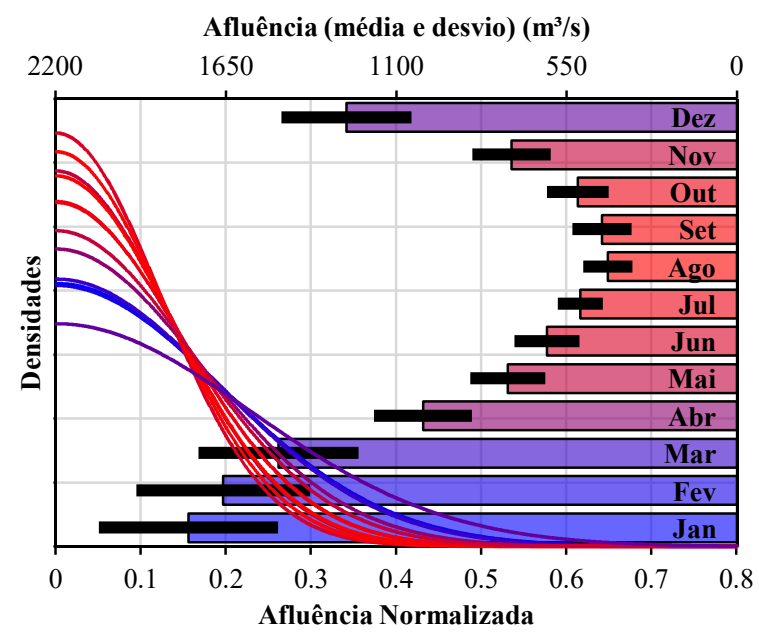

(b)

Afluência (média e desvio) $\left(\mathrm{m}^{3} / \mathrm{s}\right)$

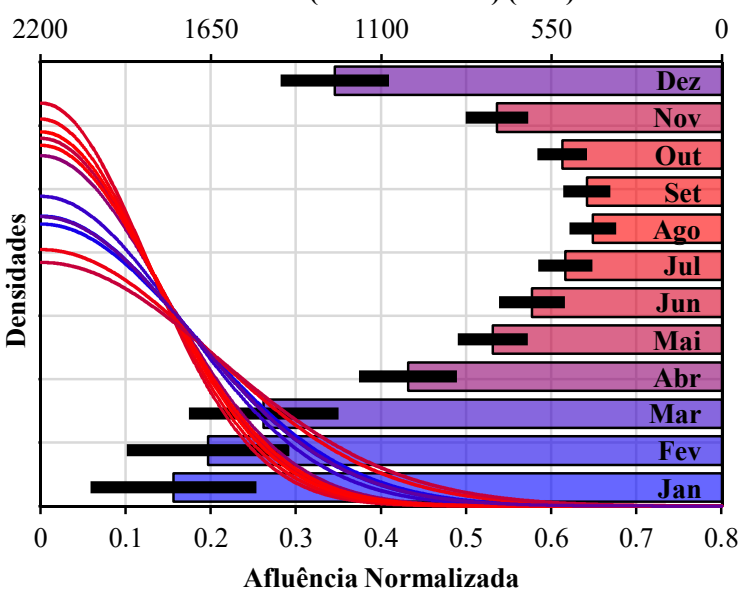

(d)

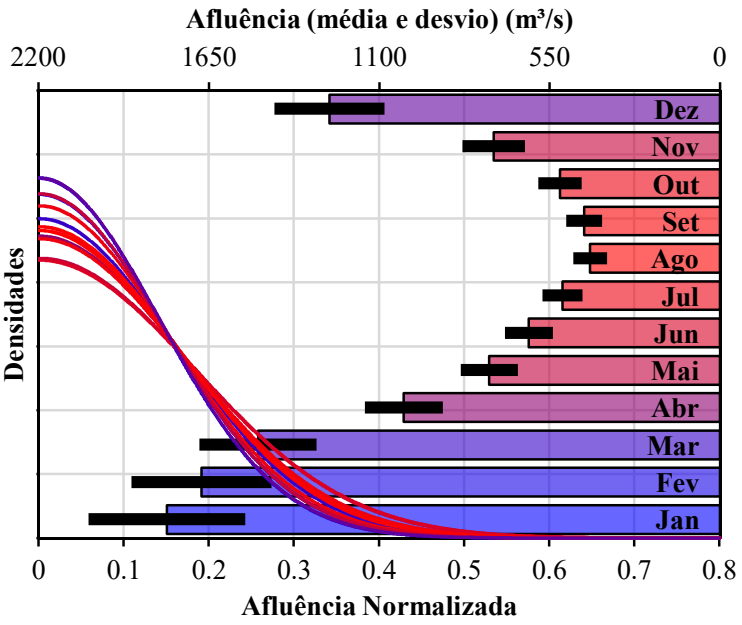

(f)

Figura 1 - Curvas normais de densidades de probabilidades de afluências, médias e desvios padrão para agregações de um mês (a), dois meses (b), três meses (c), quatro meses (d), seis meses (e) e doze meses (f). 
A Figura 1 mostra os efeitos da agregação de afluências mensais. São mostrados os valores das médias mensais (barras horizontais) e desvios padrões (barras pretas). As barras foram coloridas gradativamente entre vermelho e azul de acordo com o valor da afluência de cada mês, sendo o mês seco na tonalidade mais vermelha (agosto) e o mês mais úmido na tonalidade mais azul (janeiro). Além disso, as curvas à esquerda demonstram as distribuições normais de probabilidades para cada mês, normalizadas, seguindo o mesmo esquema de coloração das afluências médias.

A diferença entre as figuras está na quantidade de meses agrupados, 1, 2, 3, 4, 6, e 12, respectivamente. Para cada mês, no período entre 1931 e 2012, somaram-se meses à frente a fim de se obter o número de meses indicados anteriormente. Essa soma foi multiplicada pela porcentagem equivalente da média do referido mês com a média da referida soma. Como exemplo, as afluências de Janeiro e Fevereiro de 1931 foram 1476 m³/s e $2964 \mathrm{~m}^{3} / \mathrm{s}$, em uma média histórica de $1770,8 \mathrm{~m}^{3} / \mathrm{s}$ e 1658,54 m³/s, respectivamente. Com isso o valor histórico agregado de 2 meses para Janeiro de 1931 foi $2292,7 \mathrm{~m}^{3} / \mathrm{s}$. Esse mesmo processo foi executado para as 6 agregações.

Como resultado dessas agregações temos os mesmos valores médios de afluências para todos os meses. No entanto, os valores dos desvios padrões de cada mês diminuem com o aumento de meses agregados. A consequência direta disso são as diferenças entre as curvas de distribuições de probabilidades. O comportamento das curvas passa a ser parecido em todos os meses.

A característica mais interessante nesse aglomeramento de curvas é o fato de que o valor mais provável (mais a esquerda das curvas) dos meses mais secos (curvas avermelhadas) diminui, mas o valor mais provável (mais a esquerda das curvas) dos meses úmidos (curvas azuladas) aumenta. A princípio isso não faz diferença pois diminui-se a capacidade de previsão em alguns meses e aumenta-se em outros. No entanto essa informação é muito importante pois diminui o valor mais provável dos meses secos, com menores volumes de afluência mas aumenta o valor mais provável dos meses úmidos, com maiores volumes de afluências, melhorando, ao final do processo como um todo, o planejamento da geração de energia elétrica do sistema hidrotérmico.

Em [7] foi explorada a possibilidade de se trabalhar em horizontes de afluências agregadas. Foram executados estudos em uma usina hidrelétrica isolada em malha aberta e com previsores baseados em redes neurais que trabalhavam em horizontes anuais. Os resultados obtidos nas análises feitas foram muito promissores, com ganhos expressivos quando comparados os horizontes de previsões mensais e anuais. 
O objetivo deste trabalho é apresentar um novo método de tratamento das afluências na programação dinâmica estocástica para o planejamento da operação energética, com discretizações temporais plurimensais, aplicadas em sistemas com uma usina hidrelétrica. Serão apresentados diferentes métodos de modelagens de vazões e utilizações destas em modelos de PDE para usinas hidrelétricas isoladas, sendo eles:

Previsão Perfeita (PDP), apresentando uma resposta ótima global, sem interferência de erros de previsão;

Determinístico (PDD), onde a vazão afluente é assumida ser a média aritmética das vazões históricas;

Estocástico Independente (PDEI), onde as vazões são assumidas sem correlação temporal, tendo distribuições de probabilidades mensais independentes;

> Estocástico Dependente (PDEM), onde as vazões são assumidas com correlação temporal, tendo distribuições de probabilidades mensais dependentes, com o uso de um modelo Markoviano auto-regressivo de ordem 1;

Estocástico Dependente Bimestral (PDEM-k2), onde as vazões são assumidas com correlação temporal, tendo distribuições de probabilidades dependentes, com o uso de um modelo Markoviano auto-regressivo de ordem 1, como na PDEM, mas com discretizações temporais bimestrais diretas (PDEM-k2), mistas (PDEM-k2M) e com previsão perfeita (PDEM-k2P).

Estocástico Dependente Trimestral (PDEM-k3), onde as vazões são assumidas com correlação temporal, tendo distribuições de probabilidades dependentes, com o uso de um modelo Markoviano auto-regressivo de ordem 1, como na PDEM, mas com discretizações temporais trimestrais diretas (PDEM-k3), mistas (PDEM-k3M) e com previsão perfeita (PDEM-k3P).

Estocástico Dependente Quadrimestral (PDEM-k4), onde as vazões são assumidas com correlação temporal, tendo distribuições de probabilidades dependentes, com o uso de um modelo Markoviano auto-regressivo de ordem 1, como na PDEM, mas com 
discretizações temporais quadrimestrais diretas (PDEM-k4), mistas (PDEM-k4M) e com previsão perfeita (PDEM-k4P).

Estocástico Dependente Semestral (PDEM-k6), onde as vazões são assumidas com correlação temporal, tendo distribuições de probabilidades dependentes, com o uso de um modelo Markoviano auto-regressivo de ordem 1, como na PDEM, mas com discretizações temporais semestrais diretas (PDEM-k6), mistas (PDEM-k6M) e com previsão perfeita (PDEM-k6P).

Estocástico Dependente Anual (PDEM-k12), onde as vazões são assumidas com correlação temporal, tendo distribuições de probabilidades dependentes, com o uso de um modelo Markoviano auto-regressivo de ordem 1, como na PDEM, mas com discretizações temporais anuais diretas (PDEM-k12), mistas (PDEM-k12M) e com previsão perfeita (PDEM-k12P).

Os quatro primeiros métodos, PDP, PDD, PDEI e PDEM, são conhecidos e já foram muito discutidos e explorados [6], [8], [9], [10], [11] e [12]. Já as PDEM-k2, PDEM-k3, PDEMk4, PDEM-k6 e PDEM-k12 são as formulações propostas. As agregações diretas, mistas e com previsão perfeita serão explicadas e detalhadas na seção 3.6.

Serão apresentadas comparações entre os métodos a fim de se evidenciar as vantagens e diferenças nos resultados obtidos pelo novo método proposto. Essas comparações foram feitas através de simulações em diferentes usinas hidrelétricas brasileiras, localizadas em quatro regiões brasileiras, com características construtivas e sazonalidades de afluências singulares.

\subsection{Estrutura do trabalho}

O trabalho é dividido nos seguintes capítulos:

\section{Capítulo 2 - Operação de Reservatórios e Sistemas Hidrotérmicos: apresenta} um apanhado geral a respeito da operação de reservatórios de usinas hidrelétricas feita no mundo e, mais especificamente, no Brasil. Faz também uma descrição da modelagem dos sistemas hidrotérmicos. 
> Capítulo 3 - Programação Dinâmica e Modelo Proposto: descreve o processo de obtenção das probabilidades associadas às vazões discretizadas. Apresenta também o método da programação dinâmica, utilizado neste trabalho, e ilustra o método de discretização temporal plurimensal proposto.

Capítulo 4 - Simulações e Comparação dos Resultados: mostra o software desenvolvido e utilizado para a execução do trabalho. Exibe também comparações, por meio de gráficos e tabelas, entre os diferentes métodos da Programação Dinâmica e a formulação proposta.

Capítulo 5 - Conclusões: apresenta as conclusões do trabalho.

Referências Bibliográficas: lista as referências utilizadas nesse trabalho.

Apêndice A: mostra os resultados gráficos e tabelados completos das usinas hidrelétricas de Foz do Areia, Serra da Mesa e Sobradinho. 


\section{Capítulo 2}

\section{Operação de}

\section{Reservatórios e Sistemas}

\section{Hidrotérmicos}

Este capítulo apresentará uma visão geral de como funciona o planejamento energético de médio prazo, em especial, como no caso brasileiro, de cinco anos. Mostrará também a modelagem de sistemas hidrotérmicos para o planejamento energético.

\subsection{Histórico da Utilização de Reservatórios}

O primeiro reservatório de água de que se tem notícia construído pela humanidade é a represa Jawa, localizada na Jordânia, em uma região que fica a $100 \mathrm{~km}$ da atual capital, Amman. Estimativas afirmam que sua construção aconteceu por volta de 3000 a.C. e era utilizada para irrigação das plantações ao redor da antiga cidade de Jawa [13]. Tinha a função de conter as águas da chuva no inverno e distribuí-las por canais durante os períodos mais secos do ano. Feita em pedra basalto tinha uma profundidade máxima de 5 metros e estendia-se por 80 metros [14]. 
A partir desta data inúmeros relatos da construção de novos reservatórios em várias partes do mundo por várias civilizações foram ocorrendo, com a função de irrigar culturas e controlar enchentes. Os egípcios construíram seus primeiros reservatórios ao redor da cidade de Cairo, a partir de 2800 a.C. [15]. Por volta do ano 300 d.C. os indianos construíram um complexo com 16 reservatórios e canais de interligação. Chineses, Turcos e os povos da América pré-colombiana também construíram seus reservatórios.

Os romanos, com sua conhecida habilidade de engenharia, começaram a construir novos reservatórios com novas técnicas de construção e para novos usos. O uso do concreto romano proporcionou a construção de reservatórios bem maiores, e, consequentemente, o maior acúmulo de água. Além disso, eles criaram um sistema para distribuir essa água entre as casas passando todo o período seco, tendo armazenado a água do período chuvoso, com água suficiente para abastecer as casas das cidades atendidas por este sistema.

Também foram os romanos os responsáveis pelos primeiros usos da água como fonte geradora de energia. Eles usaram rodas d'água para levar água a casas e reservatórios situados em um nível mais elevado que o nível do reservatório base. Além disso, também usaram a força da água para movimentar moinhos.

Na Idade Média pouco se evoluiu no desenvolvimento de técnicas e na construção de novos reservatórios. A única inovação substancial foi feita na Holanda, no século XII. Os holandeses construíram barragens para controlar inundações dos rios e para aumentar sua área sobre as águas do oceano. Os nomes das cidades de Amsterdam e Rotterdam são provenientes desta época, da barragem de Amstel e do rio Rotter.

O grande avanço na construção de reservatórios ocorreu com a era industrial. A necessidade de maiores volumes de água nas indústrias e nas crescentes cidades impulsionou o desenvolvimento de novas técnicas e construção de maiores barragens para armazenamento de água.

A pioneira, na construção destes reservatórios maiores, foi a Inglaterra. Em 1804 os ingleses construíram Mir Alam Dam. Esse reservatório era, e continua até os dias atuais, responsável pelo abastecimento de água na cidade de Hyderabad com uma altura de 12 metros. Novas construções, cada vez maiores e com diferentes técnicas de construção, foram surgindo ao redor do mundo, crescendo em volume armazenado e altura, de acordo com as necessidades locais.

Dentre as técnicas de construção podemos citar as estruturas de concreto em arco, combinando pressão hidrostática e ação da gravidade, as estruturas com portões de aço, as estruturas feitas com aterros e as técnicas combinadas, utilizando mais de uma forma de 
construção. Cada técnica desenvolvida especificamente para diferentes regiões e necessidades locais.

Os usos desses reservatórios também se diversificaram bastante nos últimos 200 anos. Além do consumo de água e da utilização para irrigação e controle de cheias podemos também citar o uso para transporte, lazer, criação de peixes e, principalmente, geração de energia elétrica.

\subsection{Gestão de Reservatórios}

O primeiro trabalho que buscava fazer a gestão do uso de reservatórios de água foi desenvolvido por Rippl, em 1883 [16]. Ele desenvolveu um método que estimava o tamanho do reservatório necessário para manter uma determinada vazão em um determinado rio. $\mathrm{O}$ método baseava-se nas curvas de vazões médias e demandas acumulativas.

O método de Rippl, também conhecido como balanço de massa, utilizava vazões médias e fazia o cálculo do balanço de massa, subtraindo os valores da demanda média desejada. Com isso obtinha-se o tamanho do reservatório necessário para um eficiente processo de esvaziamento parcial ou total no período seco e enchimento total no período úmido. A Figura 2, mostrada a seguir, apresenta, de forma gráfica, o método de Rippl.

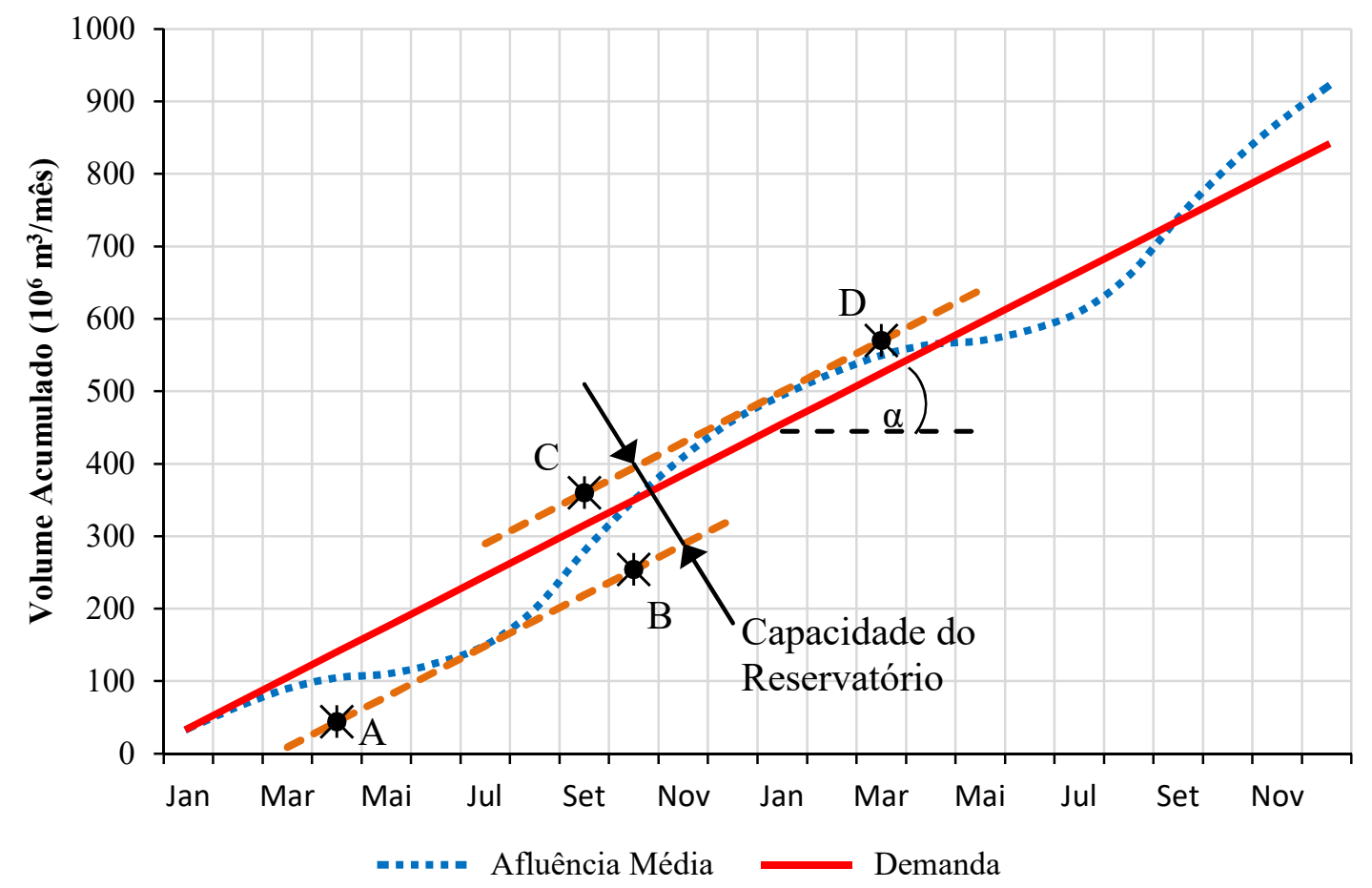

Figura 2 - Curva de Massa de Rippl. 
Na Figura 2 são mostradas as curvas da afluência média mensal e da demanda acumulada requerida, em um exemplo hipotético. Deve-se notar que a afluência acumulada, no final de um ciclo anual é superior à demanda acumulada. Além disso, o reservatório deve ser considerado completamente preenchido em qualquer ponto onde haja o cruzamento das curvas de afluência e de demanda.

Para obter-se o tamanho necessário ao reservatório deve-se, de posse do gráfico da Figura 2, traçar duas retas, paralelas a curva da demanda e tangentes a curva da afluência média, nos pontos de maior e menos afluências, mostradas no gráfico como a reta entre os pontos A e $\mathrm{B}$ e $\mathrm{C}$ e $\mathrm{D}$, respectivamente. $\mathrm{O}$ valor entre as retas paralelas é o valor do volume mínimo necessário ao reservatório.

A demanda mensal não acumulada é representada no gráfico pelo ângulo $\alpha$. O valor da tangente do ângulo $\alpha$ é a taxa de variação da demanda pela variação do tempo. Deve-se salientar que em casos onde a curva de demanda tem seus valores inferiores a curva de afluência, nunca ultrapassando seus valores, implica na não necessidade de construção de um reservatório pois somente a afluência é capaz de suprir a demanda, sem uso de um reservatório para acumulação. Em contrapartida, em casos onde a curva de demanda tem seus valores superiores a curva de afluência, a construção de um reservatório de acumulação de qualquer tamanho é insuficiente para a manutenção da desejada demanda.

Mesmo depois de cem anos o trabalho de Rippl ainda é reconhecido. O engenheiro indiano Sharma descreveu em seu livro o método de Rippl como sendo o melhor método para fixar a capacidade de um reservatório [17].

Com o passar do tempo novos aprimoramentos e usos do método de Rippl foram surgindo. Um deles foi traçar o mesmo gráfico com as afluências históricas acumuladas. Com isso se conseguia encontrar uma curva de demanda mais específica, fazendo-se um uso melhor das afluências de um determinado rio.

O método dos picos considera um maior volume de dados de afluências, diferentemente do método de Rippl, que considera apenas valores médios. A maior diferença entre os métodos é esta. Enquanto o método de Rippl trabalha com uma pequena quantidade de dados, o método dos picos trabalha com um grande volume de dados históricos.

A definição do tamanho do reservatório feita pelo método dos picos é generalizada. Ela estabelece, frente a uma quantidade significativa de dados de afluências, o tamanho do reservatório capaz de regularizar as afluências em que está inserido. Deve-se, portanto, obter uma série de dados de afluências históricas. A diferença entre o maior valor registrado e o 
menor valor registrado será o valor a ser considerado para se definir o tamanho do reservatório necessário para regularização destas afluências. A Figura 3, mostrada a seguir, ilustra o processo de obtenção do tamanho do reservatório com o uso do método dos picos.

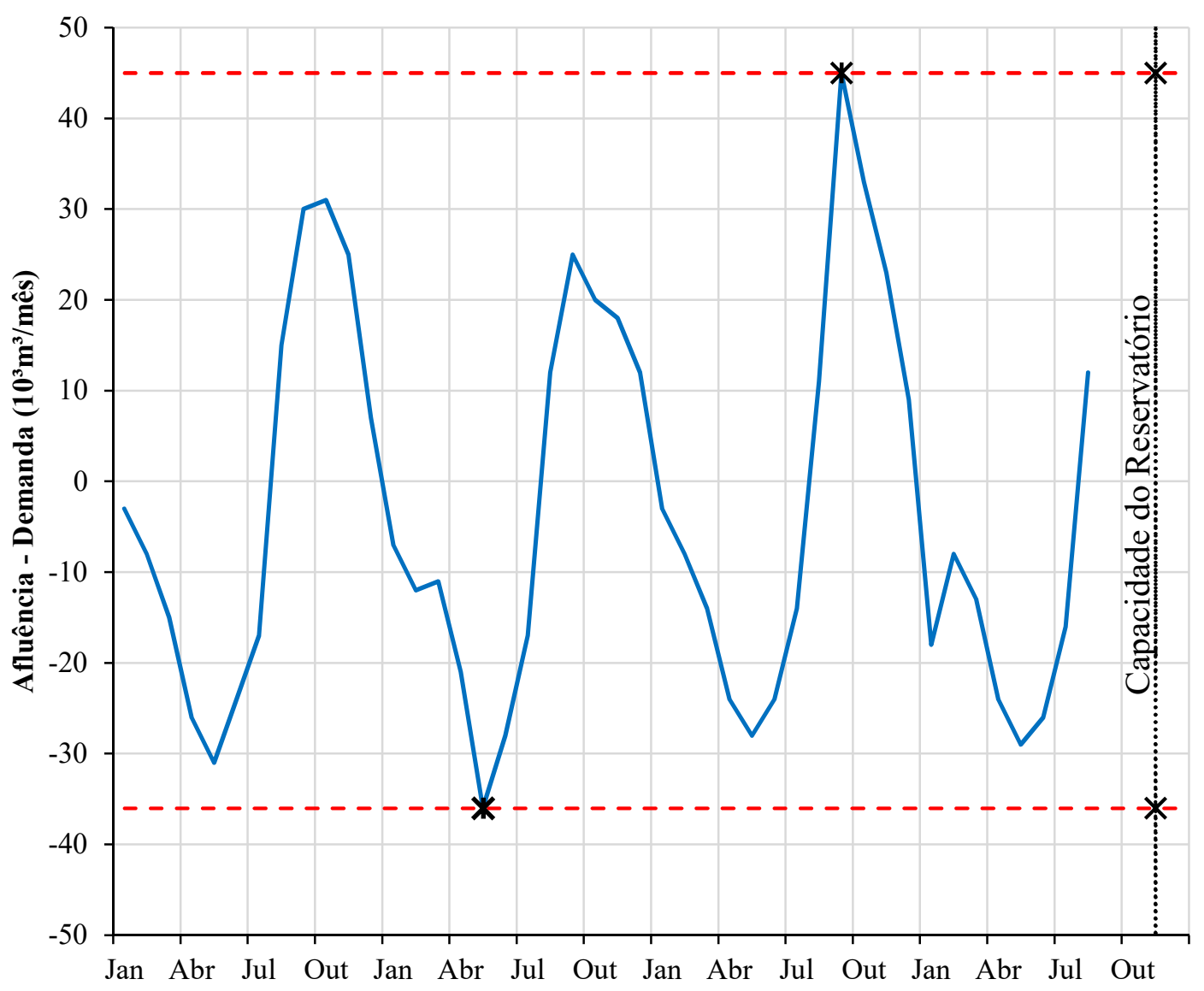

Figura 3 - Método dos picos.

O método de Rippl foi utilizado por muitos anos, em uma espécie de "regra", onde o reservatório deveria seguir padrões médios de armazenamento em cada período, seguindo uma curva pré-determinada [18]. Este método foi considerado pouco efetivo pois considerava uma regra obtida com uma afluência média. Consequentemente o reservatório liberava água quando o armazenamento do reservatório ultrapassava o limite especificado pela curva regra e, por outro lado, esperava por chuvas quando o armazenamento do reservatório ficava abaixo da curva regra [19].

Finalmente, na década de 1940, surgiram os primeiros trabalhos que originaram os métodos utilizados atualmente. Segundo Puterman, [20], o trabalho pioneiro envolvendo decisões sequenciais foi feito por Pierre Massé, em 1946, posteriormente traduzido do francês para o inglês [21]. Outro precursor dos atuais estudos em decisões sequenciais foi Wald, com a publicação, após a II Guerra Mundial, de seu livro sobre análise sequencial [22]. 
A popularização dos métodos de decisões sequenciais ocorreu com as publicações dos livros de Bellman [6] e Howard [23] que introduziram e formalizaram o conceito das decisões sequenciais no final da década de 1950 [24]. As decisões sequenciais passaram a ser conhecidas como programação dinâmica (PD). O grande entrave para a execução da PD é a "maldição da dimensionalidade" a qual aumenta exponencialmente o esforço computacional com o aumento do número de estados do sistema [25].

Em 1967 e 1968 foram publicados os primeiros trabalhos [26] e [27], respectivemente, que utilizavam a PD para determinação de regras de operação de um reservatório com afluências determinísticas (PDD). A partir destes trabalhos muitos outros surgiram, acrescentando cada vez mais detalhes na implementação da programação dinâmica. Dentre estas implementações podemos citar a Programação Dinâmica Incremental (PDI) [28] e [29], a Programação Dinâmica com Sucessivas Aproximações (PDSA) [30] e [31], a Programação Dinâmica Incremental com Sucessivas Aproximações (PDISA) [32] e [33] além de técnicas que fazem alterações e combinações das técnicas descritas anteriormente, [34], [35], [36] e [37].

Os primeiros estudos a respeito da operação estocástica de reservatórios são do início do século XX [38], seguidos por [39], onde foram considerados os usos de reservatórios associados a aquíferos. Em 1962, Bertsekas [8] formalizou os conceitos de incertezas a programação dinâmica. A programação dinâmica estocástica (PDE) é uma política de controle de malha fechada e determina decisões, para cada estado do sistema, em cada estágio do planejamento. Esta técnica tem a capacidade de trabalhar com a não linearidade do sistema e a estocasticidade. Tem, assim como na PDD, o problema da "maldição da dimensionalidade" pois o esforço computacional aumenta exponencialmente com o número de variáveis do problema.

Loucks [40] foi pioneiro nos estudos de PDE, considerando afluências passadas como sendo variáveis de estado do sistema. Com base nestes trabalhos e idéias, novas aplicações e utilizações foram propostas. Sistemas hidrotérmicos maiores foram simulados através de pocessos de agregação e desagregação [41], [42] e [43]. Foram também utilizadas interpolações do tipo "spline" cúbica para se fazer aproximações das funções de custos [44]. Com as melhorias nas performances dos computadores muitas idéias puderam ser praticadas e simuladas. Dentre elas podemos citar [45], [46], [47] e [48], fazendo um resumo histórico e prático da programação dinâmica e [17], [49], [50], [51] e [52], com modificações em diferentes aplicações da programação dinâmica. 


\subsection{Planejamento Estratégico}

Especificamente em reservatórios de armazenamento de água de usinas hidrelétricas o planejamento da operação visa determinar os volumes a serem defluidos de forma a atender restrições operativas cumprindo um ou vários objetivos, como por exemplo, maximizar a produção de energia ou minimizar custos operativos ou, ainda, minimizar vertimentos para controle de cheias a jusante. A Figura 4, mostrada a seguir, ilustra essas decisões e suas possíveis consequências.

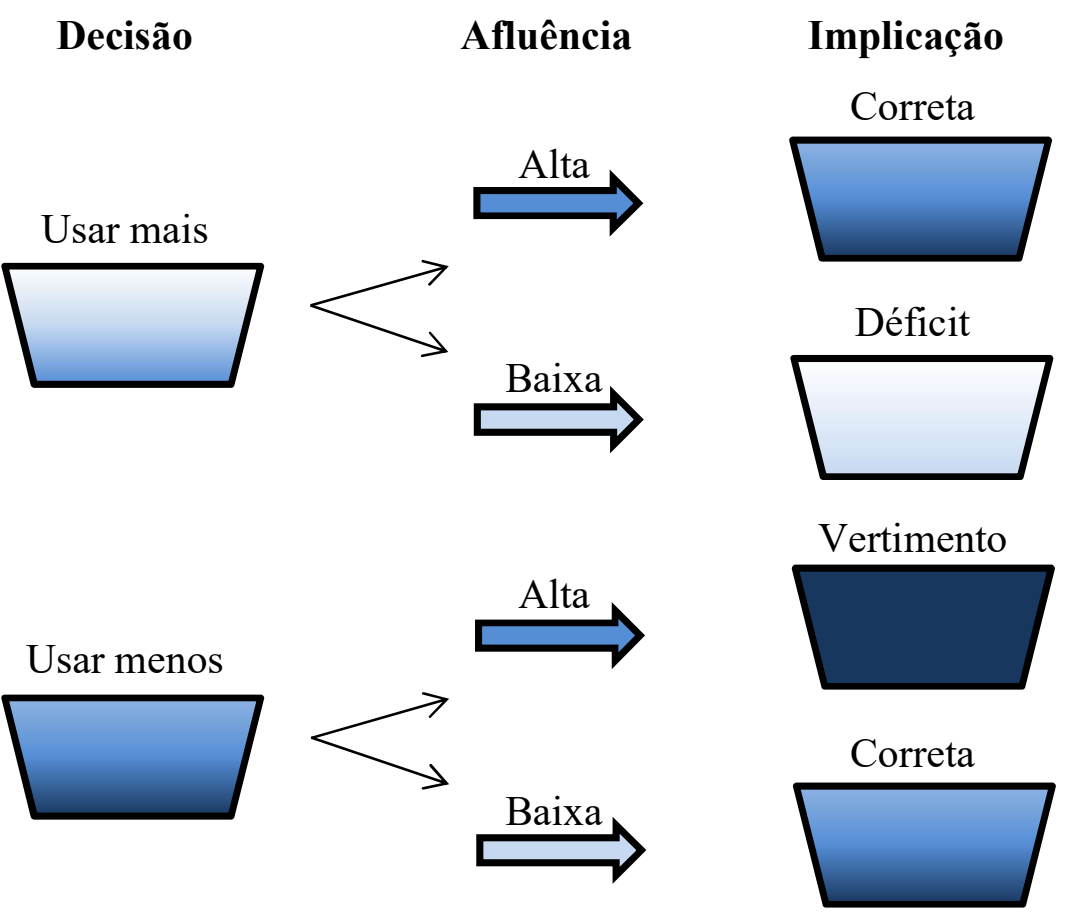

Figura 4 - Consequências das decisões do uso do reservatório sob possíveis afluências.

No caso brasileiro o planejamento energético deve minimizar os custos da operação de geração de energia elétrica, determinando a participação de usinas hidrelétricas de forma a garantir o suprimento de energia elétrica ao menor custo operacional esperado possível. Em sistemas com predominância hidrelétrica esse custo é composto pela soma do custo futuro, que representa as consequências futuras de uma decisão operativa atual e pelo custo imediato, representado pelo custo da geração de energia elétrica feito pelas usinas que complementam a geração de energia feita pelas usinas hidrelétricas, suprindo, assim, uma demanda definida [53] e [54]. A Figura 5, mostrada a seguir, ilustra esse dilema entre custo presente, custo futuro e custo total onde o ponto ótimo no qual o custo total é mínimo só é atingido com o perfeito conhecimento das afluências futuras. 


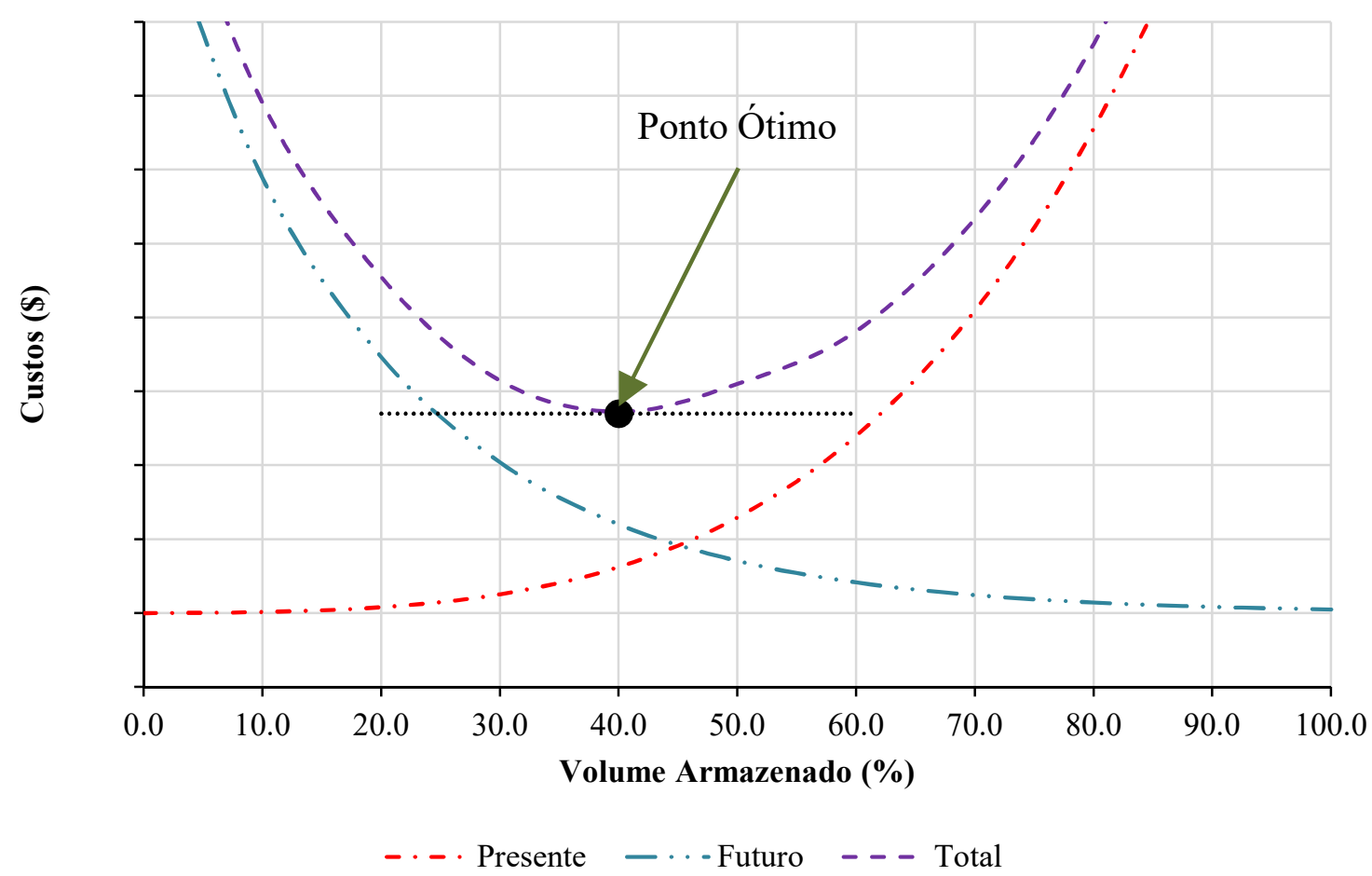

Figura 5 - Função de custos presente, futuro e total para o Planejamento Energético.

Alguns fatores tornam a solução desse problema bastante complexa destacando a não linearidade, presente na equação de geração hidráulica e no custo da geração térmica; a não separabilidade espacial, devido ao fato da decisão de quanto gerar em uma usina interferir em outra usina do sistema; a separabilidade temporal aditiva, devido à interferência de uma decisão atual em uma decisão futura e, como no caso brasileiro, o grande porte. Além destes, a aleatoriedade das vazões torna o problema essencialmente estocástico.

A solução deste problema foi inicialmente proposta em 1974 quando o governo brasileiro adotou o método da Curva Limite Inferior de Armazenamento (CLIA). O sistema hidrelétrico brasileiro era representado agregadamente, utilizando vazões históricas e operava de acordo com uma curva limite, que representava o mínimo armazenamento necessário para o atendimento à demanda com a mínima complementação de geração por termelétricas [55].

A CLIA foi utilizada por alguns anos, sendo substituída pela PDE [56], [57], [58] e [59], desenvolvida em uma parceria entre o CEPEL/ELETROBRÁS [60] e uma representação equivalente do sistema hidrelétrico brasileiro [61] e [62]. Por fim foi proposta e utilizada a PDED, Programação Dinâmica Dual Estocástica, [10], utilizando a técnica da decomposição de Benders. Este método resultou no programa NEWAVE, utilizado atualmente pelo setor elétrico brasileiro no planejamento de médio prazo. 


\subsection{Usinas Térmelétricas}

As usinas termelétricas brasileiras apresentam diferentes potências instaladas e, por utilizarem diferentes tipos de combustível, diferentes preços de geração de energia. Algumas usinas apresentam também uma geração térmica mínima, estabelecida em contrato. Todas as usinas térmicas brasileiras, disponíveis para operação, em fevereiro de 2013 são apresentadas a seguir:

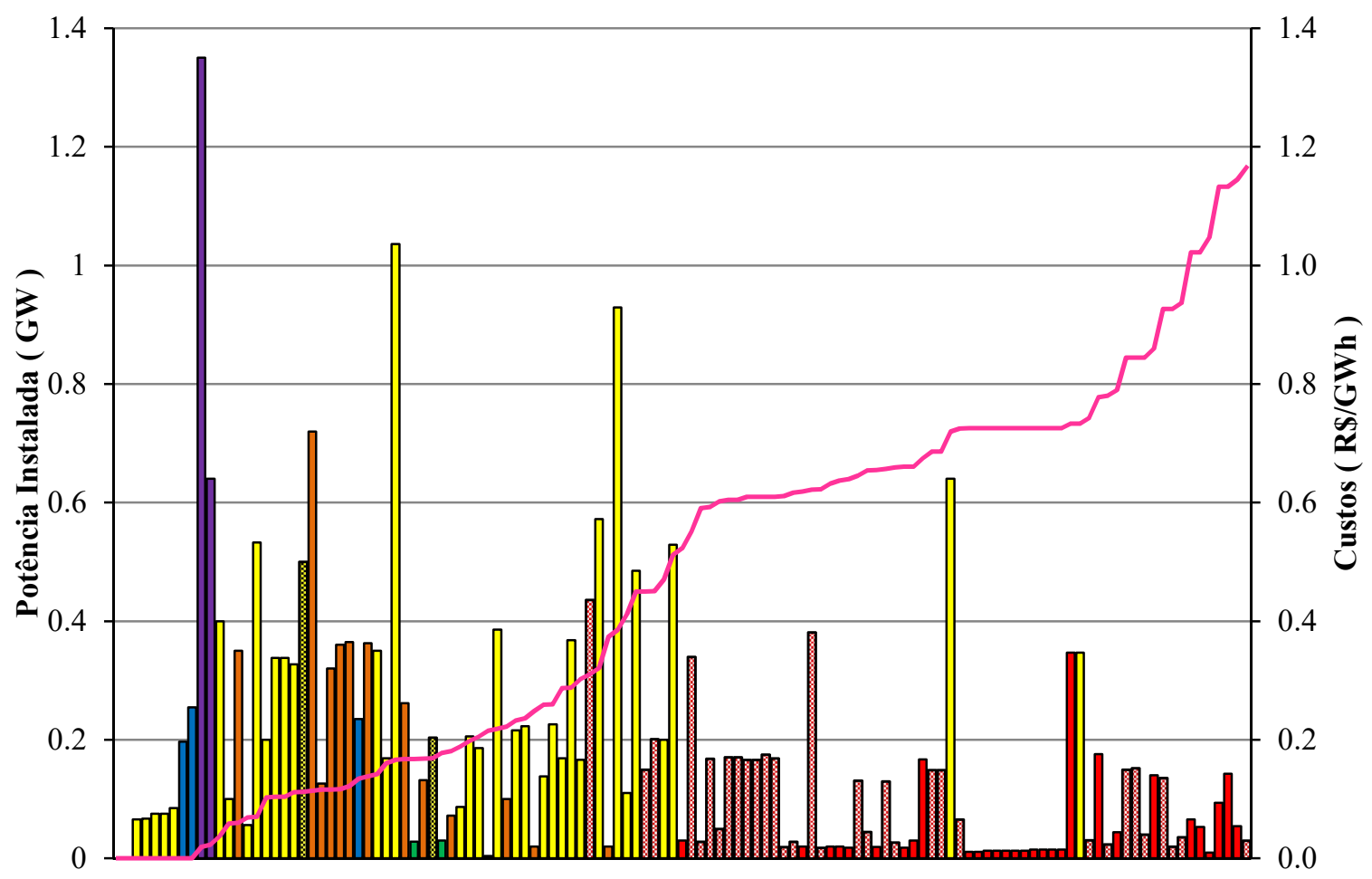

Usinas Térmicas

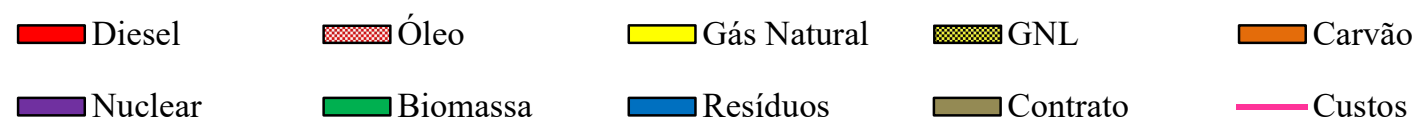

Figura 6 - Capacidade Instalada e custo de geração por usina térmica brasileira em 2013 [63].

Pela Figura 6 podemos perceber a heterogeneidade das usinas termelétricas brasileiras, tanto em potência instalada quanto em custos por GWh gerado. Os dados foram ordenados de forma crescente com relação aos custos por GWh gerado em cada usina. Percebe-se, ainda, um grande aumento de custo por GWh, chegando-se a algo ao redor de R\$1,17 por GWh. Nota-se também um predomínio de usinas termelétricas a gás natural além de usinas nucleares, a diesel, a óleo e a carvão. A Figura 7, a seguir, mostra graficamente os dados dos custos acumulados reais e aproximados. 


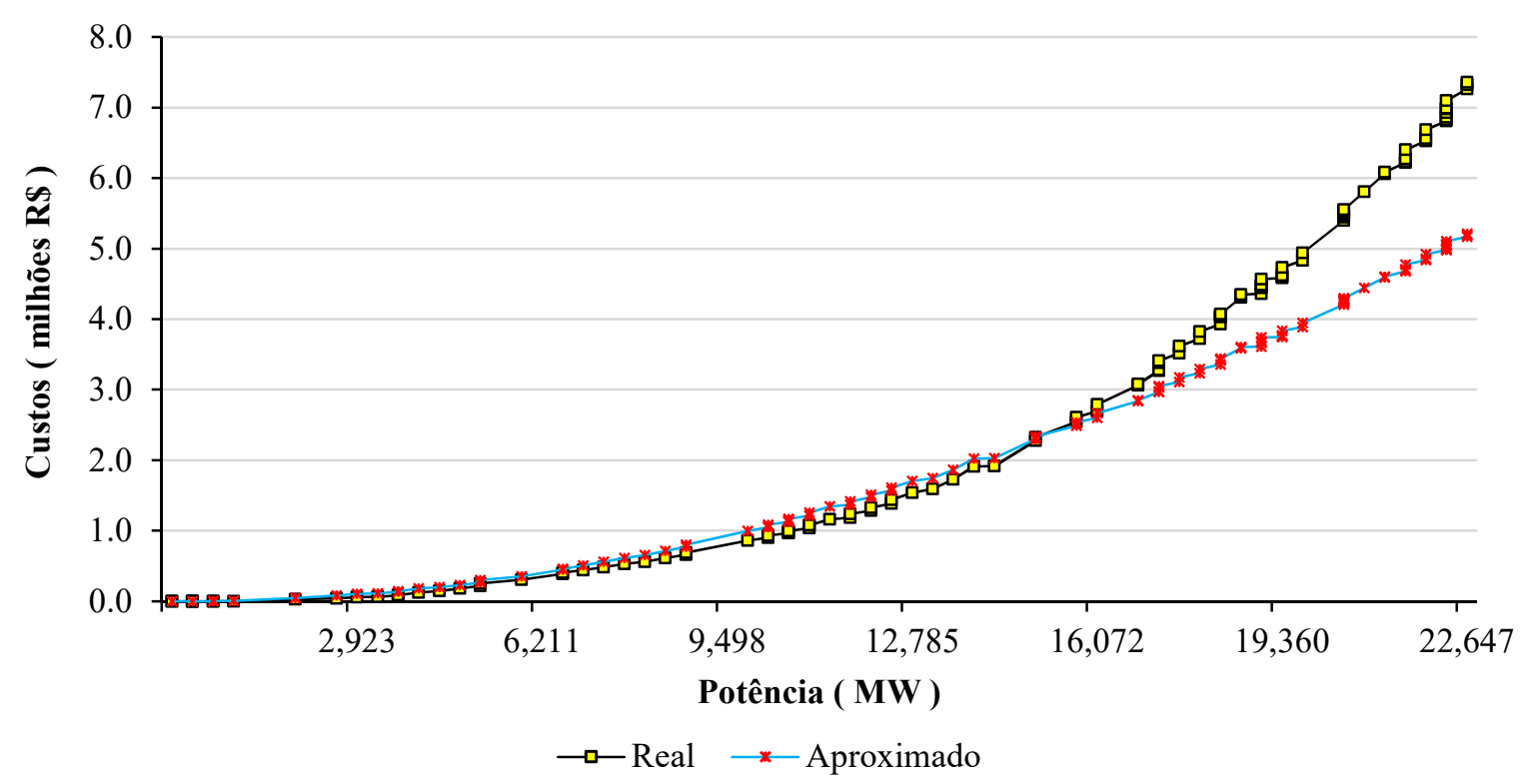

Figura 7 - Custos de geração térmica reais e aproximados.

Pode-se observar que o polinômio se aproxima bem dos valores reais de custos. Em particular, o polinômio com coeficiente 0,0002 é o que melhor se ajusta ao modelo. No entanto algumas discrepâncias, principalmente para valores de potências geradas mais elevados, são observadas. Isso não é relevante pois no processo de otimização os valores de despachos de térmicas muito elevados acabam não sendo utilizados.

O motivo de se usar uma função aproximada dos custos das usinas térmicas não está em uma necessidade do algoritmo uma vez que a programação dinâmica é capaz de trabalhar qualquer função de custo, mesmo não sendo uma função diferenciável em todo intervalo. Usase uma função de custo aproximada pelo fato de se simular uma usina hidrelétrica de forma isolada. Se a sua complementação termelétrica fosse feita com valores reais seria necessária apenas uma usina térmica, e, consequentemente, com custos lineares. Dessa forma a sua complementação iria distorcer a realidade não linear da complementação termelétrica do sistema hidrotérmico com várias usinas hidrelétricas e termelétricas.

Por fim, foram feitas várias simulações utilizando-se diferentes coeficientes na função quadrática de custos. Todos os resultados foram muito parecidos, ressaltando que o importante é o grau do polinômio da função de custo, grau 2, e não o coeficiente associado à função de custo. 


\subsection{Usinas Hidrelétricas}

Atualmente o Brasil conta com 195 usinas hidrelétricas em operação [64]. Estas usinas hidrelétricas apresentam o seguinte perfil físico-construtivo:

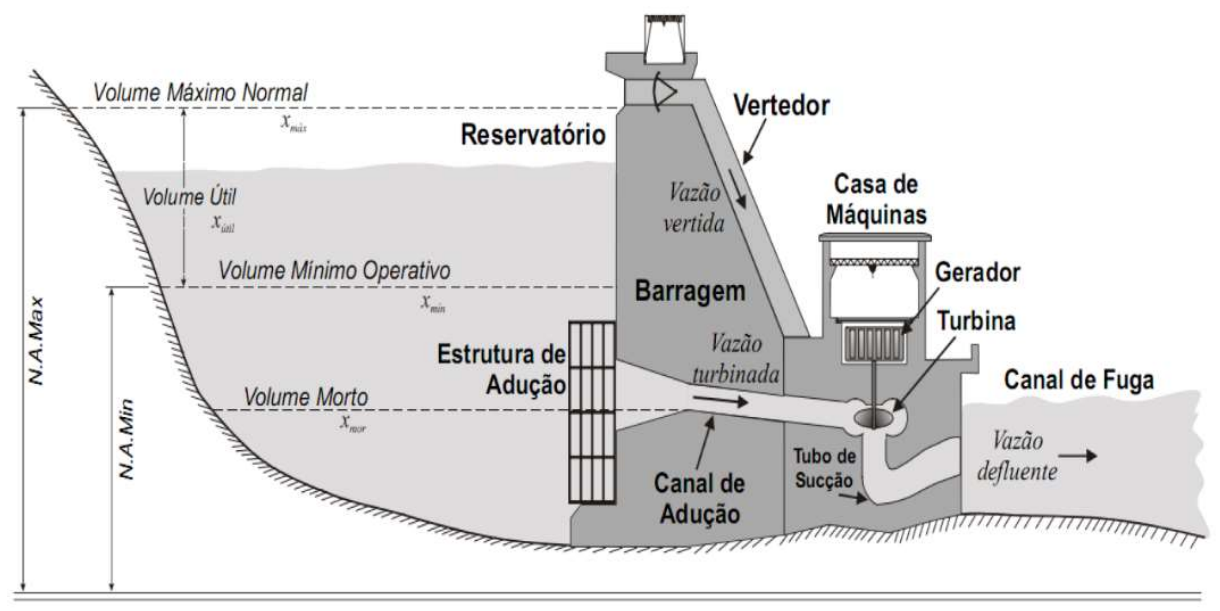

Figura 8 - Modelo de uma usina hidrelétrica [65].

Este perfil mostra as principais variáveis envolvidas no processo de modelagem e otimização de um sistema hidrotérmico com uma usina hidrelétrica. Os volumes operacionais devem estar dentro dos limites máximo e mínimo operativo. Volumes inferiores ao mínimo não são úteis ao processo de otimização pois não conseguem acionar, de maneira eficiente, as pás das turbinas das usinas. Já os volumes nunca ultrapassam os valores máximos. Se essa situação puder acontecer, os vertedouros são abertos para se evitar danos a estrutura da usina.

Quanto maior for o volume máximo de uma usina, maior será sua queda líquida, garantindo maior geração de energia. Em contrapartida, os custos de construção da usina elevam-se e a área inundada também tende a crescer significativamente. O volume mínimo, quando diminuído, aumenta o volume útil da usina, aumentando, assim, a capacidade de regularização das afluências da usina. Em contrapartida, diminui-se a queda líquida, diminuindo assim, a capacidade de produção de energia elétrica pela usina.

Usinas que têm reservatório mas não têm capacidade de regulação são chamadas de usinas a fio d'água. Nestas usinas hidrelétricas o volume mínimo é igual ao volume máximo operativo. No entanto a queda líquida não é constante como o nível de montante, acima da usina, pois depende do nível de jusante, abaixo da usina, que varia de acordo com a afluência.

Os vertedouros, no processo de otimização são responsáveis por garantir a segurança física da usina. Toda a água, decorrente do curso normal do rio, deve passar pelas turbinas, entrando pelo canal de adução, para que seja aproveitada na casa de máquinas para a geração 
de energia elétrica. Apenas os excessos devem ser vertidos. A junção da vazão turbinada com a vazão vertida é a vazão defluente.

A geração de energia elétrica é, portanto, dependente da vazão turbinada. Além disso, ela também depende da variação entre o nível de montante, acima da usina hidrelétrica, e o nível de jusante, abaixo da usina hidrelétrica. Quanto mais elevado for o nível de montante, com relação ao nível de jusante, maior será o potencial de geração de energia elétrica da usina hidrelétrica. Tanto o nível de montante quanto o nível de jusante têm valores estabelecidos e equacionados, disponibilizados em [63], e têm como base o nível do mar.

\subsection{Modelagem do problema}

A seguinte modelagem matemática é a formulação do problema do planejamento hidrotérmico com uma única usina hidrelétrica e considerando a aleatoriedade das vazões afluentes. Trata-se de um problema de programação não-linear estocástica. Sua função objetivo é minimizar o custo esperado da operação.

$$
\min E_{y}\left\{\sum_{t=1}^{T} \psi_{t}\left(d_{t}-g h_{t}\right)\right\}
$$

Sujeito a:

$$
\begin{gathered}
d_{t}=P_{\text {nom }} \\
g h_{t}=k h l_{t} q_{t} \\
h l_{t}=\phi\left(x_{t}^{\text {med }}\right)-\theta\left(u_{t}\right)-\xi(c t e) \\
x_{t}^{\text {med }}=\frac{x_{t}+x_{t-1}}{2} \\
x_{t}=x_{t-1}+\delta_{t}\left(y_{t}-u_{t}\right) \\
u_{t}=q_{t}+v_{t} \\
X^{\min } \leq x_{t} \leq X^{\max } \\
Q^{\min } \leq q_{t} \leq Q^{\max } \\
U^{\min } \leq u_{t} \\
v_{t} \geq 0
\end{gathered}
$$




$$
x_{0} \rightarrow \text { dado } \forall t \in[1, t]
$$

Onde:

$E_{y}: \quad$ valor esperado com relação as vazões afluentes;

$\delta_{t}: \quad$ fator de conversão de vazão $\left(\mathrm{m}^{3} / \mathrm{s}\right)$ em $\left(\mathrm{hm}^{3} / \mathrm{mês}\right)$;

$\psi_{t}$ : $\quad$ função de custo da complementação não hidráulica [\$];

$d_{t}: \quad$ demanda a ser atendida durante o estágio $t[M W]$;

$g h_{t}: \quad$ geração de energia hidrelétrica durante o estágio $t[M W]$;

$P_{n o m}: \quad$ Potência instalada na usina $[M W]$;

$k$ : $\quad$ produtibilidade específica da usina $\left[M W /\left(\mathrm{m}^{3} / \mathrm{s} . \mathrm{m}\right)\right]$;

$h l_{t}: \quad$ Altura de queda líquida $[\mathrm{m}]$

$q_{t}: \quad$ vazão turbinada durante o estágio $t\left[\mathrm{~m}^{3} / \mathrm{s}\right]$;

$Q^{\min }: \quad$ volume mínimo turbinável, zero para $\mathrm{PD}$ em um único reservatório $\left[m^{3} / s\right]$;

$Q^{\max }: \quad$ volume máximo turbinável $\left[\mathrm{m}^{3} / \mathrm{s}\right]$

$\phi_{t}\left(x_{t}\right)$ : função da cota montante do reservatório $[m]$;

$\theta_{t}\left(q_{t}\right)$ : função da cota jusante do reservatório $[\mathrm{m}]$;

$\xi_{t}(\phi, \theta):$ função da perda de carga hidráulica $[m]$;

$x_{t}: \quad$ volume do reservatório no final do estágio $t\left[\mathrm{hm}^{3}\right]$;

$x_{t}^{m e d}: \quad \quad$ volume médio do reservatório no final do estágio $t\left[\mathrm{hm}^{3}\right]$;

$X^{\min }: \quad$ volume mínimo armazenável $\left[\mathrm{hm}^{3}\right]$;

$X^{\max }: \quad$ volume máximo armazenável $\left[\mathrm{hm}^{3}\right]$;

$u_{t}: \quad$ vazão defluente durante o estágio $t\left[\mathrm{~m}^{3} / \mathrm{s}\right]$

$U^{\text {min }}$ : defluência mínima $\left[\mathrm{m}^{3} / \mathrm{s}\right]$;

$v_{t}: \quad$ vazão vertida durante o estágio $t\left[\mathrm{~m}^{3} / \mathrm{s}\right]$

$y_{t}: \quad$ vazão afluente durante o estágio $t\left[\mathrm{~m}^{3} / \mathrm{s}\right]$;

$t: \quad$ Estágio de tempo [mês];

$T: \quad$ número de estágios de tempo. 
$\mathrm{O}$ custo, $\psi_{t}$, representa o valor monetário associado à complementação da geração hidrelétrica por fontes termelétricas, importações e déficits. A equação (6) representa o balanço hidráulico da usina. Este balanço deve estar sujeito às restrições físicas de volume, turbinagem e vertimentos. Os custos da geração hidrelétrica não são nulos mas em função da grande diferença entre os custos da geração térmica e da geração hidrelétrica são considerados na modelagem sistema hidrotérmico.

A geração de energia hidrelétrica, dada pela equação (5), é produto de uma constante, determinada e tabelada para cada usina hidrelétrica [63], a queda líquida e a vazão turbinada. A queda líquida é obtida subtraindo-se da cota de montante, a cota de jusante e a perda hidráulica. Esta última é tipicamente uma função da vazão turbinada, mas é modelada no Brasil como um valor constante [65]. O tipo de perda hidráulica também é tabelado [63]. 


\section{Capítulo 3}

\section{Programação Dinâmica}

\section{e Modelo Proposto}

Este capítulo apresentará o método da programação dinâmica em detalhes. Será apresentada toda a teoria envolvida na programação dinâmica com exemplos. Também serão mostrados os métodos de obtenção das estatísticas para a programação dinâmica estocástica. No final do capítulo será apresentada a formulação do novo modelo proposto por este trabalho, a programação dinâmica estocástica markoviano plurimensal.

\subsection{Programação Dinâmica - Definições}

A programação dinâmica é um método que determina estratégias de decisões frente a possíveis estados do sistema. Esta técnica matemática, através do uso da inter-relação entre as decisões, estados e custos, determina quais devem ser as decisões em quais estados do sistema e quais as implicações destas decisões. A seguir serão apresentadas as definições dos elementos básicos da programação dinâmica em conjunto com exemplos aplicados ao POESH:

Estágio: O termo "dinâmica" representa como o sistema evolui passando de um ponto do sistema a outro. O termo estágio representa a transição entre dois pontos consecutivos de operação do sistema. Pode ter diferentes bases temporais, anos, meses, dias, horas, segundos, etc. dependendo, apenas, de como foi estabelecido. 
Estado: Representa a situação do sistema em um dado instante. Mostra as possíveis situações existentes para o sistema em um determinado instante (estágio), descrevendo completamente a situação do problema. Em reservatórios de armazenamento de água a variável de estado é o volume do reservatório, representado por $x_{t}$, sendo o estado, $x$, em cada estágio, $t$.

Decisão: Em cada estágio existem várias combinações possíveis de estado e decisão do sistema, dentre as quais, apenas uma deverá ser escolhida como sendo a melhor decisão operacional do sistema. As decisões tomadas em cada estágio afetam a decisão que deverá ser tomada no estágio seguinte, e, portanto, as influências de cada decisão serão avaliadas no processo como um todo. Em reservatórios de armazenamento de água a variável de decisão é a turbinagem da usina hidrelétrica, representada por $q_{t}$, sendo a decisão, $q$, em cada estágio, $t$.

$>$ Custo Elementar ou Imediato: É o custo ou penalidade associado a cada decisão tomada em cada estágio. No custo elementar não são considerados os custos ou penalidades associados à consequência da decisão tomada. É também conhecido como custo imediato e quando aplicado ao problema do planejamento energético será em função da subtração entre a demanda e a geração hidráulica, mostrado na equação (12), a seguir.

$$
\text { custo }=\psi_{t}\left(d_{t}-g h_{t}\right)
$$

Custo Futuro: É o custo associado a decisão tomada em cada estágio. O custo futuro é a soma dos custos imediatos até o final do período, $T$, decorrentes de uma consequência no estágio $t$.

Estado Inicial: É o estado em que se encontra o sistema no início do processo de otimização. O primeiro estágio deve começar a operação a partir do estado inicial do sistema.

Equação Recursiva de transição de estado: É a equação que define o estado do sistema entre dois estágios consecutivos para uma dada decisão. No problema 
do planejamento energético é definida como sendo em função do estado anterior, da decisão e da afluência. A equação recursiva de transição de estado é mostrada a seguir, na equação (13).

$$
x_{t}=x_{t-1}+\delta_{t}\left(y_{t}-u_{t}\right)
$$

Função Objetivo: É a soma dos custos elementares de cada estágio em todo o período de estudos. É representado pela seguinte equação:

$$
\sum_{t=1}^{T} \psi_{t}\left(d_{t}-g h_{t}\right)
$$

A Figura 9, mostrada a seguir, ilustra em um esquema de fluxograma o processo de variação dos estados, $x_{t}$, e decisões, $u_{t}$, do sistema sob influência das afluências, $y_{t}$, conhecidas, tendo como base os custos, $\psi_{t}$.

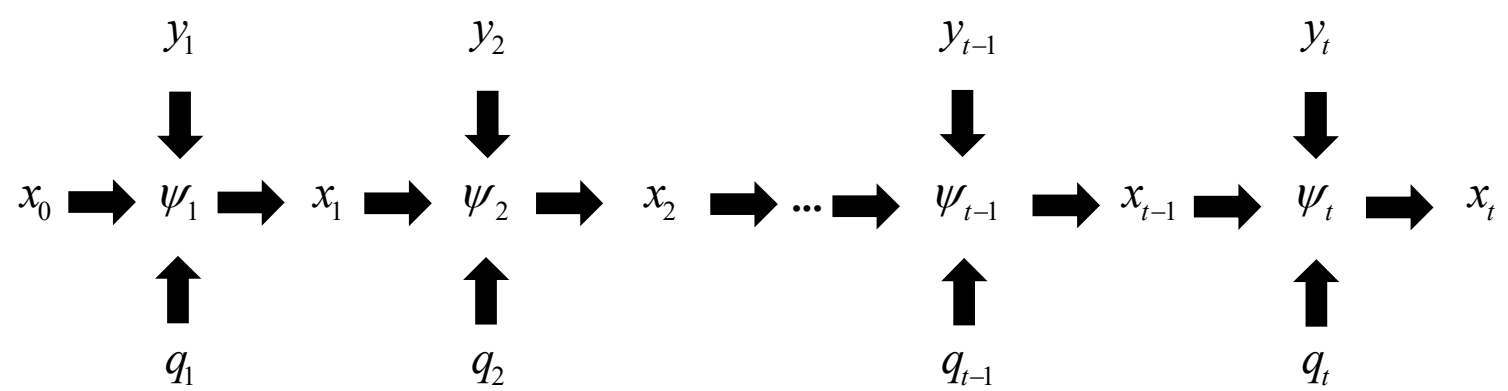

Figura 9 - Esquema de decisões da programação dinâmica com perfeita previsão.

Pela Figura 9 percebe-se que os estados do sistema, $x_{t}$, mudam de acordo com as afluências, $y_{t}$, e as decisões, $q_{t}$. Os custos referentes a consequência disto, $\psi_{t}$, indicarão qual decisão foi a melhor para o sistema naquele determinado tempo, $t$. A obtenção das tabelas com os estados e decisões do sistema pode ser feita de modo forward ou backward. O modo backward é de mais fácil implementação e o mais utilizado na literatura.

Admitindo-se o custo terminal nulo e utilizando-se o modo backward, deve-se, portanto, completar a tabela de acordo com os estados e as decisões, obtendo-se, no fim, os custos imediatos daquele referido tempo, $t=T$. A partir desse tempo, entre $t=T-1$ e $t=1$, deve- 
se somar aos custos nos meses anteriores os custos referentes aquela decisão. Com isso, ao final do processo, em $t=1$, teremos os custos totais.

Se fizermos um resumo da Programação Dinâmica em um fluxograma ele seria da seguinte forma:

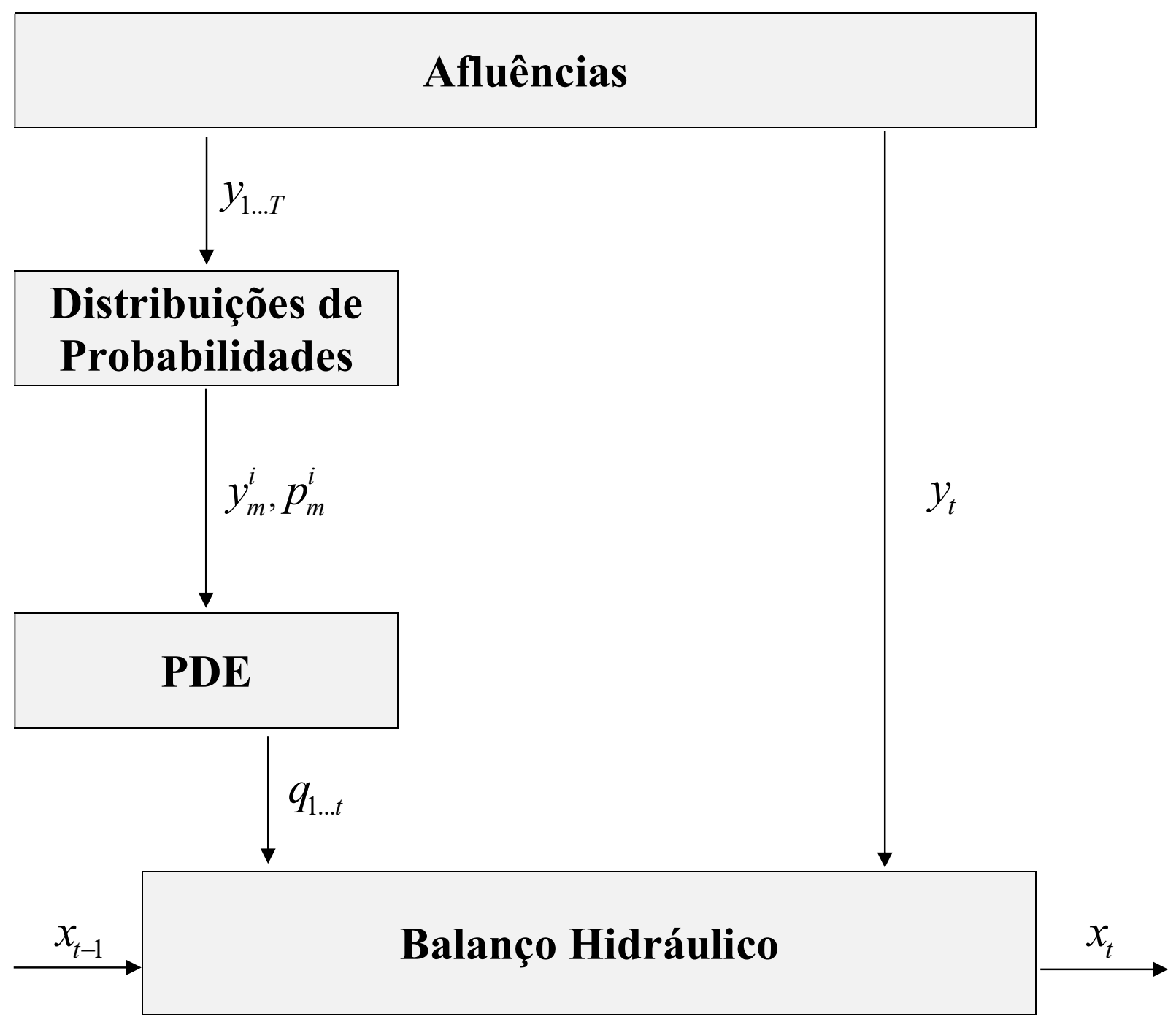

Figura 10 - Fluxograma completo da Programação Dinâmica

O esquema mostrado na Figura 10 ilustra o procedimento que deve ser adotado para obtenção dos resultados da otimização por meio da Programação Dinâmica. As diferenças ocorrem no tipo de distribuição de probabilidade, $y_{m}^{i}, p_{m}^{i}$ a ser utilizada, podendo esta ser independente, dependente, determinística ou com perfeita previsão. As afluências, $y_{t}$, alimentam o modelo que calcula as distribuições de probabilidades e o simulador que também utiliza as variáveis de decisão, $q_{t}$, para fazer o balanço hidráulico completo. 


\subsection{Programação Dinâmica com Perfeita Previsão}

Em sua forma utilizando a perfeita previsão são analisadas todas as possibilidades de decisões em todos os estados do sistema. Ao final do processo, quando estão completas todas as tabelas entre $t=T$ e $t=1$, o custo total é mostrado na tabela para $t=1$ e as variáveis de estado e de decisão também podem ser colhidas. O esquema das decisões é ilustrado pela Figura 11 , mostrada a seguir.

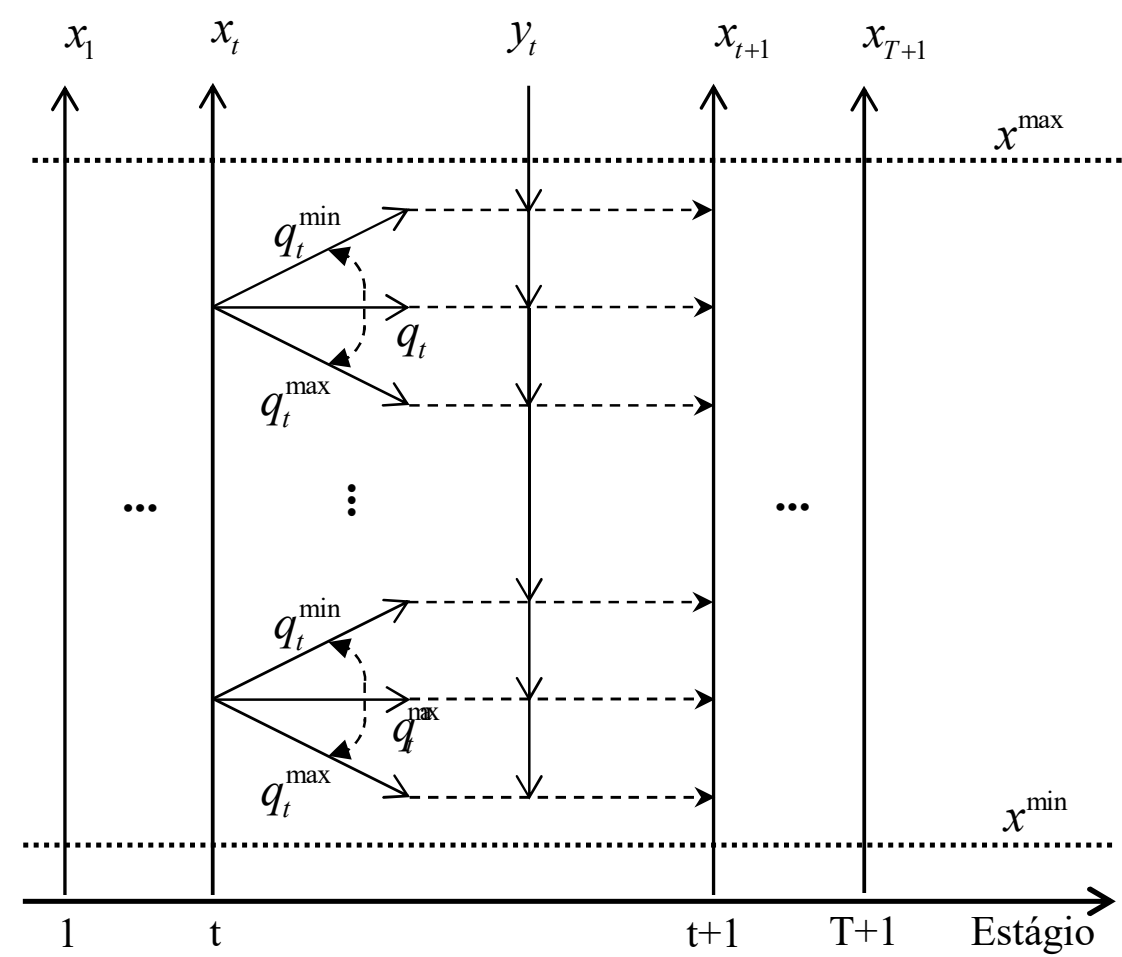

Figura 11 - Esquema da PDP.

A Figura 11 ilustra o esquema da PDP. O número de meses simulados é definido entre $t=1$ e $t=T$. Os valores dos volumes variam entre $x_{1}$ e $x_{T+1}$ devido ao fato de representarem as variações de volumes entre o início e o final do mês, como explicado na seção anterior, e entre uma faixa de valores, $x^{\min }$ e $q_{t}^{\min }$, discretizados uniformemente.

As afluências, $x_{t}$, são conhecidas em todos os meses simulados e os valores das variáveis de decisão, $q_{t}^{\max }$, variam entre $q_{t}^{\min }$ e $x^{\min }$, com valores, assim como nas variáveis de estado, discretizados uniformemente. 
A seguir será mostrado um exemplo didático da programação dinâmica com perfeita previsão.

\subsubsection{Exemplo didático da PDP}

Com o intuito de facilitar o entendimento da programação dinâmica com perfeita previsão será mostrado a seguir um exemplo prático, simples e, didático da programação dinâmica com perfeita previsão.

Nesse exemplo um sistema hidrotérmico deve atender uma demanda $d_{t=1: 9}=4$. O reservatório da usina hidrelétrica, expresso em termos energéticos, tem uma capacidade máxima de $3 \mathrm{UV}$, unidades de volume, recebe uma afluência $y_{t=1: 9}=\{2,5,3,4,6,2,2,4,1\}$, e está motorizado para gerar um máximo de 4 UP, unidades de potência. O nível inicial e final do reservatório é de $3 \mathrm{UV}$. O custo da produção térmica é dado por $c_{t}\left(g t_{t}\right)=g t_{t}^{2}$. Deve-se fazer o planejamento otimizado da operação para os nove meses de dados de afluência e demanda, usando uma discretização de 1 UV e 1 UP.

Inicialmente devemos modelar o problema:

$$
\min \sum_{t=1}^{T=9}\left(d_{t}-g h_{t}\right)^{2}
$$

Sujeito a:

$$
\begin{gathered}
x_{t}=x_{t-1}+y_{t}-g h_{t} \\
d_{t}=g t_{t}+g h_{t} \\
0 \leq x_{t} \leq 3 \\
0 \leq g h_{t} \leq 4 \\
x_{1}=x_{10}=3
\end{gathered}
$$

Para obtenção das respostas serão construídas as tabelas dinâmicas do último estágio para o primeiro, no modo backward. O custo final foi considerado nulo e os custos associados a cada decisão devem ser somados às etapas anteriores. Além disso, as operações infactíveis também devem ser repassadas aos estágios anteriores. 
O cálculo de $c_{T}^{\text {total }}$ é feito com a seguinte equação:

$$
c_{T}^{\text {total }}=c_{T}^{\text {imediato }}+c_{T}^{\text {futuro }}
$$

A Tabela 1 mostra, a seguir, os dados referentes à tabela dinâmica do mês 9 .

Tabela 1 - Tabela de Programação Dinâmica para o mês 9 do exemplo de PDP.

\begin{tabular}{|c|c|c|c|c|c|c|c|}
\hline$x_{9}$ & $g h_{9}$ & $x_{10}$ & $y_{9}$ & $d_{9}$ & $c_{9}^{\text {imediato }}$ & $c_{9}^{\text {futuro }}$ & $c_{9}^{\text {total }}$ \\
\hline 0 & 0 & 1 & 1 & 4 & 16 & 0 & INF \\
\hline 0 & 1 & 0 & 1 & 4 & 9 & 0 & INF \\
\hline 0 & 2 & -1 & 1 & 4 & 4 & 0 & INF \\
\hline 0 & 3 & -2 & 1 & 4 & 1 & 0 & INF \\
\hline 0 & 4 & -3 & 1 & 4 & 0 & 0 & INF \\
\hline 1 & 0 & 2 & 1 & 4 & 16 & 0 & INF \\
\hline 1 & 1 & 1 & 1 & 4 & 9 & 0 & INF \\
\hline 1 & 2 & 0 & 1 & 4 & 4 & 0 & INF \\
\hline 1 & 3 & -1 & 1 & 4 & 1 & 0 & INF \\
\hline 1 & 4 & -2 & 1 & 4 & 0 & 0 & INF \\
\hline 2 & 0 & 3 & 1 & 4 & 16 & 0 & 16 \\
\hline 2 & 1 & 2 & 1 & 4 & 9 & 0 & INF \\
\hline 2 & 2 & 1 & 1 & 4 & 4 & 0 & INF \\
\hline 2 & 3 & 0 & 1 & 4 & 1 & 0 & INF \\
\hline 2 & 4 & -1 & 1 & 4 & 0 & 0 & INF \\
\hline 3 & 0 & 4 & 1 & 4 & 16 & 0 & INF \\
\hline 3 & 1 & 3 & 1 & 4 & 9 & 0 & 9 \\
\hline 3 & 2 & 2 & 1 & 4 & 4 & 0 & INF \\
\hline 3 & 3 & 1 & 1 & 4 & 1 & 0 & INF \\
\hline 3 & 4 & 0 & 1 & 4 & 0 & 0 & INF \\
\hline
\end{tabular}

Foram simulados nesse exemplo nove meses. No entanto o número de volumes, $x_{t}$, variou entre 1 e 10. Isto é devido ao fato de que as variáveis de contorno volume inicial e final serem definidas no volume máximo. Com isso, no inicio do primeiro mês, $x_{1}$, o volume foi fixado no volume máximo, o mesmo ocorreu com no fim do ultimo mês, $x_{9}$. Como o final de cada mês deve ter o mesmo armazenamento do início do próximo mês opta-se por definir $x_{10}$ ao invés de $x_{9}^{\text {final }}$ ou alguma nomenclatura parecida.

A segunda coluna, $g h_{t}$, assim como a primeira tem seus valores estabelecidos de forma a varrer todas as possibilidades de acordo com seus valores mínimos e máximos. A terceira 
coluna, $x_{t+1}$, é obtida através da equação (16). A quarta e a quinta colunas são dados do exemplo. $\mathrm{O}$ custo imediato, $c_{t}^{\text {imediato }}$, na sexta coluna, é obtido com a equação $c_{t}\left(g t_{t}\right)=g t_{t}^{2}$. O custo futuro, $c_{t}^{\text {futuro }}$, na sétima coluna, é obtido de acordo com a consequência, em volume, daquela decisão, $x_{t+1}$. A última coluna, $c_{t}^{\text {futuro }}$, é obtida somando-se $c_{t}^{\text {imediato }} \operatorname{com} c_{t}^{\text {futuro }}$.

Alguns valores foram considerados infactíveis e são mostrados como sendo INF em suas colunas. Esses valores foram decisões que levariam a um $x_{10}$ diferente da condição imposta no exercício. Os custos futuros, neste último mês, foram considerados nulos, como também foi definido pelo enunciado do exemplo. Após completar a tabela da programação dinâmica de cada mês deve-se obter a tabela dinâmica de decisões, mostrada a seguir.

Tabela 2 - Tabela de Decisões da Programação Dinâmica para o mês 9 do exemplo de PDP.

\begin{tabular}{|r|r|r|r|}
\hline \multicolumn{1}{|r|}{$x_{9}$} & \multicolumn{1}{|c|}{$g h_{9}$} & \multicolumn{1}{|c|}{$x_{10}$} & \multicolumn{2}{|c|}{$c_{9}^{\text {total }}$} \\
\hline 0 & INF & INF & INF \\
\hline 1 & INF & INF & INF \\
\hline 2 & 0 & 3 & 16 \\
\hline 3 & 1 & 3 & 9 \\
\hline
\end{tabular}

O valor a ser levado para a tabela de decisões é sempre o menor custo total factível do bloco que contenha o mesmo volume, a variável de estado. Após a obtenção da tabela de decisões da programação dinâmica deve-se passar para o próximo mês, no caso, como o exemplo utiliza o modo backward, o mês 8 .

Os volumes para $x_{9}$ que forem calculados na tabela de programação dinâmica do mês 8 que forem negativos ou maiores que a capacidade máxima do reservatório devem ser infactibilizados. Além disso, valores de $x_{9}$ que forem 0 ou 1 também devem ser infactibilizados pois na tabela de decisões de programação dinâmica estes valores são infactíveis.

Devem-se copiar os valores da coluna $c_{9}^{\text {total }}$ da Tabela 2 para a coluna $c_{8}^{\text {futuro }}$ da Tabela 3 de acordo com a coluna $x_{9}$ das duas tabelas. A seguir é mostrada a tabela de programação dinâmica para o mês 8 .

Tabela 3 - Tabela de Programação Dinâmica para o mês 8 do exemplo de PDP. 


\begin{tabular}{|c|c|c|c|c|c|c|c|}
\hline$x_{8}$ & $g h_{8}$ & $x_{9}$ & $y_{8}$ & $d_{8}$ & $c_{8}^{\text {imediato }}$ & $c_{8}^{\text {futuro }}$ & $c_{8}^{\text {total }}$ \\
\hline 0 & 0 & 4 & 4 & 4 & 16 & INF & INF \\
\hline 0 & 1 & 3 & 4 & 4 & 9 & 9 & 18 \\
\hline 0 & 2 & 2 & 4 & 4 & 4 & 16 & 20 \\
\hline 0 & 3 & 1 & 4 & 4 & 1 & INF & INF \\
\hline 0 & 4 & 0 & 4 & 4 & 0 & INF & INF \\
\hline 1 & 0 & 5 & 4 & 4 & 16 & INF & INF \\
\hline 1 & 1 & 4 & 4 & 4 & 9 & INF & INF \\
\hline 1 & 2 & 3 & 4 & 4 & 4 & 9 & 13 \\
\hline 1 & 3 & 2 & 4 & 4 & 1 & 16 & 17 \\
\hline 1 & 4 & 1 & 4 & 4 & 0 & INF & INF \\
\hline 2 & 0 & 6 & 4 & 4 & 16 & INF & INF \\
\hline 2 & 1 & 5 & 4 & 4 & 9 & INF & INF \\
\hline 2 & 2 & 4 & 4 & 4 & 4 & INF & INF \\
\hline 2 & 3 & 3 & 4 & 4 & 1 & 9 & 10 \\
\hline 2 & 4 & 2 & 4 & 4 & 0 & 16 & 16 \\
\hline 3 & 0 & 7 & 4 & 4 & 16 & INF & INF \\
\hline 3 & 1 & 6 & 4 & 4 & 9 & INF & INF \\
\hline 3 & 2 & 5 & 4 & 4 & 4 & INF & INF \\
\hline 3 & 3 & 4 & 4 & 4 & 1 & INF & INF \\
\hline 3 & 4 & 3 & 4 & 4 & 0 & 9 & 9 \\
\hline
\end{tabular}

Após obter-se a tabela de programação dinâmica do mês 8 deve-se construir a tabela de decisões para o mês 8 , mostrada a seguir.

Tabela 4 - Tabela de Decisões da Programação Dinâmica para o mês 8 do exemplo de PDP.

\begin{tabular}{|r|r|r|r|}
\hline \multicolumn{1}{|r|}{$x_{8}$} & \multicolumn{1}{|c|}{$g h_{8}$} & \multicolumn{1}{|c|}{$x_{9}$} & \multicolumn{2}{|c|}{$c_{8}^{\text {total }}$} \\
\hline 0 & 1 & 3 & 18 \\
\hline 1 & 2 & 3 & 13 \\
\hline 2 & 3 & 3 & 10 \\
\hline 3 & 4 & 3 & 9 \\
\hline
\end{tabular}

Esse processo deve se repetir até que se construa à última tabela, pelo modo backward, referente ao mês 1 . O modo de construção dela é idêntico as outras. Uma única diferença deve ser lembrada por conter o volume inicial, $x_{1}$, do reservatório no início do processo de otimização. A seguir é mostrada a tabela de programação dinâmica para o mês 1 . 


\begin{tabular}{|r|r|r|r|r|r|l|l|}
\hline \multicolumn{1}{|r|}{$x_{1}$} & \multicolumn{1}{|l|}{$g h_{1}$} & \multicolumn{1}{|l|}{$x_{2}$} & \multicolumn{1}{|l|}{$y_{1}$} & \multicolumn{1}{|c|}{$d_{1}$} & \multicolumn{1}{|c|}{$c_{1}^{\text {imediato }}$} & $c_{1}^{\text {futuro }}$ & $c_{1}^{\text {total }}$ \\
\hline 0 & 0 & 2 & 2 & 4 & 16 & INF & INF \\
\hline 0 & 1 & 1 & 2 & 4 & 9 & 16 & INF \\
\hline 0 & 2 & 0 & 2 & 4 & 4 & 16 & INF \\
\hline 0 & 3 & -1 & 2 & 4 & 1 & INF & INF \\
\hline 0 & 4 & -2 & 2 & 4 & 0 & INF & INF \\
\hline 1 & 0 & 3 & 2 & 4 & 16 & INF & INF \\
\hline 1 & 1 & 2 & 2 & 4 & 9 & INF & INF \\
\hline 1 & 2 & 1 & 2 & 4 & 4 & 16 & INF \\
\hline 1 & 3 & 0 & 2 & 4 & 1 & 16 & INF \\
\hline 1 & 4 & -1 & 2 & 4 & 0 & INF & INF \\
\hline 2 & 0 & 4 & 2 & 4 & 16 & INF & INF \\
\hline 2 & 1 & 3 & 2 & 4 & 9 & INF & INF \\
\hline 2 & 2 & 2 & 2 & 4 & 4 & INF & INF \\
\hline 2 & 3 & 1 & 2 & 4 & 1 & 16 & INF \\
\hline 2 & 4 & 0 & 2 & 4 & 0 & 16 & INF \\
\hline 3 & 0 & 5 & 2 & 4 & 16 & INF & INF \\
\hline 3 & 1 & 4 & 2 & 4 & 9 & INF & INF \\
\hline 3 & 2 & 3 & 2 & 4 & 4 & INF & INF \\
\hline 3 & 3 & 2 & 2 & 4 & 1 & INF & INF \\
\hline 3 & 4 & 1 & 2 & 4 & 0 & & \\
\hline
\end{tabular}

Após obter-se a tabela de programação dinâmica do mês 1 deve-se construir a tabela de decisões para o mês 1 , mostrada a seguir.

Tabela 6 - Tabela de Decisões da Programação Dinâmica para o mês 1 do exemplo de PDP.

\begin{tabular}{|r|r|r|r|}
\hline \multicolumn{1}{|r|}{$x_{1}$} & \multicolumn{1}{|l|}{$g h_{1}$} & \multicolumn{1}{|l|}{$x_{2}$} & \multicolumn{2}{|c|}{$c_{1}^{\text {total }}$} \\
\hline 0 & INF & INF & INF \\
\hline 1 & INF & INF & INF \\
\hline 2 & INF & INF & INF \\
\hline 3 & 4 & 1 & 16 \\
\hline
\end{tabular}

Ao final deste processo obtemos as tabelas de decisões bem como as trajetórias de volumes e de decisões otimizadas para o exemplo proposto. A seguir são mostradas as tabelas de decisões para alguns meses bem como as trajetórias de volumes e decisões ótimas.

\begin{tabular}{|c|c|c|l|}
\hline$x_{1}$ & $g h_{1}$ & $x_{2}$ & $c_{1}^{\text {total }}$ \\
\hline 0 & $\mathrm{INF}$ & $\mathrm{INF}$ & $\mathrm{INF}$ \\
\hline
\end{tabular}




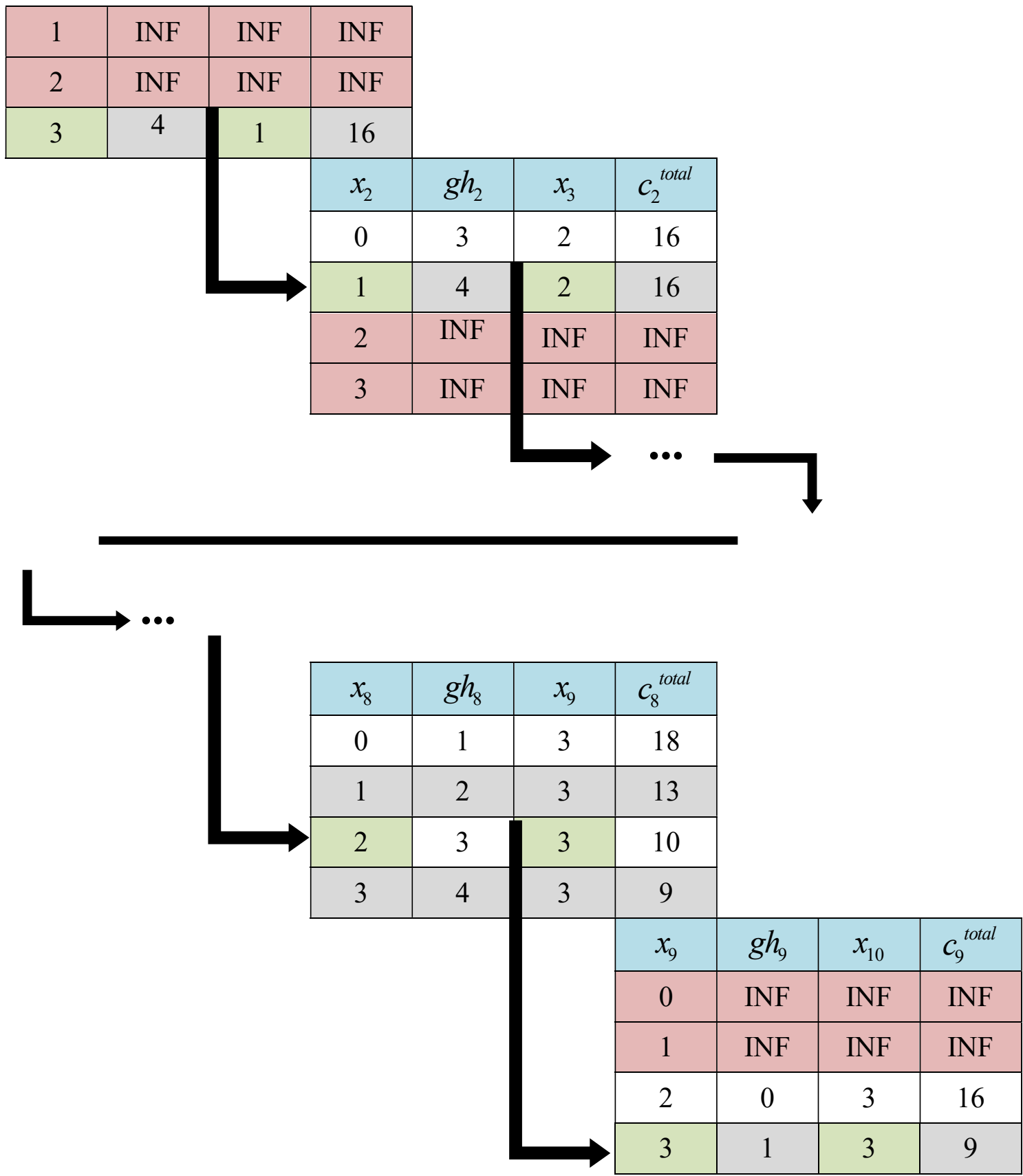

Figura 12 - Tabelas De Decisões da Programação Dinâmica do exemplo de PDP.

Para se obter as trajetórias de volumes e decisões ótimas deve-se começar na tabela do primeiro mês a partir do volume inicial. A linha referente ao volume inicial contém o custo ótimo total, a primeira decisão e o volume que o reservatório irá iniciar o próximo mês devido a decisão tomada e a afluência ocorrida. Este processo deve continuar até a tabela do ultimo mês, finalizando, assim, o processo. A Figura 13, a seguir, mostra as trajetórias de geração hidráulica e térmica e a demanda requisitada no exemplo. 


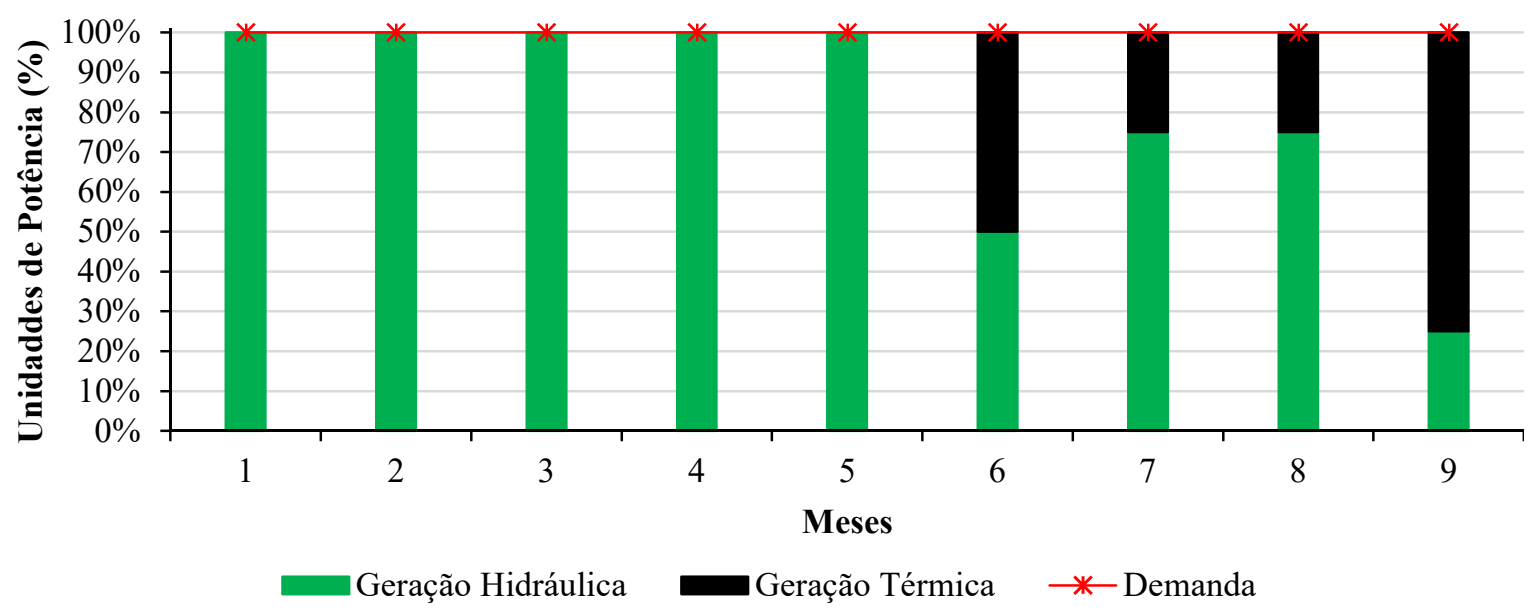

Figura 13 - Trajetórias ótimas de geração hidráulica e térmica e demanda requisitada.

Deve-se notar que na Figura 13 o número de meses e de pontos das gerações e da demanda é o mesmo. A Figura 14, a seguir, mostra a trajetória de volumes ótimos obtidos.

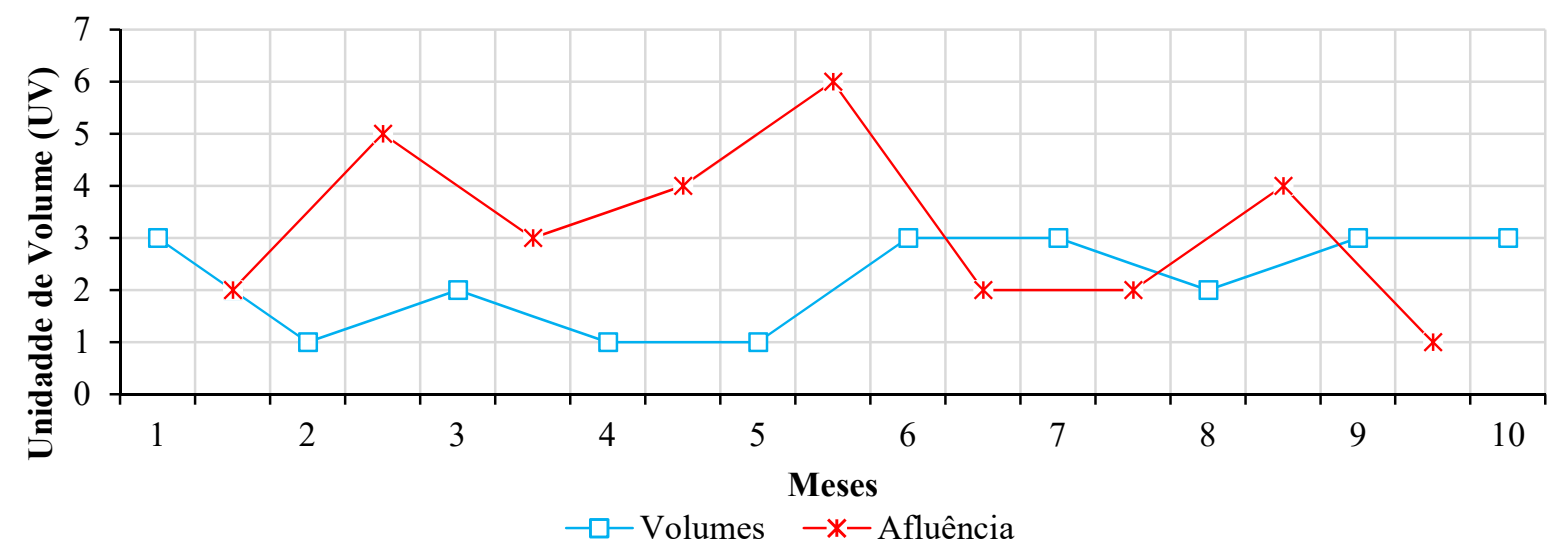

Figura 14 - Trajetórias ótimas de volumes e afluências ocorridas.

A Figura 14 contém os meses simulados mas com um número a mais, 10. Isso é devido ao fato de termos 9 meses o que implica em 10 pontos de volumes. O volume inicial é o valor no primeiro dia do primeiro mês. O volume final é o volume no último dia do último mês. Os volumes do último dia de cada mês, $t$, são os mesmos do primeiro dia do próximo mês, $t+1$. Por isso temos 9 transições de volume implicando em 10 pontos de volume neste exemplo de PDP.

\subsection{Programação Dinâmica Determinística}

Em sua forma determinística são analisadas as possibilidades de decisões discretizadas nos estados discretizados do sistema para uma condição de afluência média. Diferentemente de sua versão com previsão perfeita na PDD as afluências não são conhecidas. Toma-se como base 
o valor esperado (médio) das afluências e a partir das simulações nessas médias se criam tabelas de decisões a serem usadas posteriormente. O final do processo é alcançado quando as tabelas referentes aos mesmos períodos sazonais de tempo se igualam.

Deve-se, como no caso da perfeita previsão, conhecer todos os parâmetros do problema, exceto a afluência, que deve ser conhecida em sua média. A seguir, na Figura 15, é apresentado o esquema da PDD. A diferença, comparada à PDP, está na afluência que é repetida anualmente e tem seu valor dado pela média mensal. Além disso, o tempo de simulação é definido pela convergência do algoritmo. Nesse ponto de convergência, quando os resultados se repetem sazonalmente, o algoritmo é finalizado e as tabelas de decisões são colhidas.

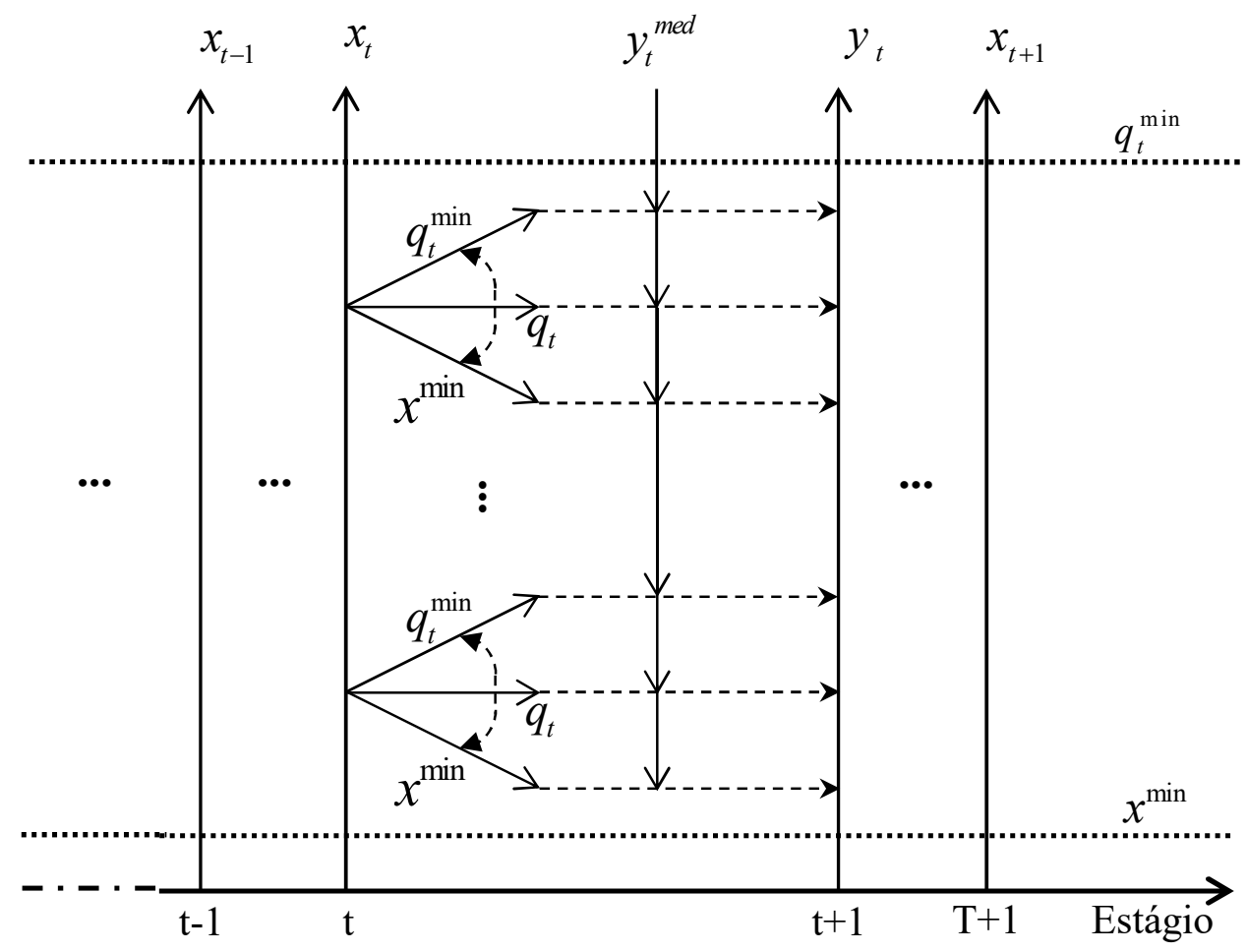

Figura 15 - Esquema da PDD.

A seguir será mostrado um exemplo didático da programação dinâmica determinística.

\subsubsection{Exemplo didático da PDD}

Com o intuito de facilitar o entendimento da programação dinâmica determinística será mostrado a seguir um exemplo prático, simples e, didático da PDD. Nesse exemplo um sistema hidrotérmico deve atender uma demanda $d_{t}=4$. O reservatório da usina hidrelétrica, expresso em termos energéticos, tem uma capacidade máxima de $3 \mathrm{UV}$, unidades de volume, recebe uma 
afluência média com sazonalidade que se repete a cada três meses de $y_{t=1: 3}=\{2,4,1\}$, e está motorizado para gerar um máximo de 4 UP, unidades de potência. O custo da produção de energia térmica é dado por $c_{t}\left(g t_{t}\right)=g t_{t}^{2}$. Deve-se fazer o planejamento otimizado da operação, usando uma discretização de 1 UV e 1 UP.

Inicialmente devemos modelar o problema:

$$
a_{0}\left(x_{0}\right)=\min E_{y}\left\{\sum_{t=1}^{T}\left(d_{t}-g h_{t}\right)^{2}\right\}
$$

Sujeito a:

$$
\begin{gathered}
x_{t}=x_{t-1}+y_{t}-g h_{t} \\
d_{t}=g t_{t}+g h_{t} \\
0 \leq x_{t} \leq 3 \\
0 \leq g h_{t} \leq 4
\end{gathered}
$$

Para obtenção das tabelas de decisões da PDD serão construídas as tabelas dinâmicas do último estágio para o primeiro, no modo backward. O custo final foi considerado nulo e os custos associados a cada decisão devem ser somados as etapas anteriores. Além disso, as operações infactíveis também devem ser repassadas aos estágios anteriores, como na PDP.

O cálculo de $c_{T}^{\text {total }}$ é feito, assim como na PDP, com a seguinte equação:

$$
c_{T}^{\text {total }}=c_{T}^{\text {imediato }}+c_{T}^{\text {futuro }}
$$

Deve-se efetuar o processo até que o critério de convergência, que é a igualdade entre as decisões de todos os meses, seja atingida. Esse número de meses a serem simulados pode variar muito, dependendo dos parâmetros de entrada do problema. A seguir é mostrada a Tabela 7 que contém os dados referentes ao ultimo mês simulado.

Tabela 7 - Tabela de Programação Dinâmica para o mês T do exemplo de PDD.

\begin{tabular}{|l|l|l|l|l|l|l|l|}
\hline$x_{T}$ & $g h_{T}$ & $x_{T+1}$ & $y_{T}$ & $d_{T}$ & $c_{T}^{\text {imediato }}$ & $c_{T}^{\text {futuro }}$ & $c_{T}^{\text {total }}$ \\
\hline
\end{tabular}




\begin{tabular}{|r|r|r|r|r|r|r|r|}
\hline 0 & 0 & 1 & 1 & 4 & 16 & 0 & 16 \\
\hline 0 & 1 & 0 & 1 & 4 & 9 & 0 & 9 \\
\hline 0 & 2 & -1 & 1 & 4 & INF & 0 & INF \\
\hline 0 & 3 & -2 & 1 & 4 & INF & 0 & INF \\
\hline 0 & 4 & -3 & 1 & 4 & INF & 0 & INF \\
\hline 1 & 0 & 2 & 1 & 4 & 16 & 0 & 16 \\
\hline 1 & 1 & 1 & 1 & 4 & 9 & 0 & 9 \\
\hline 1 & 2 & 0 & 1 & 4 & 4 & 0 & 4 \\
\hline 1 & 3 & -1 & 1 & 4 & INF & 0 & INF \\
\hline 1 & 4 & -2 & 1 & 4 & INF & 0 & INF \\
\hline 2 & 0 & 3 & 1 & 4 & 16 & 0 & 16 \\
\hline 2 & 1 & 2 & 1 & 4 & 9 & 0 & 9 \\
\hline 2 & 2 & 1 & 1 & 4 & 4 & 0 & 4 \\
\hline 2 & 3 & 0 & 1 & 4 & 1 & 0 & 1 \\
\hline 2 & 4 & -1 & 1 & 4 & INF & 0 & INF \\
\hline 3 & 0 & 4 & 1 & 4 & INF & 0 & INF \\
\hline 3 & 1 & 3 & 1 & 4 & 9 & 0 & 9 \\
\hline 3 & 2 & 2 & 1 & 4 & 4 & 0 & 4 \\
\hline 3 & 3 & 1 & 1 & 4 & 1 & 0 & 1 \\
\hline 3 & 4 & 0 & 1 & 4 & 0 & 0 & 0 \\
\hline
\end{tabular}

Novamente, como a PDP, deve-se obter a tabela de decisões para cada estado do sistema. Deve-se notar que a coluna $c_{T}^{\text {futuro }}$ é nula e que os volumes $x_{T+1}$ não são "travados" no volume máximo como uma condição de contorno do problema. A seguir é mostrada a Tabela 8 que contém as decisões referentes aos estados do sistema.

Tabela 8 - Tabela de Decisões da Programação Dinâmica para o mês T do exemplo de PDD.

\begin{tabular}{|r|r|r|r|}
\hline \multicolumn{1}{|l|}{$x_{T}$} & \multicolumn{1}{|c|}{$g h_{T}$} & \multicolumn{1}{|c|}{$x_{T+1}$} & \multicolumn{1}{|c|}{$c_{T}^{\text {total }}$} \\
\hline 0 & 1 & 0 & 9 \\
\hline 1 & 2 & 0 & 4 \\
\hline 2 & 3 & 0 & 1 \\
\hline 3 & 4 & 0 & 0 \\
\hline
\end{tabular}

Esse processo deve, como descrito na PDP, ser feito, carregando-se dados referentes aos estados do sistema, infactibilidades e custos futuros, até que a condição de convergência seja atingida. Nesse exemplo de PDD essa condição é atingida no mês $T-11$, após 12 meses de simulação. Isso quer dizer que as decisões $T-11$ foram iguais as decisões $T-8$, as decisões $T-10$ foram iguais as decisões $T-7$ e que as decisões $T-9$ foram iguais as decisões $T-6$ 
Além disso, a coluna $x_{T+1}$ assim como a coluna $c_{T}^{\text {total }}$, são úteis apenas para a criação da tabela de programação dinâmica, no carregamento dos custos futuros, $c_{T}^{\text {total }}$. Na tabela de decisões a coluna dos volumes e dos custos não são utilizadas, sendo úteis, apenas, em sua criação.

Tabela 9 - Tabelas convergidas de Decisões da Programação Dinâmica do exemplo de PDD.

\begin{tabular}{|r|r|r|r|r|r|r|}
\hline \multicolumn{1}{|c|}{$x_{T}$} & \multicolumn{1}{|c|}{$g h_{T-6}$} & \multicolumn{1}{|c|}{$g h_{T-7}$} & \multicolumn{1}{|c|}{$g h_{T-8}$} & $g h_{T-9}$ & $g h_{T-10}$ & $g h_{T-11}$ \\
\hline 0 & 1 & 2 & 2 & 1 & 2 & 2 \\
\hline 1 & 2 & 2 & 2 & 2 & 2 & 2 \\
\hline 2 & 2 & 3 & 2 & 2 & 3 & 2 \\
\hline 3 & 2 & 4 & 3 & 2 & 4 & 3 \\
\hline
\end{tabular}

Após serem obtidas as tabelas devem ser feitas as simulações da operação da usina utilizando-se as tabelas de decisões da PDD. Deverá ser usada a tabela $T-11$ para o primeiro mês, com média 2, a tabela $T-10$ para o segundo mês, com média 4 e a tabela $T-9$ para o último mês, com média 1.

Por se tratar de um exemplo didático algumas decisões em possíveis afluências levariam o sistema a pontos infactíveis pois o exemplo não permite vertimentos e as discretizações das variáveis de estado e decisão foram muito grandes. Na simulação as tabelas devem ser utilizadas de forma cíclica, tendo inicio na tabela correspondente ao mês em questão.

\subsection{Programação Dinâmica Estocástica Independente}

Na programação dinâmica estocástica independente, PDEI, as afluências, assim como na PDD, são representadas de forma estatística. Na PDD a média é tida como um valor com $100 \%$ de probabilidade de afluência. Já na PDEI são obtidas probabilidades para um determinado intervalo de valores em cada mês. Assim como na PDD, não há dependência estatística entre os valores mês a mês e a função de custo é ponderada por estes valores estatísticos independentes.

As probabilidades devem seguir uma distribuição de probabilidades ajustada aos dados de vazão afluente em cada usina. A seguir é apresentada a Figura 16 com o esquema da PDEI.

$$
\begin{array}{llll}
x_{t-1} & x_{t} & y_{t} & x_{T+1}
\end{array}
$$




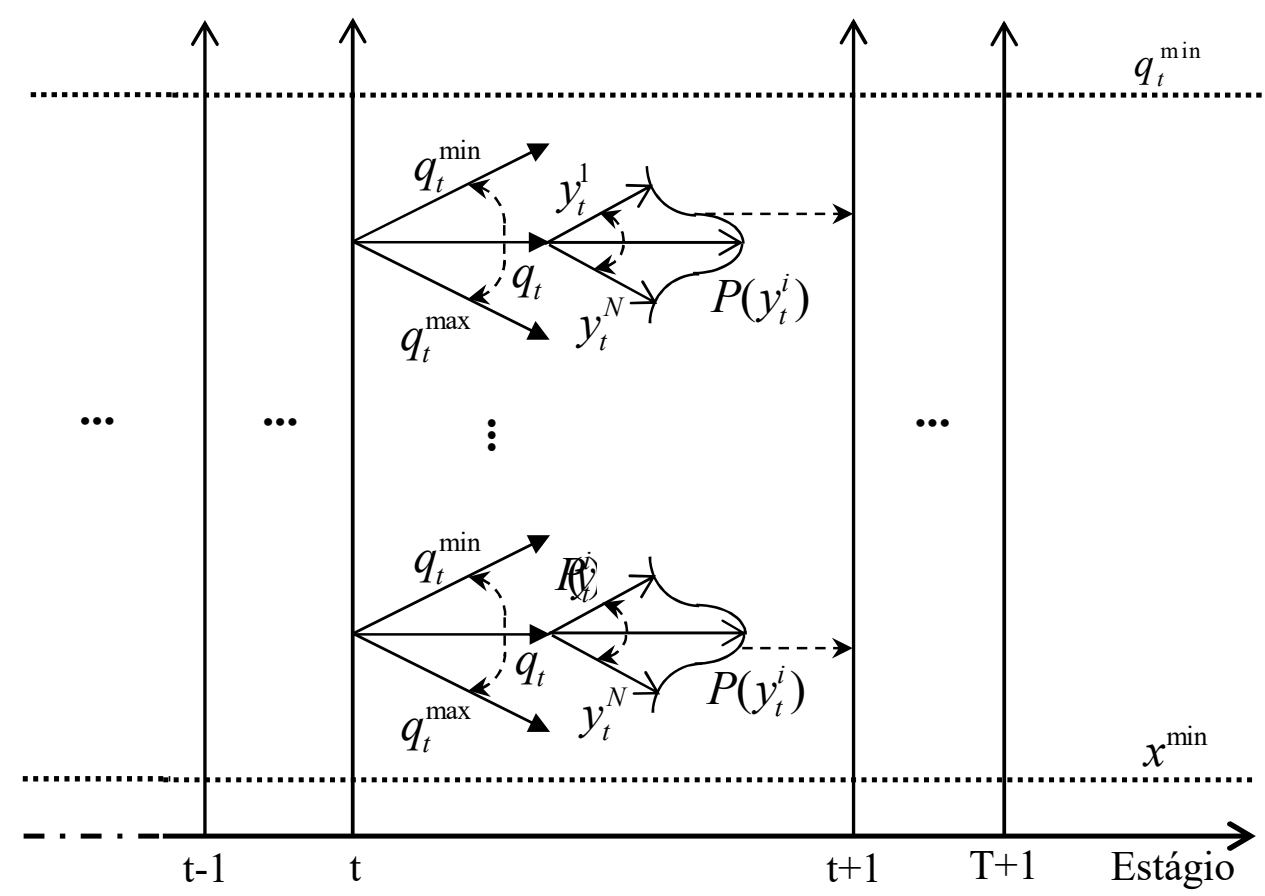

Figura 16 - Esquema da PDEI.

A seguir é mostrado o processo de obtenção desses dados probabilísticos.

\subsubsection{Ajuste de vazões na PDEI}

O ajuste das vazões na PDEI é feito com o uso de distribuições de probabilidades. A distribuição mais utilizada pelo setor é a distribuição log-normal. Vários fenômenos naturais têm seus dados ajustados pela distribuição normal [59], [66], [67]. Algumas outras distribuições também têm sido utilizadas. Dentre elas podemos citar a distribuição log-normal, que é uma alteração na distribuição normal. Considerando um histórico de vazões afluentes, $y_{r, m}$, para os meses $m=1,2,3, \ldots, 12$ e os anos $r=1,2,3, \ldots, n$ temos a função densidade da distribuição normal dada pela seguinte equação:

$$
f\left(y_{m}\right)=\frac{1}{\sqrt{2 \pi} \sigma_{m}} \cdot e^{-\left(\frac{\left(y_{m}-\mu_{m}\right)^{2}}{2 \cdot \sigma_{m}^{2}}\right)}
$$

Onde $\mu_{m}$ e $\sigma_{m}$ são a média e o desvio-padrão, respectivamente, dados por: 


$$
\begin{gathered}
\mu_{m}=\frac{1}{n} \sum_{r=1}^{n} y_{r, m} \\
\sigma_{m}=\sqrt{\frac{1}{n-1} \sum_{r=1}^{n}\left(y_{r, m}-\mu_{m}\right)^{2}}
\end{gathered}
$$

Devem-se escolher os pontos a serem simulados. Em uma primeira etapa devem-se encontrar os valores de mínimo e máximo das afluências, dados por:

$$
\begin{aligned}
& y_{m}^{\min }=\min \left\{y_{r, m} ; r=1,2,3, \ldots, n\right\} \\
& y_{m}^{\max }=\max \left\{y_{r, m} ; r=1,2,3, \ldots, n\right\}
\end{aligned}
$$

Em uma etapa seguinte deve-se escolher o número de pontos, $s$, a serem avaliados. Com esse número de pontos e os valores mínimo, $y_{m}^{\min }$, e máximo, $y_{m}^{\max }$, podemos encontrar os valores destes pontos e as respectivas probabilidades associadas a eles. A diferença entre um ponto e outro, $\Delta_{m}$, é dada pela seguinte equação:

$$
\Delta_{m}=\frac{\left(y_{m}^{\max }-y_{m}^{\min }\right)}{s-2}
$$

O primeiro ponto será dado por:

$$
y_{m}^{1}=y_{m}^{\min }-\frac{\Delta_{m}}{2}
$$

Do segundo ponto em diante deve-se somar ao ponto anterior o valor $\Delta_{m}$ até que o número total de pontos, $s$, seja alcançado.

O cálculo dos valores das probabilidades associadas deverá ser feito usando-se um valor central de cada faixa, entre os pontos calculados anteriormente, com a equação de distribuição de probabilidades normal condicionada. Os valores das probabilidades acumuladas entre esses valores centrais será a probabilidade associada a cada ponto. 
Dessa forma, com valores centrais, $E_{m}$ e $F_{m}$, sendo, $y_{m}^{\min } \leq E_{m}<F_{m} \leq y_{m}^{\max }$, temos a seguinte equação:

$$
P_{m}=\int_{E_{m}}^{F_{m}} f(u) d u
$$

A solução dessa integral não é exata e por isso devemos transformar as vazões em vazões normais, com média nula e desvio padrão unitário as quais têm probabilidades tabeladas. Considerando-se:

$$
\begin{gathered}
z_{m}=\frac{\left(y_{m}-\mu_{m}\right)}{\sigma_{m}} \\
z_{m E}=\frac{\left(E_{m}-\mu_{m}\right)}{\sigma_{m}} \\
z_{m F}=\frac{\left(F_{m}-\mu_{m}\right)}{\sigma_{m}}
\end{gathered}
$$

Pode-se, assim, calcular os valores das probabilidades acumuladas de cada faixa com o auxílio da tabela de distribuição normal padrão que contém os valores da seguinte equação já calculados.

$$
P_{m}=\int_{E_{m}}^{F_{m}} f(u) d u=\int_{z_{m E}}^{z_{m F}} f\left(z_{m}\right) d z_{m}=\varphi\left(z_{m F}\right)-\varphi\left(z_{m E}\right)
$$

E, finalmente:

$$
P_{m}=P\left(E_{m} \leq y_{m} \leq F_{m}\right)=\varphi\left(z_{m F}\right)-\varphi\left(z_{m E}\right)
$$

A seguir são apresentados, apenas como ilustração, os dados referentes ao mês de janeiro para a usina de Furnas. 


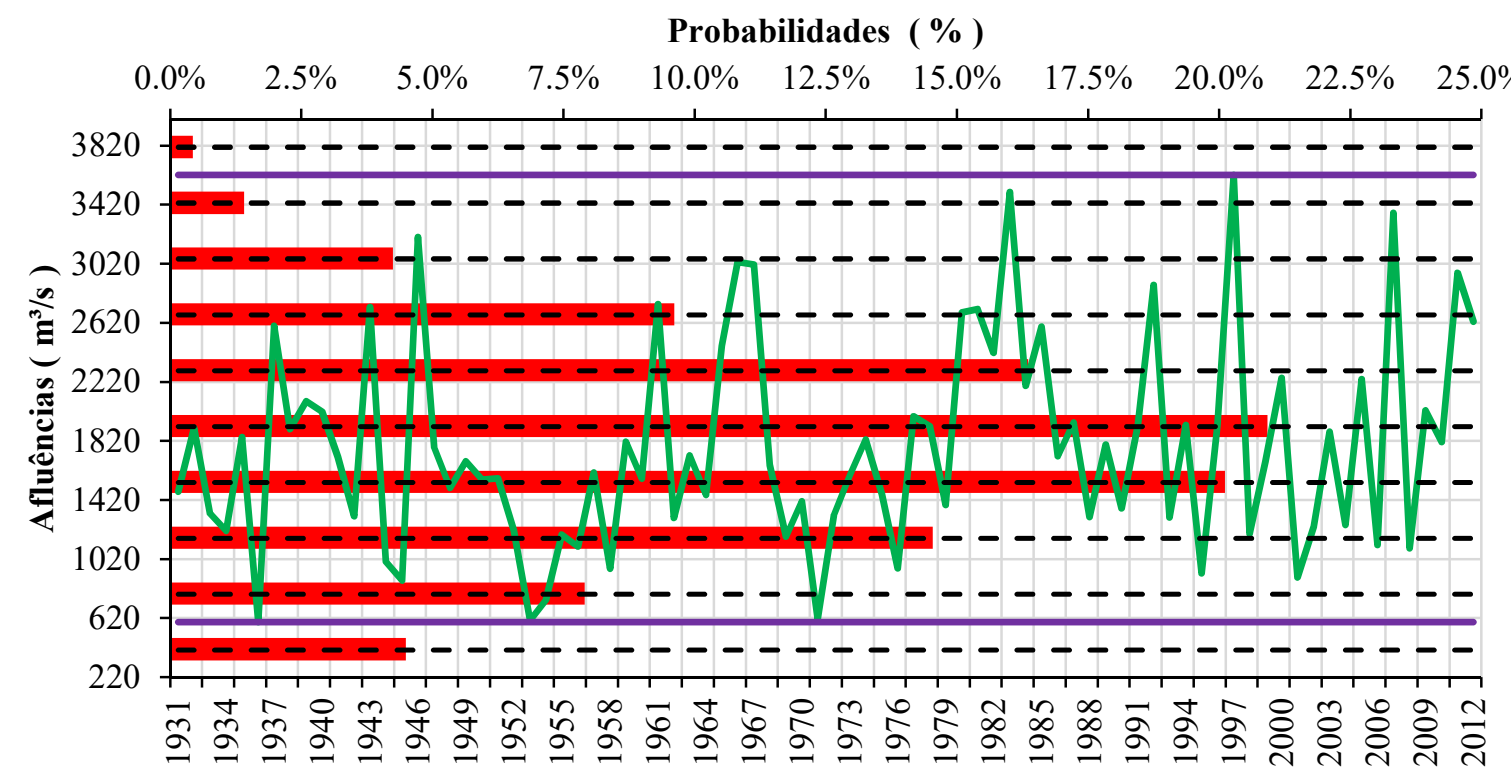

Anos

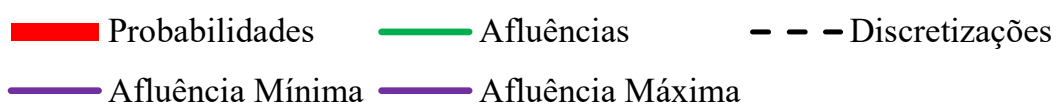

Figura 17 - Dados históricos de afluências, valores discretizados e estatísticas obtidas com a distribuição normal para a usina hidrelétrica de Furnas no mês de janeiro para a PDEI.

A seguir é apresentado um exemplo didático do uso da PDEI.

\subsubsection{Exemplo didático da PDEI}

Para a PDEI também será mostrado a seguir um exemplo prático, simples e didático.

Nesse exemplo um sistema hidrotérmico deve atender uma demanda $d_{t}=4$. O reservatório da usina hidrelétrica, expresso em termos energéticos, tem uma capacidade máxima de $3 \mathrm{UV}$, unidades de volume.

Esta usina hidrelétrica recebe uma afluência estatística com sazonalidade que se repete a cada três meses de $y_{t=A, B, C}=\{[1,2,3],[3,4,5],[0,1,2]\}$, com probabilidades associadas $p_{t=A, B, C}=\{[0,20 ; 0,55 ; 0,25],[0,15 ; 0,65 ; 0,20],[0,05 ; 0,85 ; 0,10]\}$, e está motorizado para gerar um máximo de $4 \mathrm{UP}$, unidades de potência. O custo da produção de energia térmica é dado por $c_{t}\left(g t_{t}\right)=g t_{t}^{2}$. Deve-se fazer o planejamento otimizado da operação, usando uma discretização de 1 UV e 1 UP.

Inicialmente devemos modelar o problema: 


$$
a_{0}\left(x_{0}\right)=\min E_{y}\left\{\sum_{t=1}^{T}\left(d_{t}-g h_{t}\right)^{2}\right\}
$$

Sujeito a:

$$
\begin{gathered}
x_{t}=x_{t-1}+y_{t}-g h_{t} \\
d_{t}=g t_{t}+g h_{t} \\
0 \leq x_{t} \leq 3 \\
0 \leq g h_{t} \leq 4
\end{gathered}
$$

Para obtenção das tabelas de decisões da PDEI serão construídas as tabelas dinâmicas do último estágio para o primeiro, no modo backward. O custo final foi considerado nulo e os custos associados a cada decisão devem ser somados às etapas anteriores. Além disso, as operações infactíveis também devem ser repassadas aos estágios anteriores, como na PDP.

Deve-se efetuar o processo até que o critério de convergência, que é a igualdade entre as decisões de todos os meses, seja atingido. Esse número de meses a serem simulados pode variar muito, dependendo dos dados de entrada da usina hidrelétrica a ser otimizada. A seguir é mostrada a Tabela 10 que contém os dados de entrada referentes ao último mês simulado.

Tabela 10 - Dados de entradas de afluências, probabilidades e demanda.

\begin{tabular}{|r|r|r|r|r|r|r|}
\hline$y_{T}^{A}$ & $y_{T}^{B}$ & $y_{T}^{C}$ & $p_{T}^{A}$ & $p_{T}^{B}$ & $p_{T}^{C}$ & $d_{T}$ \\
\hline 0 & 1 & 2 & 0,05 & 0,85 & 0,10 & 4 \\
\hline
\end{tabular}

O cálculo de $c_{T}^{\text {total }}$ é feito com a seguinte equação:

$$
c_{T}^{\text {total }}=p_{T}^{A} \cdot\left(\begin{array}{c}
\text { imediato } \\
c_{T}+c_{T}^{A}
\end{array}\right)+p_{T}^{B} \cdot\left(\begin{array}{c}
\text { imediato } \\
c_{T}+c_{T}^{B}
\end{array}\right)+p_{T}^{C} \cdot\left(\begin{array}{c}
\text { fimediato } \\
c_{T}+c_{T}^{C}
\end{array}\right)
$$

A Tabela 11, com a tabela de programação dinâmica para o mês T do exemplo de PDEI é mostrada a seguir.

Tabela 11 - Tabela de Programação Dinâmica para o mês T do exemplo de PDEI. 


\begin{tabular}{|c|c|c|c|c|c|c|c|c|c|}
\hline$x_{T}$ & $g h_{T}$ & $x_{T+1}^{A}$ & $x_{T+1}^{B}$ & $x_{T+1}^{C}$ & $\begin{array}{c}\text { imediato } \\
c_{T}\end{array}$ & $\begin{array}{c}\text { futuro } \\
c_{T}^{A}\end{array}$ & $\begin{array}{c}\text { futuro } \\
c_{T}^{B}\end{array}$ & $\begin{array}{l}\text { futuro } \\
c_{T}^{C}\end{array}$ & $\begin{array}{l}\text { total } \\
c_{T}\end{array}$ \\
\hline 0 & 0 & 0 & 1 & 2 & 16 & 0 & 0 & 0 & 16 \\
\hline 0 & 1 & -1 & 0 & 1 & INF & 0 & 0 & 0 & INF \\
\hline 0 & 2 & -2 & -1 & 0 & INF & 0 & 0 & 0 & INF \\
\hline 0 & 3 & -3 & -2 & -1 & INF & 0 & 0 & 0 & INF \\
\hline 0 & 4 & -4 & -3 & -2 & INF & 0 & 0 & 0 & INF \\
\hline 1 & 0 & 1 & 2 & 3 & 16 & 0 & 0 & 0 & 16 \\
\hline 1 & 1 & 0 & 1 & 2 & 9 & 0 & 0 & 0 & 9 \\
\hline 1 & 2 & -1 & 0 & 1 & INF & 0 & 0 & 0 & INF \\
\hline 1 & 3 & -2 & -1 & 0 & INF & 0 & 0 & 0 & INF \\
\hline 1 & 4 & -3 & -2 & -1 & INF & 0 & 0 & 0 & INF \\
\hline 2 & 0 & 2 & 3 & 4 & INF & 0 & 0 & 0 & INF \\
\hline 2 & 1 & 1 & 2 & 3 & 9 & 0 & 0 & 0 & 9 \\
\hline 2 & 2 & 0 & 1 & 2 & 4 & 0 & 0 & 0 & 4 \\
\hline 2 & 3 & -1 & 0 & 1 & INF & 0 & 0 & 0 & INF \\
\hline 2 & 4 & -2 & -1 & 0 & INF & 0 & 0 & 0 & INF \\
\hline 3 & 0 & 3 & 4 & 5 & INF & 0 & 0 & 0 & INF \\
\hline 3 & 1 & 2 & 3 & 4 & INF & 0 & 0 & 0 & INF \\
\hline 3 & 2 & 1 & 2 & 3 & 4 & 0 & 0 & 0 & 4 \\
\hline 3 & 3 & 0 & 1 & 2 & 1 & 0 & 0 & 0 & 1 \\
\hline 3 & 4 & -1 & 0 & 1 & INF & 0 & 0 & 0 & INF \\
\hline
\end{tabular}

Novamente, como a PDD, deve-se obter a tabela de decisões para cada estado do sistema. Deve-se notar que a coluna $c_{T}^{\text {futuro }}$ é nula e que os volumes $x_{T+1}^{A}, x_{T+1}^{B}$ e $x_{T+1}^{C}$ não são "travados" no volume máximo como uma condição de contorno do problema. A seguir é mostrada a Tabela 8 que contém as decisões referentes aos estados do sistema.

Tabela 12 - Tabela de Decisões da Programação Dinâmica para o mês T do exemplo de PDEI.

\begin{tabular}{|r|r|r|r|}
\hline \multicolumn{1}{|l|}{$x_{T}$} & \multicolumn{1}{|c|}{$g h_{T}$} & \multicolumn{1}{|c|}{$x_{T+1}$} & \multicolumn{2}{|c|}{$c_{T}^{\text {total }}$} \\
\hline 0 & 0 & 0 & 16 \\
\hline 1 & 1 & 0 & 9 \\
\hline 2 & 2 & 0 & 4 \\
\hline 3 & 3 & 0 & 1 \\
\hline
\end{tabular}

A Tabela 13 de programação dinâmica para o mês T-1 do exemplo de PDEI é mostrada a seguir.

Tabela 13 - Tabela de Programação Dinâmica para o mês T-1 do exemplo de PDEI. 


\begin{tabular}{|c|c|c|c|c|c|c|c|c|c|}
\hline$x_{T-1}$ & $g h_{T-1}$ & $x_{T}^{A}$ & $x_{T}^{B}$ & $x_{T}^{C}$ & $\begin{array}{c}\text { imediato } \\
c_{T-1}\end{array}$ & $\begin{array}{l}\text { futuro } \\
c_{T-1}^{A}\end{array}$ & $\begin{array}{l}\text { futuro } \\
c_{T-1}^{B}\end{array}$ & $\begin{array}{l}\text { futuro } \\
c_{T-1}^{C}\end{array}$ & $\begin{array}{l}\text { total } \\
c_{T-1}\end{array}$ \\
\hline 0 & 0 & 3 & 4 & 5 & INF & INF & INF & INF & INF \\
\hline 0 & 1 & 2 & 3 & 4 & INF & INF & INF & INF & INF \\
\hline 0 & 2 & 1 & 2 & 3 & 4 & 9 & 4 & 1 & 8,15 \\
\hline 0 & 3 & 0 & 1 & 2 & 1 & 16 & 9 & 4 & 10,05 \\
\hline 0 & 4 & -1 & 0 & 1 & INF & INF & INF & INF & INF \\
\hline 1 & 0 & 4 & 5 & 6 & INF & INF & INF & INF & INF \\
\hline 1 & 1 & 3 & 4 & 5 & INF & INF & INF & INF & INF \\
\hline 1 & 2 & 2 & 3 & 4 & INF & INF & INF & INF & INF \\
\hline 1 & 3 & 1 & 2 & 3 & 1 & 9 & 4 & 1 & 5,15 \\
\hline 1 & 4 & 0 & 1 & 2 & 0 & 16 & 9 & 4 & 9,05 \\
\hline 2 & 0 & 5 & 6 & 7 & INF & INF & INF & INF & INF \\
\hline 2 & 1 & 4 & 5 & 6 & INF & INF & INF & INF & INF \\
\hline 2 & 2 & 3 & 4 & 5 & INF & INF & INF & INF & INF \\
\hline 2 & 3 & 2 & 3 & 4 & INF & INF & INF & INF & INF \\
\hline 2 & 4 & 1 & 2 & 3 & 0 & 9 & 4 & 1 & 4,15 \\
\hline 3 & 0 & 6 & 7 & 8 & INF & INF & INF & INF & INF \\
\hline 3 & 1 & 5 & 6 & 7 & INF & INF & INF & INF & INF \\
\hline 3 & 2 & 4 & 5 & 6 & INF & INF & INF & INF & INF \\
\hline 3 & 3 & 3 & 4 & 5 & INF & INF & INF & INF & INF \\
\hline 3 & 4 & 2 & 3 & 4 & INF & INF & INF & INF & INF \\
\hline
\end{tabular}

Esse processo deve, como descrito na PDD, ser feito, carregando-se dados referentes aos estados do sistema, infactibilidades e custos futuros, até que a condição de convergência seja atingida. Nesse exemplo de PDD essa condição é atingida no mês 5, após 6 meses de simulação. Isso quer dizer que as decisões $T-5$ foram iguais às decisões $T-2$, as decisões $T-4$ foram iguais às decisões $T-1$ e que as decisões $T-3$ foram iguais às decisões $T$.

Tabela 14 - Tabelas convergidas de Decisões da Programação Dinâmica do exemplo de PDEI.

\begin{tabular}{|r|r|r|r|r|r|r|}
\hline \multicolumn{1}{|c|}{$x_{T}$} & \multicolumn{1}{|l|}{$g h_{T}$} & \multicolumn{1}{|c|}{$g h_{T-1}$} & \multicolumn{1}{|c|}{$g h_{T-2}$} & $g h_{T-3}$ & $g h_{T-4}$ & $g h_{T-5}$ \\
\hline 0 & 0 & 2 & 1 & 0 & 2 & 1 \\
\hline 1 & 1 & 3 & 2 & 1 & 3 & 2 \\
\hline 2 & 2 & 4 & 3 & 2 & 4 & 3 \\
\hline 3 & 3 & INF & 4 & 3 & INF & 4 \\
\hline
\end{tabular}

O fato da decisão do mês 2 ter um valor infactível para o volume máximo quer dizer que se o reservatório chegar ao segundo mês, em um volume máximo, tem-se uma chance de operação em uma região infactível. Isso, na prática, não deve ocorrer nunca e a tabela de decisões deve ter uma decisão para todos os estados possíveis do reservatório. A ocorrência 
nesse caso se dá pela impossibilidade de vertimentos e pela discretização grosseira das variáveis de estado e de decisão.

Apenas como demonstração são mostradas a seguir, de forma gráfica, na Figura 18, as tabelas de programação dinâmica e, em destaque, a tabela de decisões para a usina de Serra da Mesa com uma discretização de 100 pontos nas variáveis de estado e decisão e com distribuição normal de probabilidades.

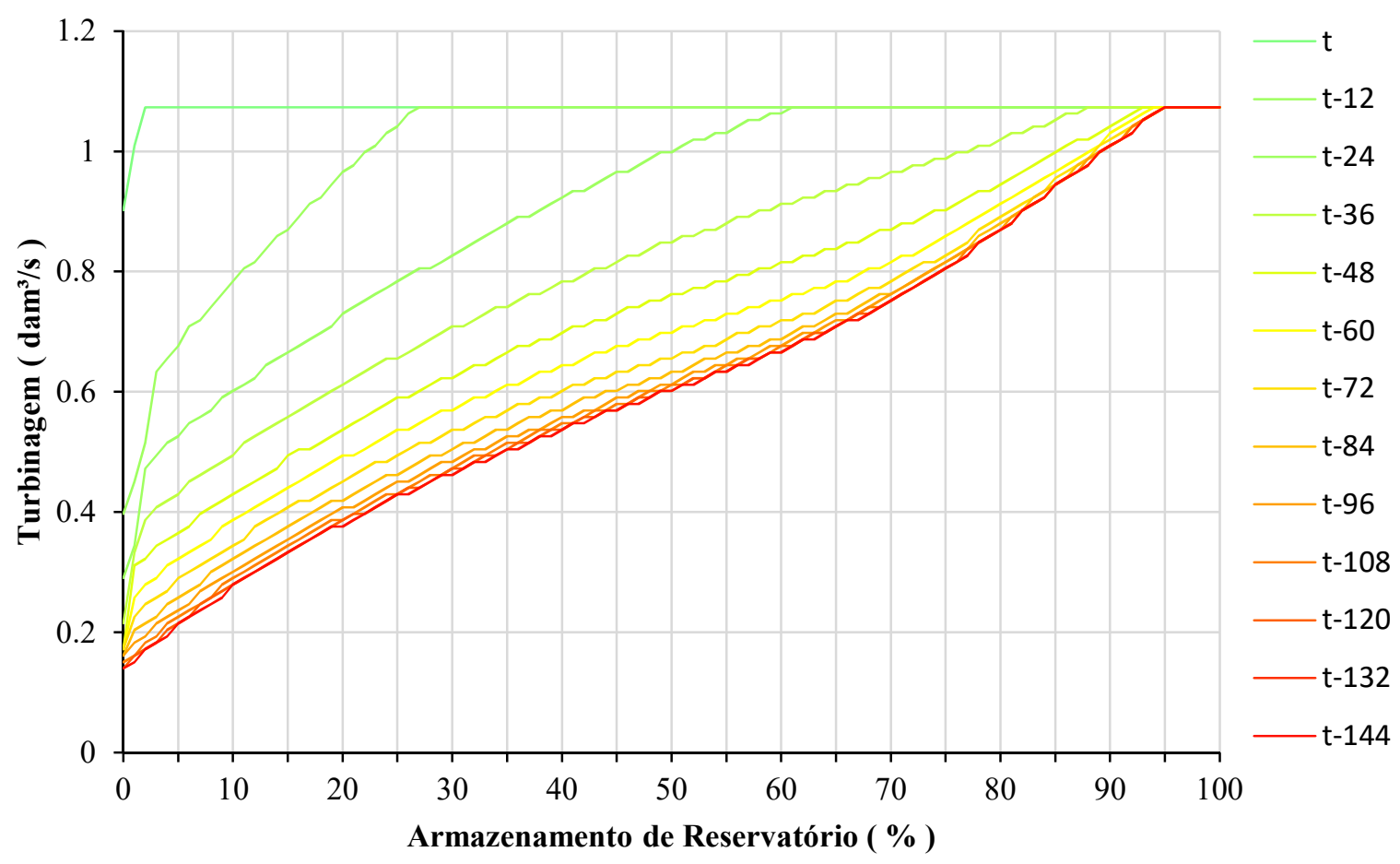

Figura 18 - Tabelas de decisões da programação dinâmica em forma gráfica para a usina de Serra da Mesa para o mês de dezembro.

Nesse exemplo da usina de Serra da Mesa são necessários 12 anos de simulação até que a convergência seja alcançada. A curva em vermelho é a curva a ser usada como tabela de decisões para a usina de Serra da Mesa no mês de dezembro. As decisões se iniciam em patamares mais altos pois os custos futuros, no início do processo, influenciam pouco as decisões. Com o passar dos anos simulados esses custos passam a influenciar mais nas decisões até que o ponto de equilíbrio seja alcançado e o processo convirja. 
A programação dinâmica estocástica dependente ou Markoviana, PDEM, é o modo da programação dinâmica onde as vazões afluentes ocorridas anteriormente tem influência sobre as decisões para cada estado do sistema.

$\mathrm{Na}$ PDEM, assim como na PDEI, devem ser obtidas distribuições de probabilidades para as afluências, mas, diferentemente da PDEI, estas estatísticas serão dependentes de vazões ocorridas anteriormente.

As probabilidades devem seguir uma distribuição dependente de probabilidades ajustada aos dados de vazão afluente em cada usina. A seguir, na Figura 19, é mostrado o esquema da PDEM.

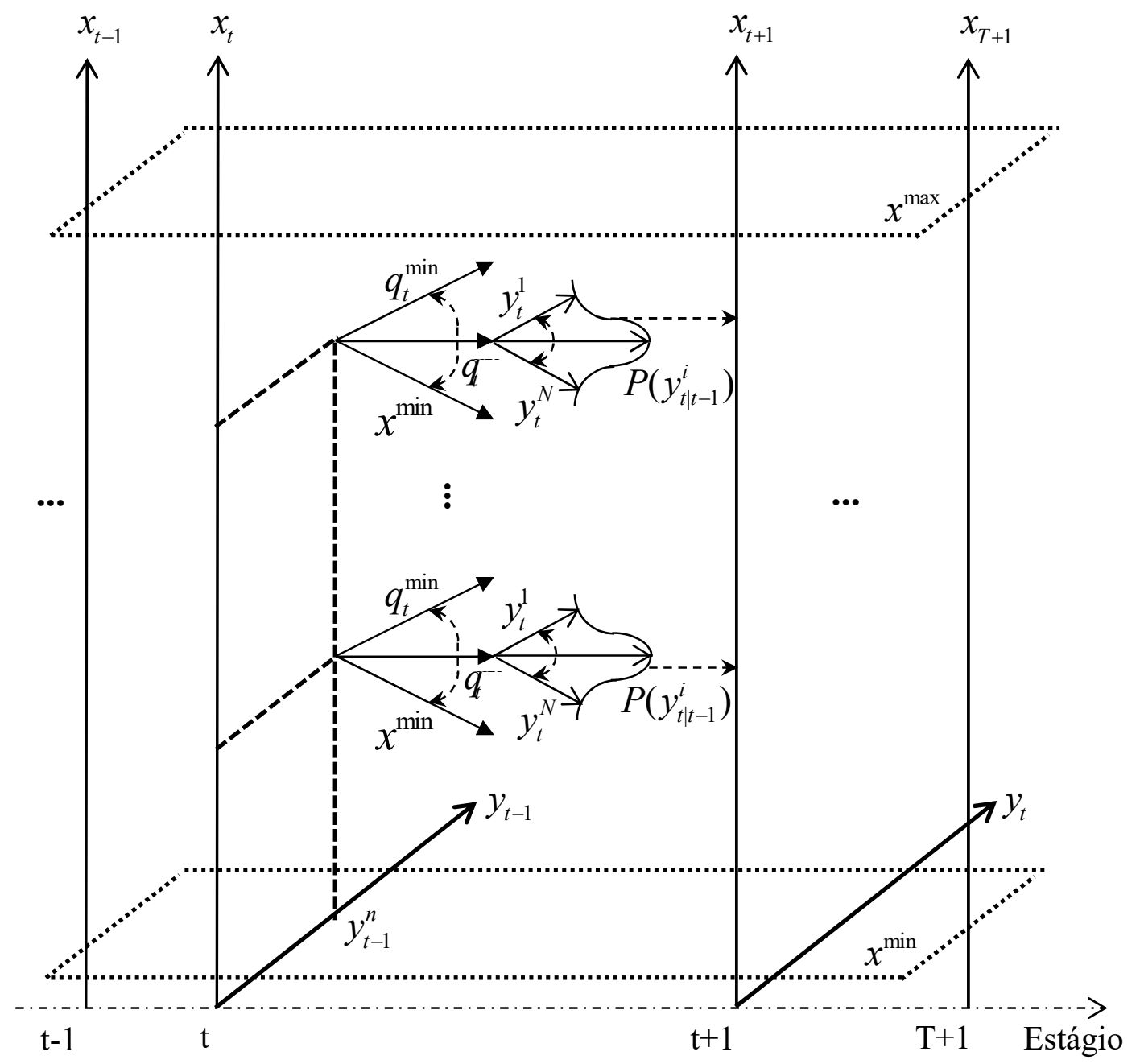

Figura 19 - Esquema da PDEM.

A seguir é mostrado o processo de obtenção desses dados probabilísticos. 


\subsubsection{Ajuste de vazões na PDEM}

O ajuste das vazões na PDEM é feito de maneira similar ao ajuste feito na PDEI. O processo de obtenção dos pontos é o mesmo da PDEI. Já as probabilidades diferem um pouco, pois considera-se média e desvio padrão condicionados à vazão anterior. Considerando um histórico de vazões afluentes, $y_{r, m}$, para os meses $m=1,2,3, \ldots, 12$ e os anos $r=1,2,3, \ldots, n$ temos a função densidade condicionada da distribuição normal dada pela seguinte equação:

$$
f\left(y_{m} \mid y_{m-1}\right)=\frac{1}{\sqrt{2 \pi} \sigma_{m \mid m-1}} \cdot e^{-\left(\frac{\left(y_{m}-\mu_{m \mid m-1}\right)^{2}}{2 \cdot \sigma_{m \mid m-1}^{2}}\right)}
$$

Onde $\mu_{m}$ a média do referido período, $\mu_{m \mid m-1}$ anterior ao referido período, $\sigma_{m}$ o desvio-padrão do referido período e $\sigma_{m \mid m-1}$ o desvio padrão anterior ao referido período. Os valores de $\mu_{m \mid m-1}$ e $\sigma_{m \mid m-1}$ são, respectivamente, dados por:

$$
\begin{gathered}
\mu_{m \mid m-1}=\mu_{m}+\rho_{m} \frac{\sigma_{m}}{\sigma_{m-1}}\left(y_{m-1}-\mu_{m-1}\right) \\
\sigma_{m \mid m-1}=\sigma_{m} \sqrt{1-\rho_{m}^{2}}
\end{gathered}
$$

Sendo $\rho_{m}$, a correlação cruzada entre os dados, dada por:

$$
\rho_{m}=\frac{\sum_{r=1}^{n}\left[\left(y_{r, m}-\mu_{m}\right)\left(y_{r, m-1}-\mu_{m-1}\right)\right]}{\sigma_{m} \sigma_{m-1}}
$$

O processo de obtenção dos valores das distribuições de probabilidades é o mesmo da PDEI, diferenciando-se, apenas, pelo uso de funções modificadas de distribuições de probabilidades. 
A seguir são apresentados, apenas como ilustração, os dados referentes ao mês de fevereiro para a usina de Furnas.
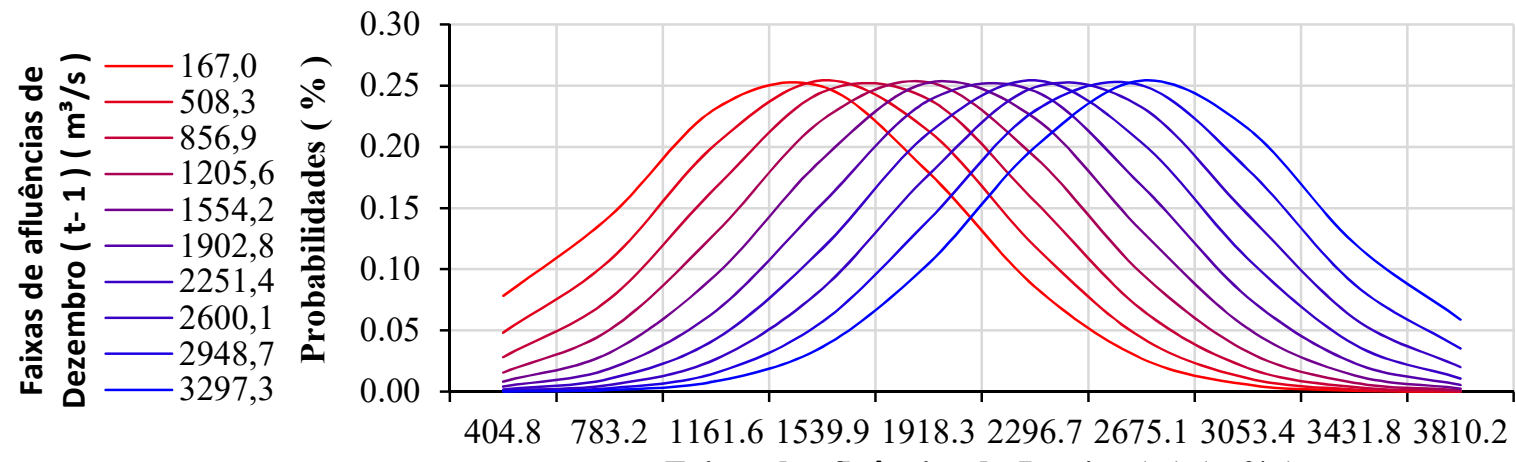

Faixas de afluências de Janeiro ( $\mathrm{t}$ ) ( $\left.\mathrm{m}^{3} / \mathrm{s}\right)$

Figura 20 - Dados históricos de afluências, valores discretizados e estatísticas obtidas com a distribuição normal para a usina hidrelétrica de Furnas no mês de Janeiro para a PDEM.

A seguir é apresentado um exemplo didático do uso da PDEM.

\subsubsection{Exemplo didático da PDEM}

Para a PDEM também será mostrado a seguir um exemplo prático, simples e didático. Nesse exemplo um sistema hidrotérmico deve atender uma demanda $d_{t}=4$. O reservatório da usina hidrelétrica, expresso em termos energéticos, tem uma capacidade máxima de $3 \mathrm{UV}$, unidades de volume.

Esta usina hidrelétrica recebe uma afluência estatística com sazonalidade que se repete a cada três meses com probabilidades associadas mostradas na Tabela 15, a seguir, e está motorizado para gerar um máximo de $4 \mathrm{UP}$, unidades de potência. O custo da produção de energia térmica é dado por $c_{t}\left(g t_{t}\right)=g t_{t}^{2}$. Deve-se fazer o planejamento otimizado da operação, usando uma discretização de 1 UV e 1 UP.

Tabela 15 - Afluências e probabilidades para o exemplo da PDEM.

\begin{tabular}{|c|c|c|c|c|c|c|c|c|c|c|c|c|}
\hline$y_{t-1}[\mathrm{UV}]$ & \multicolumn{2}{|c|}{0} & \multicolumn{2}{|c|}{1} & \multicolumn{2}{|c|}{1} & \multicolumn{2}{|c|}{2} & \multicolumn{3}{|c|}{3} & \multicolumn{2}{|c|}{4} \\
\hline$y_{t}[\mathrm{UV}]$ & 1 & 2 & 1 & 2 & 3 & 4 & 3 & 4 & 0 & 1 & 0 & 1 \\
\hline$p_{t}[\%]$ & 0,6 & 0,4 & 0,2 & 0,8 & 0,7 & 0,3 & 0,1 & 0,9 & 0,6 & 0,4 & 0,4 & 0,6 \\
\hline
\end{tabular}


A modelagem do problema e o modo de construção das tabelas na PDEM é a mesma que na PDEI. A seguir é mostrada a tabela inicial da PDEM.

Tabela 16 - Tabela de Programação Dinâmica para o mês T do exemplo de PDEM.

\begin{tabular}{|c|c|c|c|c|c|c|c|c|c|c|}
\hline$x_{T}$ & $g h_{T}$ & $x_{T+1}^{A}$ & $x_{T+1}^{B}$ & $y_{T-1}$ & $y_{T}^{A}$ & $y_{T}^{B}$ & $\begin{array}{c}\text { imediato } \\
c_{T}\end{array}$ & $\begin{array}{c}\text { futuro } \\
c_{T}^{A}\end{array}$ & $\begin{array}{c}\text { futuro } \\
c_{T}^{B}\end{array}$ & $\begin{array}{l}\text { total } \\
c_{T}\end{array}$ \\
\hline 0 & 0 & 0 & 1 & 3 & 0 & 1 & 16 & 0 & 0 & 16 \\
\hline 0 & 1 & -1 & 0 & 3 & 0 & 1 & INF & 0 & 0 & INF \\
\hline 0 & 2 & -2 & -1 & 3 & 0 & 1 & INF & 0 & 0 & INF \\
\hline 0 & 3 & -3 & -2 & 3 & 0 & 1 & INF & 0 & 0 & INF \\
\hline 0 & 4 & -4 & -3 & 3 & 0 & 1 & INF & 0 & 0 & INF \\
\hline 1 & 0 & 1 & 2 & 3 & 0 & 1 & 16 & 0 & 0 & 16 \\
\hline 1 & 1 & 0 & 1 & 3 & 0 & 1 & 9 & 0 & 0 & 9 \\
\hline 1 & 2 & -1 & 0 & 3 & 0 & 1 & INF & 0 & 0 & INF \\
\hline 1 & 3 & -2 & -1 & 3 & 0 & 1 & INF & 0 & 0 & INF \\
\hline 1 & 4 & -3 & -2 & 3 & 0 & 1 & INF & 0 & 0 & INF \\
\hline 2 & 0 & 2 & 3 & 3 & 0 & 1 & 16 & 0 & 0 & 16 \\
\hline 2 & 1 & 1 & 2 & 3 & 0 & 1 & 9 & 0 & 0 & 9 \\
\hline 2 & 2 & 0 & 1 & 3 & 0 & 1 & 4 & 0 & 0 & 4 \\
\hline 2 & 3 & -1 & 0 & 3 & 0 & 1 & INF & 0 & 0 & INF \\
\hline 2 & 4 & -2 & -1 & 3 & 0 & 1 & INF & 0 & 0 & INF \\
\hline 3 & 0 & 3 & 4 & 3 & 0 & 1 & INF & 0 & 0 & INF \\
\hline 3 & 1 & 2 & 3 & 3 & 0 & 1 & 9 & 0 & 0 & 9 \\
\hline 3 & 2 & 1 & 2 & 3 & 0 & 1 & 4 & 0 & 0 & 4 \\
\hline 3 & 3 & 0 & 1 & 3 & 0 & 1 & 1 & 0 & 0 & 1 \\
\hline 3 & 4 & -1 & 0 & 3 & 0 & 1 & INF & 0 & 0 & INF \\
\hline 0 & 0 & 0 & 1 & 4 & 0 & 1 & 16 & 0 & 0 & 16 \\
\hline 0 & 1 & -1 & 0 & 4 & 0 & 1 & INF & 0 & 0 & INF \\
\hline 0 & 2 & -2 & -1 & 4 & 0 & 1 & INF & 0 & 0 & INF \\
\hline 0 & 3 & -3 & -2 & 4 & 0 & 1 & INF & 0 & 0 & INF \\
\hline 0 & 4 & -4 & -3 & 4 & 0 & 1 & INF & 0 & 0 & INF \\
\hline 1 & 0 & 1 & 2 & 4 & 0 & 1 & 16 & 0 & 0 & 16 \\
\hline 1 & 1 & 0 & 1 & 4 & 0 & 1 & 9 & 0 & 0 & 9 \\
\hline 1 & 2 & -1 & 0 & 4 & 0 & 1 & INF & 0 & 0 & INF \\
\hline 1 & 3 & -2 & -1 & 4 & 0 & 1 & INF & 0 & 0 & INF \\
\hline 1 & 4 & -3 & -2 & 4 & 0 & 1 & INF & 0 & 0 & INF \\
\hline 2 & 0 & 2 & 3 & 4 & 0 & 1 & 16 & 0 & 0 & 16 \\
\hline 2 & 1 & 1 & 2 & 4 & 0 & 1 & 9 & 0 & 0 & 9 \\
\hline 2 & 2 & 0 & 1 & 4 & 0 & 1 & 4 & 0 & 0 & 4 \\
\hline 2 & 3 & -1 & 0 & 4 & 0 & 1 & INF & 0 & 0 & INF \\
\hline 2 & 4 & -2 & -1 & 4 & 0 & 1 & INF & 0 & 0 & INF \\
\hline 3 & 0 & 3 & 4 & 4 & 0 & 1 & INF & 0 & 0 & INF \\
\hline 3 & 1 & 2 & 3 & 4 & 0 & 1 & 9 & 0 & 0 & 9 \\
\hline 3 & 2 & 1 & 2 & 4 & 0 & 1 & 4 & 0 & 0 & 4 \\
\hline 3 & 3 & 0 & 1 & 4 & 0 & 1 & 1 & 0 & 0 & 1 \\
\hline 3 & 4 & -1 & 0 & 4 & 0 & 1 & INF & 0 & 0 & INF \\
\hline
\end{tabular}


Ao final do processo de construção das tabelas teremos a seguinte tabela de decisões:

Tabela 17 - Tabelas convergidas de Decisões da Programação Dinâmica do exemplo de PDEM.

\begin{tabular}{|c|c|c|c|c|c|c|}
\hline$x_{T}$ & $y_{3}$ & $g h_{1}$ & $y_{1}$ & $g h_{2}$ & $y_{2}$ & $g h_{3}$ \\
\hline \multirow{2}{*}{0} & 0 & 1 & 1 & 2 & 3 & 0 \\
\hline & 1 & 1 & 2 & 2 & 4 & 0 \\
\hline \multirow{2}{*}{1} & 0 & 2 & 1 & 2 & 3 & 1 \\
\hline & 1 & 2 & 2 & 2 & 4 & 1 \\
\hline \multirow{2}{*}{2} & 0 & 2 & 1 & 3 & 3 & 2 \\
\hline & 1 & 2 & 2 & 3 & 4 & 2 \\
\hline \multirow{2}{*}{3} & 0 & 3 & 1 & 4 & 3 & 3 \\
\hline & 1 & 3 & 2 & 4 & 4 & 3 \\
\hline
\end{tabular}

Neste exemplo didático da PDEM as decisões obtidas variaram apenas com o volume armazenado e não com as afluências anteriores. Isso foi devido ao fato de estarmos trabalhando com probabilidades hipotéticas em um reservatório com volume e geração hidráulica reduzidos e com uma discretização muito grande. Deve-se ressaltar que se trata de um exemplo didático com o intuito de demonstrar a técnica utilizada neste trabalho. A seguir é mostrada a Figura 21 com as tabelas, em forma gráfica, de um exemplo real da aplicação da PDEM.

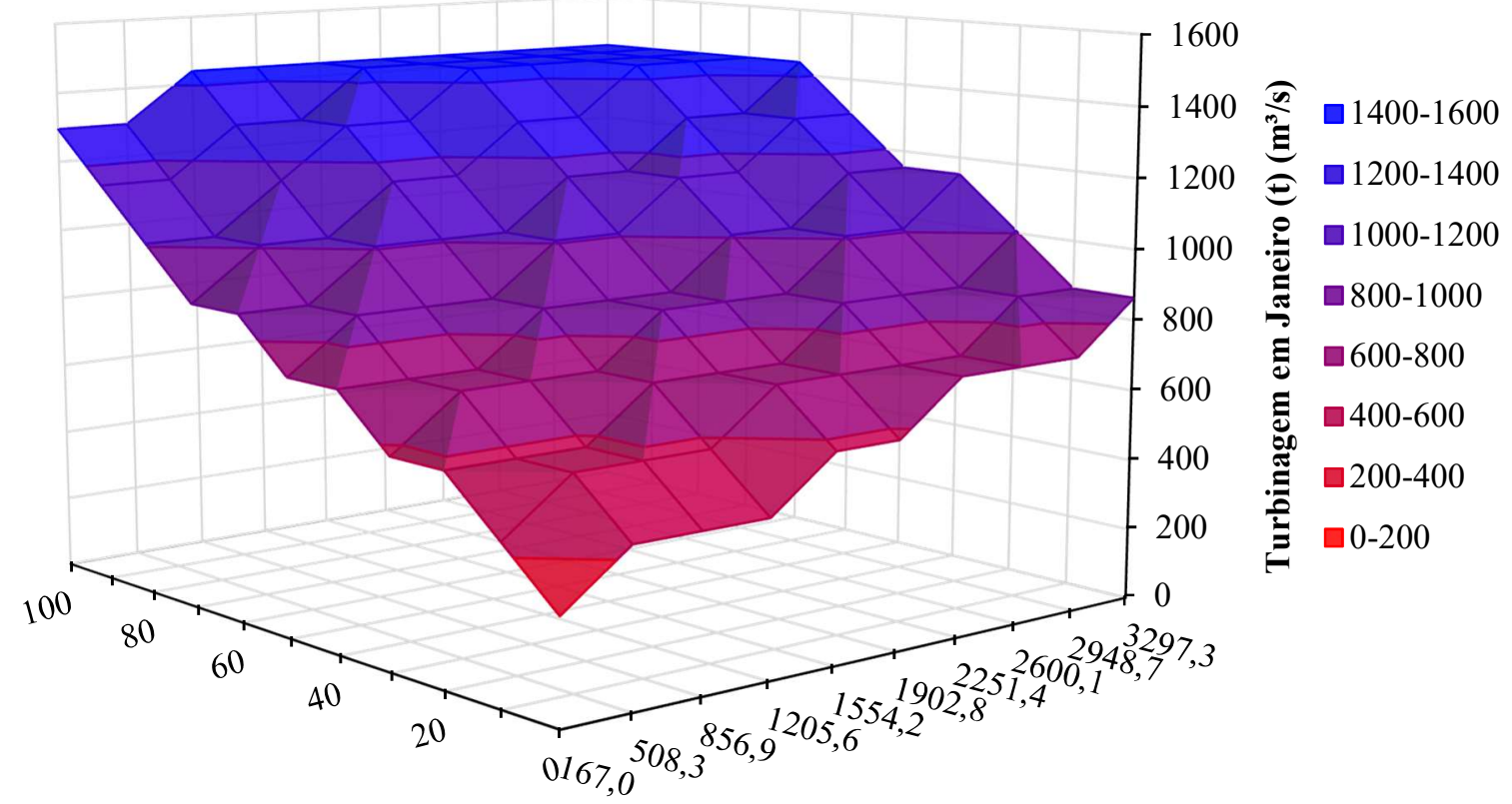

Volume armazenado em Janeiro (t) (\%)

Afluência de Dezembro (t-1) $\left(\mathrm{m}^{3} / \mathrm{s}\right)$

Figura 21 - Tabelas de decisões da PDEM em forma gráfica para a usina de Furnas para o mês de janeiro. 
Pelo exemplo da tabela PDEM da usina hidrelétrica de Furnas para o mês de janeiro percebemos que a variável de decisão, a turbinagem da usina, varia com a variável de estado, o volume armazenado no início do referido mês, janeiro, e com a afluência ocorrida no mês anterior, dezembro.

\subsection{Modelagem Proposta}

A modelagem proposta por este trabalho, a Programação Dinâmica Estocástica Markoviana (PDEM-k), utiliza toda a técnica da Programação Dinâmica, em sua versão estocástica dependente Markoviana, mas com alterações na forma de tratamento dos dados de afluências e na questão da discretização temporal.

O processo de desenvolvimento da técnica proposta passou por alguns passos intermediários os quais serão discutidos detalhadamente. Assim como na PDEM, a técnica de modelagem proposta utiliza 3 fases para todo o processo da PDEM, sendo eles: modelagem probabilística que é a criação das faixas discretizadas de valores de afluências e probabilidades associadas a cada faixa, otimização que é a criação das tabelas de decisão de turbinagem e simulação com base nas afluências reais ocorridas e nas tabelas obtidas no passo anterior.

A primeira tentativa feita foi a de se trabalhar com valores de afluências simplesmente somados em grupos anuais, como descrito pela equação (51).

$$
y_{m}^{a g}=\frac{\sum_{m=1}^{12} y_{m}}{12}
$$

Dessa forma passamos a ter 12 valores de afluências a cada 12 meses. Como exemplo podemos citar Julho de 1931 que na abordagem agregada anual continha os dados das afluências mensais somadas entre Julho de 1931 e Junho de 1932. Deve-se salientar que Julho de 1931 é a base temporal de dados e não a afluência ocorrida no mês de Julho de 1931. Além disso, o fator divisor 12 foi adicionado apenas com o intuito de facilitar a criação das tabelas de decisões, evitando-se assim a alteração do fator $\delta$.

A Figura 22 mostrada a seguir ilustra com detalhes a comparação entre a abordagem clássica mensal e a abordagem agregada anual, inicialmente proposta. Nela são mostrados os dados das densidades de probabilidades log-normal independentes mensais e agregados anuais de todos os meses além das densidades de probabilidades log-normal dependentes para Janeiro e Julho na abordagem agregada anual. 

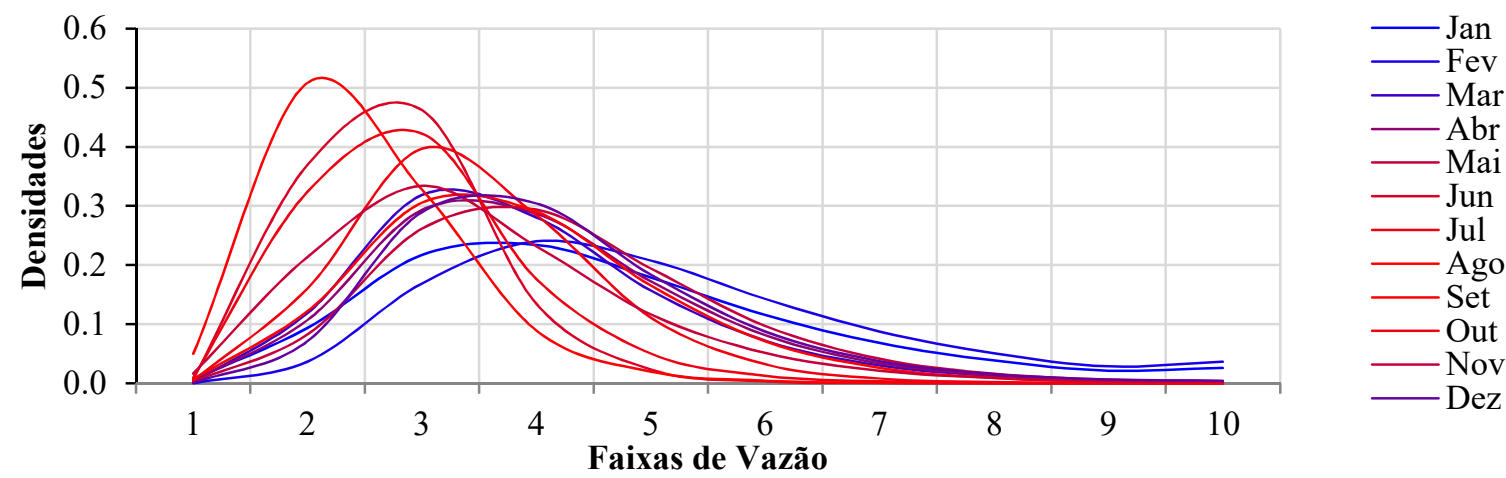

(a)

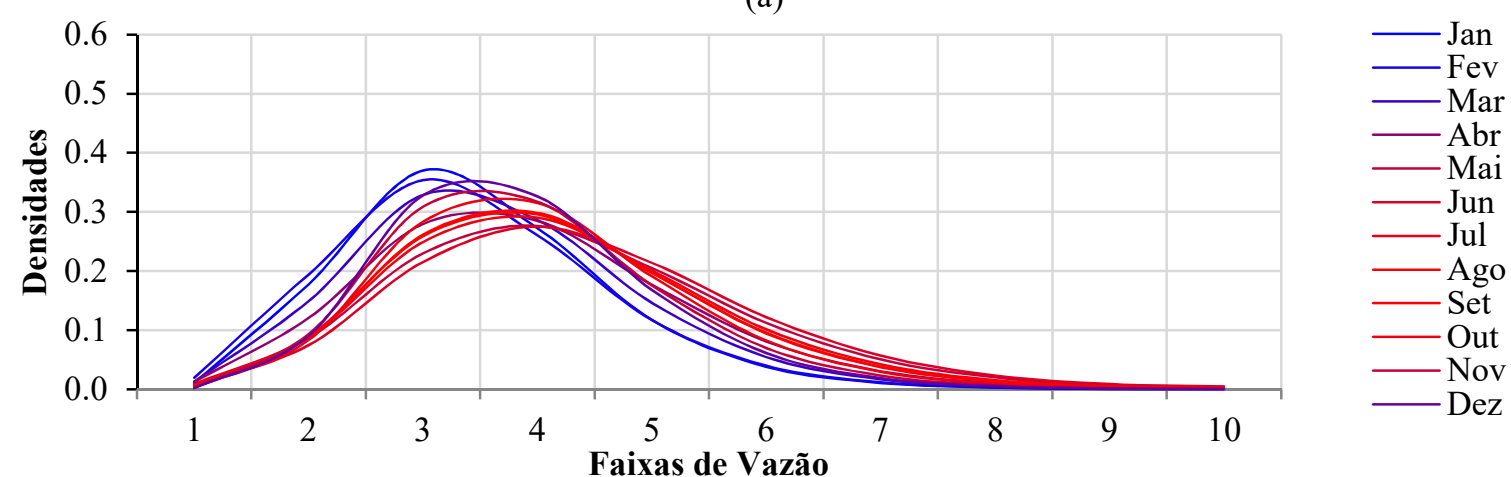

(b)
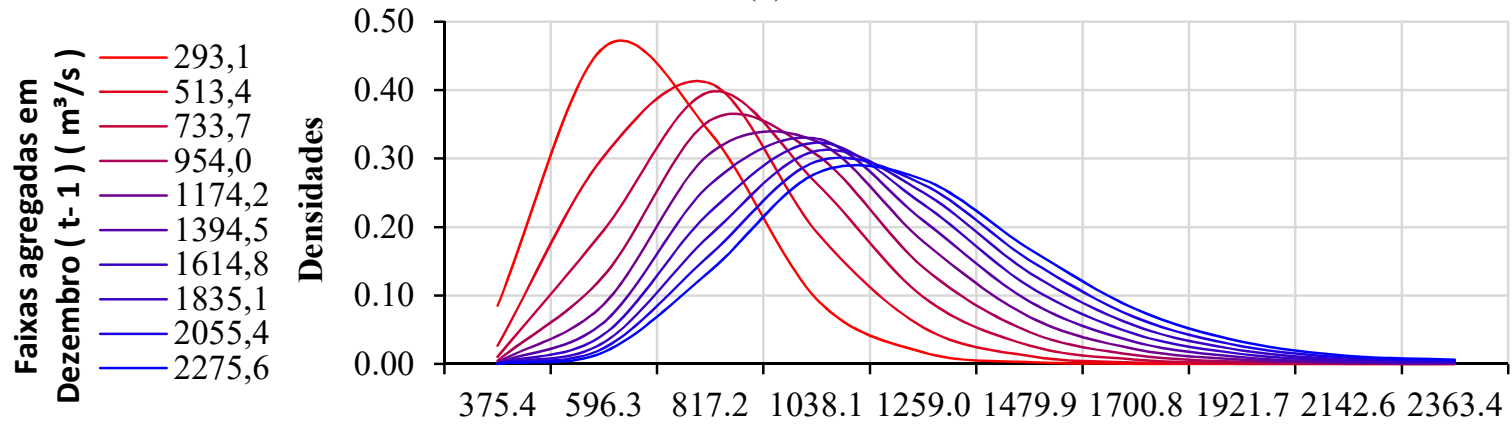

Faixas de afluências agregadas em Janeiro $(t)\left(\mathrm{m}^{3} / \mathbf{s}\right)$

(c)
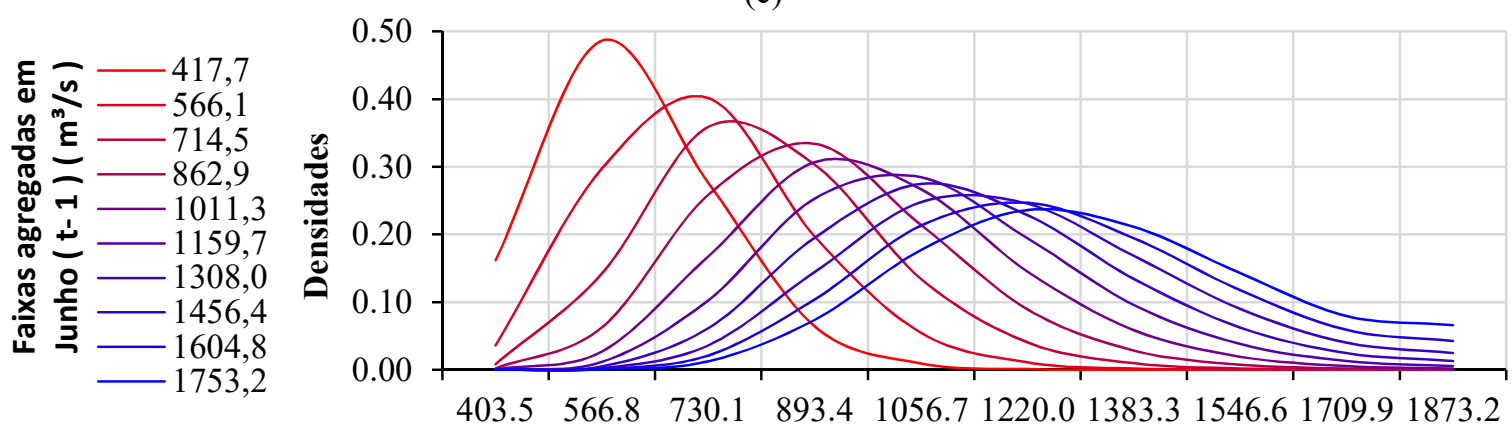

Faixas de afluências agregadas em Julho ( $t)\left(\mathrm{m}^{3} / \mathrm{s}\right)$

(d)

Figura 22 - Densidades de probabilidades log-normal mensal independente (a), agregada anual independente (b), agregada anual dependente com base em Janeiro (c) e agregada anual dependente com base em Julho (d) para a usina hidrelétrica de Furnas. 
A gradação de cores foi feita entre os tons mais azuis para os meses mais úmidos e mais avermelhados para os meses mais secos. O mês mais úmido é o mês de Janeiro com uma média de afluência de $1781,3 \mathrm{~m}^{3} / \mathrm{s}$ e o mês mais seco é Agosto, com uma média de $416,2 \mathrm{~m}^{3} / \mathrm{s}$. Embora esses valores médios não se mantenham para a abordagem agregada anual, onde o valor médio com base em Janeiro é $924,2 \mathrm{~m}^{3} / \mathrm{s}$ e o valor médio com base em Julho é $924,1 \mathrm{~m}^{3} / \mathrm{s}$, o padrão de cores foi mantido na Figura 22 (b). Já na Figura 22 (c) e (d) o padrão de gradação entre tons azulados e avermelhados foi referente às afluências ocorridas anteriormente, sendo a mais azul referente à faixa 10, mais úmida, e a mais vermelha referente à faixa 1 , mais seca.

A característica mais evidente na comparação entre a Figura 22 (a) e (b) é o adensamento das curvas de distribuições de probabilidades. Na abordagem clássica mensal há uma grande diferença entre as curvas dos meses mais úmidos e as curvas dos meses mais secos. Enquanto isso, na abordagem agregada anual, as curvas dos meses mais úmidos apresentam uma grande proximidade as curvas dos meses mais secos. Com isso a previsibilidade dos meses mais úmidos aumenta na abordagem agregada anual. Por outro lado a previsibilidade dos meses mais secos diminui.

Na Figura 22 (c) e (d) são mostradas as curvas de densidades de probabilidades lognormal dependentes para os meses de Janeiro e Julho, respectivamente, na abordagem agregada anual. O primeiro ponto a se notar é a proximidade entre os valores médios das faixas de afluências dos meses, invariavelmente em meses mais úmidos ou em meses mais secos. Esses valores não são exatamente iguais devido ao fato de que os somatórios têm sempre 12 meses, mas em diferentes meses bases. Com isso os valores máximos de cada mês acabam afetando os valores dos somatórios na abordagem agregada anual.

Por fim, embora pareça que a Figura 22 (d) seja um "espalhamento" da Figura 22 (c), isso não é verdade. Devido às implicações dos valores máximos de cada mês, descritos no parágrafo anterior, a escala utilizada para as faixas do mês de Julho acaba "abrindo" as densidades de probabilidades, comparativamente as densidades de Janeiro. No entanto, ao trazermos as faixas para os mesmos patamares, percebemos o quão próximas são as curvas de densidades de probabilidades dos dois e dos demais meses na abordagem agregada anual.

O passo seguinte, a criação das tabelas de decisões de turbinagens, não é alterado, restando-se apenas, a simulação destas decisões com base nos dados de afluências reais ocorridas. Um importante ponto a salientar é o de que deve-se olhar como dados de afluências passadas a soma das últimas 12 afluências mensais somadas. Com isso há uma troca de tabela de decisão e de afluência ocorrida em cada mês. Como exemplo, em Setembro de 1935, na 
simulação de resultados, deve olhar para a soma de afluências mensais ocorridas entre Setembro de 1934 e Agosto de 1935, utilizando-se a tabela de decisões de Setembro.

Os resultados das trajetórias de volumes simulados, das gerações e todos os outros resultados pertinentes a este passo intermediário descrito acima bem como dos outros passos intermediários e finais serão mostrados e discutidos na seção de resultados. As simulações estudadas nas usinas hidrelétricas deste trabalho, com este modelo de PDEM-k12 descrito acima, foram inconclusivos e os resultados encontrados não foram economicamente viáveis em todas as usinas hidrelétricas simuladas, quando comparados aos custos da PDEM na geração de energia elétrica. Uma análise mais criteriosa e minuciosa nos dados de afluências das usinas hidrelétricas estudadas neste trabalho foi então executada. A seguir são mostrados na Figura 23 os dados das correlações de algumas agregações.

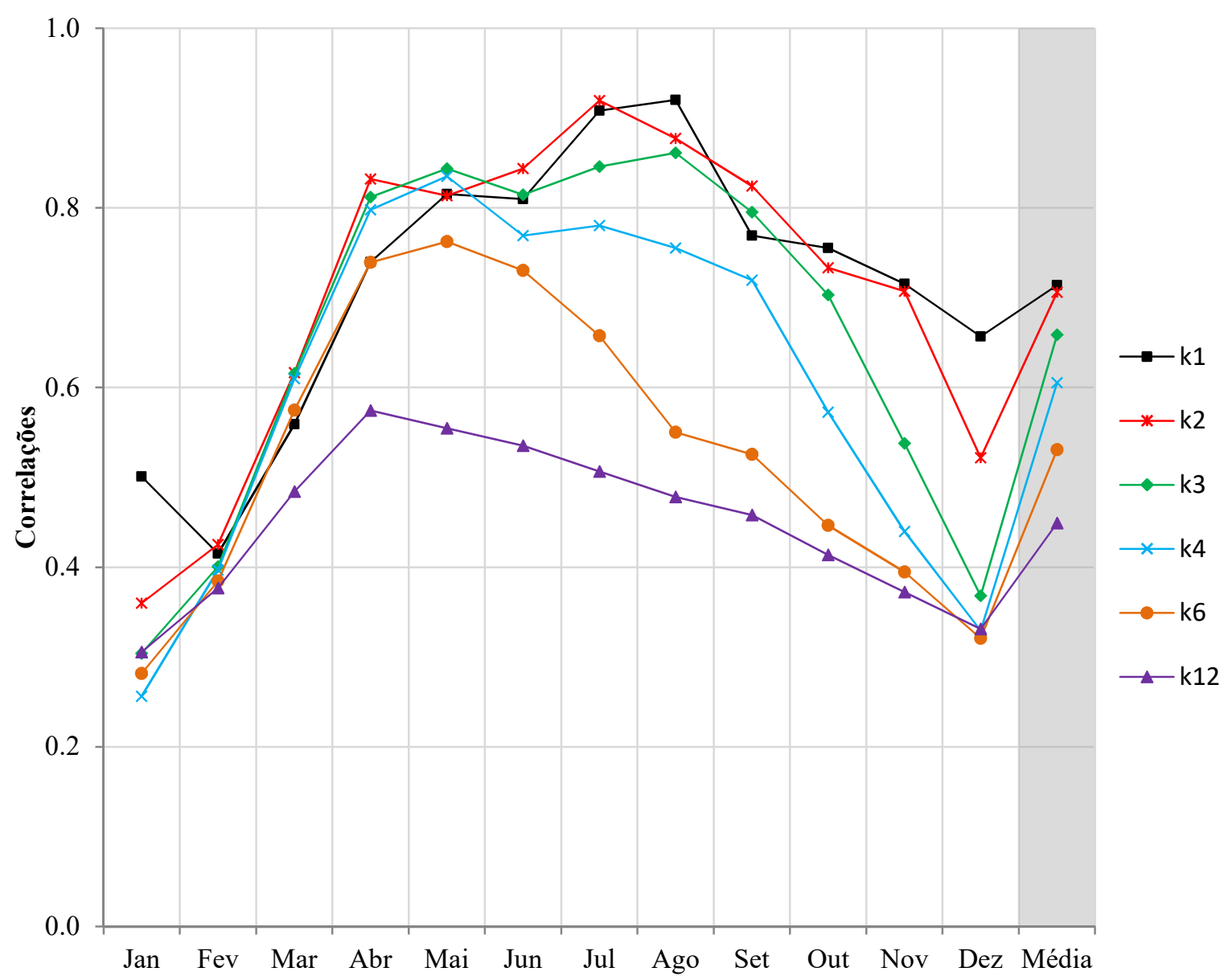

Figura 23 - Correlações cruzadas com base nos 12 meses do ano e média em agregações mensais (k1), bimestrais $(\mathrm{k} 2)$, trimestrais $(\mathrm{k} 3)$, quadrimestrais $(\mathrm{k} 4)$, semestrais (k6) e anuais (k12) para as afluências da usina hidrelétrica de Furnas. 
$\mathrm{Na}$ Figura 23 os valores de afluências mensais foram somados em grupos de k meses e os valores calculados sempre correlacionavam os últimos k meses e os próximos k meses. Podese perceber que há uma tendência decrescente nos valores das correlações cruzadas quando um maior número de meses é agregado. No entanto esse decrescimento não é muito acentuado em agregações com poucos meses (k2 e k3). Além disso, alguns meses não apresentam um decréscimo expressivo, sendo Fevereiro o mês pelo qual as correlações cruzadas em todas as agregações são muito próximas.

Esse foi o fator motivador para a segunda abordagem estudada. Se por um lado os desvios padrão diminuem com o aumentar de afluências mensais agregadas, as correlações diminuem. Com isso tentou-se uma abordagem intermediária, fazendo-se o mesmo padrão e modelo de simulações PDEM-k12 mas em agregações intermediárias, com k2, k3, k4, k6 e k12 meses agrupados. Dessa forma os valores de afluências foram simplesmente somados em grupos de k meses, como descrito pela equação (52).

$$
y_{m}^{a g}=\frac{\sum_{m=1}^{k} y_{m}}{k}
$$

As afluências mensais foram então agrupadas em k1 (que é a mesma abordagem que a PDEM clássica), k2, k3, k4, k6 e k12 (que é a mesma abordagem da PDEM-k12 descrita anteriormente) meses, grupos bimestrais, trimestrais, quadrimestrais, semestrais e anuais, sempre em doze valores por ano. Os dados de afluências foram somados, de acordo com um número de meses definidos anteriormente, e as distribuições de probabilidades puderam ser obtidas da mesma forma com que são obtidas as distribuições mensais.

A diferença é que ao invés de terem-se os dados de um mês referentes aos dados do mês anterior, por exemplo, Janeiro condicionado a Dezembro, tem-se, agora, dados de um período com um número determinado de meses somados referentes ao mesmo número de meses somados anteriores, por exemplo, a soma dos dados de Janeiro e Fevereiro condicionados a soma dos dados de Novembro e Dezembro ou ainda, em uma abordagem PDEM-k3, a soma dos dados mensais de Julho, Agosto e Setembro condicionados a soma dos dados mensais de Abril, Maio e Junho. A Figura 24 mostrada a seguir ilustra essa comparação entre a PDEM com a PDEM-k2. 

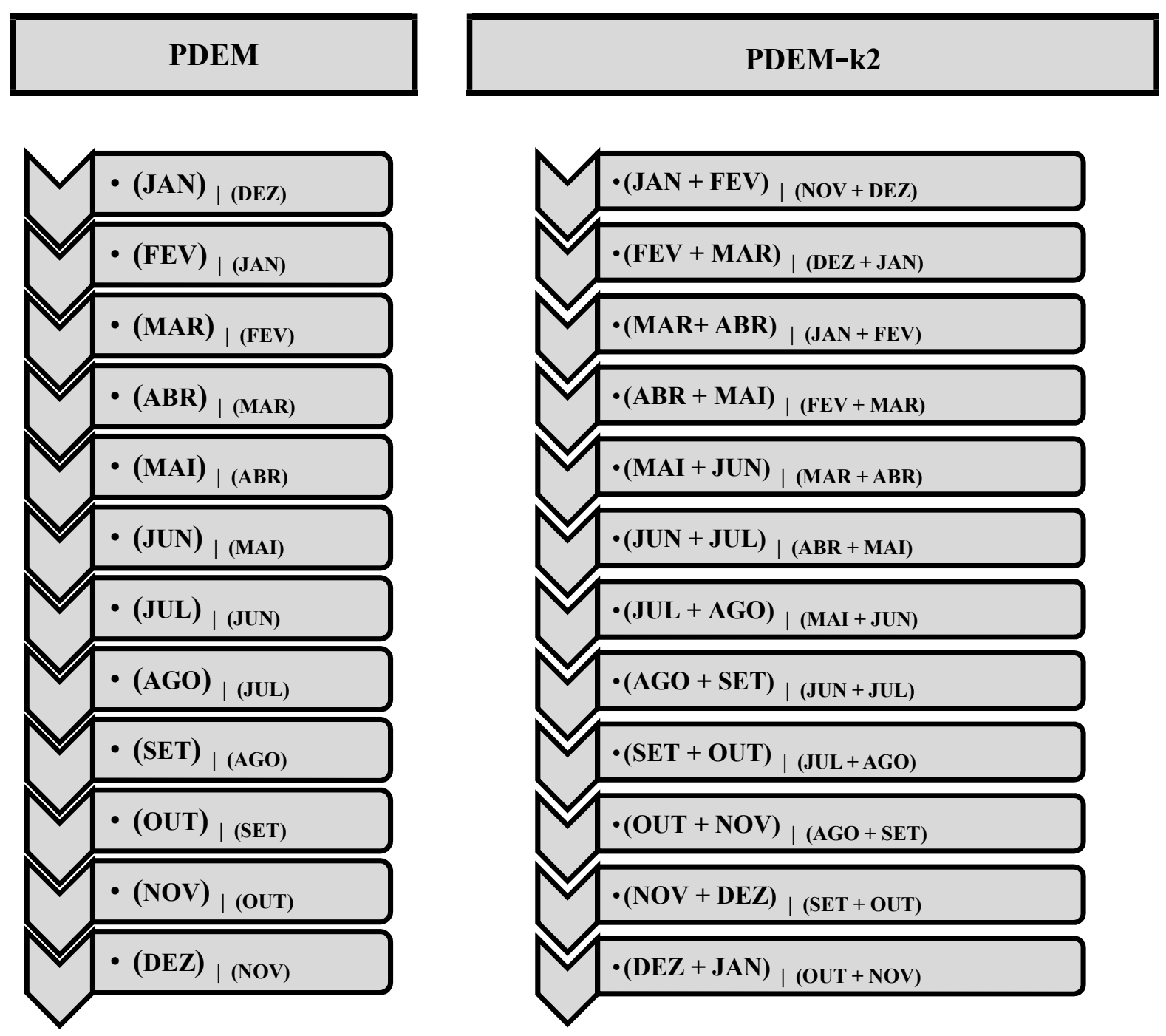

Figura 24 - Esquema do tratamento das vazões afluentes entre a PDEM mensal e a PDEM-k2.

A Figura 24, mostrada acima, ilustra a comparação dos dados das afluências entre a PDEM e a PDEM-k2. Nota-se que os dados de afluências passam a ser tratados de maneira bimestral, somando-se os meses 2 a 2 [68]. Além disso, outras formas com agrupamentos maiores, trimestral, quadrimestral, semestral e anual, também foram feitas.

No caso do agrupamento bimestral, a sazonalidade anual, que se repete a cada 12 meses no caso da PDEM, continua a se repetir a cada 12 meses mais de forma mais suve, uma vez que alguns meses passam a ficar de forma sobreposta.

As simulações estudadas nas usinas hidrelétricas deste trabalho, com as abordagens PDEM-k2, PDEM-K3, PDEM-k4 e PDEM-k6, assim como na PDEM-k12, obtiveram melhores resultados em algumas usinas hidrelétricas e em alguns agrupamentos de meses mas inconclusivos quando comparados aos custos da PDEM na geração de energia elétrica. 
Por fim, optou-se por uma abordagem mista, reunindo os pontos positivos relacionados ao desvio padrão menor da abordagem anual (PDEM-k12) e os pontos positivos relacionados à correlação cruzada da abordagem multimensal (PDEM-kM). A Figura 25, mostrada a seguir, ilustra os valores dos coeficientes de variação das agregações feitas.

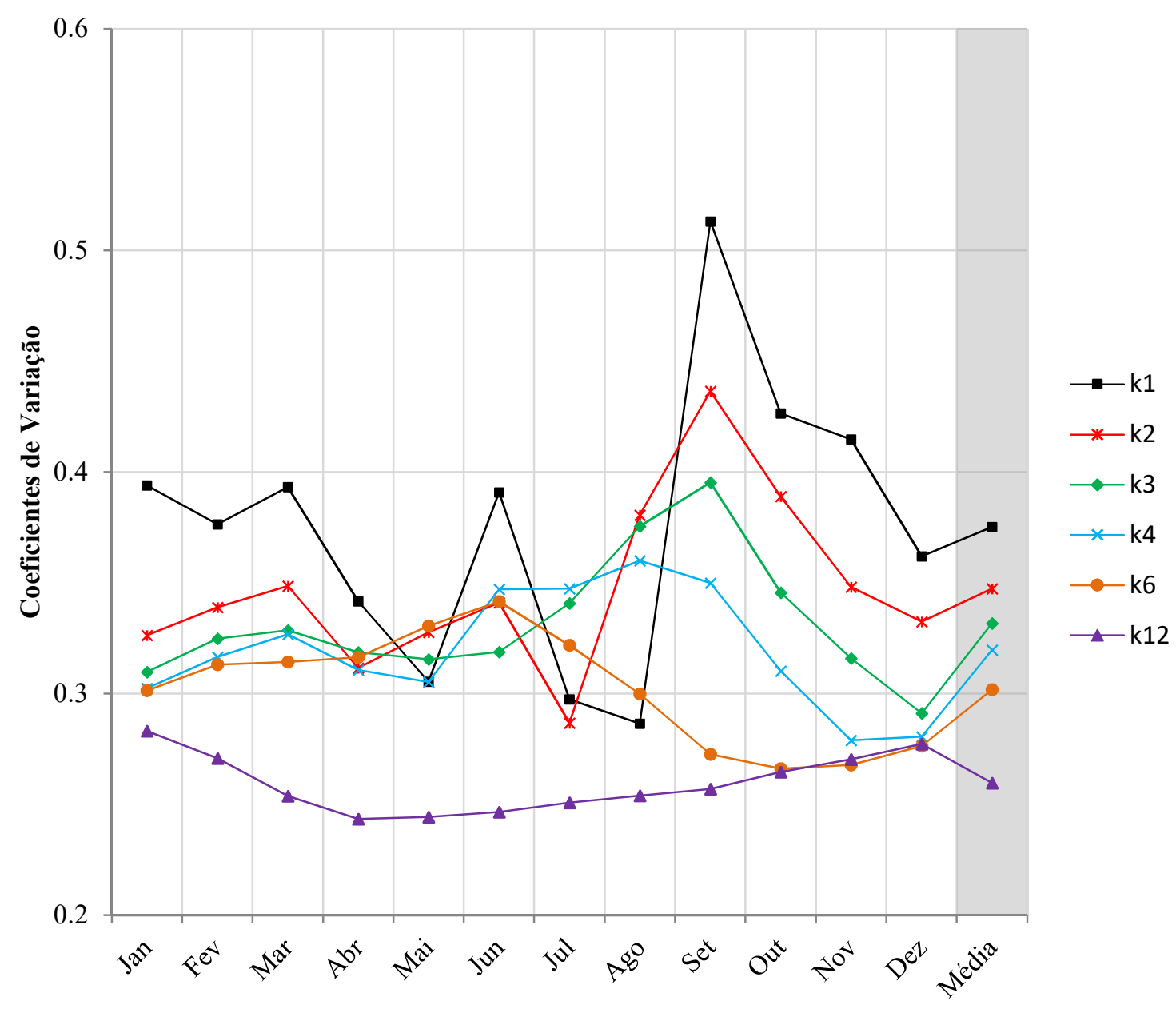

Figura 25 - Coeficientes de variação com base nos 12 meses do ano e média em agregações mensais (k1), bimestrais (k2), trimestrais (k3), quadrimestrais (k4), semestrais (k6) e anuais (k12) para as afluências da usina hidrelétrica de Furnas.

O coeficiente de variação é resultado da divisão entre o desvio padrão e a média de algum conjunto de dados. Com isso, quanto maior for essa relação, menos comportada será essa amostra de dados. Nota-se, portanto, o comportamento mais suave do coeficiente de variação da agregação anual, em uma diminuição gradual do coeficiente de variação a partir dos dados mensais. A contrapartida disso é a correlação cruzada entre dados consecutivos, que é maior nos dados mensais e tem uma diminuição gradativa até os dados anuais. 
O modelo misto proposto usa estas duas informações de forma a utilizar essa correlação cruzada em agregações de menos meses e também usar o comportamento menos variante das agregações com mais meses.

A primeira fase, discretização das faixas de afluências e probabilidades associadas segue o mesmo padrão utilizado na PDEM-k. No entanto, as agregações devem ser todas feitas, desde as discretizações mensais com probabilidades associadas (PDEM) até as agregações anuais (PDEM-k12), passando por todas as agregações intermediárias (PDEM-k2, PDEM-k3, PDEM-k4 e PDEM-k6).

A segunda fase, criação das tabelas de decisões de turbinagens, também segue o mesmo padrão descrito anteriormente e deve ser executada para todas as agregações. O resultado disso é a criação de uma tabela com 4 dimensões, sendo elas a agregação (k1, k2, k3, k4, k6 e k12), a afluência anterior para cada agregação, os volumes discretizados e a decisão associada.

Por fim, na terceira fase, têm-se as maiores modificações. Na simulação o modelo misto proposto (PDEM-k12M) utiliza as tabelas de decisões não apenas no próximo mês mas também nos próximos 12 meses. Para isso duas novas ferramentas são necessárias: um previsor de afluências e um otimizador determinístico.

O previsor utilizado foi o modelo periódico auto-regressivo de ordem 1 (PAR-1). Ressalta-se que por se tratarem de modelos agregados de vazão, o índice 1 refere-se a previsão da soma dos próximos meses agregados com base na soma dos últimos meses agregados. Já para a otimização determinística foi utilizado o software Matlab com a toolbox de otimização fmincon. A ferramenta configurada para busca do ponto ótimo foi a Programação Quadrática Sequencial (PQS).

$\mathrm{Na}$ fase de simulação deve-se, portanto, fazer uma consulta em todas as tabelas agregadas com base nos valores de afluências agregados. Esses valores de turbinagens consultados com base nas afluências agregadas, juntamente com os valores de afluências agregadas previstas são passadas ao otimizador. As escalas de afluências agregadas, $b$, com $b \in\{1,2,3,4,6,12\}$, e as regras de decisão, $q_{t}^{b}\left(x_{t-1}, y_{t-1}\right)$, podem ser obtidas. Note que $q_{t}^{1}\left(x_{t-1}, y_{t-1}\right)=q_{t}^{*}\left(x_{t-1}, y_{t-1}\right)$ é a tabela de decisão obtida pelo método clássico mensal, PDEM. As afluências agregadas previstas, $\hat{y}^{j},\{j \in Z / 1 \leq j \leq 12\}$, para os próximos 4 meses são dadas pelas equações a seguir:

$$
\hat{y}_{t}^{t+1}=\hat{y}_{t}^{1}
$$




$$
\begin{aligned}
& \hat{y}_{t}^{t+2}=\hat{y}_{t}^{2}\left(\frac{\bar{y}^{2}}{\sum_{l=1}^{2} \bar{y}^{l}}\right) \\
& \hat{y}_{t}^{t+3}=\hat{y}_{t}^{3}\left(\frac{\bar{y}^{3}}{\sum_{l=1}^{3} \bar{y}^{l}}\right) \\
& \hat{y}_{t}^{t+4}=\hat{y}_{t}^{4}\left(\frac{\bar{y}^{4}}{\sum_{l=1}^{4} \bar{y}^{l}}\right)
\end{aligned}
$$

Onde $\bar{y}^{j}$ é a afluência média mensal, $j$ meses a frente de $t$. O quinto mês a frente e o sexto mês a frente, $\hat{y}_{t}^{t+j}, j=\{5,6\}$, podem ser calculados por:

$$
\hat{y}_{t}^{t+j}=\hat{y}_{t}^{6}\left(\frac{\bar{y}^{j}}{\sum_{l=1}^{6} \bar{y}^{l}}\right)
$$

A previsão para os últimos seis meses, do sétimo ao décimo segundo mês à frente, $\hat{y}_{t}^{t+j}, j=\{7,12\}$, pode ser calculada por:

$$
\hat{y}_{t}^{t+j}=\hat{y}_{t}^{12}\left(\frac{\bar{y}^{j}}{\sum_{l=1}^{12} \bar{y}^{l}}\right)
$$

O último parâmetro necessário para o otimizador da simulação determinística da PDEM-k12M é a condição de armazenamento ao final do ano a frente, calculada por: 


$$
x_{t+12}=x_{t}+\delta *\left(\sum_{t=1}^{12} \hat{y}_{t}^{t+1}-\left[q_{t}^{1}+q_{t}^{2}+q_{t}^{3}+q_{t}^{4}+2 q_{t}^{6}+6 q_{t}^{12}\right]\right)
$$

Com isso a PQS pode ser executada em cada mês $t$ do período completo de simulações. A decisão a ser tomada pelo simulador é a primeira resposta de decisão de turbinagem suprida pelo otimizador determinístico. O fluxograma a seguir define as etapas do modelo proposto.

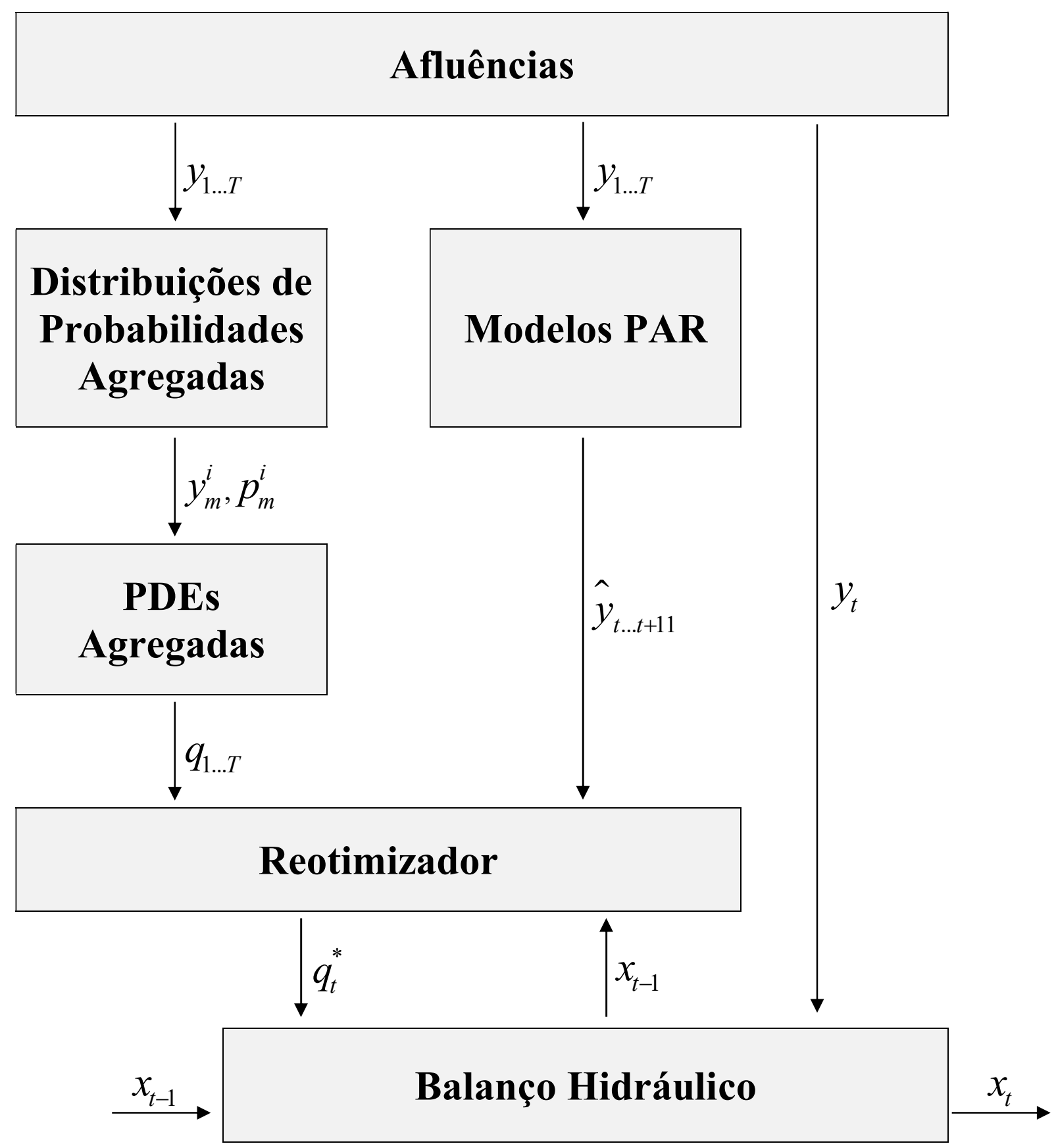

Figura 26 - Fluxograma completo do modelo proposto (PDEM-k) 


\section{Capítulo 4}

\section{Simulações e}

\section{Comparação dos}

\section{Resultados}

Com o intuito de considerar grande parte da diversidade hidrológica brasileira, foram escolhidas quatro usinas hidrelétricas, localizadas em quatro diferentes regiões geográficas brasileira e com quatro bacias hidrográficas diferentes. Foram escolhidas as usinas hidrelétricas de Furnas, localizada na bacia do Rio Grande e na Região Sudeste do Brasil, a usina hidrelétrica de Foz do Areia, localizada na bacia do Rio Iguaçu e na Região Sul do Brasil, a usina hidrelétrica de Serra da Mesa, localizada na bacia do Rio Tocantins e na Região Norte do Brasil e a usina hidrelétrica de Sobradinho, localizada na bacia do Rio São Francisco, na Região Nordeste do Brasil.

Foram simuladas 19 estratégias de otimização, descritas nos Capítulos I, II e III deste trabalho. As estratégias simuladas foram a PDP, PDEI, PDD, PDEM, PDEM-k2, PDEM-k2M, PDEM-k2P, PDEM-k3, PDEM-k3M, PDEM-k3P, PDEM-k4, PDEM-k4M, PDEM-k4P, PDEM-k6, PDEM-k6M, PDEM-k6P, PDEM-k12, PDEM-k12M e PDEM-k12P. A PDP, que utiliza dados perfeitos de previsão, foi tida como base ótima de comparações. Os índices "k" 
são referentes ao número de meses agrupados, o índice "M" no final indica multi das estratégias multi mensais e o índice "P" indica previsão perfeita de vazões.

Este capítulo mostrará os resultados destas simulações efetuadas. São mostrados os resultados das distribuições de probabilidades obtidas, os resultados das tabelas de decisões obtidas e os resultados gráficos e tabelados das operações efetuadas.

\subsection{Software desenvolvido}

As simulações foram feitas utilizando-se o software desenvolvido inicialmente por Scarcelli [52] e aprimorado para que as novas possibilidades e abordagens pudessem ser simuladas. O software, desenvolvido em linguagem Matlab, contém dados de várias usinas hidrelétricas brasileiras. Além disso são possíveis, com o uso do software, a simulação de técnicas de operação com previsão perfeita e com abordagens estocásticas.

USINESTIMADOR_Rio_Grande_V1

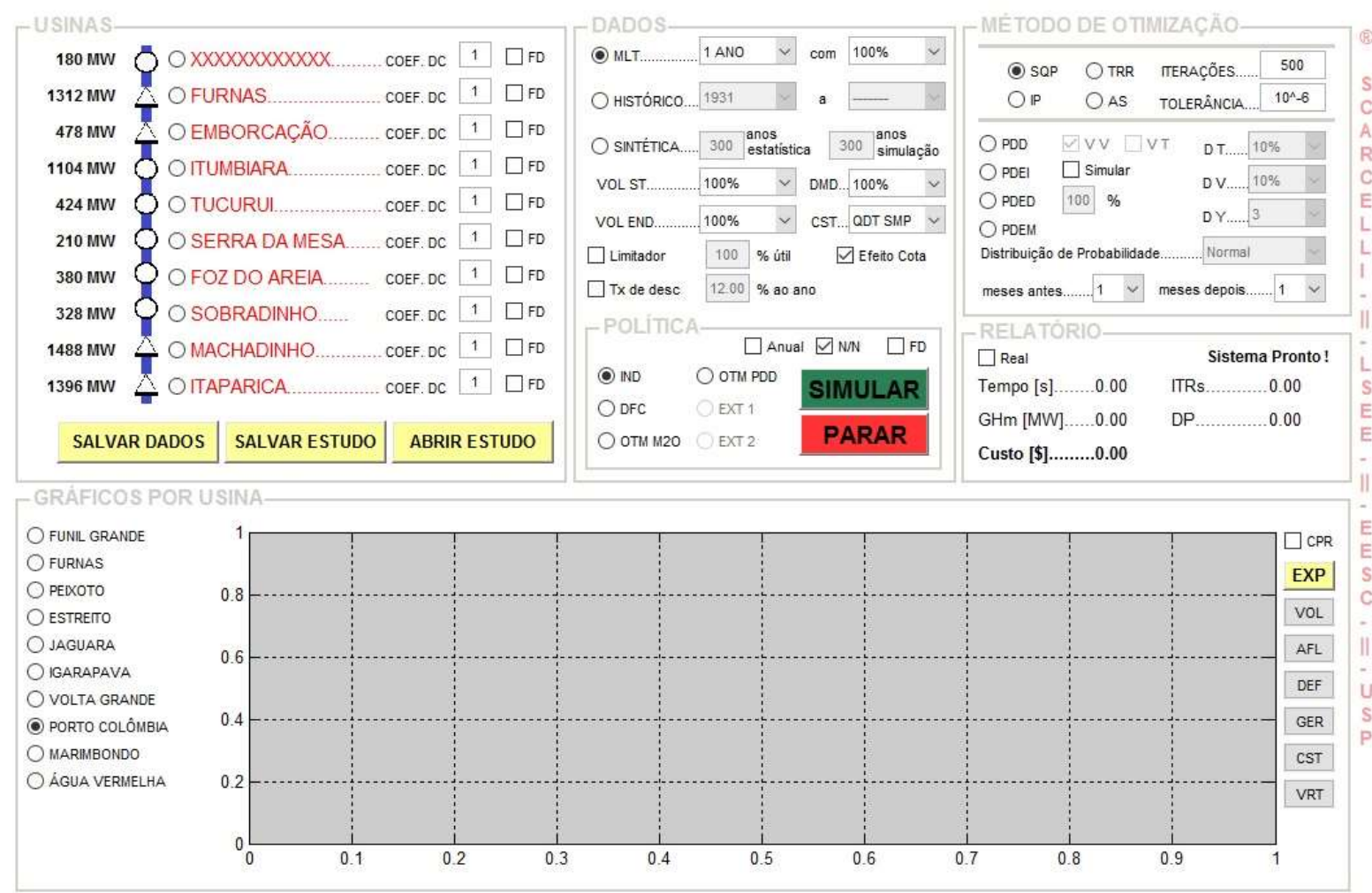

Figura 27 - Tela inicial do software desenvolvido.

O uso do software foi muito importante pois possibilitou a obtenção de resultados de forma rápida. Além disso, resultados e comparações puderam ser analisadas com o uso de diferentes técnicas de otimização e simulação. 


\subsection{Dados operativos das usinas}

Os dados operativos das usinas, potência instalada, volume máximo e volume mínimo dos reservatórios, engolimento máximo, constante de produtibilidade e coeficientes dos polinômios cota montante e cota jusante são mostrados nas tabelas a seguir.

Tabela 18 - Limites operativos das usinas hidrelétricas simuladas.

\begin{tabular}{|c|c|c|c|c|c|}
\hline $\begin{array}{l}\text { Usina } \\
\text { Hidrelétrica }\end{array}$ & $\begin{array}{l}P^{\max } \\
{[\mathbf{M W}]}\end{array}$ & $\begin{array}{l}X^{\max } \\
{\left[\mathbf{h m}^{3}\right]}\end{array}$ & $\begin{array}{l}X^{\min } \\
{\left[\mathbf{h m}^{3}\right]}\end{array}$ & $\begin{array}{l}Q^{\max } \\
{\left[\mathbf{m}^{3 / s}\right]}\end{array}$ & $\begin{array}{c}k \\
{\left[\mathbf{M W} / \mathbf{m}^{3} \cdot \mathbf{m}\right]}\end{array}$ \\
\hline Furnas & 1312 & 22950 & 5733 & 1402,7 & 0,008633 \\
\hline Foz do Areia & 1676 & 5779 & 1974 & 1222,4 & 0,009022 \\
\hline Serra da Mesa & 1275 & 54400 & 11150 & 1094,8 & 0,009134 \\
\hline Sobradinho & 1050 & 34116 & 5447 & 3600,8 & 0,009023 \\
\hline
\end{tabular}

Tabela 19 - Coeficientes dos polinômios cota volume, $\phi\left(x_{t}^{\text {med }}\right)$, e cota jusante, $\theta\left(u_{t}\right)$.

\begin{tabular}{l|c|c|c|c|c}
\hline \hline $\begin{array}{l}\text { Usina } \\
\text { Hidrelétrica }\end{array}$ & Furnas & Foz do Areia & Serra da Mesa & Sobradinho \\
\hline \multirow{6}{*}{$\phi\left(x_{t}^{\text {med }}\right)$} & $a_{0}$ & $7,3525 E+02$ & $6,5088 E+02$ & $3,9140 E+02$ & $3,7418 E+02$ \\
& $a_{1}$ & $3,4966 E-03$ & $3,4987 E-02$ & $2,7722 E-03$ & $1,3967 E-03$ \\
& $a_{3}$ & $-1,9744 E-07$ & $-6,5001 E-06$ & $-4,3573 E-08$ & $-5,3516 E-08$ \\
& $a_{4}$ & $-9,77737 E-17$ & $-3,9529 E-14$ & 0,0000 & $-9,5460 E-18$ \\
\hline \multirow{6}{*}{$\theta\left(u_{t}\right)$} & $b_{0}$ & $6,7163 E+02$ & $6,0189 E+02$ & $3,3280 E+02$ & $3,5965 E+02$ \\
& $b_{1}$ & $1,0174 E-03$ & $1,1058 E-03$ & $1,3430 E-03$ & $1,9640 E-03$ \\
& $b_{3}$ & $2,5133 E-11$ & $-8,3115 E-11$ & $-1,6277 E-11$ & $2,5083 E-11$ \\
& $b_{4}$ & 0,0000 & $4,7611 E-15$ & 0,0000 & $-7,7023 E-16$ \\
\hline \hline
\end{tabular}

Os dados, apresentados anteriormente, foram utilizados em todas as simulações feitas. As demandas consideradas foram as iguais às potências instaladas em cada usina hidrelétrica. 
Já o custo da complementação térmica foi o mesmo apresentado na formulação do problema, apresentado na seção 2.6.

\subsection{Curvas de distribuições de probabilidades}

Esta seção apresenta os resultados das curvas de distribuições de probabilidades obtidas com as políticas PDEM, PDEM-k2, PDEM-k3, PDEM-k4, PDEM-k6 e PDEM-k12 nos meses de Janeiro e Julho para a usina hidrelétrica de Furnas. Os resultados gráficos para os mesmos meses e para as mesmas políticas das outras usinas hidrelétricas simuladas, por uma questão de organização do documento (Foz do Areia, Serra da Mesa e Sobradinho) são mostrados no Apêncdice A, no final deste trabalho.

Deve-se ressaltar a diferença entre as curvas para a PDEM e para a PDEM-k. Na PDEM os dados mensais são condicionados às vazões ocorridas no mês anterior. Já na PDEM-k os dados das distribuições de probabilidades são divididos por faixas de valores de afluências somadas dos meses " $k$ ", condicionados a faixas de valores de afluências somadas dos " $k$ " meses anteriores.

Os dados utilizados para obtenção das curvas foram as vazões afluentes ocorridas nas usinas hidrelétricas entre janeiro 1931 e dezembro de 2012. Os dados de 1931 foram considerados apenas como dados somados para os meses anteriores e os dados de 2012 foram considerados apenas como dados somados para os meses posteriores. Os valores de todas as probabilidades somadas para cada faixa, tanto na PDEM quanto nas PDEM-k, é unitário.

Alguns fatores devem ser ressaltados nas curvas obtidas para as usinas hidrelétricas simuladas. Deve-se notar que a grande maioria das probabilidades para os valores extremos das faixas, curvas mais vermelhas e mais azuis, são menores nas estratégias PDEM-k, quando comparadas aos valores das probabilidades das faixas da PDEM. Essa característica fica mais evidente com o aumento do número de meses agrupados.

$\mathrm{Na}$ Figura 28, mostrada adiante, as densidades de probabilidades log-normais dos gráficos são referentes à divisão das afluências em dez faixas. As cores variam linearmente entre o vermelho, representando a faixa mais seca de afluências do período anterior (mensal ou somado) e representando a faixa mais úmida de afluências do período anterior (mensal ou somado). 


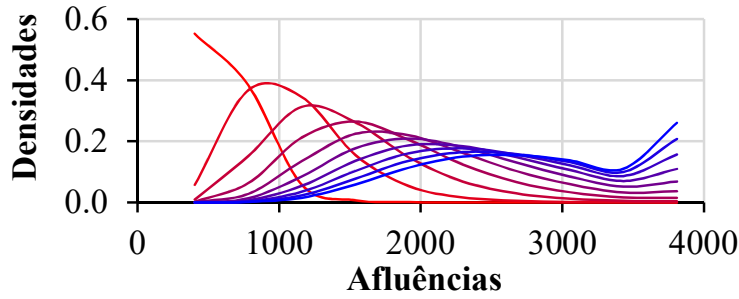

(a)

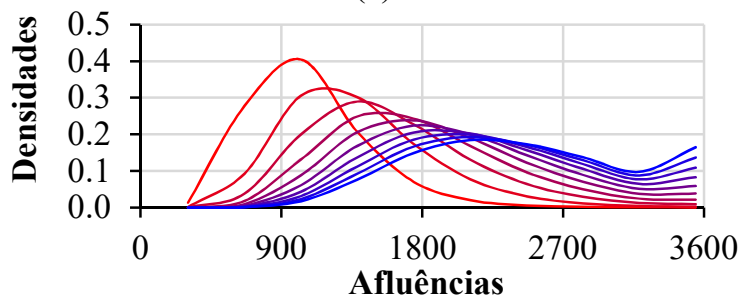

(b)

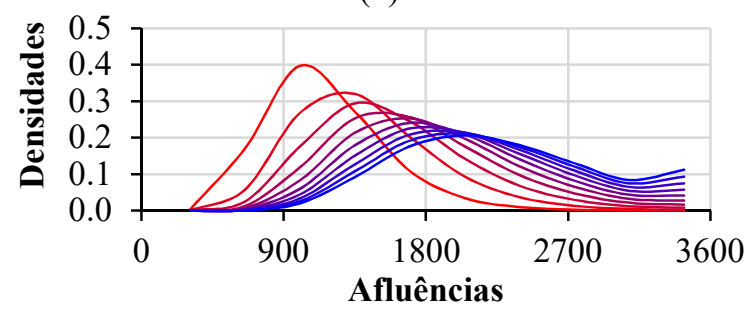

(c)

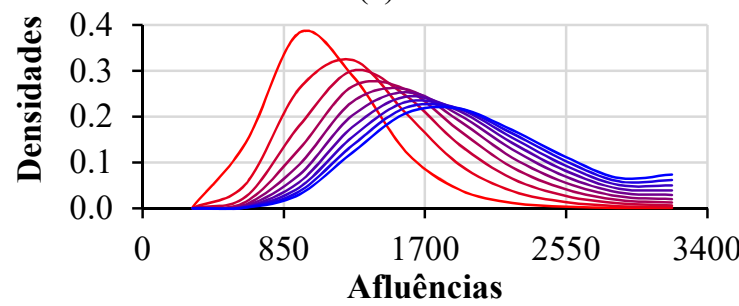

(d)

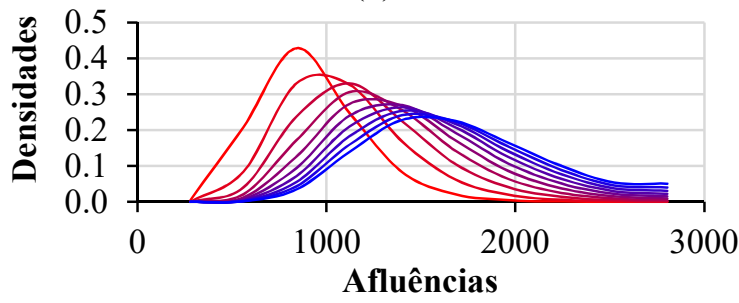

(e)

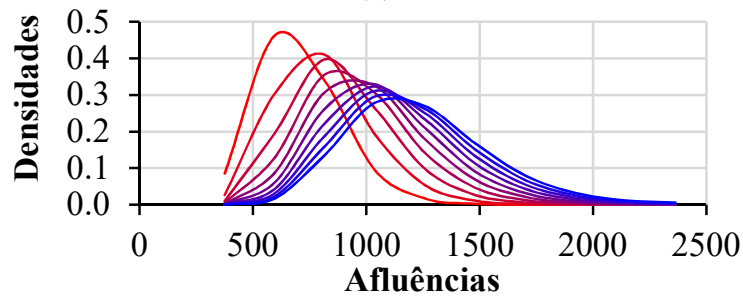

(f)

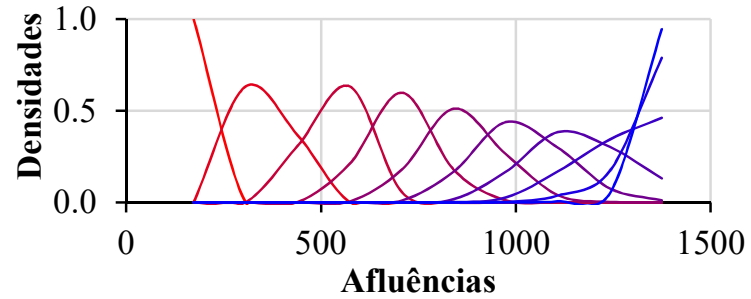

(g)

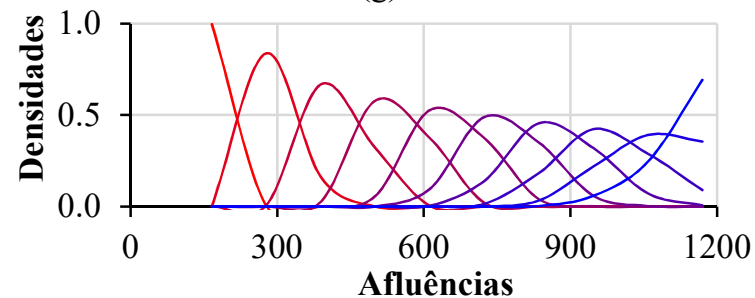

(h)

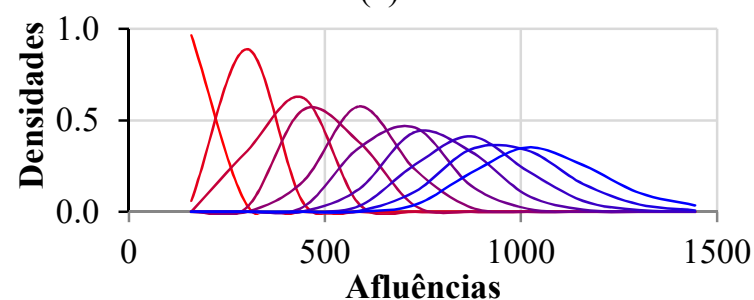

(i)

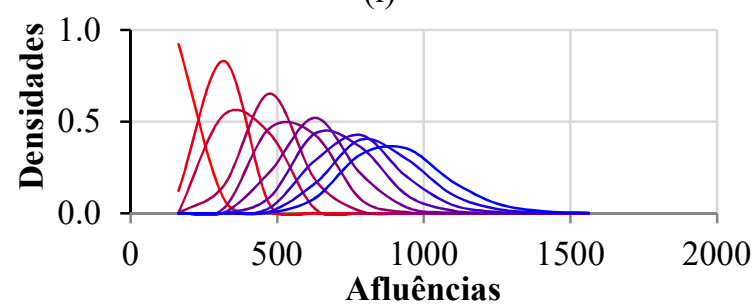

(j)

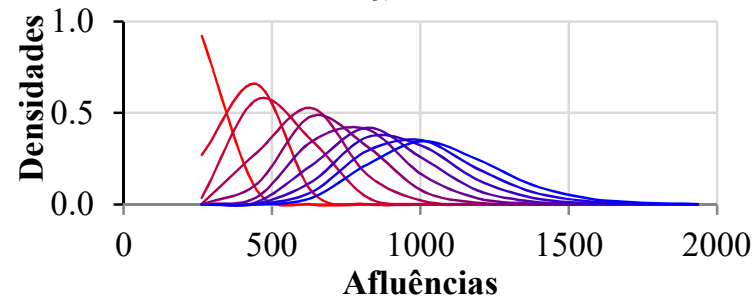

(k)

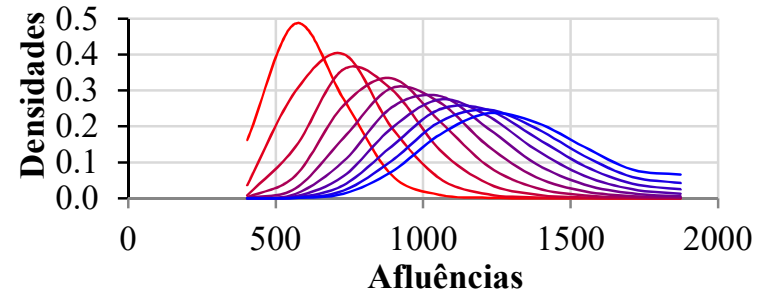

(1)

Figura 28 - Densidades de probabilidades log-normais para a usina hidrelétrica de Furnas com base no mês de Janeiro mensal (a), bimestral (b), trimestral (c), quadrimestral (d), semestral (e) e anual (f) e no mês de Julho mensal (g), bimestral (h), trimestral (i), quadrimestral (j), semestral (k) e anual (l). 
$\mathrm{Na}$ grande maioria dos meses simulados, os valores máximos das probabilidades são menores nas estratégias PDEM-k, quando comparados à estratégia PDEM. Essa diminuição dos valores máximos também fica mais evidente com o aumento do número de meses agrupados.

Deve-se notar também a diminuição das sazonalidades dos dados, implicando em maiores, menores ou, até mesmo, quase nulas diferenças entre as distribuições de probabilidades de cada mês, para as diferentes usinas simuladas. As curvas de distribuições de probabilidades log-mensais dos meses de Janeiro e Julho, bem como todas as curvas dos outros meses, na usina hidrelétrica de Furnas e nas outras usinas hidrelétricas simuladas são muito próximas.

Outros dois pontos a serem notados nas curvas de distribuições de probabilidades lognormais são o limite máximo e mínimo das faixas de valores de afluências. Enquanto os limites mínimos tendem a aumentar, os limites máximos tendem a diminuir com o aumento do número de meses agrupados.

Pode-se observar, portanto, um "adensamento ou compactamento" de curvas de distribuições de probabilidades log-normais. Diminuindo-se assim, as faixa de variação dos valores das afluências estatísticas, e a sazonalidade mensal presente nas curvas de distribuições de probabilidades.

\subsection{Tabelas de decisões}

Esta seção apresenta os resultados comparativos das tabelas de decisões obtidas com a PDEM e as PDEM-k para os meses de Janeiro e Julho. São mostrados os resultados de cada estratégia em uma gradação de cores igual à feita nas curvas de distribuição de probabilidades log-normais.

Na Figura 29, apresentada a seguir, as curvas mais vermelhas são referentes à condição mais seca de afluência anterior. As curvas mais azuladas são referentes à condição mais úmida de afluência ocorrida anteriormente. As decisões, mostradas na vertical, são tomadas de acordo com a afluência anterior e com o estado de armazenamento do reservatório, mostrado na horizontal. 


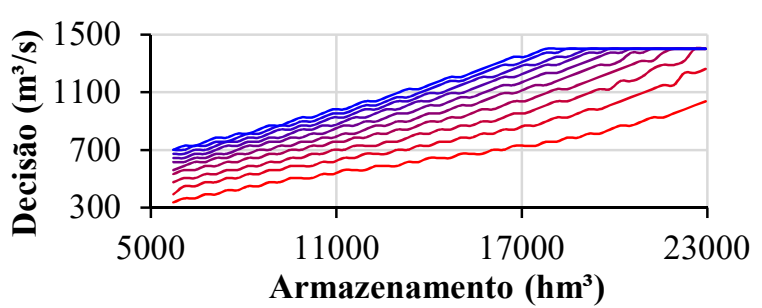

(a)

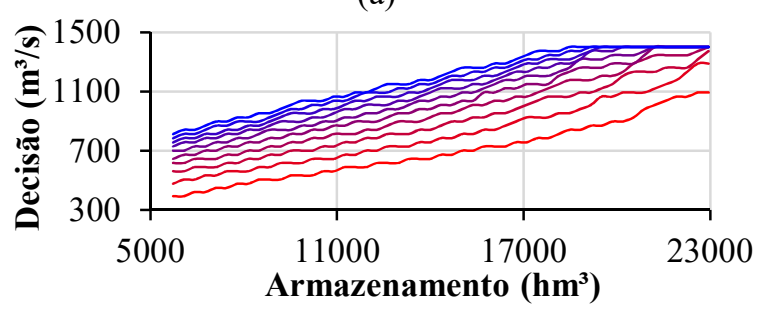

(b)

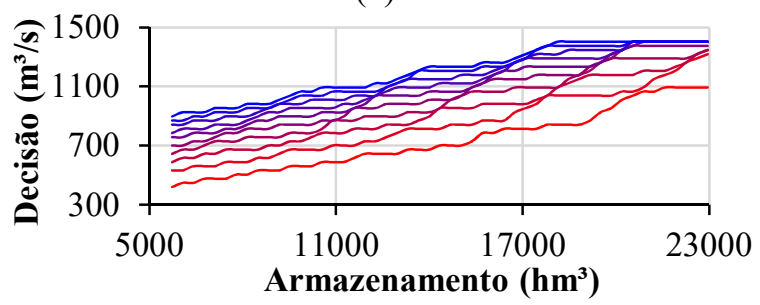

(c)

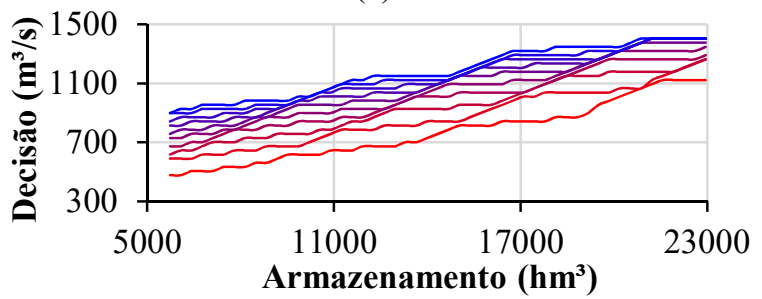

(d)

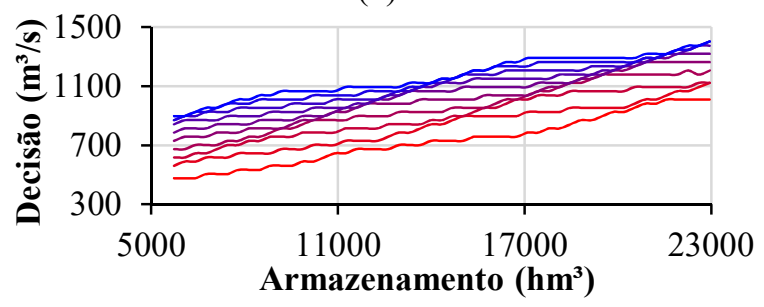

(e)

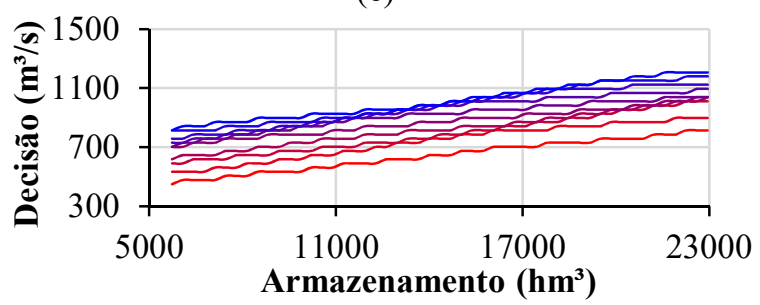

(f)

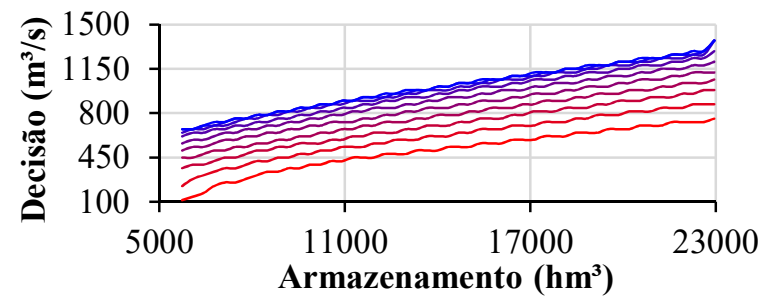

(g)

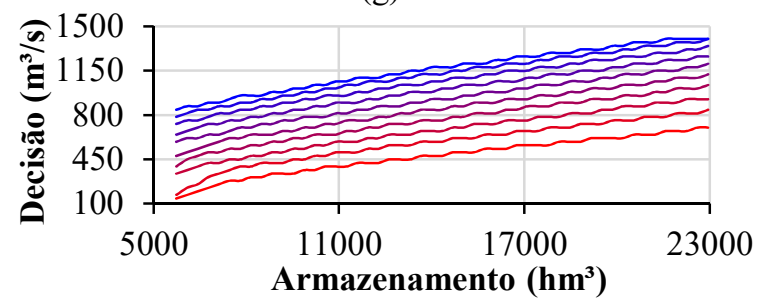

(h)

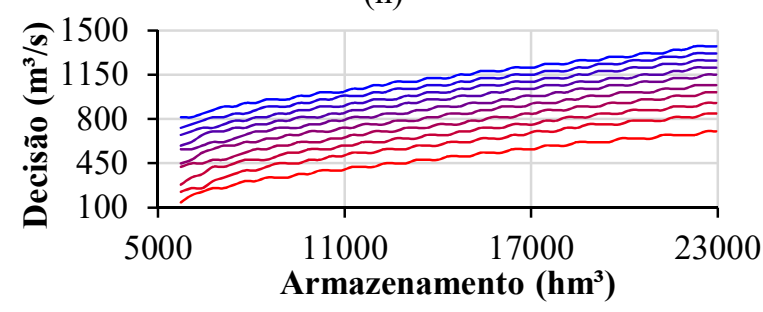

(i)

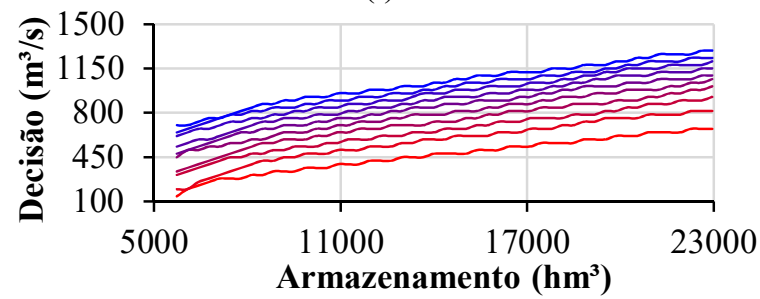

(j)

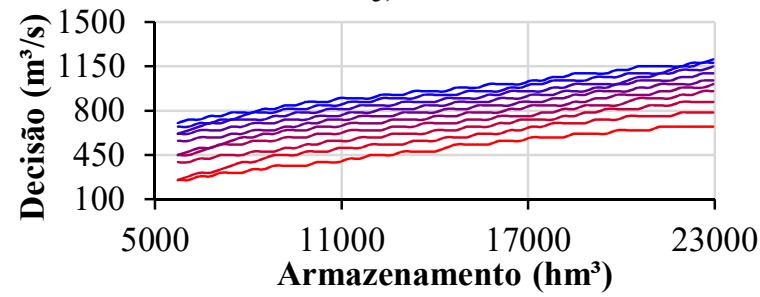

(k)

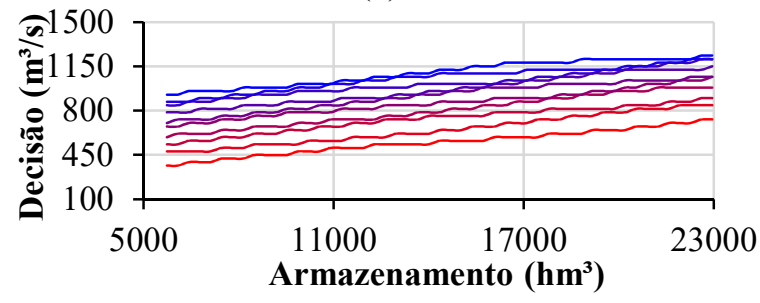

(1)

Figura 29 - Tabelas de decisões de turbinagens para a usina hidrelétrica de Furnas para no mês de Janeiro mensal (a), bimestral (b), trimestral (c), quadrimestral (d), semestral (e) e anual (f) e para o mês de Julho mensal (g), bimestral (h), trimestral (i), quadrimestral (j), semestral (k) e anual (l). 
As tabelas de decisões, como era de se esperar devido às curvas de distribuições de probabilidades log-normais apresentadas, apresentam o mesmo "adensamento e compactação" de curvas com o aumento do número de meses agrupados.

Diferentemente das curvas de decisões PDEM, as curvas PDEM-k12 não têm uma forte sazonalidade mensal. Observando-se o mês de Janeiro e Julho vemos uma grande diferença nas decisões comparativas destes dois meses para a PDEM. No mês de Janeiro, inclusive, a decisão de turbinagem fica saturada a partir de um armazenamento de, aproximadamente, $17.000 \mathrm{hm}^{3}$.

Já nas decisões para Janeiro e Julho as curvas PDEM-k12 apresentam uma diferença muito pequena. A saturação de decisões também não ocorre, mesmo no mês de Janeiro e em um armazenamento superior a $17.000 \mathrm{hm}^{3}$.

\subsection{Previsões}

Esta seção apresenta os resultados comparativos dos erros quadráticos médios das previsões efetuadas com os modelos PAR-1 desenvolvidos e utilizados. Foram utilizados 72 modelos PAR-1, em cada usina hidrelétrica, para que se conseguisse uma previsão composta e completa de 12 meses a frente.

O primeiro modelo PAR-1 com uma previsão de um mês a frente utilizou apenas os dados do ultimo mês. A técnica PDEM-k1 (que é a mesma que a PDEM clássica mensal) criou 12 modelos PAR-1, uma para cada mês do ano, fazendo 12 previsões (um mês a frente). Essas previsões foram utilizadas apenas nos modelos onde a soma dos meses foi igual ou maior a dois. Na PDEM a tabela de decisões é utilizada diretamente, sem a necessidade de previsões ou otimizações na fase de simulação.

As técnicas PDEM-k2, PDEM-k3, PDEM-k4, PDEM-k6 e PDEM-k12 também criaram 12 modelos PAR-1, sendo um para cada mês do ano. Em cada mês, os modelos criados para cada grupo de meses têm a mesma entrada de dados referentes à soma dos " $k$ " últimos meses. A saída destes modelos PAR-1 com “ $k$ ” meses será a soma dos próximos “ $k$ ” meses a frente. A obtenção dos dados mensais a partir destes dados somados é feita a partir de uma distribuição proporcional a MLT (Média de Longo Termo).

Como exemplo, na técnica PDEM-k2, no modelo PAR-1 de previsões para Janeiro e Fevereiro, as afluências de Novembro e Dezembro são somadas. O resultado será uma previsão da soma de Janeiro e Fevereiro. Após a distribuição proporcional à MLT obtêm-se a previsão para Janeiro, com um mês a frente e para Fevereiro com dois meses a frente. 
Da mesma forma, com o modelo PAR-1 e com a técnica PDEM-k3, pode-se obter a previsão de Janeiro com 3 meses a frente. Para isso, deve-se utilizar neste modelo os dados somados de Agosto, Setembro e Outubro. O resultado será a soma de Novembro, Dezembro e Janeiro. Após a distribuição proporcional a MLT, teremos a previsão de Janeiro com 3 meses a frente. A Figura 30, mostrada a seguir, ilustra os resultados dos erros quadráticos médios dos modelos PAR-1 na forma gráfica.

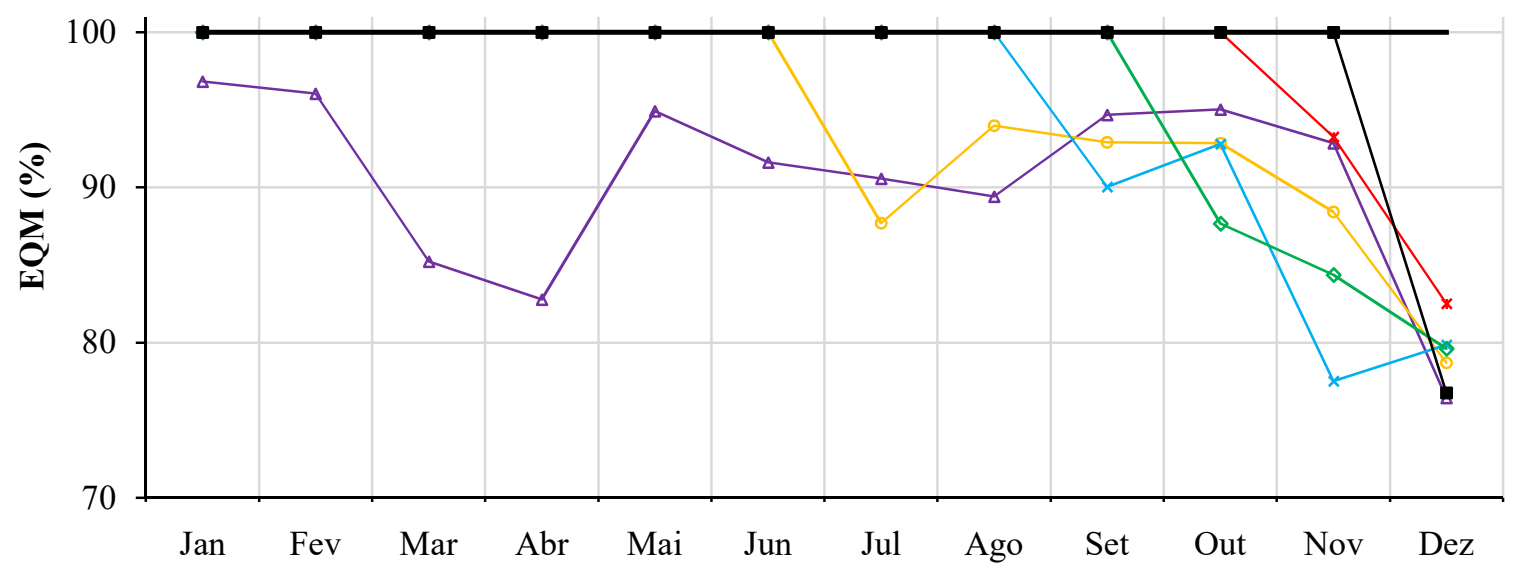

(a)

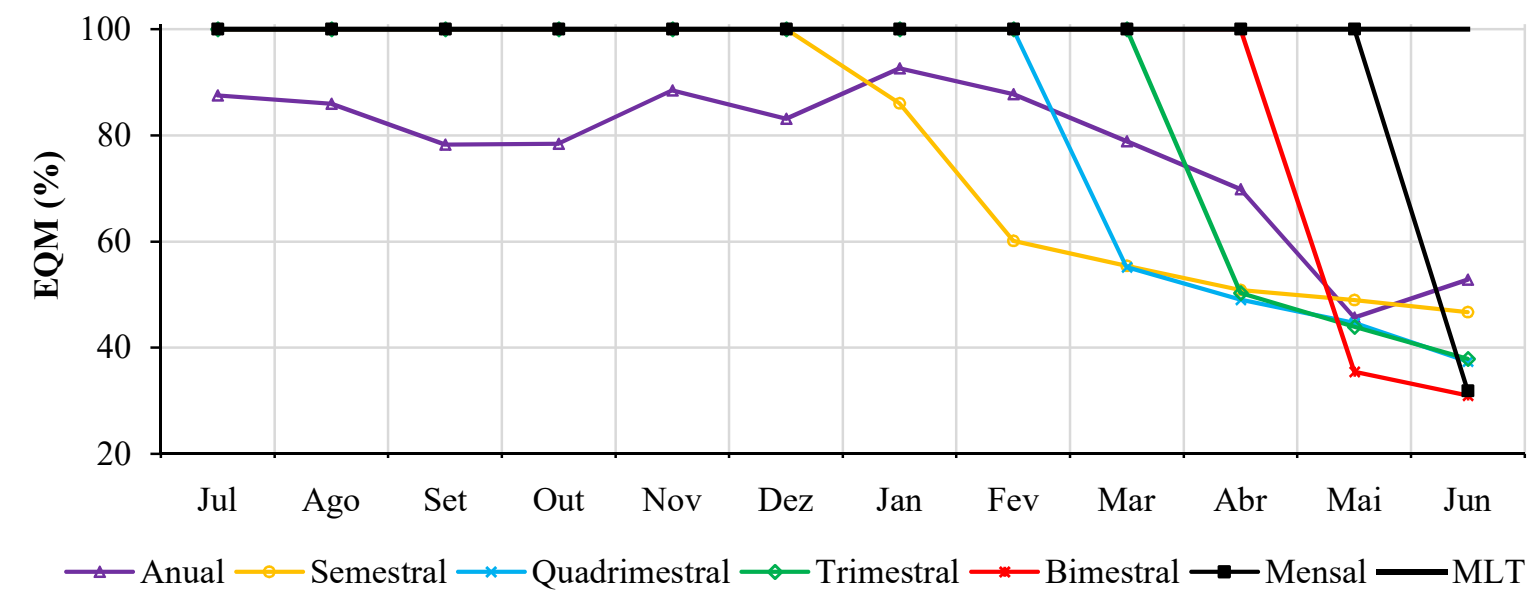

(b)

Figura 30 - Erros quadráticos médios percentuais a MLT das previsões com o modelo PAR-1 para os meses de Janeiro (a) e Julho (b) na usina hidrelétrica de Furnas.

Na Figura 30 a barra preta contínua, na região superior do gráfico representa o erro quadrático médio do valor da afluência média de cada mês e foi utilizada como base de comparações em $100 \%$. Os erros quadráticos médios das outras previsões foram sempre calculados percentualmente e esse valor base.

As previsões PDEM-k1 mostram apenas um valor previsto. Isso é justamente porque no modelo PDEM-k1 não existe uma distribuição de valores proporcionais à MLT. A previsão de mais de um mês a frente com o modelo PAR-1, na técnica PDEM-k1 não faz sentido. Já com o 
modelo PAR-1, na técnica PDEM-k2, a previsão de até dois meses a frente é possível e é mostrada no gráfico em vermelho. O mesmo padrão de meses a frente pode ser seguido até a obtenção de 12 meses a frente com o modelo PAR-1 e a técnica PDEM-k12.

Na Figura 30 (a) a previsão de Janeiro foi mantida como base de comparações. O ponto mais a direita (Dezembro) de todas as técnicas é a previsão de Janeiro estando-se em Dezembro. A mesma previsão de Janeiro foi feita estando-se em Novembro com todos os modelos (exceto com a técnica PDEM-k1) e assim por diante até que a partir de Junho do ano anterior, a única técnica que prevê Janeiro próximo é a técnica PDEM-k12.

Optou-se para a obtenção do modelo composto de previsões de k meses a frente por se utilizar a PDEM-k1 para o primeiro mês a frente, a PDEM-k2 para o segundo mês a frente, a PDEM-k3 para o terceiro mês a frente, a PDEM-k4 para o quarto mês a frente, a PDEM-k6 para o quinto e o sexto mês a frente e a PDEM-k12 do sétimo ao décimo segundo mês a frente.

\subsection{Volumes armazenados}

Esta seção apresenta os resultados comparativos dos volumes armazenados obtidos com as técnicas simuladas. São mostrados os resultados de cada estratégia em valores mensais e médios do período histórico completo simulado.

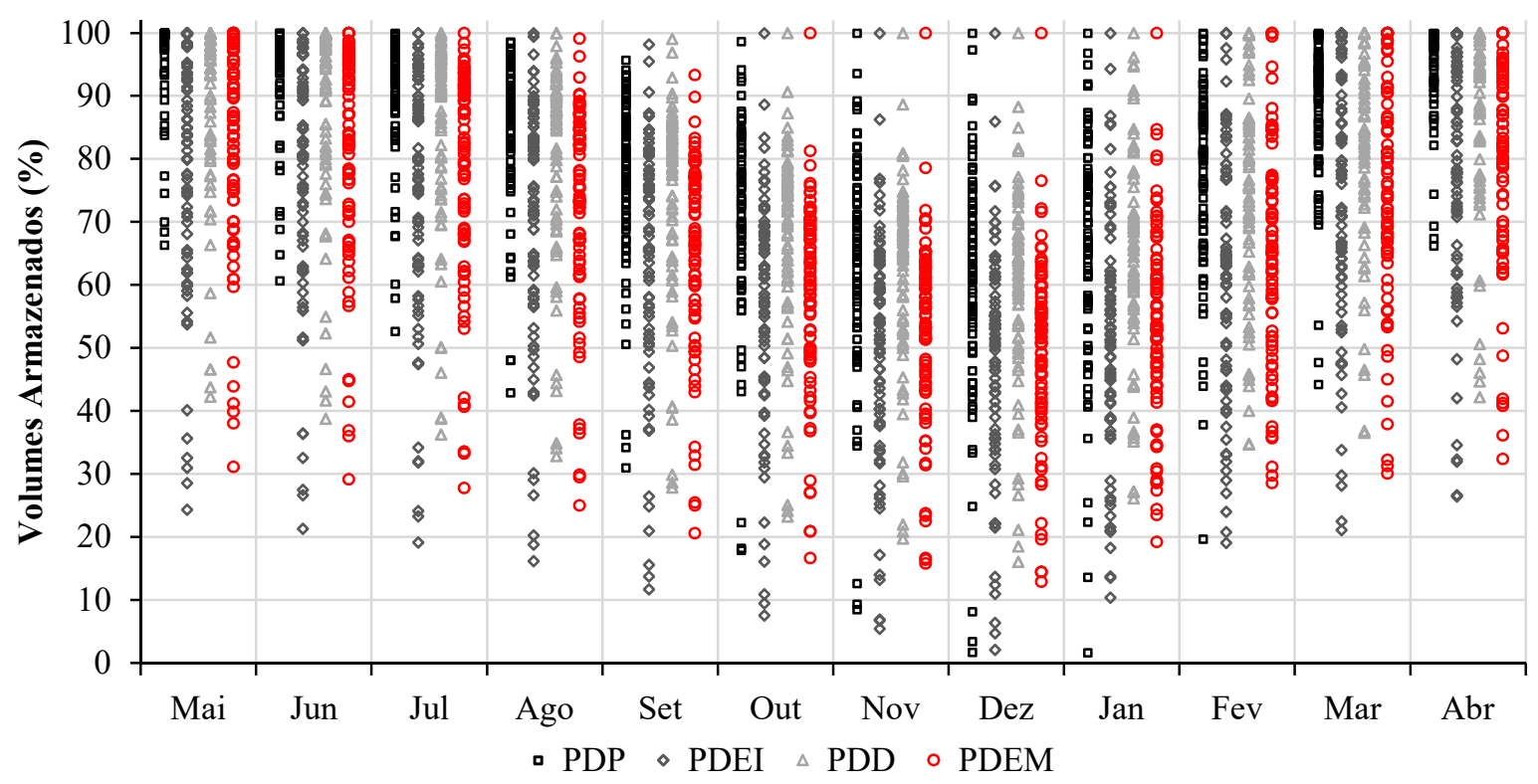

Figura 31 - Volumes mensais armazenados na usina hidrelétrica de Furnas com as técnicas clássicas. 


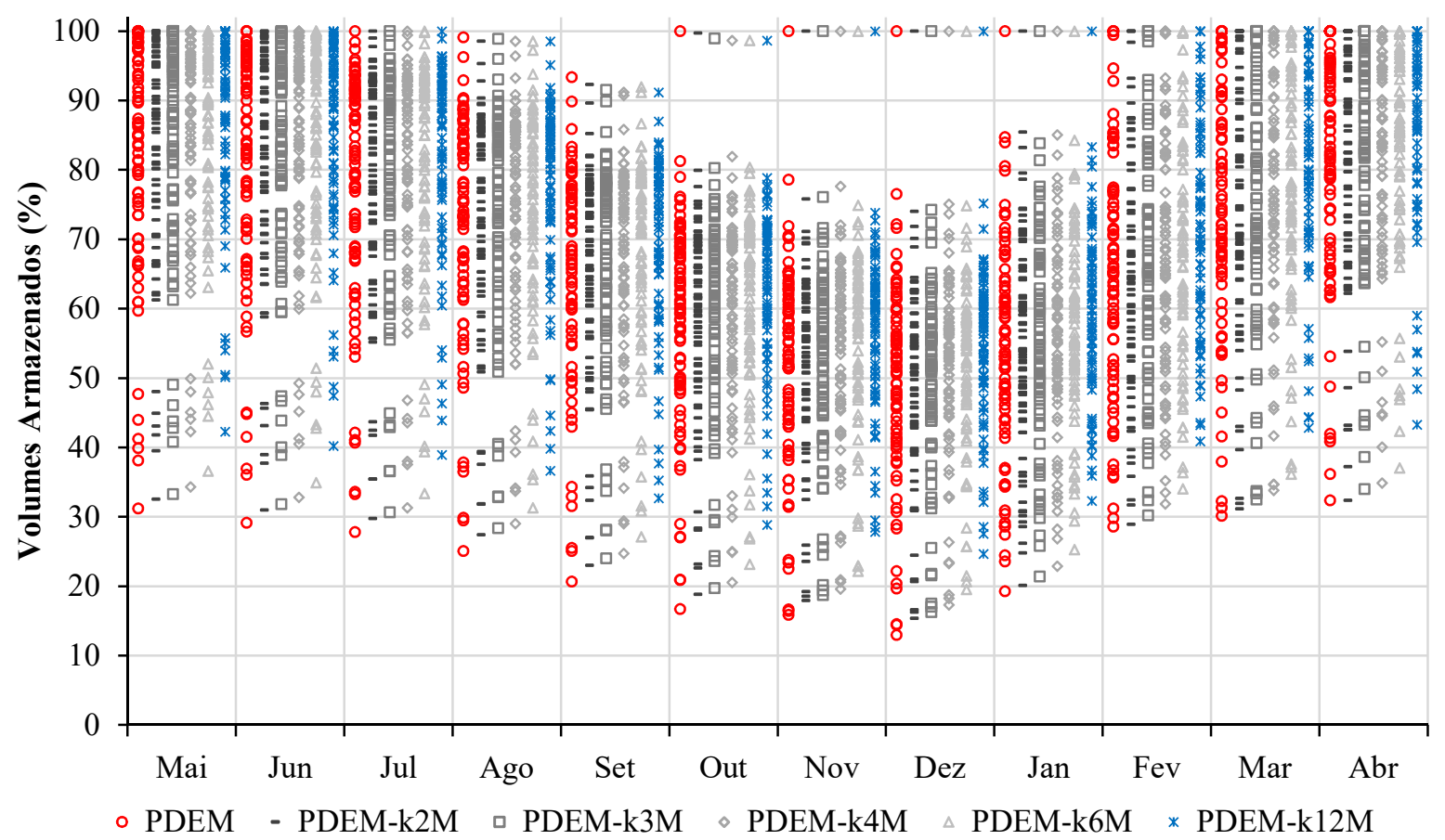

Figura 32 - Volumes mensais armazenados na usina hidrelétrica de Furnas com as técnicas propostas.

A Figura 31 e a Figura 32 ilustram os valores mensais de volumes armazenados para as técnicas simuladas. Ela está dividida em duas para facilitar a comparação entre as técnicas clássicas e as técnicas propostas. Na Figura 31 nota-se que as técnicas PDD, PDEI, PDED e PDEM têm um mesmo padrão tentativa de enchimento do reservatório em Maio e mínimos armazenamentos do reservatório registrados em Dezembro. Estas mesmas características são observadas na Figura 32.

No entanto ao observarem-se os volumes mínimos de cada mês nota-se que a técnica PDD é a mais conservadora, mantendo o reservatório sempre com um armazenamento maior. A PDEI é a técnica menos conservadora e, consequentemente, a que mantém o reservatório em uma condição de armazenamento menor. Já a PDEM, técnica clássica atualmente adotada, obteve resultados de armazenamento mínimos intermediários, entre a PDEI e a PDED. O mesmo comportamento é observado com relação aos armazenamentos máximos

$\mathrm{Na}$ Figura 32, a comparação com a PDEM fica diferente. Ao se acrescentarem meses às técnicas propostas os volumes mínimos passam a aumentar o nível de armazenamento e os volumes máximos passam a diminuir os níveis de armazenamento na maioria dos meses. Um resumo desses comportamentos pode ser obtido através dos valores médios de armazenamento mensais do reservatório, apresentados a seguir na Figura 33. 


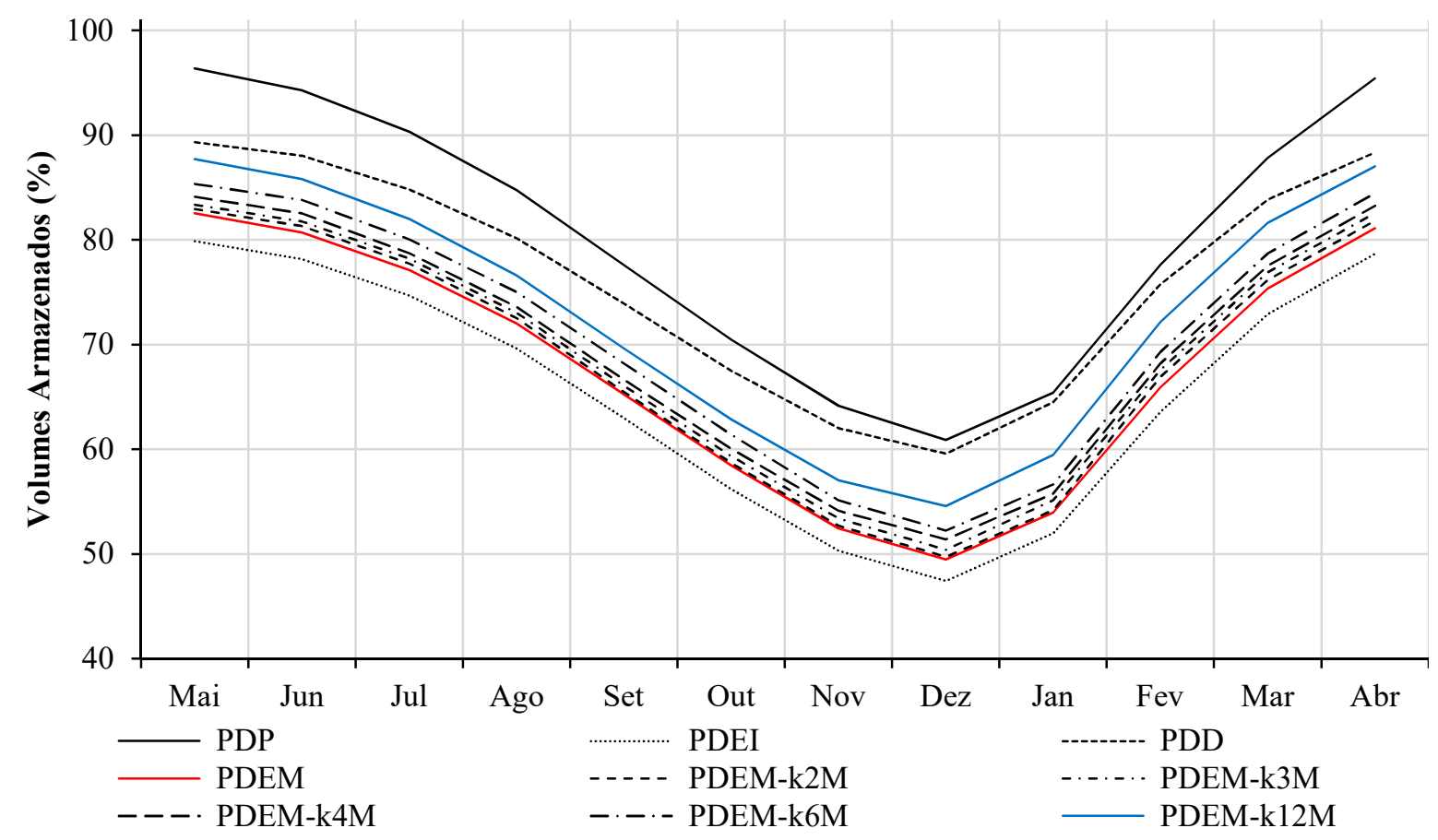

Figura 33 - Volumes armazenados médios mensais da usina hidrelétrica de Furnas.

Os resultados dos volumes médios armazenados na usina hidrelétrica de Furnas, mostrados na Figura 33, vêm ao encontro das informações levantadas na Figura 31 e Figura 32. Os valores médios de volumes da técnica PDD são os mais elevados. Os valores médios de volumes armazenados são os obtidos com a técnica PDEI. A partir da PDEM e adicionando-se meses às composições PDEM-k, os volumes médios armazenados aumentam. O maior volume médio de armazenamento é obtido com a PDED.

A variação menor de volumes observada na Figura 32 com o aumento do número de meses somados e o aumento do volume médio armazenado é interessante pois garante à usina hidrelétrica uma maior altura de queda para geração de energia elétrica. Por outro lado, ele implica em uma maior chance de vertimentos devido ao canal de adução e as turbinas de geração terem limites físicos de volumes a serem turbinados. A seção seguinte trata especificamente a questão dos vertimentos médios observados.

\subsection{Vertimentos}

Esta seção apresenta os resultados comparativos dos volumes médios mensais vertidos com as técnicas clássicas e propostas. 


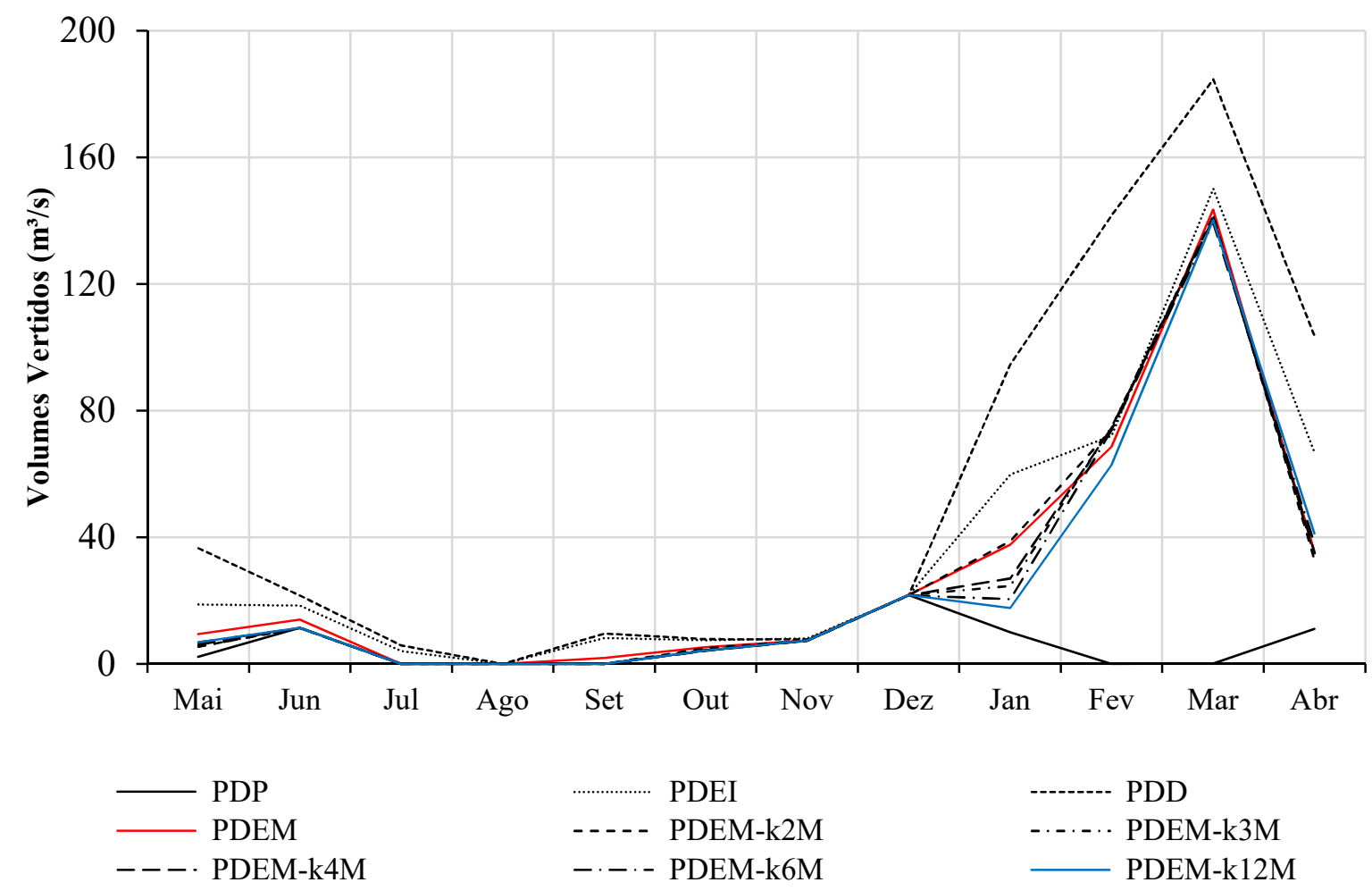

Figura 34 - Volumes médios mensais vertidos na usina hidrelétrica de Furnas.

$\mathrm{Na}$ Figura 34 pode-se observar que os maiores vertimentos em todas as técnicas estocásticas ocorreram em Março. Nota-se também que no mês de Janeiro há um aumento gradual de volumes médios vertidos a partir da PDEM-k12 até a PDEM. Nos outros meses há uma equivalência entre os volumes médios vertidos com a PDEM, PDEM-k2, PDEM-k3, PDEM-k4, PDEM-k6 e PDEM-k12.

A técnica que apresenta os maiores volumes médios de vertimentos é a PDED, principalmente nos meses de Janeiro, Fevereiro Março e Abril. A PDEI apresenta um ligeiro aumento dos volumes médios vertidos com relação a PDEM e as técnicas propostas. Os menores volumes médios vertidos são os que foram obtidos com a PDD. A consequência direta entre volumes armazenados e volumes vertidos é a geração hidrelétrica, apresentada na seção seguinte.

\subsection{Gerações Hidrelétricas}

Esta seção apresenta os resultados comparativos das gerações hidrelétricas obtidas. São mostrados os resultados médios mensais de geração de energia elétrica na usina hidrelétrica de Furnas com as técnicas clássicas e propostas na Figura 35, a seguir. 


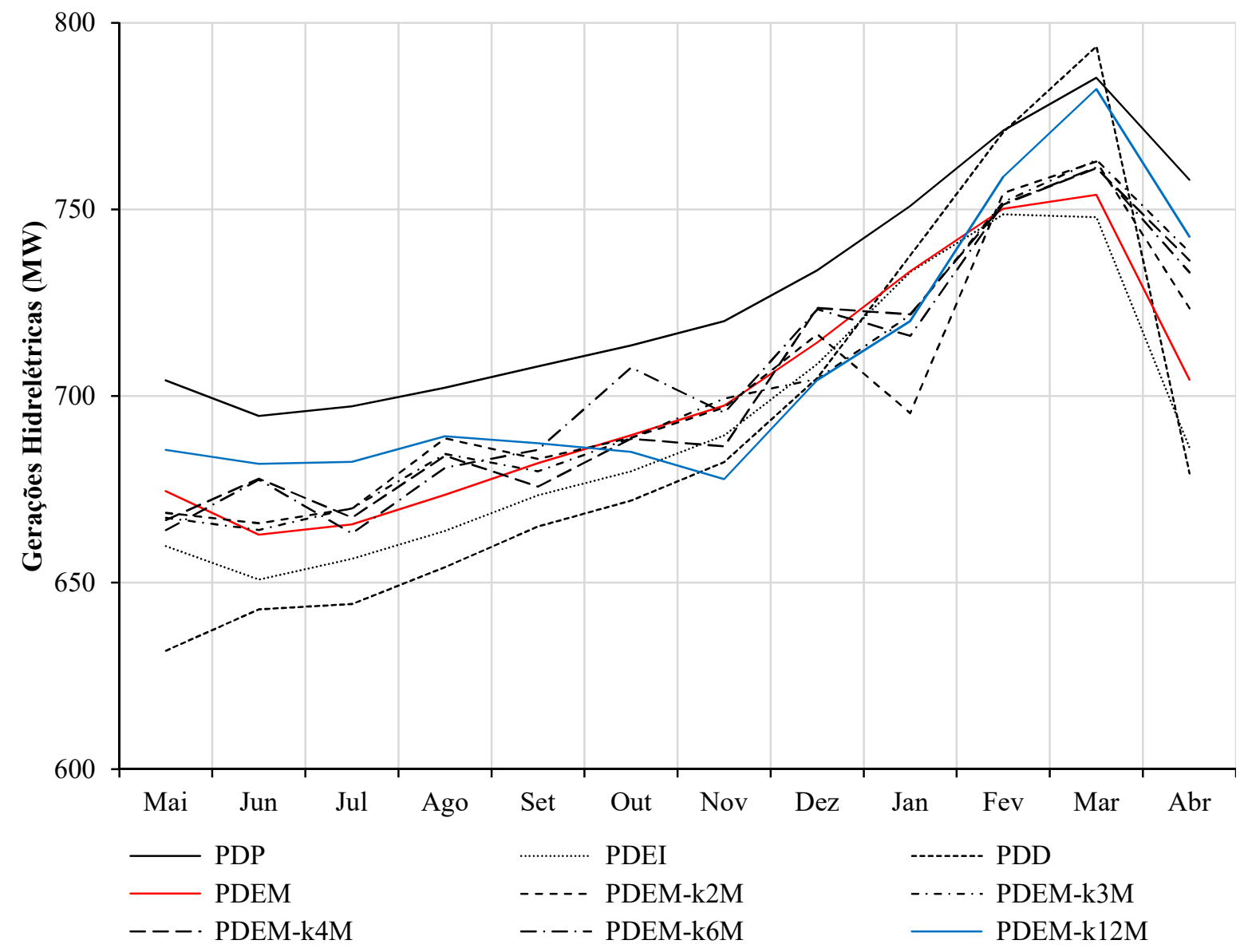

Figura 35 - Gerações hidrelétricas médias para a usina hidrelétrica de Furnas.

Diferentemente da Figura 31, Figura 32, Figura 33 e Figura 34 onde os padrões crescentes ou decrescentes dos volumes armazenados e vertidos eram evidentes com o aumento do número de meses agregados, as gerações hidrelétricas não seguem um mesmo padrão o tempo todo. No entanto alguns padrões podem ser identificados.

No mês de Abril, o último do ano hidrológico em simulações feitas na usina hidrelétrica de Furnas, há uma "quebra" nos valores de geração hidrelétrica justamente pelo fato de Abril ser o ultimo mês do ano hidrológico. Nas outras usinas hidrelétricas simuladas isso também pode ser observado. Essa característica ocorre em todas as técnicas simuladas.

Observa-se também que os valores mensais atendem a uma tendência crescente de gerações hidrelétricas. Na comparação entre PDEM e PDEM-k12M nota-se que nos 5 primeiros meses a média de gerações hidrelétricas da PDEM-k12M é maior que na PDEM. Entre Outubro e Novembro a geração hidrelétrica da PDEM passa a ser maior e nos meses finais, a partir de Fevereiro, a geração hidrelétrica da PDEM-k12M volta a ser maior.

Uma forma mais resumida e abrangente de se observar os resultados de geração hidrelétrica é através das curvas de permanência apresentadas a seguir. 


\subsection{Curvas de permanência}

Esta seção apresenta os resultados comparativos das curvas de permanência obtidas com a PDEM e a PDEM-k12M para o período entre maio de 1932 e abril de 2012. São mostrados os resultados obtidos nas usinas de Furnas, Foz do Areia, Serra da Mesa e Sobradinho.

\subsubsection{Usina de Furnas}

Esta seção apresenta os resultados das curvas de permanências de gerações hidrelétricas (linhas) e as diferenças percentuais entre PDEM e PDEM-k12M (áreas).

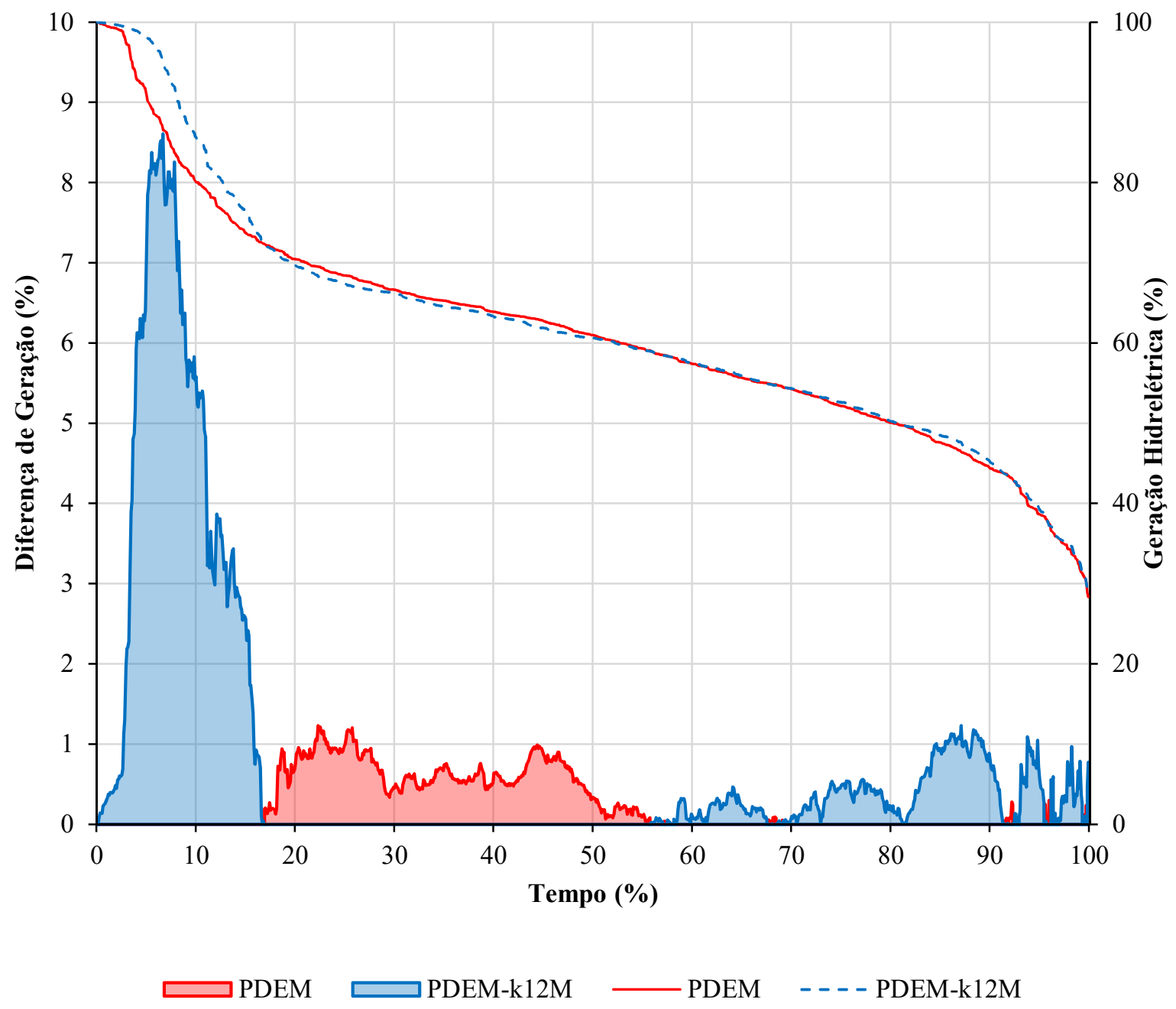

Figura 36 - Curvas de permanência e de diferenças entre PDEM e PDEM-k12M da usina de Furnas. 
As curvas de permanência são uma versão organizada de forma decrescente das gerações hidrelétricas. Os valores mais a esquerda representam as maiores gerações hidrelétricas. Os valores mais a direita representam as menores gerações hidrelétricas. Com isso, pode-se afirmar, por exemplo, que a PDEM manteve em 10\% do tempo total simulado a geração hidrelétrica superior a, aproximadamente, $80 \%$ do valor máximo gerado. Por outro lado, como exemplo, pode-se afirmar que a PDEM-k12M manteve em 90\% do período simulado uma geração hidrelétrica superior a, aproximadamente, 45\% da geração hidrelétrica máxima. Pode-se, ainda, afirmar que a usina hidrelétrica de Furnas manteve uma geração em $100 \%$ do tempo superior a, aproximadamente, $30 \%$ de sua capacidade de geração hidrelétrica instalada com a PDEM-k12M.

As curvas de diferenças percentuais entre as curvas de permanência de geração hidrelétricas ilustram o quanto, percentualmente, a geração hidrelétrica foi superior em uma técnica comparada à outra. Com isso, pode-se afirmar que nos valores $18 \%$ maiores de geração hidrelétrica a PDEM-k12M foi superior à PDEM.

A análise simples do gráfico das curvas de permanência (linhas) não é muito clara. Notase que há uma vantagem na porção inicial (até 15\%) para a PDEM-k12M comparada a PDEM. No entanto, a partir disto, nada se pode afirmar com clareza. As curvas de diferenças percentuais expõem de maneira mais clara as diferenças entre as gerações hidrelétricas.

Nos 15\% mais a esquerda das curvas de permanência, com maiores gerações hidrelétricas, a geração da PDEM-k12M é superior a PDEM, chegando a uma diferença percentual maior que $8 \%$. Nos $40 \%$ mais a direita das curvas de permanência, com menores gerações hidrelétricas, a geração PDEM-k12M também é superior a PDEM, chegando a diferenças superiores a $1 \%$.

O padrão de resposta comparativa entre a PDEM-k12M e a PDEM é que em períodos onde a geração hidrelétrica é próxima dos valores máximos e próxima dos valores mínimos a PDEM-k12M consegue obter maiores gerações hidrelétricas e melhores resultados. Já nas regiões intermediárias de geração hidrelétrica a PDEM consegue maiores gerações hidrelétricas.

Esse padrão também pode ser observado nas outras usinas hidrelétricas simuladas. Por isso, são mostrados esses resultados das outras usinas hidrelétricas simuladas a seguir. 


\subsubsection{Usinas de Foz do Areia, Serra da Mesa e Sobradinho}

Nesta seção são mostradas as mesmas curvas de permanências e de diferenças de geração para as usinas hidrelétricas de Foz do Areia, Serra da Mesa e Sobradinho.

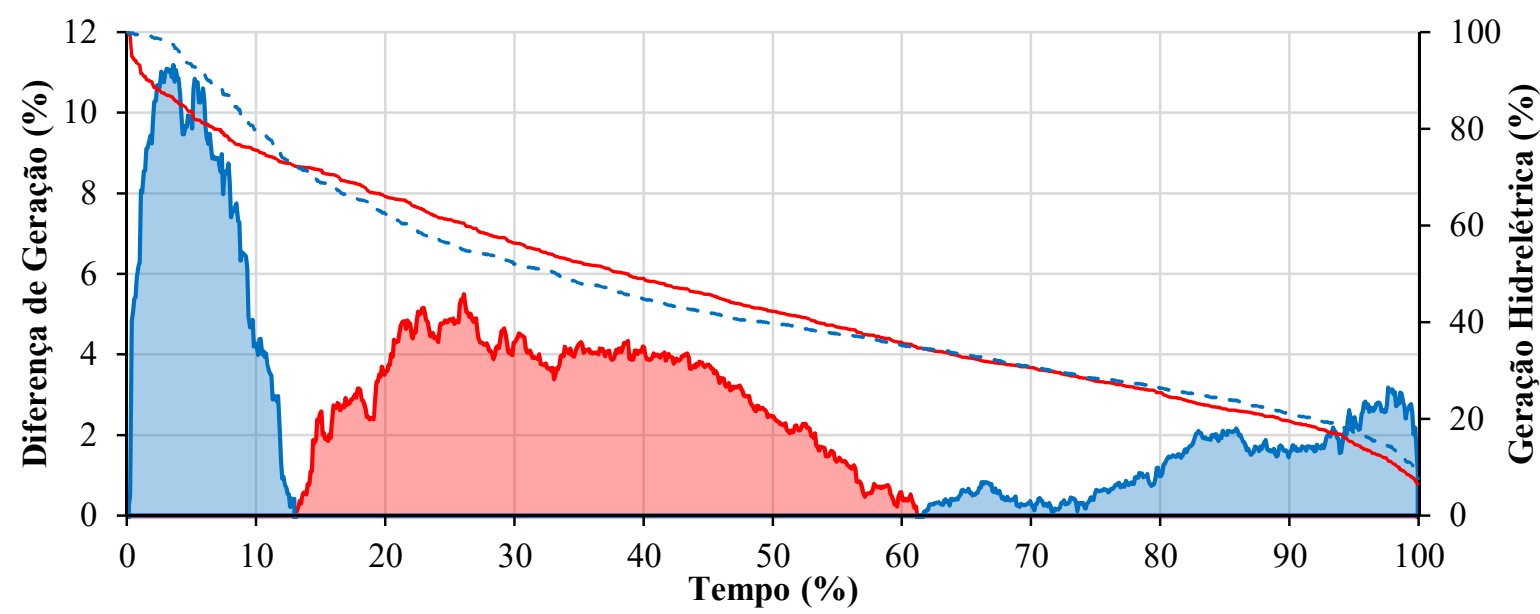

(a)

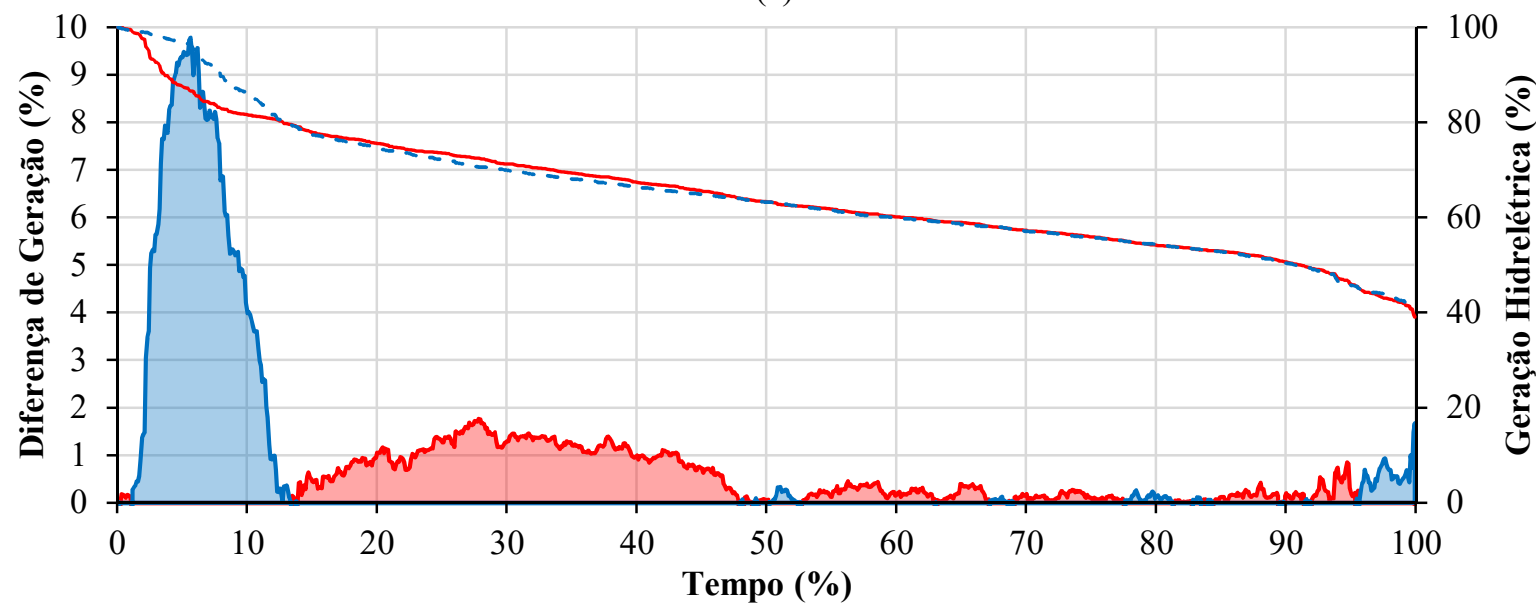

(b)

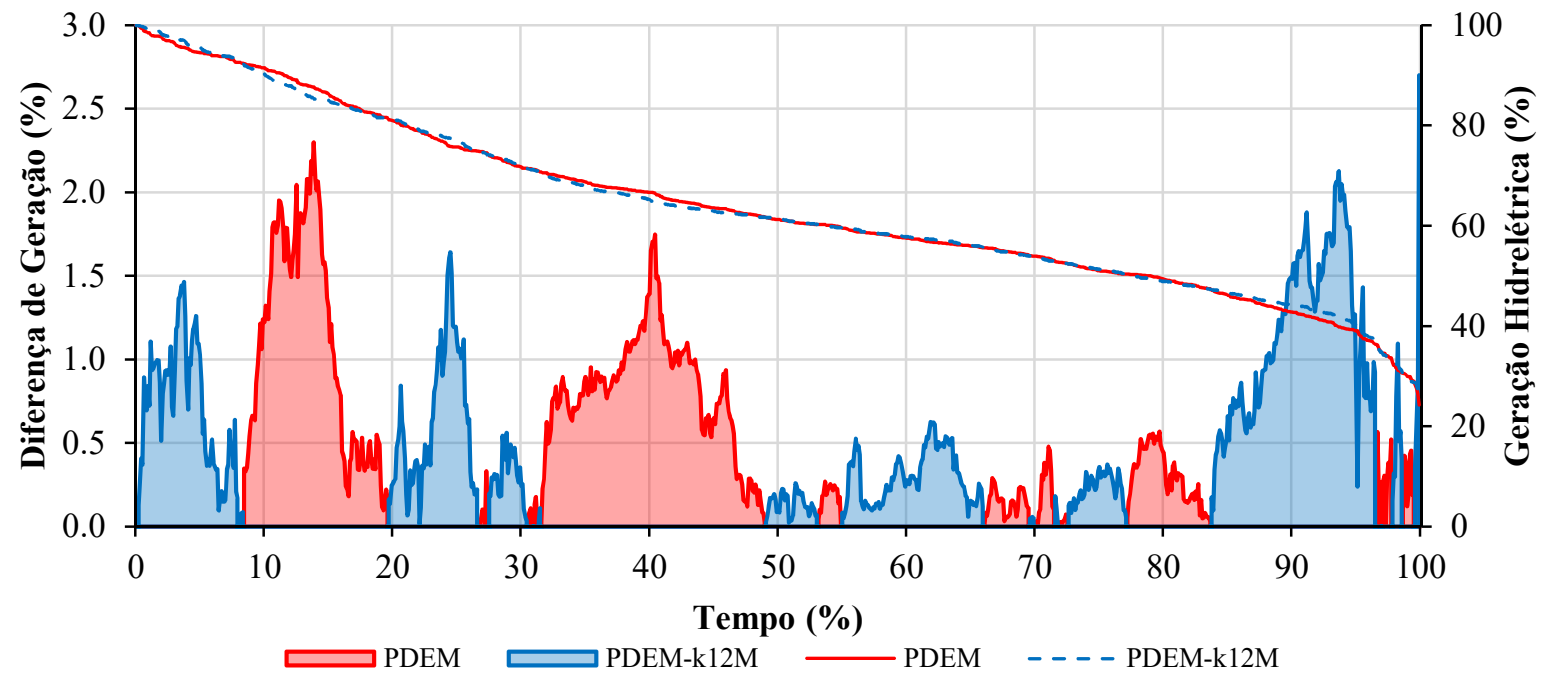

(c)

Figura 37 - Curvas de permanência e de diferenças entre PDEM e PDEM-k12M das usinas hidrelétricas de Foz do Areia (a), Serra da Mesa (b) e Sobradinho (c). 
Assim como na usina hidrelétrica de Furnas, o padrão de resposta onde as gerações hidrelétricas PDEM-k12M são maiores que a PDEM é o mesmo. Nas porções iniciais e finais dos gráficos a operação PDEM-k12M tem ampla vantagem sobre a operação PDEM. Essa vantagem é maior em alguns casos, chegando a mais de 10\% na usina hidrelétrica de Foz do Areia, na porção com maiores gerações hidrelétricas, mais a esquerda das curvas de permanência.

Nas 4 usinas hidrelétricas simuladas a operação PDEM-k12M foi superior, em aproximadamente, $10 \%$ da porção com maiores gerações hidrelétricas, mais a esquerda, e também foi maior na porção com as menores gerações hidrelétricas, mais a direita, variando entre 40\% na usina hidrelétrica de Furnas e 5\% na usina hidrelétrica de Serra da Mesa, aproximadamente.

Esse resultado tem ligação direta com as tabelas de decisões. Embora seja definida a turbinagem de cada mês de acordo com a resposta do otimizador determinístico, os valores das tabelas utilizados são menos variantes com o aumentar de meses agregados.

Essas variações menores garantem um reservatório mais cheio, em média, nas situações menos favoráveis hidrologicamente. No entanto, essa mesma variação menor garante, tembém, um reservatório menos cheio em situações hidrológicas mais favoráveis. Com isso temos um reservatório com maior espaço para armazenamento em situações de afluências acima da média e um reservatório com maior altura de queda em situações de afluências abaixo da média. A Figura 38, a seguir, comprova essas informações. 


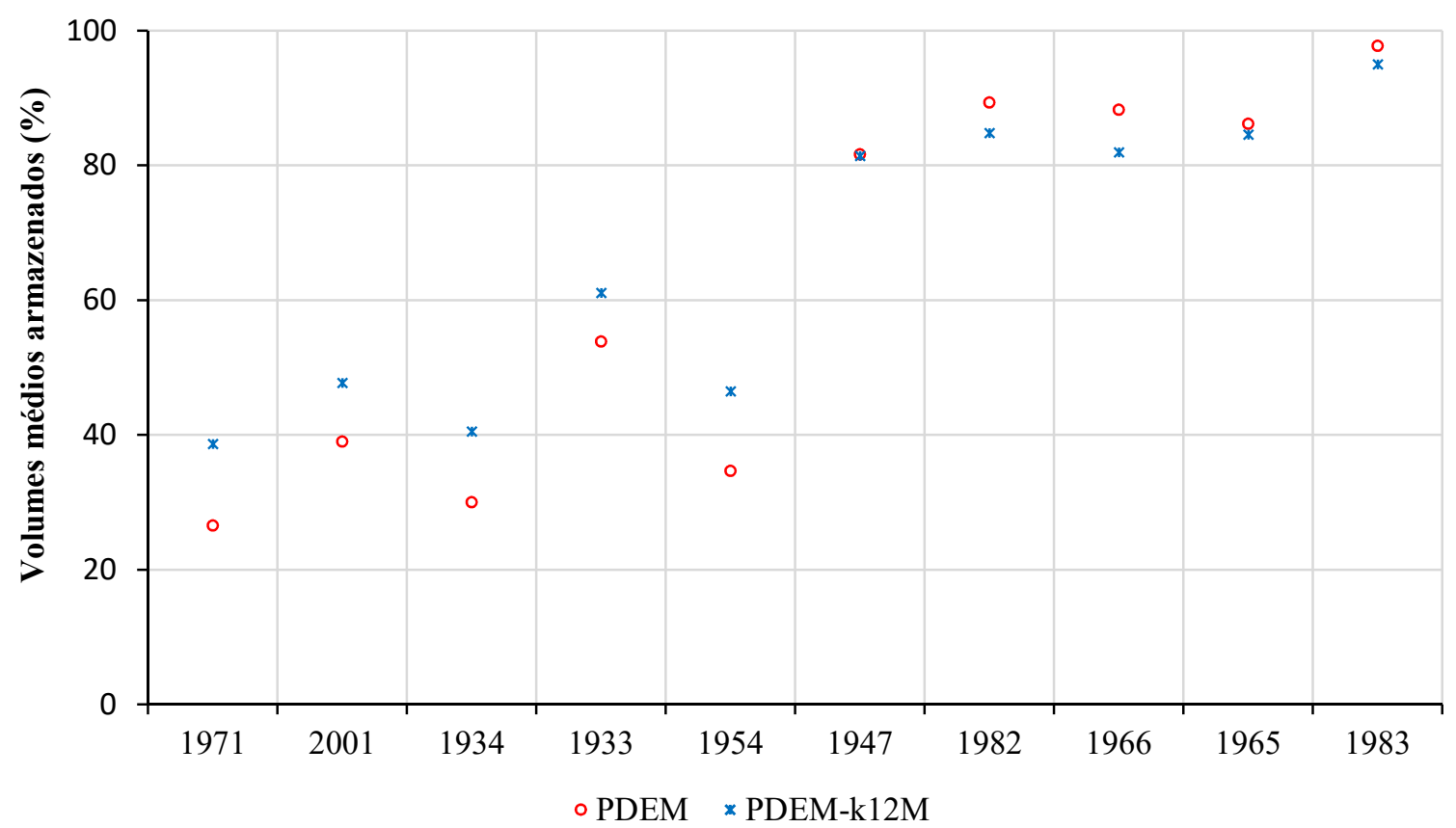

Figura 38 - Volumes médios anuais armazenados na usina hidrelétrica de Furnas para os 5 anos de hidrologias menos favoráveis e para os 5 anos com hidrologias mais favoráveis.

A Figura 38 contém os dados dos cinco anos com os menores volumes mensais de afluência acumulados, 1971, 2001, 1934, 1933 e $1954 \mathrm{com} 5.830 \mathrm{~m}^{3} / \mathrm{s}, 6.134 \mathrm{~m}^{3} / \mathrm{s}, 6.318 \mathrm{~m}^{3} / \mathrm{s}$, $6.506 \mathrm{~m}^{3} / \mathrm{s}$, e $6.548 \mathrm{~m}^{3} / \mathrm{s}$, respectivamente, e os maiores volumes mensais de afluência, 1947 , $1982,1966,1965$ e $1983 \mathrm{com} 15.620 \mathrm{~m}^{3} / \mathrm{s}, 16.261 \mathrm{~m}^{3} / \mathrm{s}, 16.569 \mathrm{~m}^{3} / \mathrm{s}, 18.328 \mathrm{~m}^{3} / \mathrm{s}$, e $27.036 \mathrm{~m}^{3} / \mathrm{s}$, respectivamente.

Nota-se que nos anos em que ocorreram as menores afluências os volumes médios dos reservatórios com a operação PDEM são menores que os volumes médios com a operação PDEM-k12M, implicando, assim, em uma menor altura de queda e, consequentemente, uma menor geração hidrelétrica com o mesmo volume de afluência.

Por outro lado, nos anos em que ocorreram as maiores afluências, os volumes médios dos reservatórios com a operação PDEM são mais elevados, implicando, em decorrência da afluência ser muito acima da média, em um aumento do volume vertido e, consequentemente, em uma menor geração hidrelétrica.

Essa variação nos reservatórios das usinas hidrelétricas também ocorre nas usinas hidrelétricas de Foz do Areia e de Serra da Mesa. Na usina de Sobradinho isso não ocorre de maneira clara. O padrão de reservatórios mais cheios em anos hidrologicamente menos favoráveis e menos cheios em anos hidrologicamente mais favoráveis é indefinido entre as operações PDEM e PDEM-k12M. Um indicativo da não ocorrência desse padrão é a relação 
entre a capacidade de turbinagem e afluência da usina hidrelétrica de Sobradinho, mostrada a seguir na Tabela 20 na coluna Eficiência.

\subsection{Resultados comparativos}

Esta seção apresenta os resultados comparativos tabelados das operações das políticas propostas neste trabalho. São apresentados os resultados comparativos de gerações hidrelétricas, vertimentos, eficiência, produtividade, gerações hidrelétricas e, principalmente, custos da complementação de geração térmica. Além das técnicas clássicas e das técnicas propostas por este trabalho são apresentados também os resultados tabelados da operação feita com tabelas PDEM-k, nas diferentes agregações de dados de afluências propostas por este trabalho, mas com previsões de afluências, utilizadas pelo otimizador, "perfeitas", com dados reais do histórico de operações.

Tabela 20 - Resultados médios comparativos para a usina hidrelétrica de Furnas - utilização da água em estatísticas de eficiência e produtividade.

\begin{tabular}{|c|c|c|c|c|}
\hline & $\begin{array}{l}\text { Turbinagem } \\
\qquad\left(\mathrm{m}^{3} / \mathrm{s}\right)\end{array}$ & $\begin{array}{l}\text { Vertimento } \\
\qquad\left(\mathrm{m}^{3} / \mathrm{s}\right)\end{array}$ & $\begin{array}{c}\text { Eficiência } \\
(\%)\end{array}$ & $\begin{array}{l}\text { Produtividade } \\
\left(\mathrm{MW} / \mathrm{m}^{3} / \mathrm{s}\right)\end{array}$ \\
\hline PDP & 918,2 & 5,6 & 99,39 & 1,0691 \\
\hline $\begin{array}{l}\text { PDEI } \\
{[\%]}\end{array}$ & $\begin{array}{ll}889,1 & \\
& \mathbf{- 3 , 1 7} \\
\end{array}$ & $\begin{array}{ll}35,9 & \\
& \mathbf{5 4 1 , 1} \\
\end{array}$ & 95,96 & $\begin{array}{r}1,0169 \\
\mathbf{- 4 , 8 8} \\
\end{array}$ \\
\hline $\begin{array}{l}\text { PDD } \\
{[\mathbf{\%}]}\end{array}$ & $\begin{array}{ll}872,1 & \\
& \mathbf{- 5 , 0 2} \\
\end{array}$ & $\begin{array}{rr}52,3 & \\
& \mathbf{8 3 3 , 9} \\
\end{array}$ & 94,00 & $\begin{array}{r}1,0104 \\
-5,49 \\
\end{array}$ \\
\hline $\begin{array}{ll}\text { PDEM } & \\
& {[\%]} \\
\end{array}$ & $\begin{array}{rr}896,4 & \\
& -2,37 \\
\end{array}$ & $\begin{array}{ll}28,4 & \\
& 407,1 \\
\end{array}$ & 96,83 & $\begin{array}{r}1,0212 \\
-4,48 \\
\end{array}$ \\
\hline $\begin{array}{l}\text { PDEM-k2 } \\
\quad[\%]\end{array}$ & $\begin{array}{rr}898,2 & \\
& \mathbf{- 2 , 1 8}\end{array}$ & $\begin{array}{rr}26,5 & \\
& \mathbf{3 7 3 , 2}\end{array}$ & 97,05 & $\begin{array}{r}1,0133 \\
-5,22\end{array}$ \\
\hline $\begin{array}{c}\text { PDEM-k2M } \\
{[\%]}\end{array}$ & $\begin{array}{rr}896,9 & \\
& \mathbf{- 2 , 3 2}\end{array}$ & $\begin{array}{rr}27,9 & \\
& \mathbf{3 9 8 , 2}\end{array}$ & 96,89 & $\begin{array}{r}1,0245 \\
\quad-4,17\end{array}$ \\
\hline $\begin{array}{l}\text { PDEM-k2P } \\
{[\%]}\end{array}$ & $\begin{array}{rr}902,8 & \\
& \mathbf{- 1 , 6 8} \\
\end{array}$ & $\begin{array}{lr}21,9 & \\
& \mathbf{2 9 1 , 1} \\
\end{array}$ & 97,57 & $\begin{array}{r}1,0157 \\
\mathbf{- 4 , 9 9} \\
\end{array}$ \\
\hline $\begin{array}{l}\text { PDEM-k3 } \\
{[\%]}\end{array}$ & $\begin{array}{rr}897,9 & \\
& \mathbf{- 2 , 2 1} \\
\end{array}$ & $\begin{array}{rr}26,8 & \\
\quad \mathbf{3 7 8 , 6} 6 \\
\end{array}$ & 97,02 & $\begin{array}{r}1,0023 \\
-6,25 \\
\end{array}$ \\
\hline $\begin{array}{c}\text { PDEM-k3M } \\
{[\%]}\end{array}$ & $\begin{array}{ll}898,0 & \\
& -\mathbf{2 , 2 0}\end{array}$ & $\begin{array}{l}26,8 \\
\quad \mathbf{3 7 8 , 6} \\
\end{array}$ & 97,02 & $\begin{array}{r}1,0244 \\
-4,18\end{array}$ \\
\hline $\begin{array}{l}\text { PDEM-k3P } \\
{[\%]}\end{array}$ & $\begin{array}{ll}904,5 & \\
& -1,49\end{array}$ & $\begin{array}{ll}20,2 & \\
& \mathbf{2 6 0}, 7\end{array}$ & 97,77 & $\begin{array}{r}1,0062 \\
-\mathbf{5 , 8 8}\end{array}$ \\
\hline $\begin{array}{l}\text { PDEM-k4 } \\
{[\%]}\end{array}$ & $\begin{array}{rr}896,3 & \\
& \mathbf{- 2 , 3 9} \\
\end{array}$ & $\begin{array}{rr}28,3 & \\
& \mathbf{4 0 5 , 4} \\
\end{array}$ & 96,84 & $\begin{array}{r}0,9893 \\
-\mathbf{7 , 4 6}\end{array}$ \\
\hline $\begin{array}{r}\text { PDEM-k4M } \\
{[\%]}\end{array}$ & $\begin{array}{rr}897,7 & \\
& \mathbf{- 2 , 2 3} \\
\end{array}$ & $\begin{array}{lr}27,0 & \\
& \mathbf{3 8 2 , 1}\end{array}$ & 96,99 & $\begin{array}{r}1,0247 \\
-4,15\end{array}$ \\
\hline PDEM-k4P & 906,3 & 18,2 & 97,99 & 0,9979 \\
\hline
\end{tabular}




\begin{tabular}{|c|c|c|c|c|}
\hline [\%] & $-1,30$ & 225,0 & & $-6,66$ \\
\hline $\begin{array}{r}\text { PDEM-k6 } \\
\\
{[\%]}\end{array}$ & $\begin{array}{ll}895,9 & \\
& \mathbf{- 2 , 4 3} \\
\end{array}$ & $\begin{array}{ll}28,8 & \\
& \mathbf{4 1 4 , 3} \\
\end{array}$ & 96,79 & $\begin{array}{r}0,9806 \\
\mathbf{- 8 , 2 8}\end{array}$ \\
\hline $\begin{array}{l}\text { PDEM-k6M } \\
{[\%]}\end{array}$ & $\begin{array}{ll}898,1 & \\
& \mathbf{- 2 , 1 9}\end{array}$ & $26,6 \quad 3$ & 97,04 & $\begin{array}{r}1,0287 \\
-\mathbf{3 , 7 8}\end{array}$ \\
\hline $\begin{array}{l}\text { PDEM-k6P } \\
{\left[\begin{array}{l}{[\%]} \\
\end{array}\right.}\end{array}$ & $\begin{array}{ll}910,8 & \\
& \mathbf{- 0 , 8 1} \\
\end{array}$ & $13,7 \quad \mathbf{1 4 4 , 6}$ & 98,50 & $\begin{array}{l}1,0006 \\
-6,41\end{array}$ \\
\hline $\begin{array}{r}\text { PDEM-k12 } \\
{[\%]}\end{array}$ & $\begin{array}{ll}898,4 & \\
& \mathbf{- 2 , 1 6}\end{array}$ & $\begin{array}{ll}26,3 \quad \\
& \mathbf{3 6 9 , 6}\end{array}$ & 97,07 & $\begin{array}{r}0,9971 \\
\mathbf{- 6 , 7 3}\end{array}$ \\
\hline $\begin{array}{r}\text { PDEM-k12M } \\
{[\%]}\end{array}$ & $\begin{array}{ll}898,8 & \\
& -2,11\end{array}$ & $\begin{array}{ll}25,8 & \\
& \mathbf{3 6 0}, 7\end{array}$ & 97,13 & $\begin{array}{r}1,0306 \\
-\mathbf{3}, 60\end{array}$ \\
\hline $\begin{array}{l}\text { PDEM-k12P } \\
{[\%]}\end{array}$ & $\begin{array}{ll}916,9 & \\
& \mathbf{- 0 , 1 4}\end{array}$ & 7,7 & 99,16 & $\begin{array}{r}1,0361 \\
\mathbf{- 3 , 0 9}\end{array}$ \\
\hline
\end{tabular}

Nos resultados comparativos da usina hidrelétrica de Furnas são destacadas duas políticas de operação: a PDEM, em vermelho, e a PDEM-k12M, proposta por este trabalho, em azul. O parâmetro base de comparações é a PDD, que trabalha com a programação dinâmica em afluências do histórico de operações. A PDD representa a operação ótima global. Os valores em negrito representam a porcentagem de cada medida com relação à operação PDD. Em cada uma das agregações propostas são apresentados os resultados da operação agregada direta, da operação agregada mista e da agregação mista mas com previsão perfeita.

A coluna Eficiência representa a relação percentual entre os volumes turbinados e os volumes vertidos. Já a coluna Produtividade representa a relação entre energia elétrica gerada e o volume de afluência ao longo do histórico completo simulado.

Um fator a se destacar é a eficiência da usina hidrelétrica de Furnas. Como a operação PDD é o valor ótimo global, pode-se afirmar que apenas $0,24 \%$ do volume total de afluência da usina hidrelétrica de Furnas é "desperdiçado" sob a forma de vertimento e não gerando, consequentemente, energia elétrica.

De maneira geral, há um aumento nos volumes turbinados, um aumento na produtivdade e uma diminuição dos volumes vertidos com o aumento dos meses agregados. Já a eficiência da usina hidrelétrica de Furnas manteve-se, praticamente, constante com o aumento dos meses agregados.

A seguir são apresentados os resultados de gerações hidrelétricas e custos comparativos tabelados da usina hidrelétrica de Furnas. 
Tabela 21 - Resultados comparativos para a usina hidrelétrica de Furnas - custos e geração hidrelétrica.

\begin{tabular}{|c|c|c|c|c|c|c|}
\hline & \multicolumn{2}{|c|}{$\begin{array}{c}\text { Geração Hidrelétrica } \\
\text { (MW) }\end{array}$} & \multicolumn{4}{|c|}{$\begin{array}{c}\text { Custos } \\
(\$)\end{array}$} \\
\hline & Média & $\begin{array}{l}\text { Desvio } \\
\text { Padrão }\end{array}$ & $\begin{array}{c}\text { Totais } \\
\left({ }^{*} 10^{\wedge} 6\right) \\
\end{array}$ & $\begin{array}{l}P D D \\
(\%)\end{array}$ & $\begin{array}{l}\text { PDEM } \\
(\%)\end{array}$ & $\begin{array}{c}P D D / P D E M \\
(\%)\end{array}$ \\
\hline PDP & 726,9 & 143,5 & 3,71 & 0,00 & $-9,24$ & $-100,00$ \\
\hline PDEI & $\begin{array}{r}692,6 \\
\quad-4,72 \\
\end{array}$ & $\begin{array}{r}146,9 \\
\mathbf{2 , 3 9} \\
\end{array}$ & 4,15 & 11,65 & 1,33 & 14,42 \\
\hline PDD & $\begin{array}{r}690,7 \\
-\mathbf{4 , 9 8} \\
\end{array}$ & $\begin{array}{r}154,6 \\
\mathbf{7 , 8 0} \\
\end{array}$ & 4,19 & 12,94 & 2,50 & 27,08 \\
\hline PDEM & $\begin{array}{r}701,0 \\
-\mathbf{3}, \mathbf{5 7} \\
\end{array}$ & $\begin{array}{r}162,9 \\
\mathbf{1 3 , 5 6} \\
\end{array}$ & 4,09 & 10,18 & 0,00 & 0,00 \\
\hline PDEM-k2 & $\begin{array}{r}703,1 \\
\quad \mathbf{3 , 2 7}\end{array}$ & $\begin{array}{r}173,9 \\
\mathbf{2 1 , 2 0}\end{array}$ & 4,10 & 10,47 & 0,26 & 2,78 \\
\hline $\begin{array}{ll}\text { PDEM-k2M } & \\
& {[\%]}\end{array}$ & $\begin{array}{c}701,9 \\
-\mathbf{3 , 4 3}\end{array}$ & $\begin{array}{c}164,4 \\
\mathbf{1 4 , 6 1}\end{array}$ & 4,08 & 9,99 & $-0,17$ & $-1,87$ \\
\hline PDEM-k2P & $\begin{array}{r}706,9 \\
-\mathbf{2 , 7 5} \\
\end{array}$ & $\begin{array}{c}177,3 \\
\mathbf{2 3 , 6 1}\end{array}$ & 4,07 & 9,53 & $-0,59$ & $-6,38$ \\
\hline PDEM-k3 & $\begin{array}{c}703,5 \\
\quad \mathbf{- 3 , 2 2}\end{array}$ & $\begin{array}{r}180,6 \\
\mathbf{2 5 , 9 2} \\
\end{array}$ & 4,12 & 11,03 & 0,76 & 8,26 \\
\hline $\begin{array}{cc}\text { PDEM-k3M } & \\
{[\%]}\end{array}$ & $\begin{array}{c}703,5 \\
-\mathbf{3 , 2 1}\end{array}$ & $\begin{array}{r}166,9 \\
\mathbf{1 6 , 3 3}\end{array}$ & 4,07 & 9,68 & $-0,46$ & $-4,94$ \\
\hline PDEM-k3P & $\begin{array}{c}708,7 \\
-2,51\end{array}$ & $\begin{array}{c}184,6 \\
\mathbf{2 8 , 6 6}\end{array}$ & 4,07 & 9,68 & $-0,46$ & $-4,96$ \\
\hline PDEM-k4 & $\begin{array}{l}703,0 \\
\quad \mathbf{3}, 29\end{array}$ & $\begin{array}{c}188,8 \\
\mathbf{3 1}, \mathbf{6 2}\end{array}$ & 4,16 & 12,02 & 1,67 & 18,02 \\
\hline PDEM-k4M & $\begin{array}{c}704,1 \\
-\mathbf{3}, \mathbf{1 4}\end{array}$ & $\begin{array}{r}167,2 \\
\quad \mathbf{1 6 , 5 8}\end{array}$ & 4,07 & 9,54 & $-0,59$ & $-6,35$ \\
\hline PDEM-k4P & $\begin{array}{c}710,7 \\
-\mathbf{2 , 2 3} \\
\end{array}$ & $\begin{array}{c}192,1 \\
\mathbf{3 3 , 9 1} \\
\end{array}$ & 4,08 & 9,78 & $-0,36$ & $-3,93$ \\
\hline PDEM-k6 & $\begin{array}{c}704,1 \\
\quad \mathbf{3 , 1 4} \\
\end{array}$ & $\begin{array}{l}193,2 \\
\quad \mathbf{3 4 , 6 5} \\
\end{array}$ & 4,16 & 12,10 & 1,74 & 18,78 \\
\hline PDEM-k6M & $\begin{array}{c}705,5 \\
-\mathbf{2 , 9 4}\end{array}$ & $\begin{array}{l}169,1 \\
\quad \mathbf{1 7 , 9 1}\end{array}$ & 4,06 & 9,23 & $-0,87$ & $-9,39$ \\
\hline PDEM-k6P & $\begin{array}{c}714,9 \\
-\mathbf{- 1 , 6 4} \\
\end{array}$ & $\begin{array}{r}190,0 \\
\mathbf{3 2 , 4 6} \\
\end{array}$ & 4,02 & 8,16 & $-1,83$ & $-19,84$ \\
\hline PDEM-k12 & $\begin{array}{l}707,6 \\
-\mathbf{2}, 66\end{array}$ & $\begin{array}{r}189,4 \\
\mathbf{3 2 , 0 2}\end{array}$ & 4,10 & 10,55 & 0,33 & 3,55 \\
\hline PDEM-k12M & $\begin{array}{c}708,4 \\
-2,54\end{array}$ & $\begin{array}{r}174,0 \\
\mathbf{2 1 , 2 9}\end{array}$ & 4,04 & 8,73 & $-1,32$ & $-14,33$ \\
\hline PDEM-k12P & $\begin{array}{r}721,0 \\
-\mathbf{0}, \mathbf{8 0}\end{array}$ & $\begin{array}{c}164,6 \\
\mathbf{1 4 , 7 5}\end{array}$ & 3,85 & 3,69 & $-5,89$ & $-63,76$ \\
\hline
\end{tabular}

Nesta tabela de resultados são apresentados os valores médios e desvio padrões de geração hidrelétrica da usina hidrelétrica de Furnas. São mostrados também os custos e suas relações percentuais. A primeira coluna de custos apresenta o valor absoluto, em unidades de 
\$. Já as outras colunas representam percentuais com relação a PDD e a PDEM, respectivamente, e a relação PDD/PDEM, admitindo-se a PDD com sendo -100\% e a PDEM 0\%.

Nota-se que com o aumento do número de meses agregados há também um aumento nos valores médios de geração hidrelétrica e nos valores médios de desvios padrões. No entanto, com o aumento do número de meses agregados, há uma diminuição dos custos de complementação térmica da operação.

Em valores comparativos entre a PDEM e a PDEM-k12M há uma diminuição de custos de 1,45\% com relação a PDD na usina hidrelétrica de Furnas. Estes mesmos valores comparativos para a usina hidrelétrica de Foz do Areia são de 2,12\%, para a usina hidrelétrica de Serra da Mesa 1,14\% e para a usina hidrelétrica de Sobradinho 0,48\%.

Considerando um preço médio hipotético de $\mathrm{R} \$ 50,00$ por MWh teríamos uma economia, ao longo de todo o histórico de operações, de, aproximadamente, 1,5 bilhão de reais somente na usina hidrelétrica de Furnas.

Além da vantagem econômica, temos também a vantagem ambiental da PDEM-k12M. Em termos do uso da água, a relação MW de energia gerada por volume de água utilizada passa de $1,0212 \mathrm{MW} / \mathrm{m}^{3} / \mathrm{s}$ para $1,0306 \mathrm{MW} / \mathrm{m}^{3} / \mathrm{s}$, melhorando em $88 \%$ essa relação na usina hidrelétrica de Furnas.

A seguir são apresentadas três tabelas comparativas resumidas contendo a maioria dos resultados mais relevantes das otimizações e simulações das políticas clássicas, PDD, PDEI e PDEM comparadas a política ótima, PDP, e as políticas propostas, PDEM-k.

São apresentados os resultados de forma direta, numérica, e também em uma forma gráfica, com barras coloridas, onde o valor da área hachurada de cada barra corresponde a um percentual entre o máximo por setor, $100 \%$, com a barra completamente hachurada, e o mínimo por setor, $0 \%$, com a barra não hachurada.

As duas últimas colunas da Tabela 24 apresentam, ainda, um padrão diferente das demais pois tem como base a comparação de valores com a política PDEM, com resultados maiores e menores, comparativamente. Dessa forma, as barras destas duas ultimas colunas tem duas cores diferentes, sendo as vermelhas definidas para valores maiores que os obtidos com a PDEM e azuis para valores menores.

Na Tabela 22 são apresentados os resultados comparativos de turbinagens, vertimentos, eficiência, que é a relação entre volume turbinado e volume vertido, e produtividade que é a relação entre energia gerada e afluência. 
Tabela 22 - Resultados comparativos entre as usinas hidrelétricas de Furnas, Foz do Areia, Serra da Mesa e Sobradinho com relação ao uso da água.

\begin{tabular}{|c|c|c|c|c|c|}
\hline & & $\begin{array}{c}\text { Turbinagens } \\
\qquad\left(\mathbf{m}^{3} / \mathbf{s}\right)\end{array}$ & $\begin{array}{c}\text { Vertimentos } \\
\left(\mathbf{m}^{3} / \mathbf{s}\right)\end{array}$ & $\begin{array}{c}\text { Eficiência } \\
(\%)\end{array}$ & $\begin{array}{c}\text { Produtividade } \\
\left(\mathrm{MW} / \mathrm{m}^{3} / \mathbf{s}\right)\end{array}$ \\
\hline \multirow{6}{*}{ 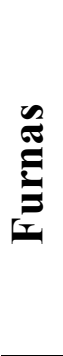 } & PDEM & 896.4 & 28.4 & 96.83 & 1.0212 \\
\hline & PDEM-k2 & 896.9 & 27.9 & 96.89 & 1.0245 \\
\hline & PDEM-k3 & 898.0 & 26.8 & 97.02 & 1.0244 \\
\hline & PDEM-k4 & 897.7 & 27.0 & 96.99 & 1.0247 \\
\hline & PDEM-k6 & 898.1 & 26.6 & 97.04 & 1.0287 \\
\hline & PDEM-k12 & 898.8 & 25.8 & 97.13 & 1.0306 \\
\hline \multirow{6}{*}{ 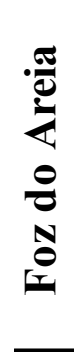 } & PDEM & 573.1 & 81.5 & 85.78 & 1.3137 \\
\hline & PDEM-k2 & 581.3 & 73.0 & 87.44 & 1.3351 \\
\hline & PDEM-k3 & 581.5 & 73.0 & 87.45 & 1.3431 \\
\hline & PDEM-k4 & 581.5 & 72.7 & 87.50 & 1.3498 \\
\hline & PDEM-k6 & 580.4 & 73.7 & 87.30 & 1.3573 \\
\hline & PDEM-k12 & 580.7 & 73.5 & 87.34 & 1.3605 \\
\hline \multirow{6}{*}{ 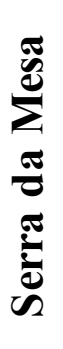 } & PDEM & 741.1 & 35.6 & 95.20 & 1.8579 \\
\hline & PDEM-k2 & 740.9 & 35.7 & 95.18 & 1.8627 \\
\hline & PDEM-k3 & 742.5 & 34.5 & 95.35 & 1.8582 \\
\hline & PDEM-k4 & 742.5 & 34.1 & 95.41 & 1.8579 \\
\hline & PDEM-k6 & 743.9 & 32.7 & 95.60 & 1.8606 \\
\hline & PDEM-k12 & 744.6 & 31.8 & 95.73 & 1.8730 \\
\hline \multirow{6}{*}{ 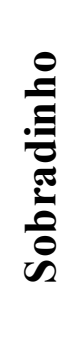 } & PDEM & 2419.7 & 237.1 & 90.20 & 0.3061 \\
\hline & PDEM-k2 & 2421.9 & 235.0 & 90.30 & 0.3073 \\
\hline & PDEM-k3 & 2440.6 & 216.7 & 91.12 & 0.3069 \\
\hline & PDEM-k4 & 2447.0 & 210.4 & 91.40 & 0.3060 \\
\hline & PDEM-k6 & 2464.4 & 193.3 & 92.16 & 0.3091 \\
\hline & PDEM-k12 & 2476.2 & 181.7 & 92.66 & 0.3137 \\
\hline
\end{tabular}

Podem-se notar algumas tendências e comportamentos com o aumento dos meses agrupados. Na coluna das turbinagens, azul, há um aumento dos valores médios turbinados. $\mathrm{Na}$ coluna de vertimentos, verde, há uma diminuição. As consequências diretas disto são as colunas de eficiências,amarela, e de produtividade, lilás. A única usina que não segue essa tendência é a usina de Foz do Areia. No entanto pode-se perceber que a coluna de produtividade da usina de Foz do Areia tem um crescente aumento. A seguir são apresentados os resultados das gerações hidrelétricas e de custos. 
Tabela 23 - Resultados comparativos entre as usinas hidrelétricas de Furnas, Foz do Areia, Serra da Mesa e Sobradinho com relação a energia elétrica gerada e aos custos.

\begin{tabular}{|c|c|c|c|c|}
\hline & & $\begin{array}{c}\text { Geração Média } \\
\text { (MW) }\end{array}$ & $\begin{array}{c}\text { Desvio Padrão } \\
\text { (MW) }\end{array}$ & $\begin{array}{c}\text { Custos } \\
\left(\$ \times 10^{\wedge} 6\right)\end{array}$ \\
\hline \multirow{6}{*}{$\underset{\Xi}{E}$} & PDEM & 701.0 & 162.9 & 4.0913 \\
\hline & PDEM-k2 & 701.9 & 164.4 & 4.0843 \\
\hline & PDEM-k3 & 703.5 & 166.9 & 4.0727 \\
\hline & PDEM-k4 & 704.1 & 167.2 & 4.0673 \\
\hline & PDEM-k6 & 705.5 & 169.1 & 4.0558 \\
\hline & PDEM-k12 & 708.4 & 174.0 & 4.0372 \\
\hline \multirow{6}{*}{ 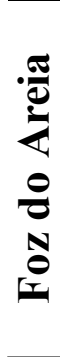 } & PDEM & 660.8 & 311.4 & 11.5355 \\
\hline & PDEM-k2 & 671.7 & 333.8 & 11.4560 \\
\hline & PDEM-k3 & 673.4 & 332.0 & 11.4112 \\
\hline & PDEM-k4 & 675.5 & 331.8 & 11.3671 \\
\hline & PDEM-k6 & 676.1 & 331.0 & 11.3503 \\
\hline & PDEM-k12 & 677.1 & 331.0 & 11.3292 \\
\hline \multirow{6}{*}{ 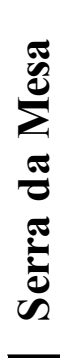 } & PDEM & 790.5 & 151.8 & 2.6374 \\
\hline & PDEM-k2 & 791.4 & 156.0 & 2.6415 \\
\hline & PDEM-k3 & 792.4 & 156.9 & 2.6348 \\
\hline & PDEM-k4 & 793.3 & 158.4 & 2.6311 \\
\hline & PDEM-k6 & 795.4 & 161.7 & 2.6210 \\
\hline & PDEM-k12 & 797.5 & 165.3 & 2.6118 \\
\hline \multirow{6}{*}{ 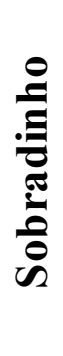 } & PDEM & 583.2 & 156.9 & 2.4810 \\
\hline & PDEM-k2 & 583.6 & 157.7 & 2.4798 \\
\hline & PDEM-k3 & 584.0 & 158.7 & 2.4791 \\
\hline & PDEM-k4 & 584.6 & 159.7 & 2.4766 \\
\hline & PDEM-k6 & 584.7 & 158.3 & 2.4708 \\
\hline & PDEM-k12 & 583.6 & 154.8 & 2.4707 \\
\hline
\end{tabular}

Novamente algumas tendências e comportamentos com o aumento dos meses agrupados são notados. Na coluna das gerações médias, roxa, e dos desvios padrão, cinza, há um aumento na maioria dos casos. Esse aumento não ocorre em todas as usinas com o aumento dos meses agregados. Já na coluna dos custos, vermelha, um comportamento é observado em todas as usinas simuladas. Com o aumento do número de meses agrupados há uma diminuição dos valores, partindo de um valor máximo com a política PDEM, diminuindo com as políticas PDEM-k2, PDEM-k3, PDEM-k4, PDEM-k6 e sendo mínimo na política PDEM-k12.

A seguir é apresentada a Tabela 24 que faz uma comparação mais detalhada entre as políticas simuladas. 
Tabela 24 - Resultados comparativos entre as usinas hidrelétricas de Furnas, Foz do Areia, Serra da Mesa e Sobradinho com relação aos custos comparativos.

\begin{tabular}{|c|c|c|c|c|c|}
\hline & & Custos $\left(\$ .10^{\wedge} \mathbf{6}\right)$ & 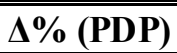 & $\Delta \%$ (PDEM) & $\Delta \%$ (PDP-PDEM) \\
\hline \multirow{6}{*}{$\underset{:}{\overparen{E}}$} & PDD & 3.7132 & 0.00 & -9.24 & -100.00 \\
\hline & PDEI & 4.1459 & 11.65 & 1.33 & 14.42 \\
\hline & PDED & 4.1937 & 12.94 & 2.50 & 27.08 \\
\hline & PDEM & 4.0913 & 10.18 & 0.00 & 0.00 \\
\hline & PDEM-k12M & 4.0372 & 8.73 & -1.32 & -14.33 \\
\hline & PDEM-k12P & 3.8502 & 3.69 & -5.89 & -63.76 \\
\hline \multirow{6}{*}{ 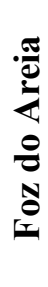 } & PDD & 9.7290 & 0.00 & -15.66 & -100.00 \\
\hline & PDEI & 11.7386 & 20.66 & 1.76 & 11.25 \\
\hline & PDED & 12.1876 & 25.27 & 5.65 & 36.10 \\
\hline & PDEM & 11.5355 & 18.57 & 0.00 & 0.00 \\
\hline & PDEM-k12M & 11.3292 & 16.45 & -1.79 & -11.42 \\
\hline & PDEM-k12P & 9.7643 & 0.36 & -15.35 & -98.05 \\
\hline \multirow{6}{*}{ 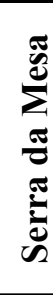 } & PDD & 2.2521 & 0.00 & -14.91 & -100.00 \\
\hline & PDEI & 2.6567 & 17.97 & 0.73 & 5.01 \\
\hline & PDED & 2.7002 & 19.90 & 2.38 & 16.30 \\
\hline & PDEM & 2.6374 & 17.11 & 0.00 & 0.00 \\
\hline & PDEM-k12M & 2.6118 & 15.97 & -0.97 & -6.63 \\
\hline & PDEM-k12P & 2.5011 & 11.06 & -5.17 & -35.37 \\
\hline \multirow{6}{*}{ 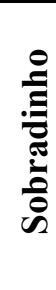 } & PDD & 2.1408 & 0.00 & -13.71 & -100.00 \\
\hline & PDEI & 2.5785 & 20.45 & 3.93 & 28.68 \\
\hline & PDED & 2.5616 & 19.66 & 3.25 & 23.72 \\
\hline & PDEM & 2.4810 & 15.89 & 0.00 & 0.00 \\
\hline & PDEM-k12M & 2.4707 & 15.41 & -0.41 & -3.01 \\
\hline & PDEM-k12P & 2.1510 & 0.48 & -13.30 & -97.00 \\
\hline
\end{tabular}

Na Tabela 24 são mostrados os resultados de custos totais, coluna roxa, e três colunas com resultados comparativos. Na segunda coluna, $\Delta \%$ PDP, os custos são comparados percentualmente a PDP, sendo que o o valor de 100\% é atribuído a política PDP e os valores mostrados são os aumentos relativos a cada política. Já na terceira coluna, $\Delta \%$ (PDEM), o valor de $100 \%$ é atribuído a política PDEM e os valores mostrados são os aumentos ou diminuições percentuais relativos a cada coluna. Por fim, na terceira coluna, $\Delta \%($ PDP-PDEM), os valores dos custos da política PDP são considerados os ótimos globais (-100\%) e os valores dos custos da política PDEM são considerados os valores bases ( $0 \%)$. A partir destes valores bases são calculados os valores percentuais referentes a cada política. Nas colunas 3 e 4 existem valores percentuais negativos (azuis) e positivos (vermelhos), representando diminuições e aumentos de custos, respectivamente. 
Pode-se notar que a política PDEM tem custos menores que as políticas PDD e PDEI. No entanto tem custos menores que a política proposta PDEM-k12M. Em todas as usinas a política PDEM-k12P também é mostrada. Nessa política, que considera perfeitas previsões de afluências, os resultados em custos foram melhores que os da PDEM-k12M, ficando, em alguns casos, bem próximos aos ótimos globais PDP. Isso mostra que, de certa forma, a política PDEM-k12M tem pontos a serem melhorados, e dentre eles, a forma como são feitas e desagragadas as previsões de afluências para os meses agregados a frente. 


\section{Capítulo 5}

\section{Conclusões}

Neste trabalho foi proposta uma nova política de operação de usinas hidrelétricas. Esta proposta inclui uma nova modelagem da programação dinâmica estocástica markoviana associada com uma nova modelagem para obtenção das distribuições de probabilidades.

Foram simuladas e comparadas quatro políticas já conhecidas e existentes na literatura, as políticas PDP, programação dinâmica com previsão perfeita, $\mathrm{PDD}$, programação dinâmica determinística, PDEI, programação dinâmica estocástica independente, PDEM, programação dinâmica estocástica markoviana e as políticas propostas por esta tese, a PDEM-k, programação dinâmica estocástica markoviana plurimensal. A política PDEM-k, por sua vez, foi feita em agregações bimestrais, trimestrais, quadrimestrais, semestrais e anuais, com previsões agregadas, plurimensais e perfeitas. Os métodos de agregação e modelagem destes agrupamentos foram descritos na seção 3.6 desta tese.

Para a validação dos resultados obtidos com a nova política proposta foram utilizadas quatro usinas hidrelétricas, sendo elas: a usina hidrelétrica de Furnas, localizada no rio Grande, na região Sudeste do Brasil, a usina hidrelétrica de Foz do Areia, localizada no Rio Iguaçu, na região Sul, a usina hidrelétrica de Serra da Mesa, localizada no rio Tocantins, na região Norte e a usina hidrelétrica de Sobradinho, localizada no rio São Francisco, na região Nordeste do Brasil.

A comparação dos resultados teve como base as políticas PDP, que foi o limitante inferior, com relação aos custos de complementação térmica, e admitida ser a solução ótima global. As outras políticas simuladas, PDD, PDEI e PDEM, foram comparadas para se ter uma 
segunda base de comparações, fazendo-se, assim, um paralelo entre os resultados das políticas existentes a os resultados da política proposta, a PDEM-k, plurimensal.

Os resultados da política PDEM-k12M foram os melhores, em custos, em todas as usinas hidrelétricas simuladas. Essa melhoria, comparada a estratégia PDEM, foi de 1,32\% na usina hidrelétrica de Furnas, 1,79\% na usina hidrelétrica de Foz do Areia, 0,97\% na usina hidrelétrica de Serra da Mesa e de 0,41\% na usina hidrelétrica de Sobradinho.

As simulações com outras agregações de meses, bimestrais, trimestrais, quadrimestrais e semestrais também obtiveram resultados melhores do que os obtidos com a política PDEM, sendo que essas melhorias se incrementaram com o aumento do número de meses agregados. A usina de Furnas passou de $0,17 \%$ na PDEM-k2M para 0,46\% na PDEM-k3M, 0,59\% na PDEM-k4M, 0,87\% na PDEM-k6M até chegar nos 1,32\% na PDEM-k12M. A usina hidrelétrica de Foz do Areia passou de 0,66\% na PDEM-k2M para 1,08\% na PDEM-k3M, 1,46\% na PDEM-k4M, 1,61\% na PDEM-k6M até chegar nos 1,79\% na PDEM-k12M. A usina hidrelétrica de Serra da Mesa passou de $-0,16 \%$ na PDEM-k2M para 0,10\% na PDEM-k3M, 0,24\% na PDEM-k4M, 0,62\% na PDEM-k6M até chegar nos 0,97\% na PDEM-k12M. A usina hidrelétrica de Sobradinho passou de $0,05 \%$ na PDEM-k2M para 0,07\% na PDEM-k3M, 0,18\% na PDEM-k4M, 0,41\% na PDEM-k6M até chegar nos 0,41\% na PDEM-k12M.

As operações que consideraram a agregação direta de meses não obtiveram bons resultados em custos sendo superiores aos obtidos pela PDEM. Já os resultados das operações PDEM-k12P foram tabelados para mostrar o tamanho da "folga" existente entre os resultados obtidos com uma previsão dos modelos PAR-1 e os obtidos sem a interferência dos erros de previsão. Em alguns casos essas diferenças de custos, com as mesmas tabelas de decisões e comparadas a PDD, foram inferiores a $0,5 \%$.

\subsection{Continuidade da pesquisa}

Como continuidade da pesquisa pretende-se:

- Aumentar o número de usinas simuladas;

- Utilizar séries sintéticas para obtenção dos resultados; 
- Fazer alterações nas condições de turbinagem, armazenamento e afluências das usinas hidrelétricas;

- Utilizar diferentes previsores na PDEM-k para comparação e validação de resultados em diferentes usinas hidrelétricas. 


\section{Referências}

\section{Bibliográficas}

1. EPE. Plano Decenal de Expansão de Energia 2024. Ministério de Minas e Energia. Brasília, p. 467. 2015.

2. EPE. Empresa de Pesquisa Energética, Rio de Janeiro, p. 324. Disponivel em: <www.epe.gov.br>. Acesso em: 06 jan. 2016.

3. SIMONOVIC, S. P. Tools for water manegement - one view of future. Water International, Winnipeg, v. 25, n. 1, p. 12, jan. 2000.

4. FORTUNATO, L. A. M.; NETO, A.; ALENCAR, T. Introdução ao Planejamento da Expansão e Operação de Sistemas de Produção de Energia Elétrica. EDUFF. Niterói, RJ. 1990.

5. DATTA, B. Operation models for single and multipurpose reservoirs - a review. Jalvigyan Sameeksha-A Publication of Indian National Committee on Hydrology. [S.1.]: [s.n.]. 1993. p. 12.

6. BELLMAN, R. Dynamic Programming. Princeton, NJ: Princeton University Press, 1957. 
7. ZAMBELLI, M. S.; LUNA, I.; SOARES, S. Long-Term Hydropower Scheduling Based on Deterministic Nonlinear Optimization and Annual Inflow Forecasting Models. IEEE Power Tech Conference. Bucharest, Romênia: [s.n.]. 2009. p. 8.

8. BERTSEKAS, D. P. Dynamic Programming - Deterministic and Stochastic Models. [S.1.]: Prentice Hall, NJ, 1962.

9. PEREIRA, M. V. F. Optimal Scheduling of Hydrothermal System - An Overview. Symposium on Planning and Operation of Electric Energy Systems. Rio de Janeiro, p. 19. 1985.

10. PEREIRA, M. V. F.; PINTO, L. M. V. G. Stochastic Optimization of a Multireservoir Hydroelectric System: A Decomposition Approach. Water Resources Research, v. 7, n. 6, p. 779-792, 1985.

11. SIQUEIRA, T. G. Comparação entre Programação Dinâmica Estocástica Primal e Dual no Planejamento da Operação Energética. Dissertação (Mestrado em Engenharia Elétrica) - Universidade Estadual de Campinas. Campinas. 2003.

12. SIQUEIRA, T. G. Comparação entre Diferentes Abordagens de Programação Dinâmica no Planejamento da Operação Energética de Sistemas Hidrotérmicos de Potência. Tese (Doutorado em Engenharia Elétrica) - Universidade Estadual de Campinas. Campinas. 2009.

13. FAHLBUSCH, H. Early Dams. Proceedings of the Institution of Civil Engineers, n. 162, p. 13-18, 2009.

14. HELMS, S. W. Jawa - Lost City of the Black Desert. [S.1.]: Cornell University Press , 1981.

15. BAZZA, M. Overview of the History of Water Supply. Water Science and Technology, v. 7, n. 1, p. 201, 2007.

16. RIPPL, W. The Capacity of Storage Reservoirs for Water Supply. Minutes of Proceedings of the Institution of Civil Engineers. [S.1.], p. 270-278. 1883. (71).

17. SHARMA, R. K. A Text Book of Hydrology \& Water Resources. 2. ed. Nova Delhi: J. C. Kapur, 1983.

18. CASTELLETTI, A. et al. Neuro-dynamic programming for designing water reservoir network management policies. Control Engineering Practice, v. 15, p. 1031-1038, ago. 2007. 
19. MAAS, A. et al. Design of water resource systems. Boston, MA: Harvard University Press, 1962.

20. PUTERMAN, M. L. Markov Decision Processes - Discrete Stochastic Dynamic Programming. [S.1.]: Wiley-Interscience, 1994.

21. GESSFORD, J.; KARLIN, S. Studies in theMathematical Theory of Inventory and Production. [S.1.]: Stanford University Press, 1958.

22. WALD, A. Sequential Analyses. Nova York: John Wiley, 1947.

23. HOWARD, R. A. Dynamic Programming and Markov Processes. Cambridge, MA: MIT Press, 1960.

24. BARRETO, A. M. S. Soluções Aproximadas para Problemas de Tomada de Decisão Sequencial. Tese (Doutorado em Engenharia Elétrica) - Universidade Federal do Rio de Janeiro. Rio de Janeiro. 2008.

25. BELlMAN, R. E.; DREYFUS, S. B. Applied dynamic programming. Princeton, NJ: Princeton University Press, v. 1, 1962.

26. YOUNG, G. K. Finding reservoir operation rules. Journal of Hydraulics Division, v. 63, n. 6, p. 297 - 322, Novembro 1967.

27. HALL, W. A.; BUTCHER, W. S.; ESOGBUE, A. Optimization of operation of a multiplepurpose reservoir by dynamic programming. Water Resources Research, v. 4, n. 3, p. 471 - 477, Junho 1968.

28. FULTS, D. M.; LOGAN, G. R.; HANCOCK, L. F. A practical monthly optimum operations model. Journal of Water Resources Planning and Management Division, v. 102, n. 1, p. 63 - 76, Abril 1976.

29. YURTAL, R.; SECKIN, G.; ARDICLIOGLU, M. Hydropower optimization for the lower Seyhan system in Turkey using dynamic programming. Water International, v. 30, n. 4, p. $522-529,2005$.

30. SHIM, K. C. F. D. G.; LABADIE, J. W. Spatial decision support system for integrated river basin flood control. Journal of Water Resources Planning and Management, v. 128, n. 3, p. 190 - 201, Maio 2002.

31. YI, J.; LABADIE, J. W.; STITT, S. Dynamic optimal unit commitment and loading in hydropower systems. Journal of Water Resources Planning and Management, v. 129, n. 5, p. 388- - 398, Setembro 2003. 
32. TROTT, W. J.; YEH, W. W. G. Optimization of multiple reservoir system. Journal of Hydraulics Division, v. 99, n. 10, p. 1865 - 1884, Outubro 1973.

33. GILES, J. E.; WUNDERLICH, W. O. Weekly multipurpose planning model for TVA reservoir system. Journal of the Water Resources Planning and Management Division, v. 107, n. 2, p. 495 - 511, Outubro 1981.

34. KUMAR, D. N.; BALIARSINGH, F. Folded dynamic programming for optimal operation of multireservoir system. Water Resources Management, v. 17, n. 5, p. 337 - 353, Outubro 2003.

35. JACOBSON, D. H.; MYNE, D. Q. Differential dynamic programming. Universidade da Califórnia: American Elsevier, 1970.

36. MURRAY, D. M.; YAKOWITZ, S. J. Constrained differential dynamic programming and its application to multireservoir control. Water Resources Research, v. 15, n. 5, p. 1017 - 1027, Outubro 1979.

37. YANG, C. et al. Multiobjective planning of surface water resources by multiobjective genetic algorithm with constrained diferential dynamic programming. Journal of Water Resources Planning and Management, v. 133, n. 6, p. 499 - 508, Novembro 2007.

38. LITTLE, J. D. C. Use of storage water in a hydroelectric system. Journal of the Operations Research Society of America, v. 3, n. 2, p. 187 - 197, Maio 1955.

39. BURAS, N. Conjuctive operation of dams and aquifers. Journal of Hydraulics Division, v. 89 , n. 6, p. 111 - 131, Novembro 1963.

40. LOUCKS, D. P. Computer models for Reservoir Regulation. Journal of the Sanitary Engineering Division, v. 94, n. 4, p. 657 - 670, Julho 1968.

41. GILBERT, K. C.; SHANE, R. M. TVA hydro scheduling model - theoretical aspects. Journal of Water Resources Planning and Management Division, v. 108, n. 1, p. 21 36, Março 1982.

42. MACEIRA, M. E.; KELMAN, J. Long term hydro-thermal coordination based on sampling stochastic dynamic programming. CEPEL - Centro de Pesquisas de Energia Elétrica. Brasil. 1991.

43. TURGEON, A.; CHARBONNEAU, R. An aggregation-disaggregation approach to longterm reservoir management. Water Resources Research, v. 34, n. 12, p. 3585 - 3594, Dezembro 1995. 
44. TEJADA-GUIBERT, J. A.; JOHNSON, S. A.; STEDINGER, J. R. Comparison of two approaches for implementing multireservoir operating policies derived using stochastic dynamic programming. Water Resources Research, v. 29, n. 12, p. 3969 - 3980, Dezembro 1993.

45. YAKOWITZ, S. Dynamic Programming Applications in Water Resources. Water Resources Research, v. 18, p. 673-696, 1982.

46. YEH, W. Reservoir Management and Operations Models - A State of the art Review. Water Resources Research, v. 21, p. 1797-1818, 1985.

47. RANI, D.; MOREIRA, M. Simulation-Optimization Modeling: A Survey and Potential Application in Reservoir Systems Operation. Water Resources Management, v. 24, n. 6, p. 1107 - 1138, Abril 2010.

48. STEDINGER, J. R.; FABER, B. A.; LAMONTAGNE, J. R. Developments in Stochastic Dynamic Programming for Reservoir Operating Optimization. World Environmental and Water Resources Congress 2013: Showcasing the Future. Cincinnati, OH: [s.n.]. 2013. p. $1266-1278$.

49. TURGEON, A. A Decomposition Method for the Long Term Scheduling of Reservoir in Series. Water Resources Research, n. 17, p. 1565-1570, 1981.

50. TEJADA, J. G.; JOHNSON, S.; STEDINGER, J. The Value of Hydrologic Information in Stochastic Dynamic Programming Models of a Multreservoir System. Water Resources Research, v. 31, p. 2571-2579, 1995.

51. ZAMBELLI, M. S. Planejamento da Operação Energética Via Curvas-Guias de Armazenamento. Dissertação (Mestrado em Engenharia Elétrica) - Universidade Estadual de Campinas. Campinas. 2006.

52. SCARCELli, R. O. C. Programação Dinâmica Aplicada à Otimização Individualizada e Desacoplada das Usinas Hidrelétricas de Sistemas Hidrotérmicos. Dissertação (Mestrado em Engenharia Elétrica) - Universidade de São Paulo. São Carlos. 2012 .

53. PROVENÇANO, F. Despacho Econômico em Usinas Hidrelétricas. Dissertação (Mestrado em Engenharia Elétrica) - Universidade Estadual de Campinas. Campinas. 2003.

54. ENCINA, A. S. A. Despacho Ótimo de Unidades Geradoras em Sistemas Hidrelétricos via Heurística Baseada em Relaxação Lagrangeana e Programação Dinâmica. Tese 
(Doutorado em Engenharia Elétrica) - Universidade Estadual de Campinas. Campinas. 2006.

55. ZAMBELLI, M. S. Planejamento da Operação Energética do Sistema Interligado Nacional Baseado em Modelo de Controle Preditivo. Tese (Doutorado em Engenharia Elétrica) - Universidade Estadual de Campinas. Campinas. 2009.

56. SILVA, L. F. C. A. Modelo de Intercâmbio a Subsistemas Equivalentes. Dissertação (Mestrado em Engenharia Elétrica) - Universidade Federal do Rio de Janeiro - COPPEUFRJ. Rio de Janeiro. 1981.

57. STEDINGER, J. W.; SULA, B. F.; LOUCKS, D. P. Stochastic Dynamic Programming Models for Reservoir Operation. Water Resources Research, p. 1499-1505, 1984.

58. THANOS, T.; YEH, W. W. G. Use of Stochastic Dynamic Programming for Reservoir Management. Water Resources Research, p. 983-996, 1987.

59. LOUCKS, D. P. et al. Water Resources Systems Planning and Management: An Introduction to Methods, Models and Applications. Water Resources Systems Planing and Management - UNESCO, Paris, 2005.

60. CEPEL/ELETROBRÁS. Modelo de Programação Dinâmica Estocástica para a Operação de Sistemas Hidrotérmicos. CEPEL/ELETROBRÁS. [S.1.]. 1977. (144/77).

61. TERRY, L. A. Modelo a Sistema Equivalente - Descrição Geral. CEPEL/Eletrobrás. Rio de Janeiro. 1980.

62. CEPEL. Modelo de Programação Dinâmica Estocástica para a Operação de Sistemas Hidrotérmicos. Eletrobrás. Rio de Janeiro. 1977. (144).

63. WWW.CCEE.ORG.BR. Câmara de Comercialização de Energia Elétrica. Disponivel em: <http:/www.ccee.org.br>. Acesso em: 15 set. 2013.

64. WWW.ANEEL.GOV.BR. Agência Nacional de Energia Elétrica (ANEEL). Disponivel em: <http://www.aneel.gov.br>. Acesso em: 10 jan. 2014.

65. DONATO, D. F. Dimensionamento de Usinas Hidroelétricas Através de Técnicas de Otimização Evolutiva. Tese (Doutorado em Engenharia Elétrica) - Universidade São Paulo - EESC/USP. São Carlos. 2003.

66. PAPOULIS, A. Probability, Random Variables, and Stochastic Processes. 4. ed. [S.1.]: McGray-Hill, 1921. 
67. BOX, G. E. P.; JENKINS, G. Time Series Analysis. Englewood Cliffs, NJ: Prentice-Hall, 1994.

68. SCARCELLI, R. O. C. et al. Aggregated Inflows on Stochastic Dynamic Programming for Long Term Hydropower Scheduling. NAPS - North American Power Symposium. Pullman, WA: IEEE. 2014. p. 6. 


\section{Apêndice A}

Nesta seção são apresentados os resultados gráficos das curvas de distribuição de probabilidades, das tabelas de decisões, das previsões, dos volumes armazenados, dos vertimentos e das gerações hidrelétricas das usinas de Foz do Areia, Serra da Mesa e Sobradinho. 


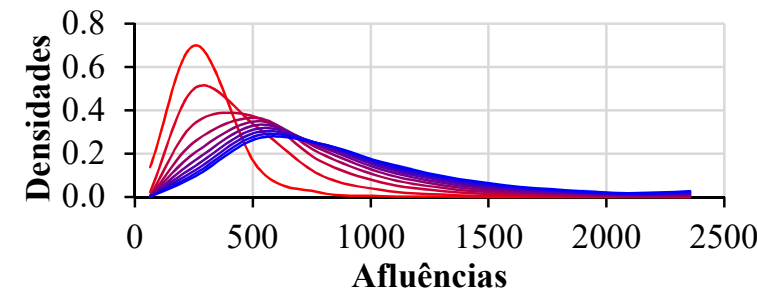

(a)

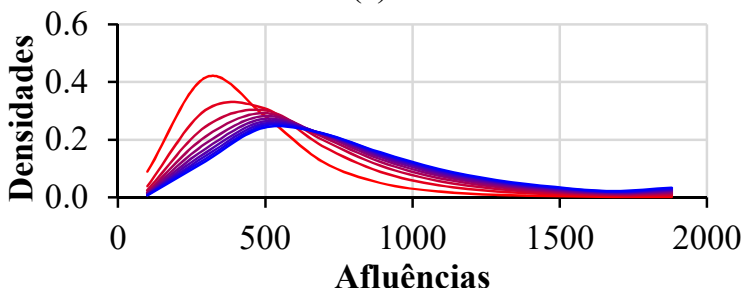

(b)

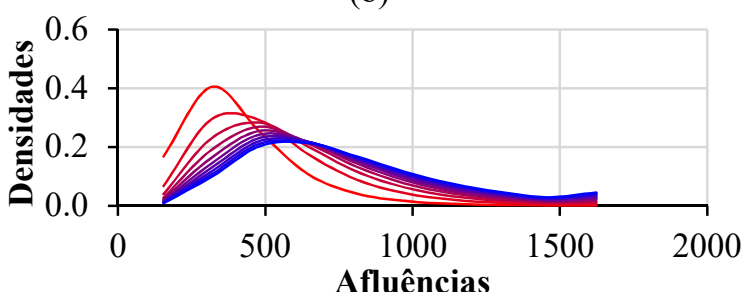

(c)

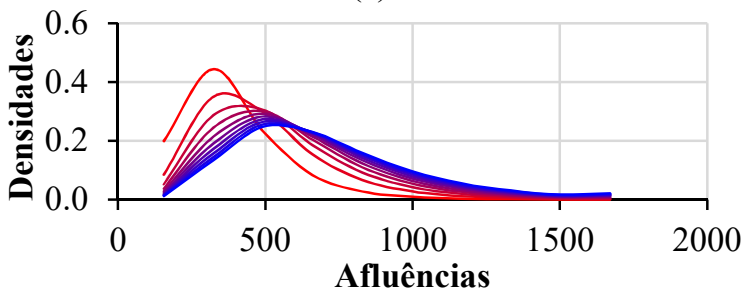

(d)

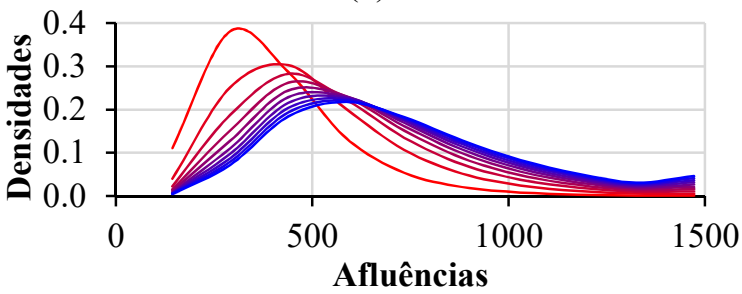

(e)

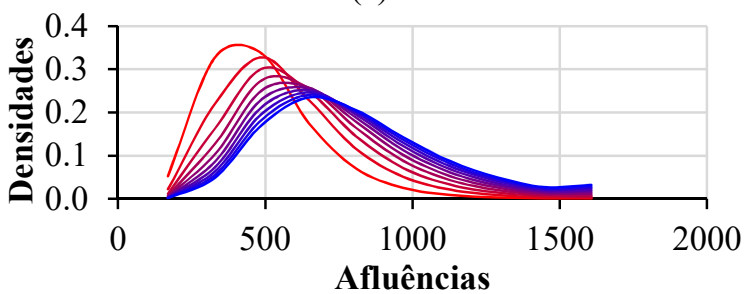

(f)

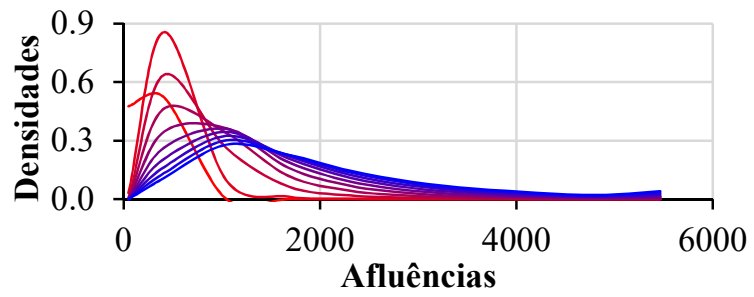

(g)

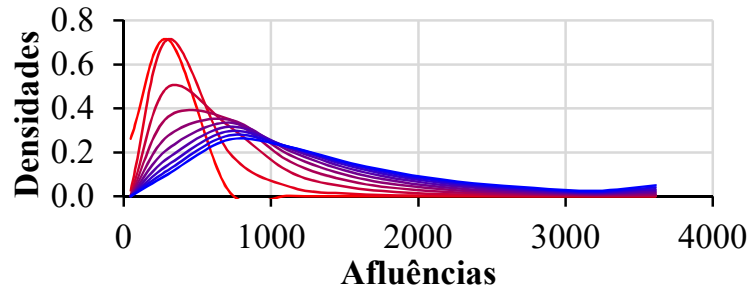

(h)

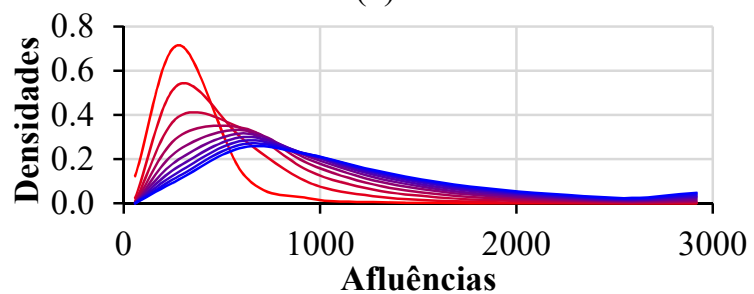

(i)

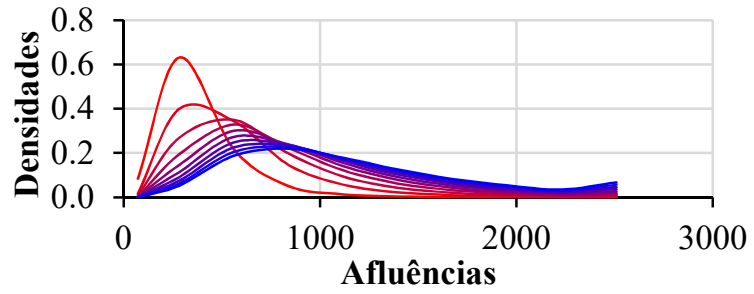

(j)

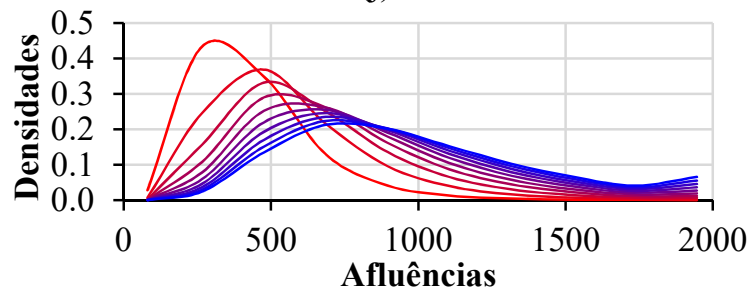

(k)

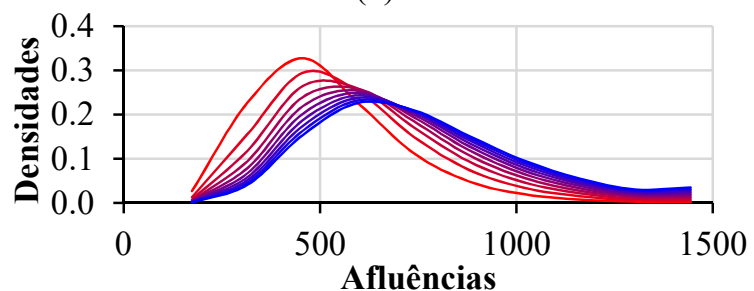

(1)

Figura 39 - Densidades de probabilidades log-normais para a usina hidrelétrica de Foz do Areia com base no mês de Janeiro mensal (a), bimestral (b), trimestral (c), quadrimestral (d), semestral (e) e anual (f) e no mês Julho mensal (g), bimestral (h), trimestral (i), quadrimestral (j), semestral (k) e anual (l). 


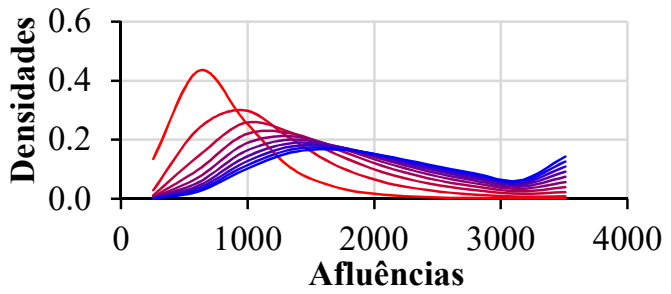

(a)

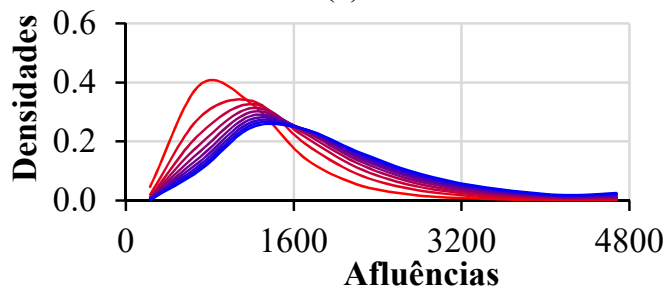

(b)

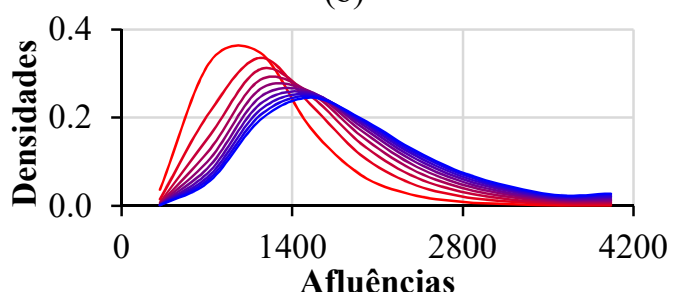

(c)

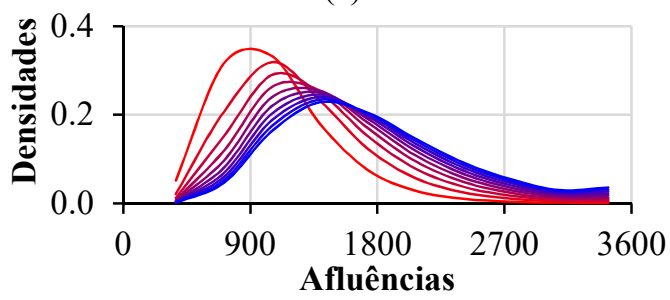

(d)

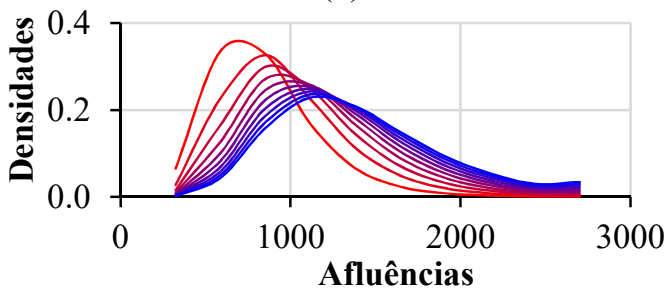

(e)

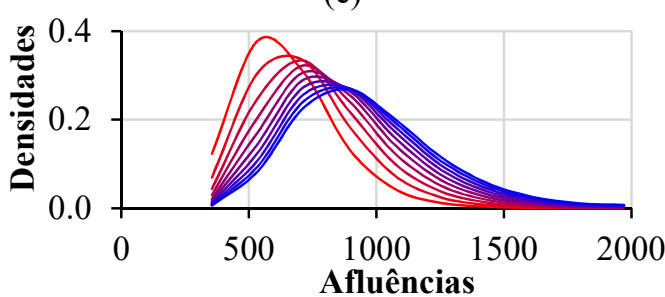

(f)

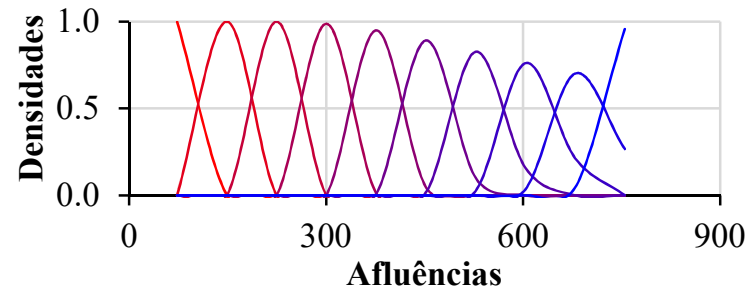

(g)

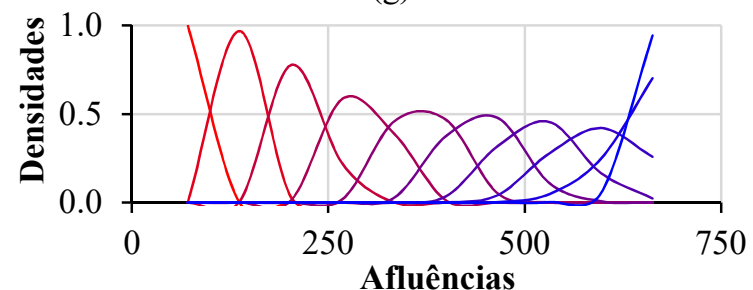

(h)

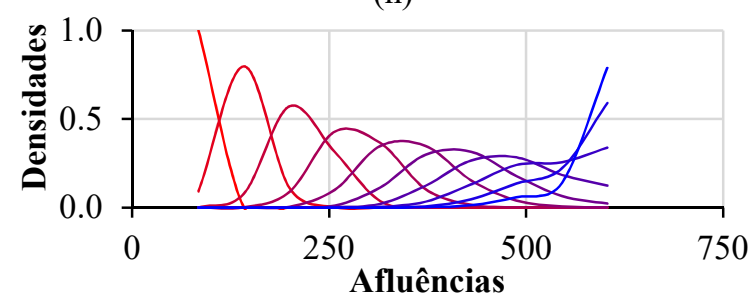

(i)

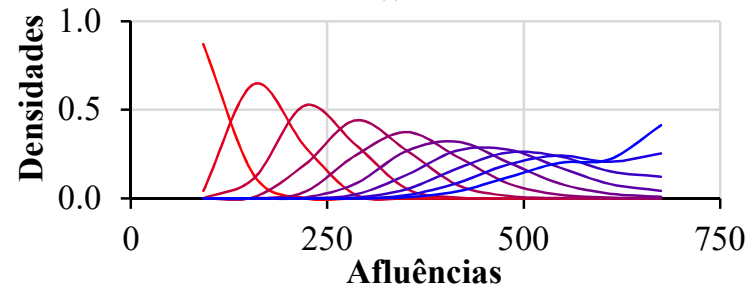

(j)

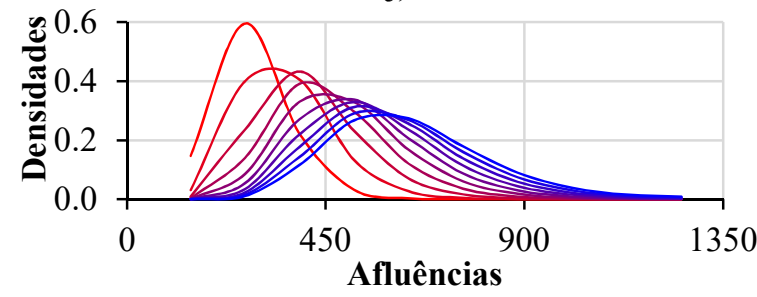

(k)

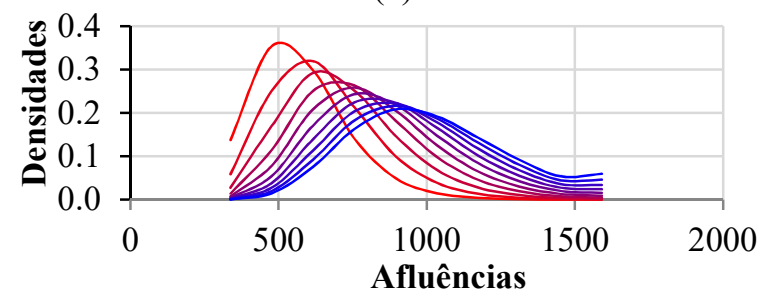

(1)

Figura 40 - Densidades de probabilidades log-normais para a usina hidrelétrica de Serra da Mesa com base no mês de Janeiro mensal (a), bimestral (b), trimestral (c), quadrimestral (d), semestral (e) e anual (f) e no mês de Julho mensal (g), bimestral (h), trimestral (i), quadrimestral (j), semestral (k) e anual (l). 


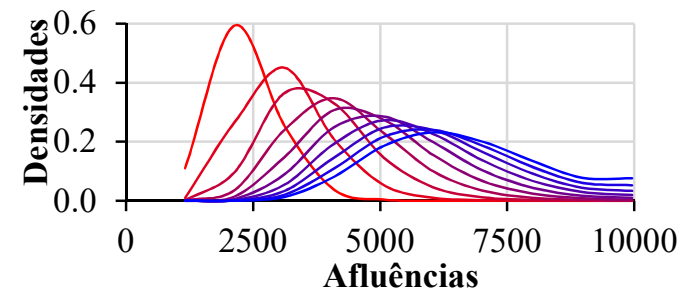

(a)

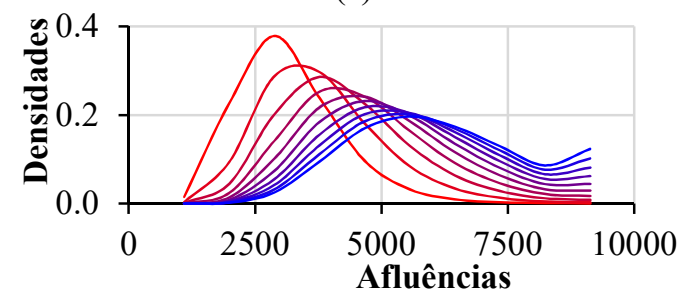

(b)

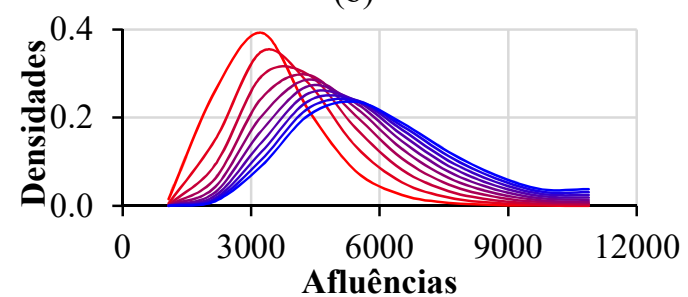

(c)

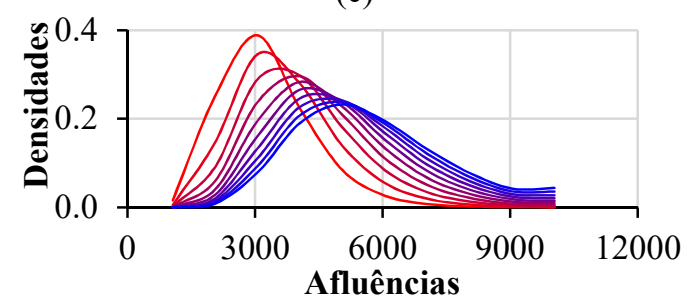

(d)

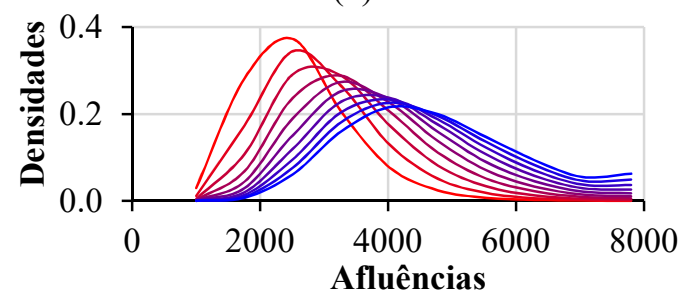

(e)

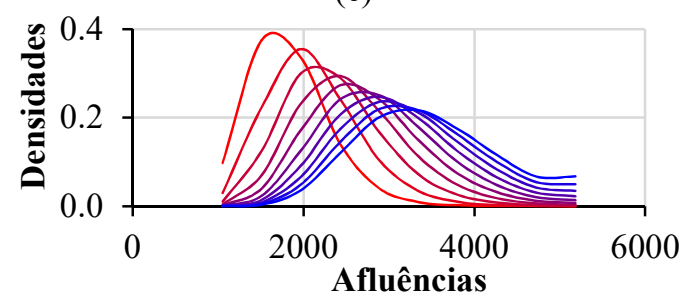

(f)

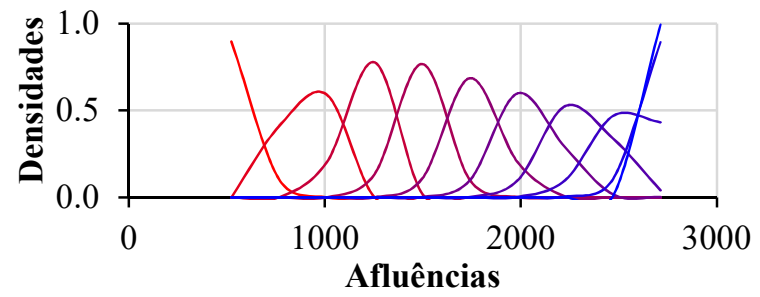

(g)

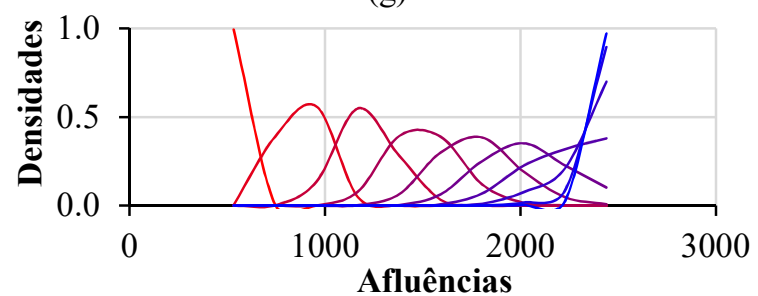

(h)

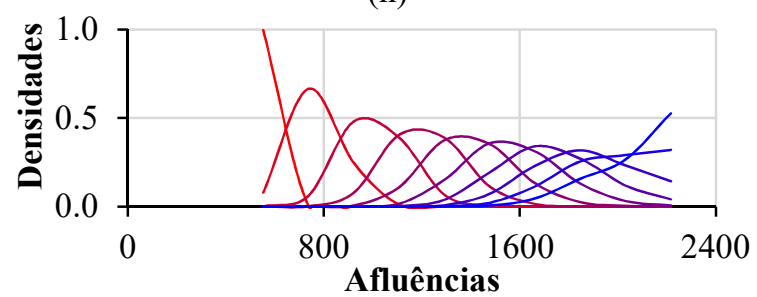

(i)

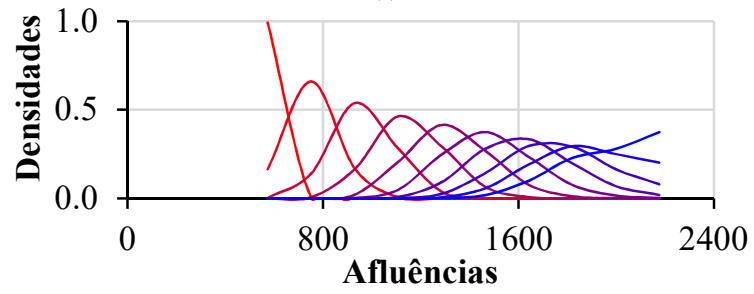

(j)

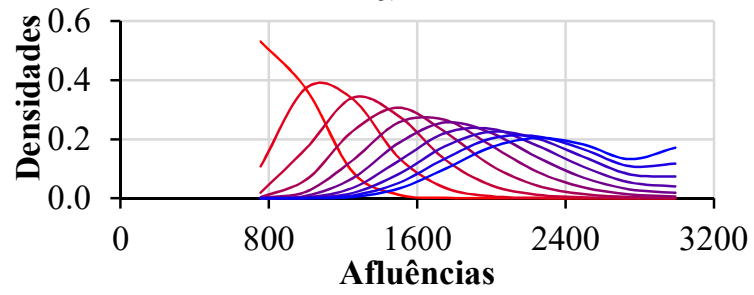

(k)

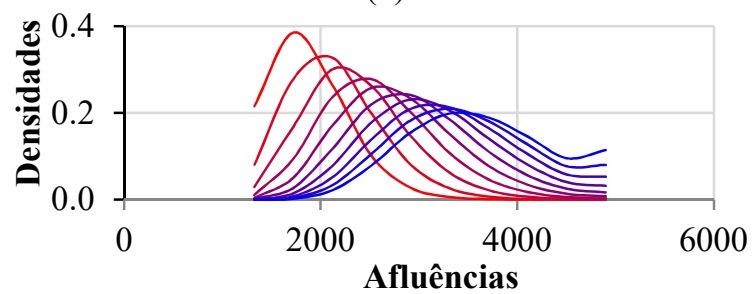

(1)

Figura 41 - Densidades de probabilidades log-normais para a usina hidrelétrica de Sobradinho com base no mês de Janeiro mensal (a), bimestral (b), trimestral (c), quadrimestral (d), semestral (e) e anual (f) e no mês de Julho mensal (g), bimestral (h), trimestral (i), quadrimestral (j), semestral (k) e anual (l). 


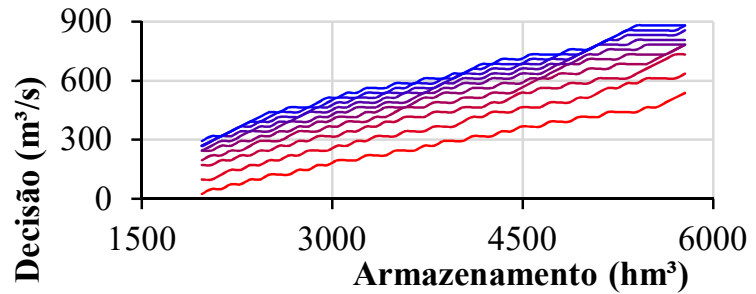

(a)

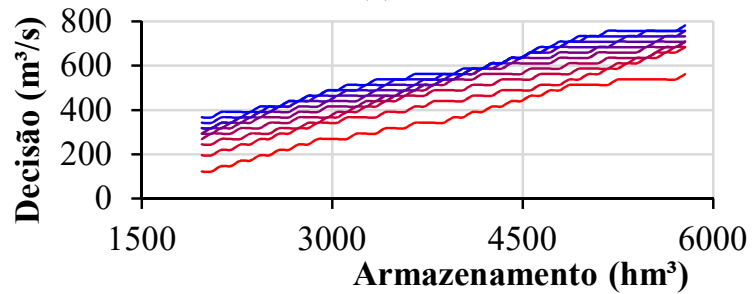

(b)

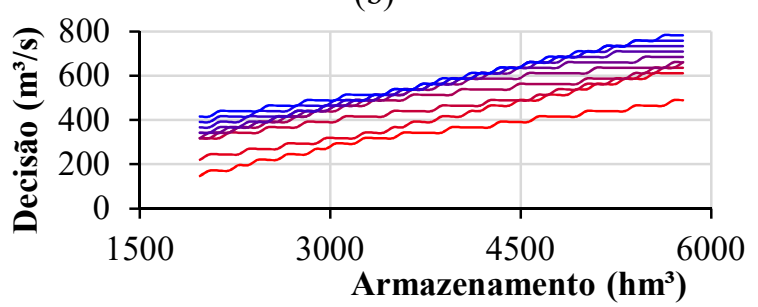

(c)

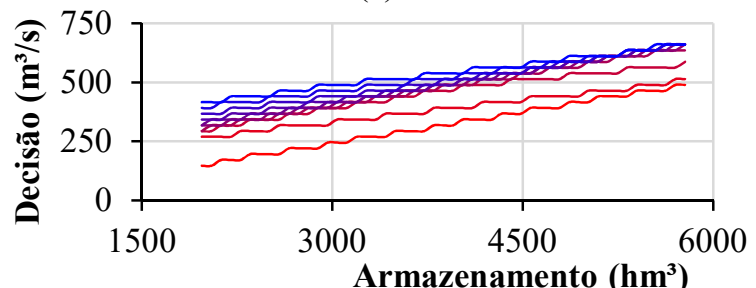

(d)

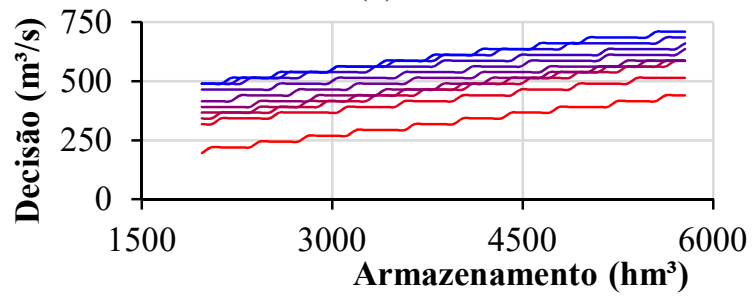

(e)

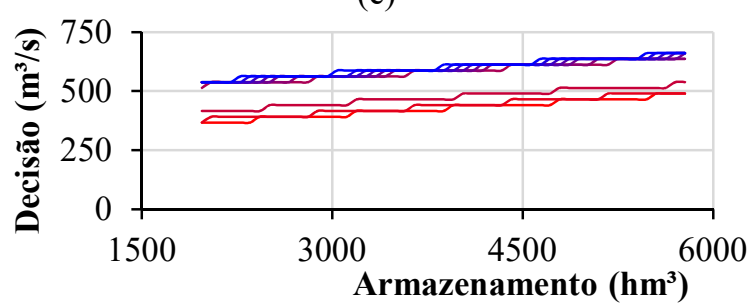

(f)

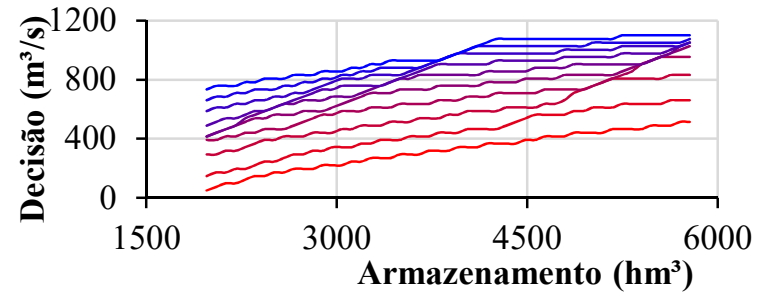

(g)

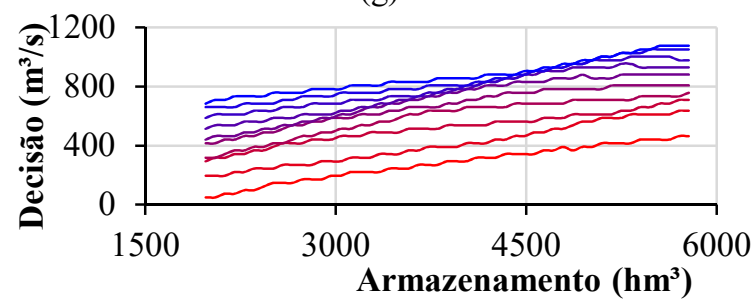

(h)

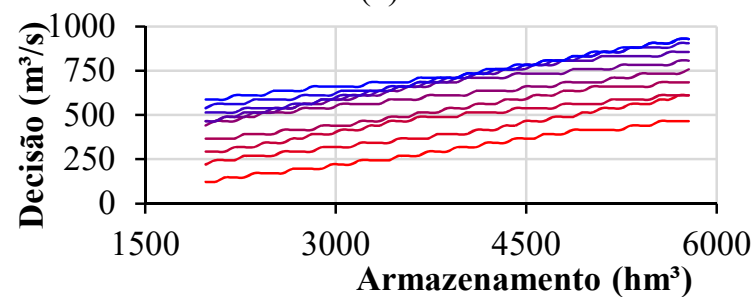

(i)

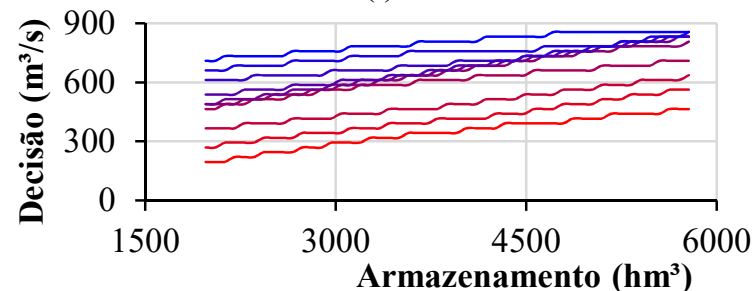

(j)

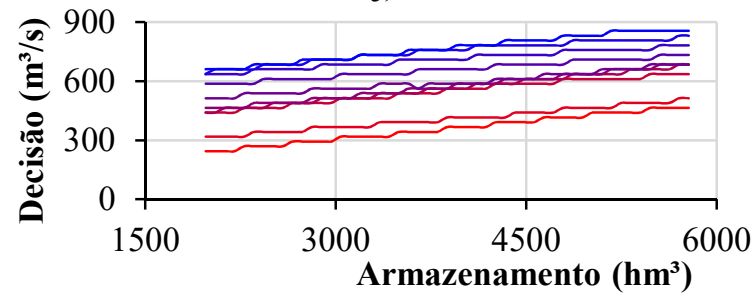

(k)

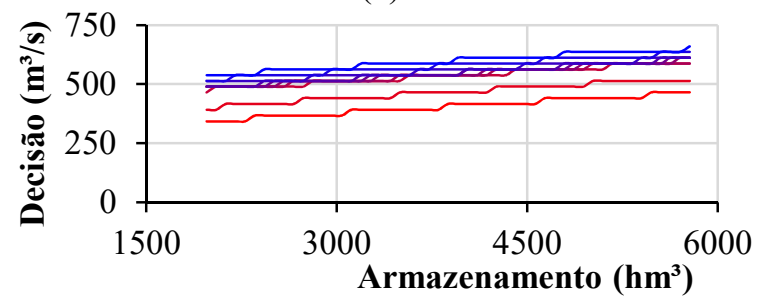

(1)

Figura 42 - Tabelas de decisões de turbinagens para a usina hidrelétrica de Foz do Areia para no mês de Janeiro mensal (a), bimestral (b), trimestral (c), quadrimestral (d), semestral (e) e anual (f) e para o mês de Julho mensal (g), bimestral (h), trimestral (i), quadrimestral (j), semestral (k) e anual (l). 


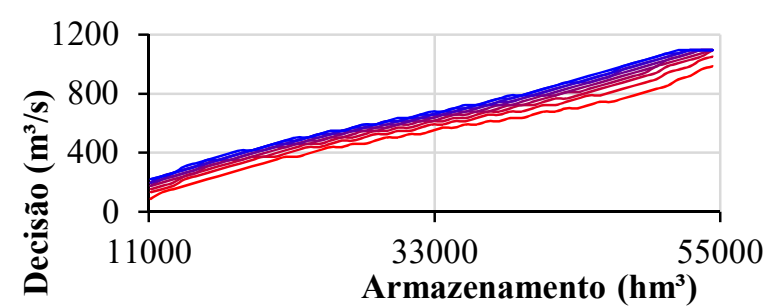

(a)

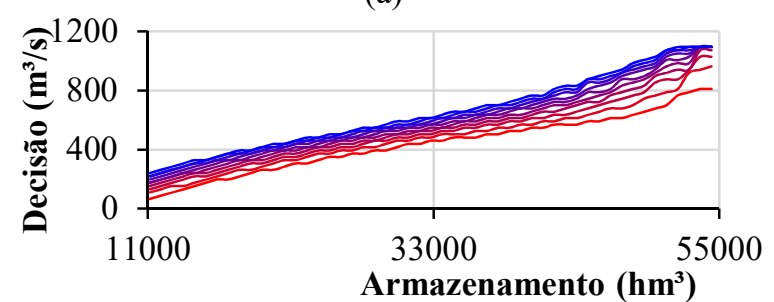

(b)

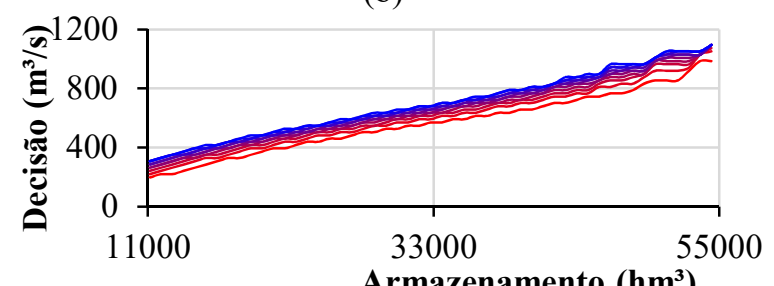

(c)

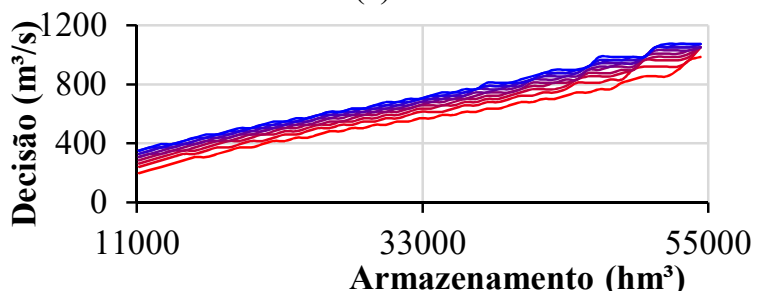

(d)

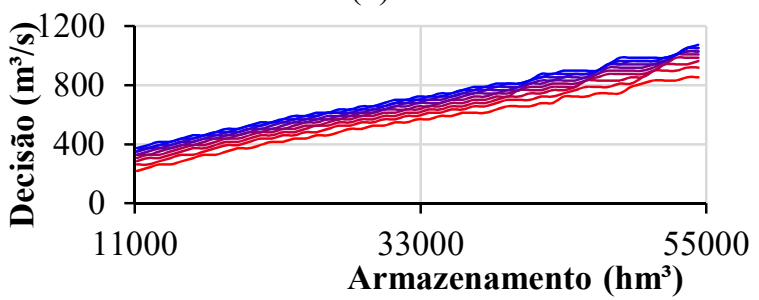

(e)

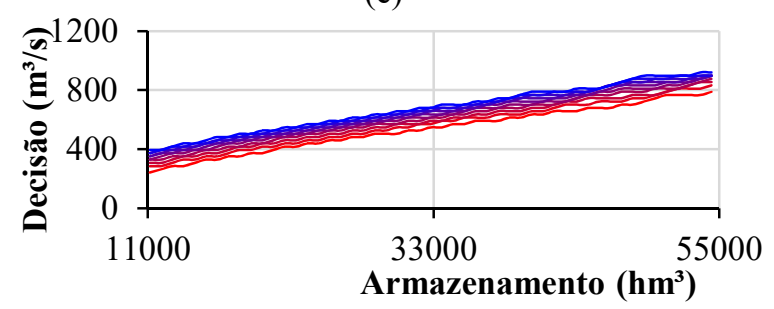

(f)

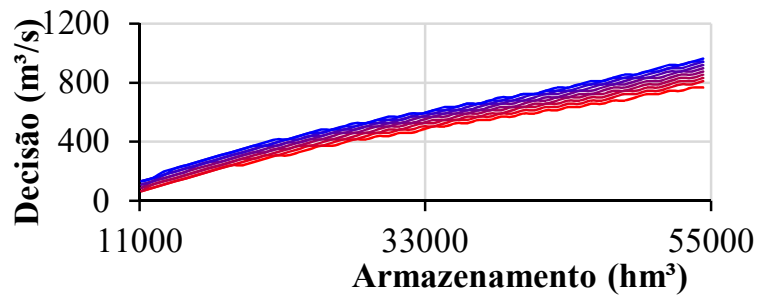

(g)

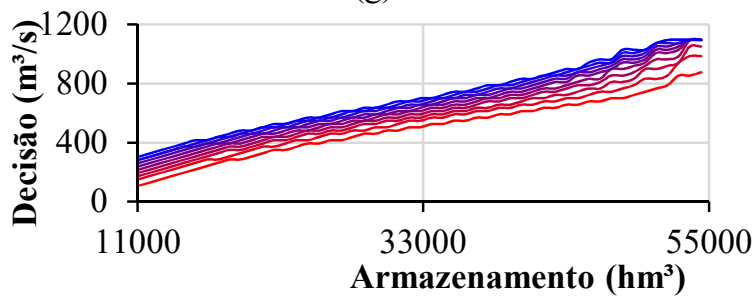

(h)

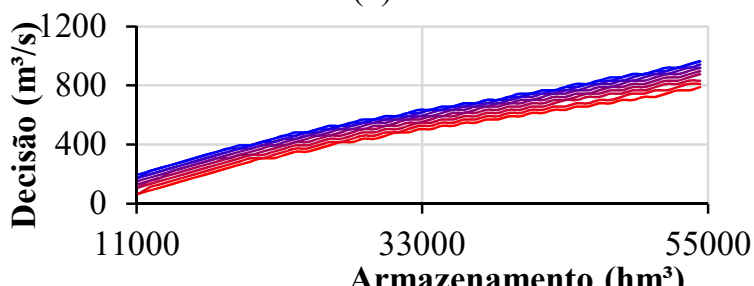

(i)

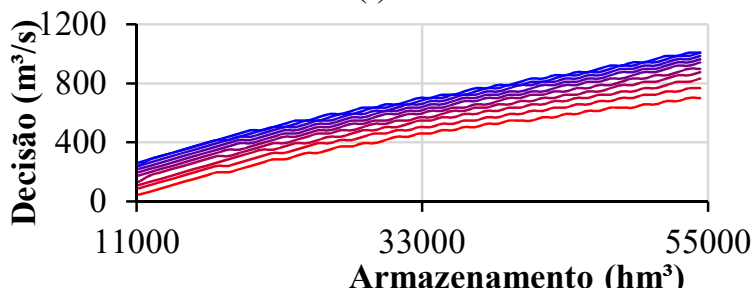

(j)

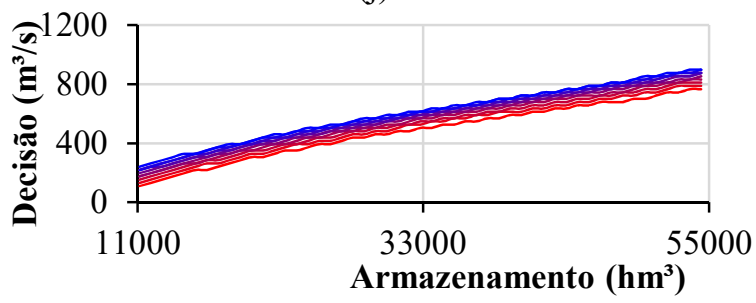

(k)

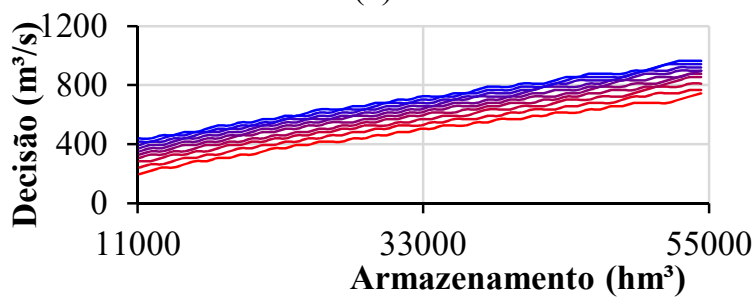

(1)

Figura 43 - Tabelas de decisões de turbinagens para a usina hidrelétrica de Serra da Mesa para no mês de Janeiro mensal (a), bimestral (b), trimestral (c), quadrimestral (d), semestral (e) e anual (f) e para o mês de Julho mensal $(\mathrm{g})$, bimestral (h), trimestral (i), quadrimestral (j), semestral (k) e anual (l). 


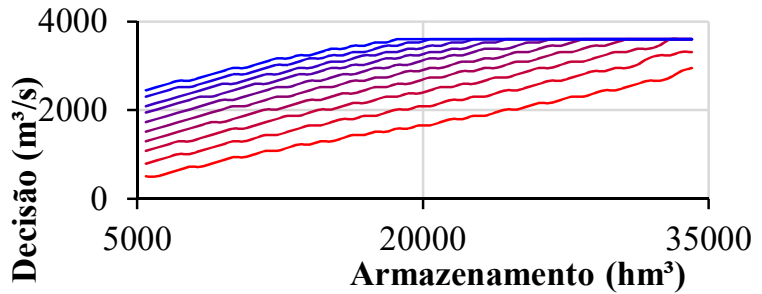

(a)

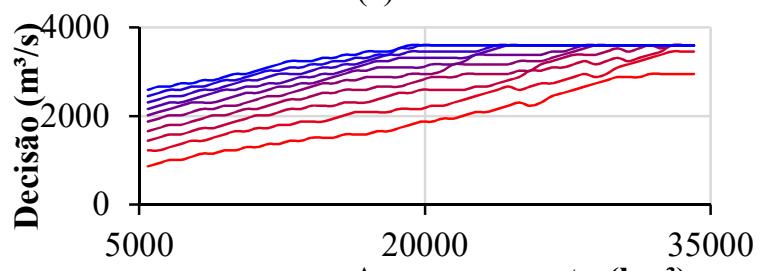

Armazenamento $\left(\mathrm{hm}^{3}\right)$

(b)

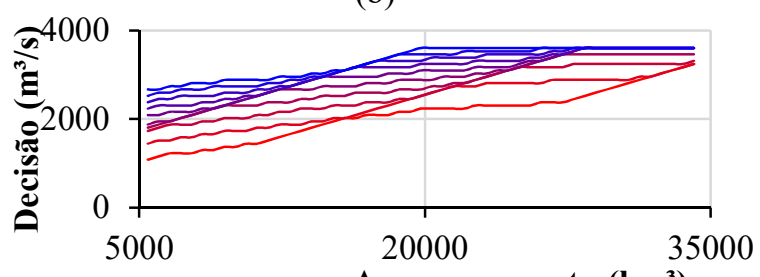

Armazenamento $\left(\mathrm{hm}^{3}\right)$

(c)

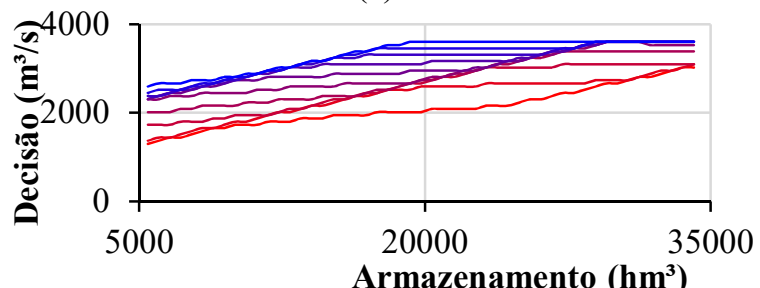

(d)

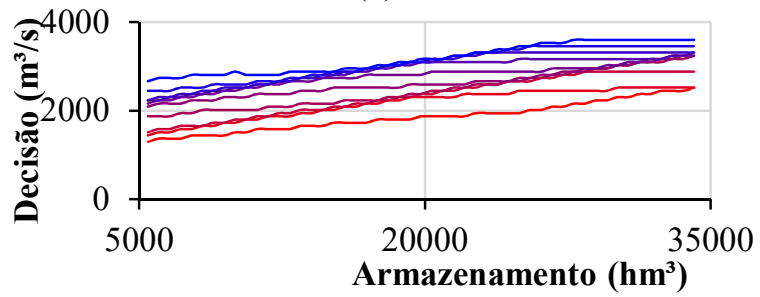

(e)

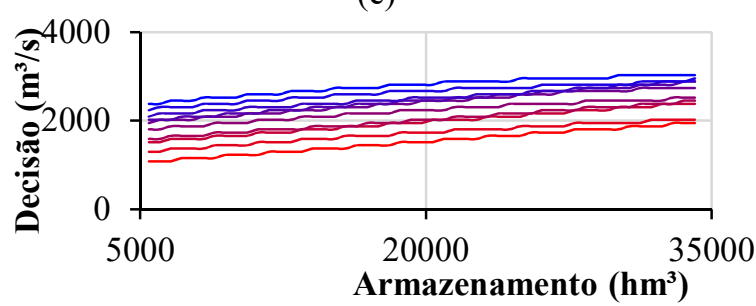

(f)

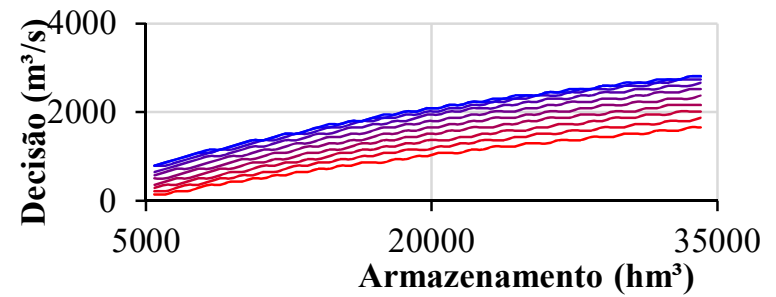

(g)

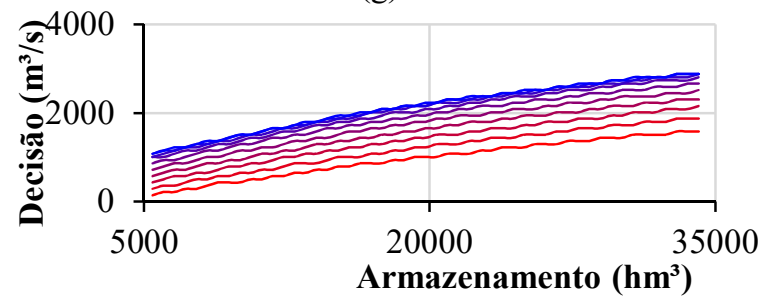

(h)

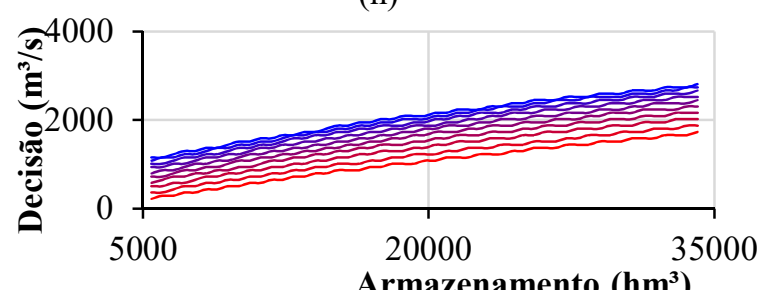

(i)

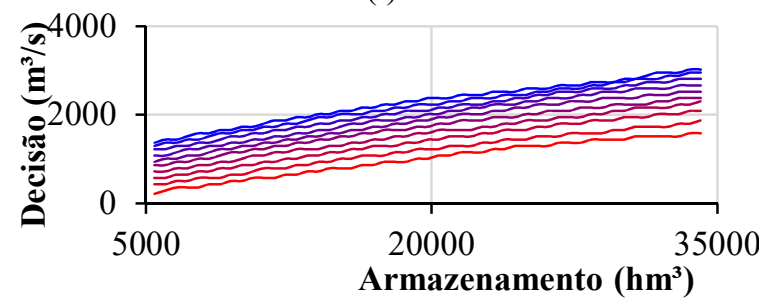

(j)

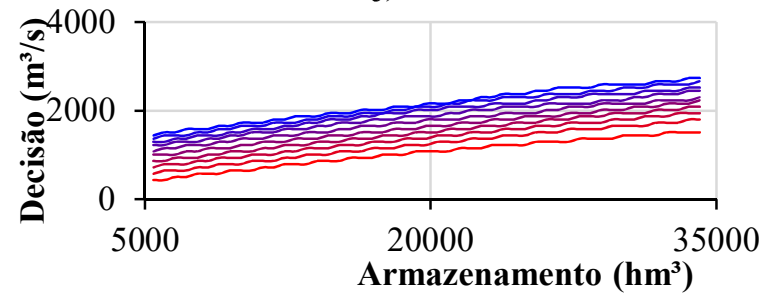

(k)

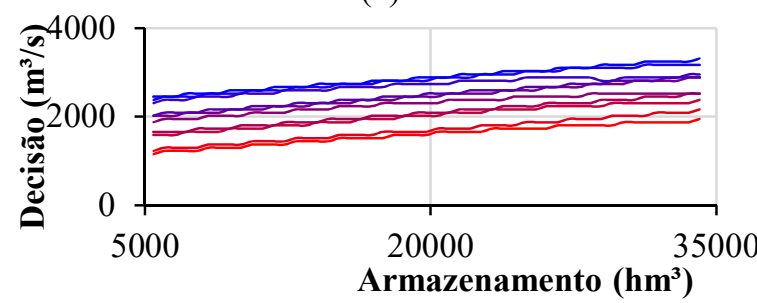

(1)

Figura 44 - Tabelas de decisões de turbinagens para a usina hidrelétrica de Sobradinho para no mês de Janeiro mensal (a), bimestral (b), trimestral (c), quadrimestral (d), semestral (e) e anual (f) e para o mês de Julho mensal (g), bimestral (h), trimestral (i), quadrimestral (j), semestral (k) e anual (l). 


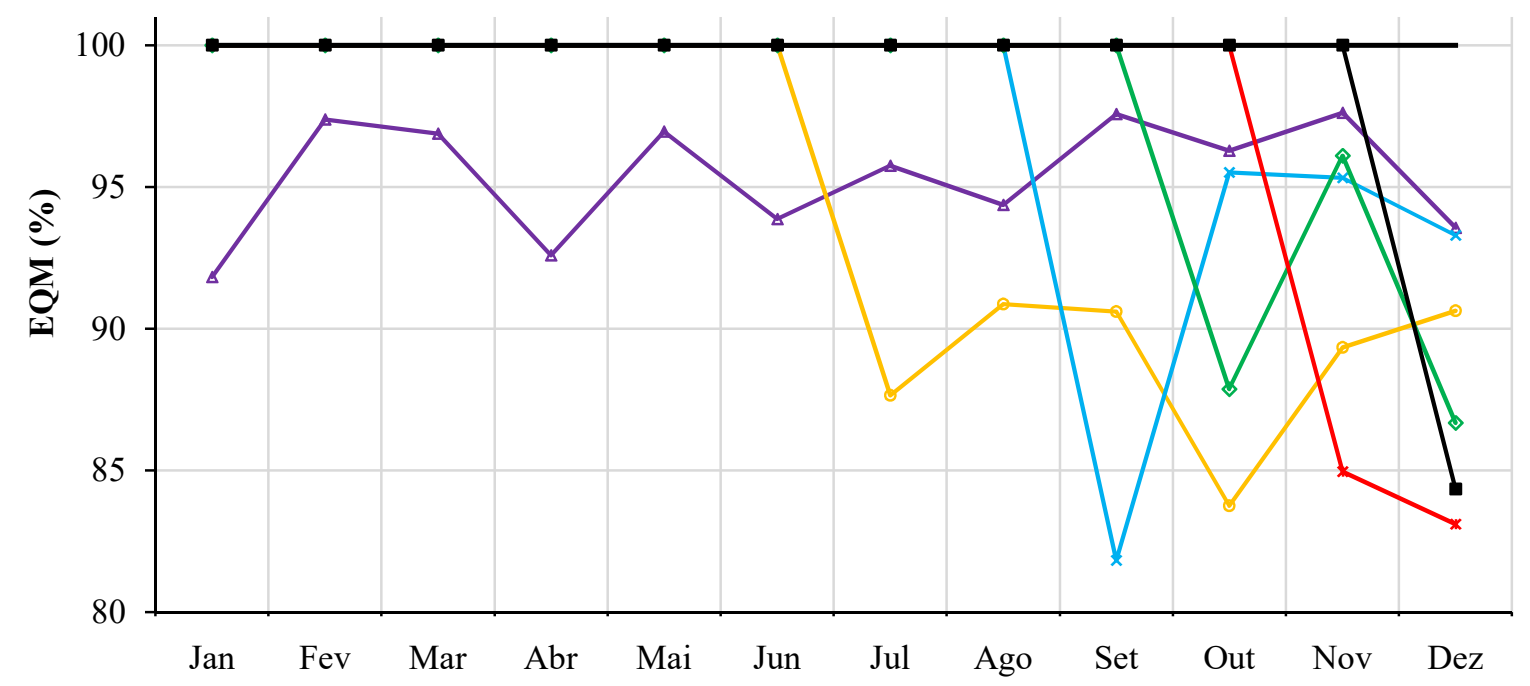

$\multimap$ Anual $\multimap$ Semestral $\multimap$ Quadrimestral $\multimap$ Trimestral $\multimap$ Bimestral $\rightarrow$ Mensal $\longrightarrow$ MLT

(a)

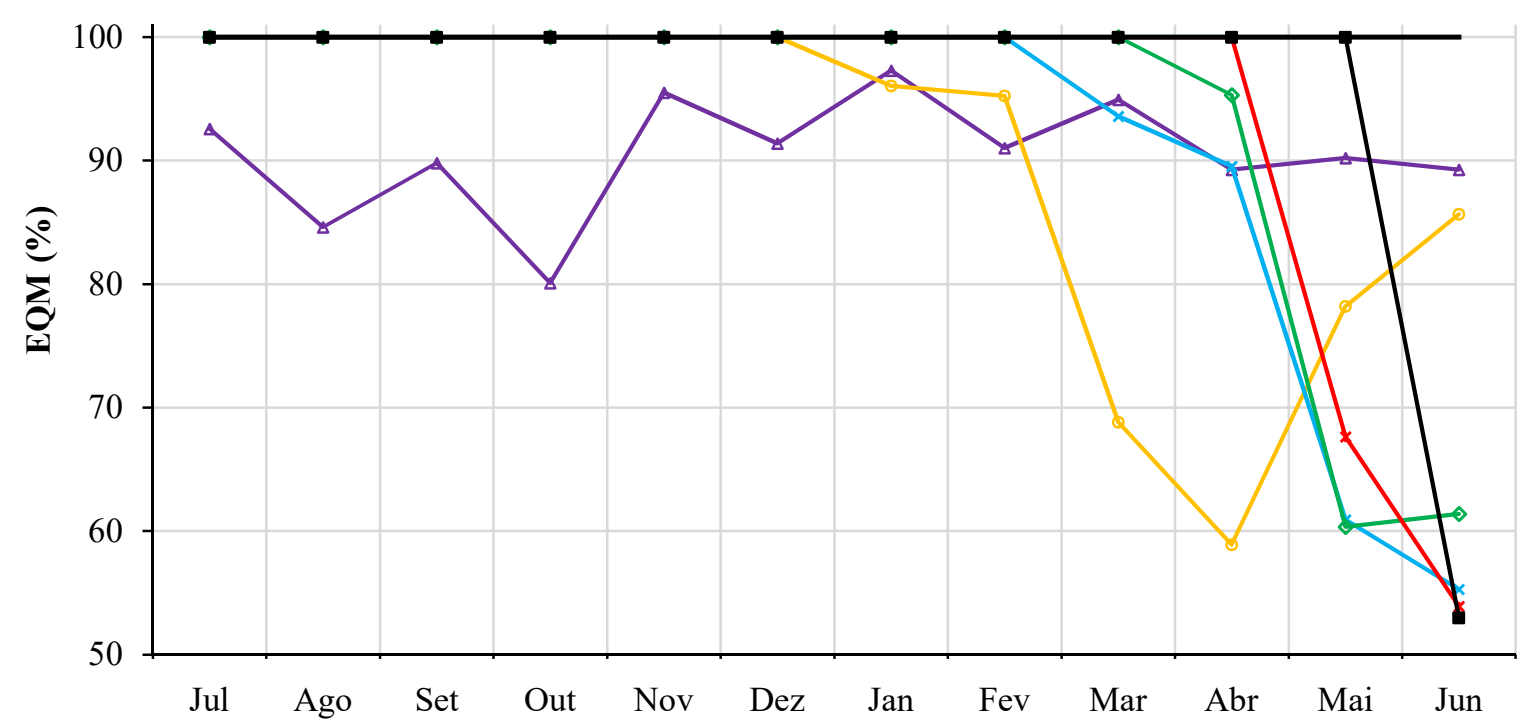

$\multimap$ Anual $\multimap$ Semestral $\multimap$ Quadrimestral $\multimap$ Trimestral $\multimap$ Bimestral $\rightarrow$ Mensal $\longrightarrow$ MLT

(b)

Figura 45 - Erros quadráticos médios percentuais a MLT das previsões com o modelo PAR-1 para os meses de Janeiro (a) e Julho (b) na usina hidrelétrica de Foz do Areia. 


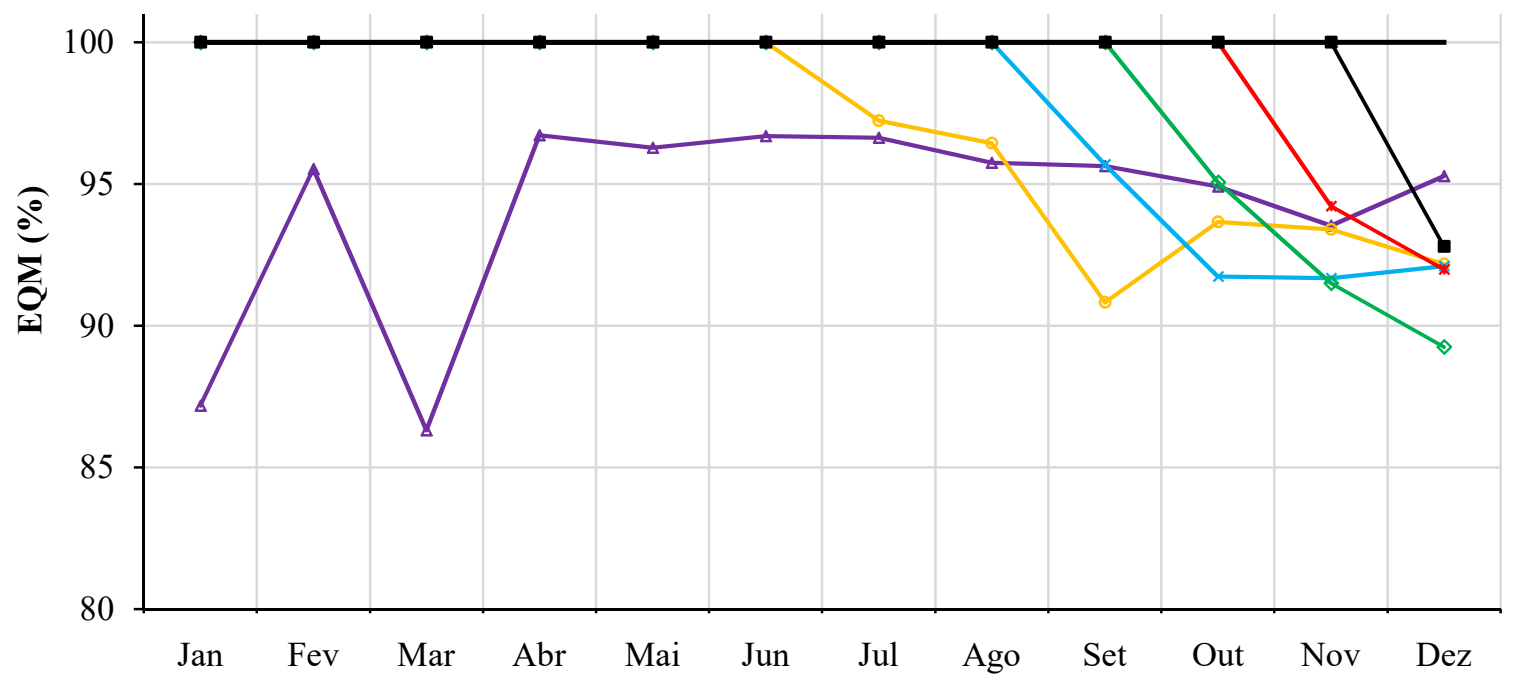

$\multimap$ Anual $\multimap$ Semestral $\leadsto$ Quadrimestral $\multimap$ Trimestral $\multimap$ Bimestral $\rightarrow$ Mensal $\longrightarrow$ MLT

(a)

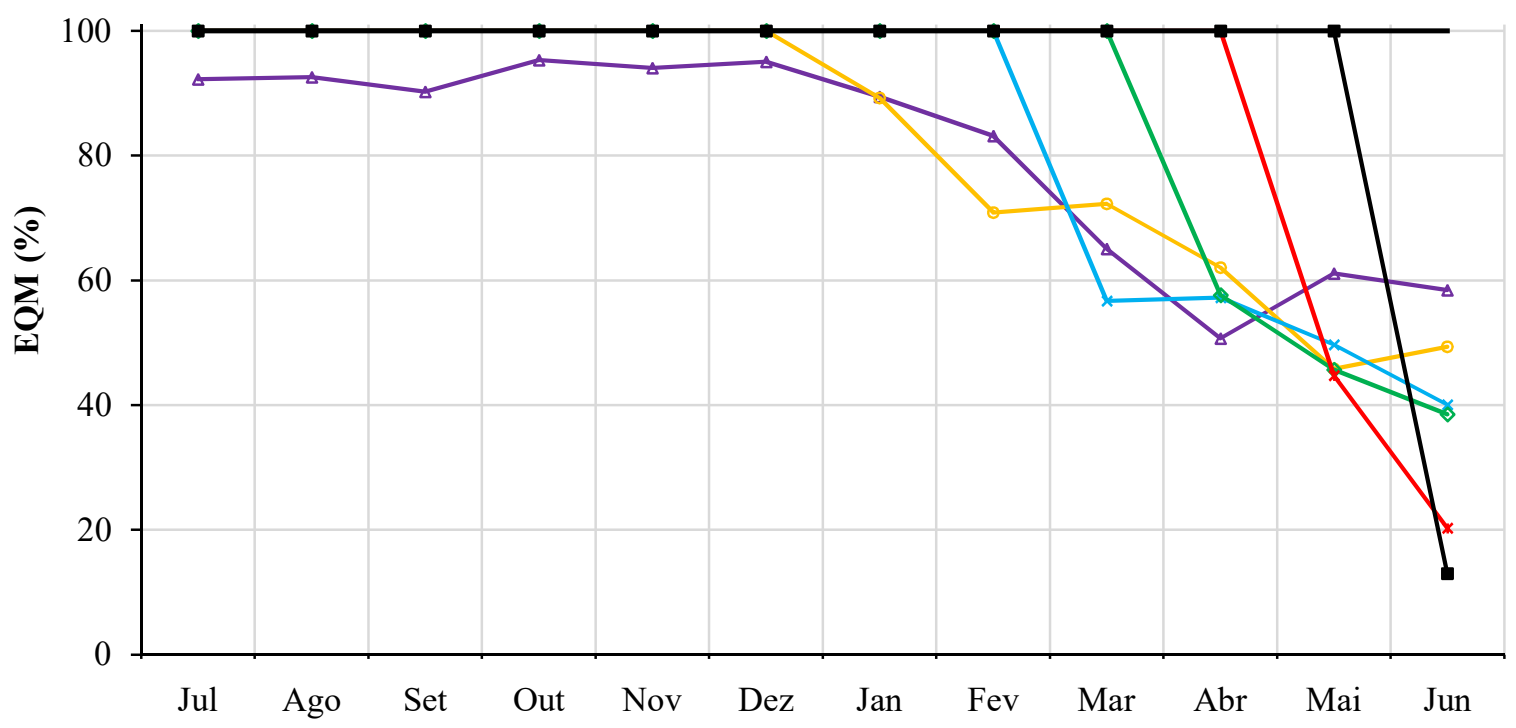

$\multimap$ Anual $\multimap$ Semestral $\multimap$ Quadrimestral $\multimap$ Trimestral $\multimap$ Bimestral $\rightarrow$ Mensal $\longrightarrow$ MLT

(b)

Figura 46 - Erros quadráticos médios percentuais a MLT das previsões com o modelo PAR-1 para os meses de Janeiro (a) e Julho (b) na usina hidrelétrica de Serra da Mesa. 


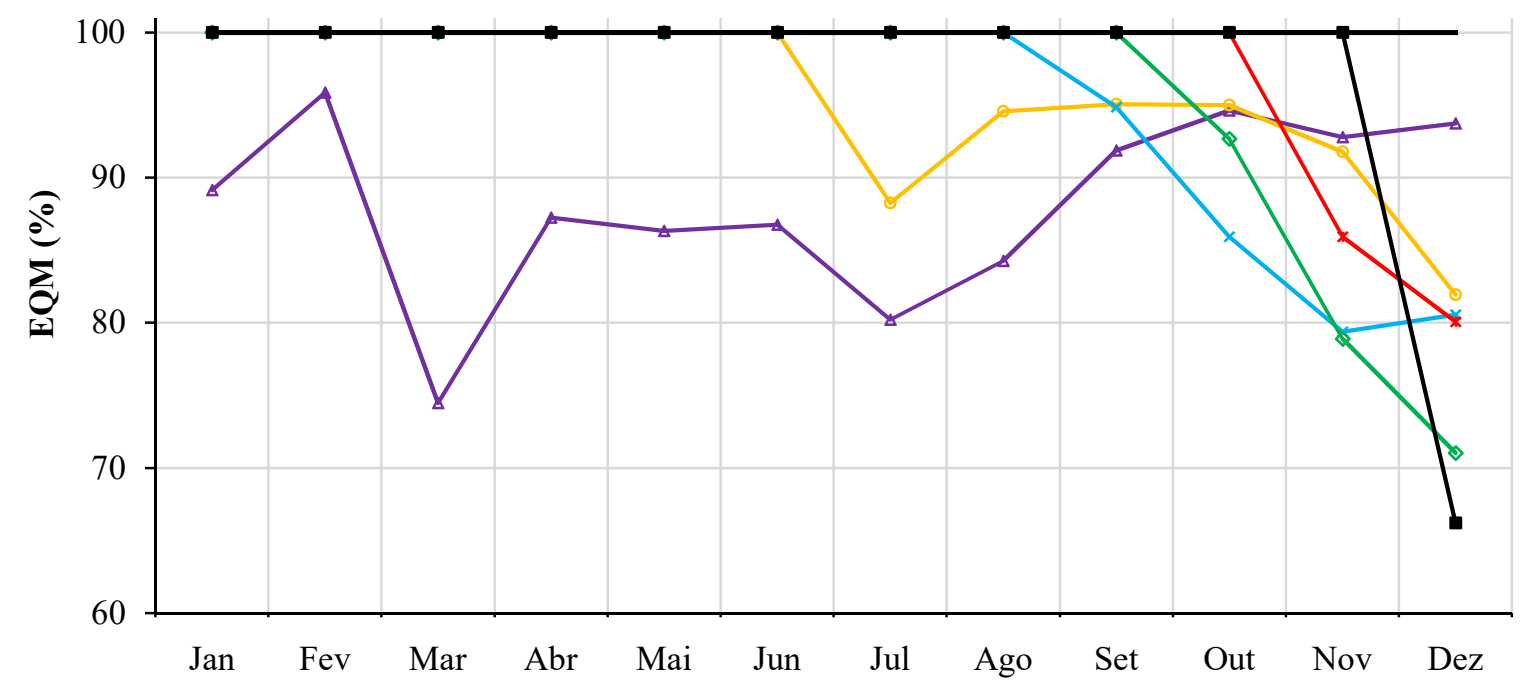

$\multimap$ Anual $\longrightarrow$ Semestral $\multimap$ Quadrimestral $\multimap$ Trimestral $\longrightarrow$ Bimestral $\rightarrow$ Mensal $\longrightarrow$ MLT

(a)

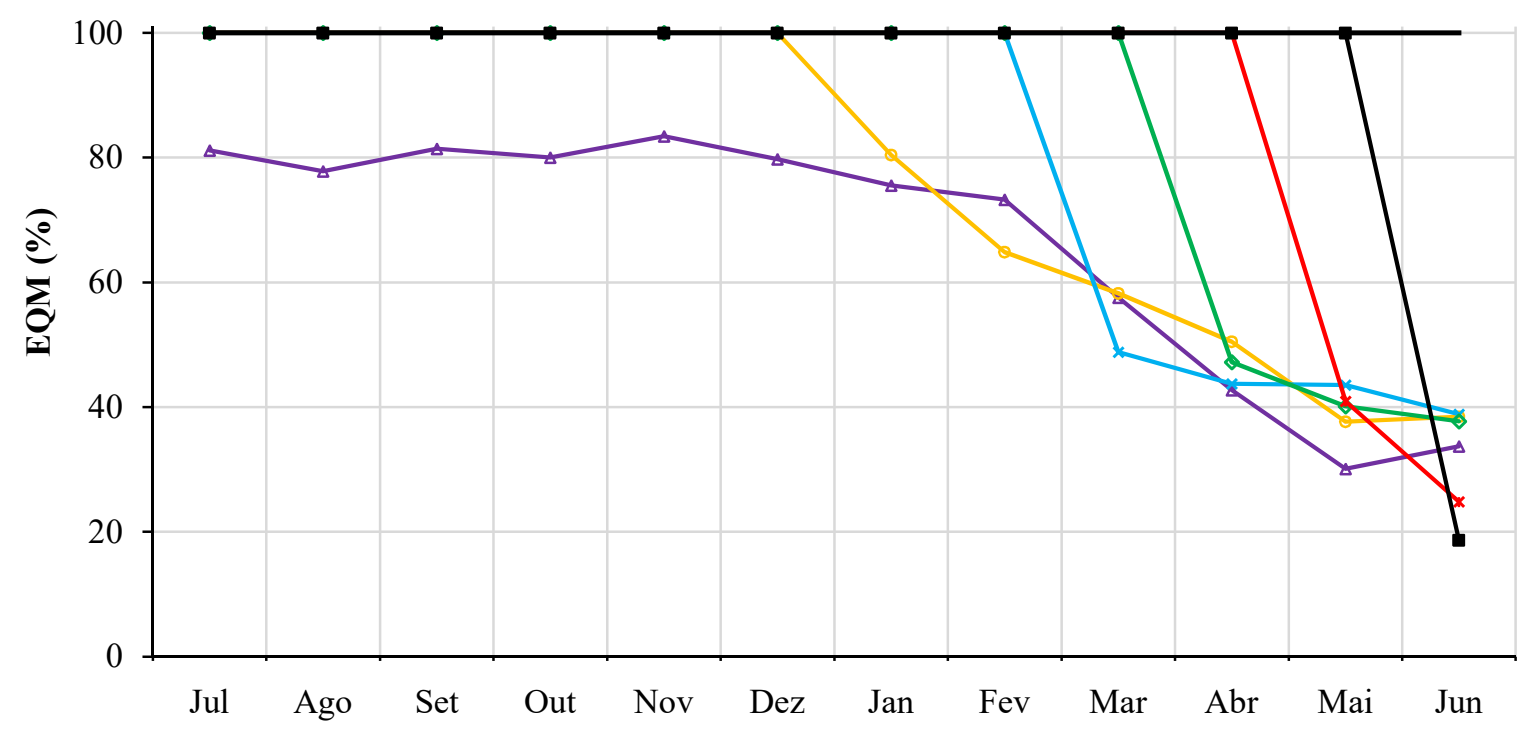

$\multimap$ Anual $\multimap$ Semestral $\multimap$ Quadrimestral $\multimap$ Trimestral $\multimap$ Bimestral $\rightarrow$ Mensal $\longrightarrow$ MLT

(b)

Figura 47 - Erros quadráticos médios percentuais a MLT das previsões com o modelo PAR-1 para os meses de Janeiro (a) e Julho (b) na usina hidrelétrica de Sobradinho. 


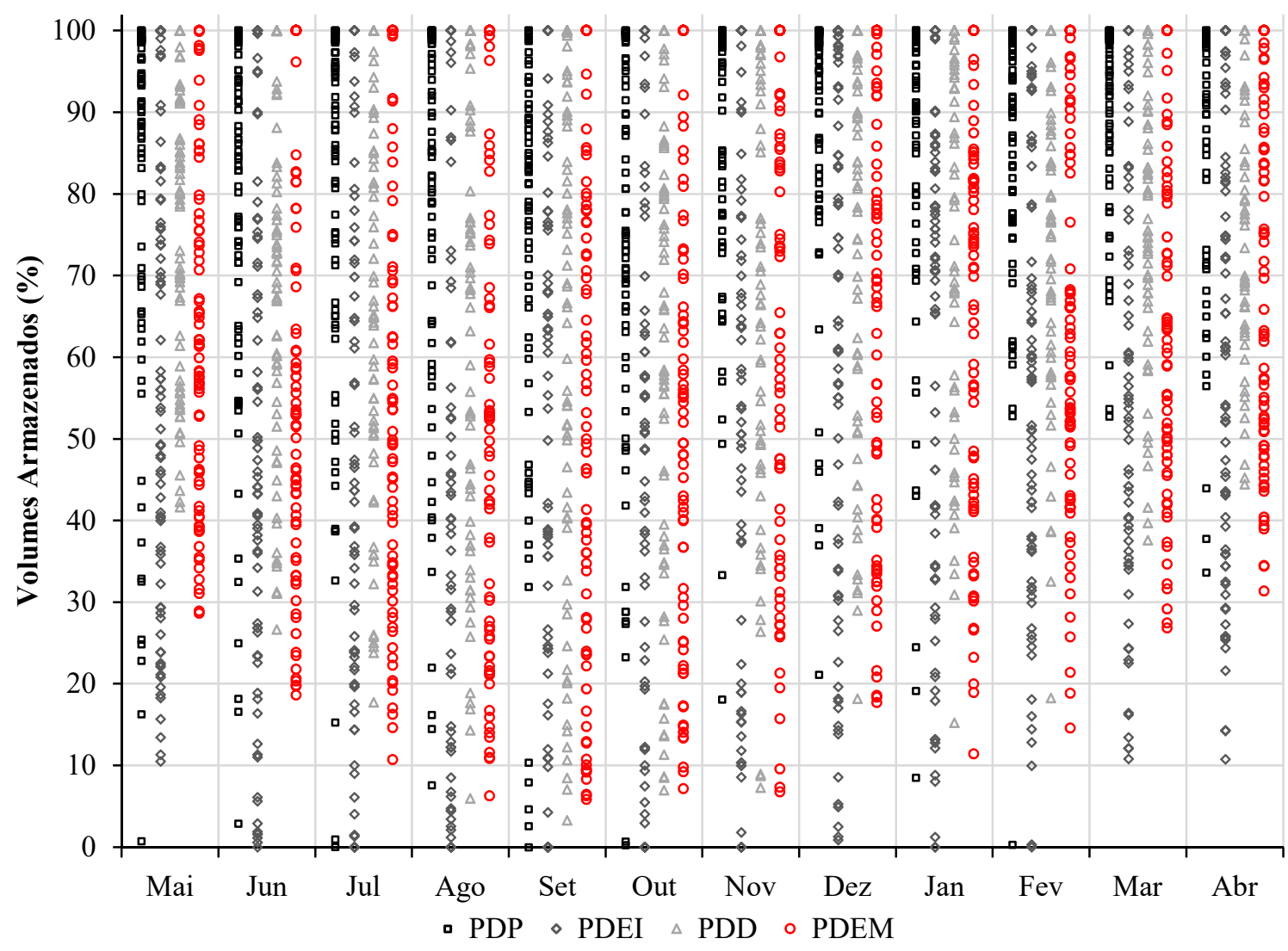

(a)

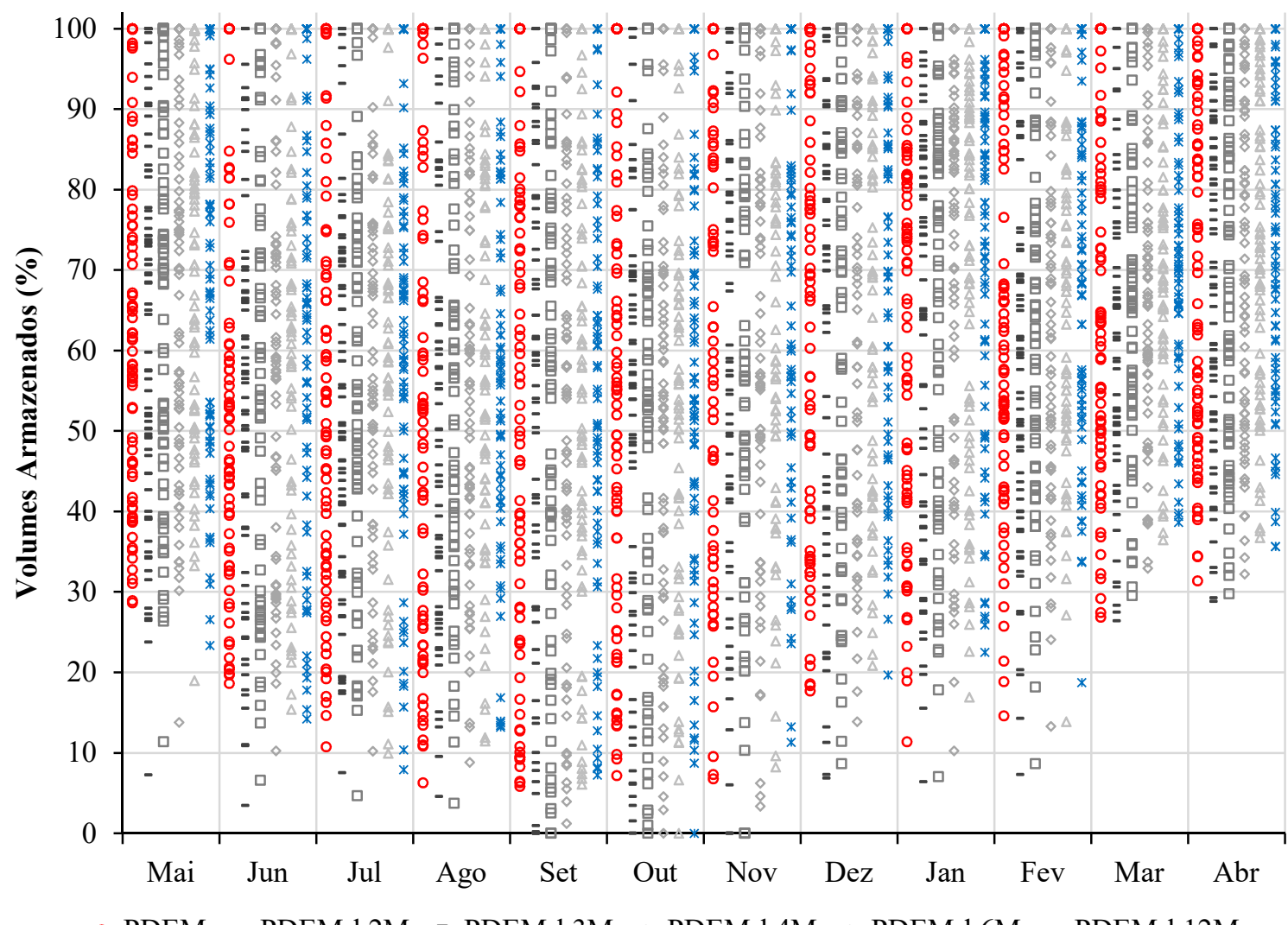

- PDEM - PDEM-k2M व PDEM-k3M 。PDEM-k4M $\triangle$ PDEM-k6M * PDEM-k12M

(b)

Figura 48 - Volumes mensais armazenados na usina hidrelétrica de Foz do Areia com as técnicas clássicas (a) e com as técnicas propostas (b). 


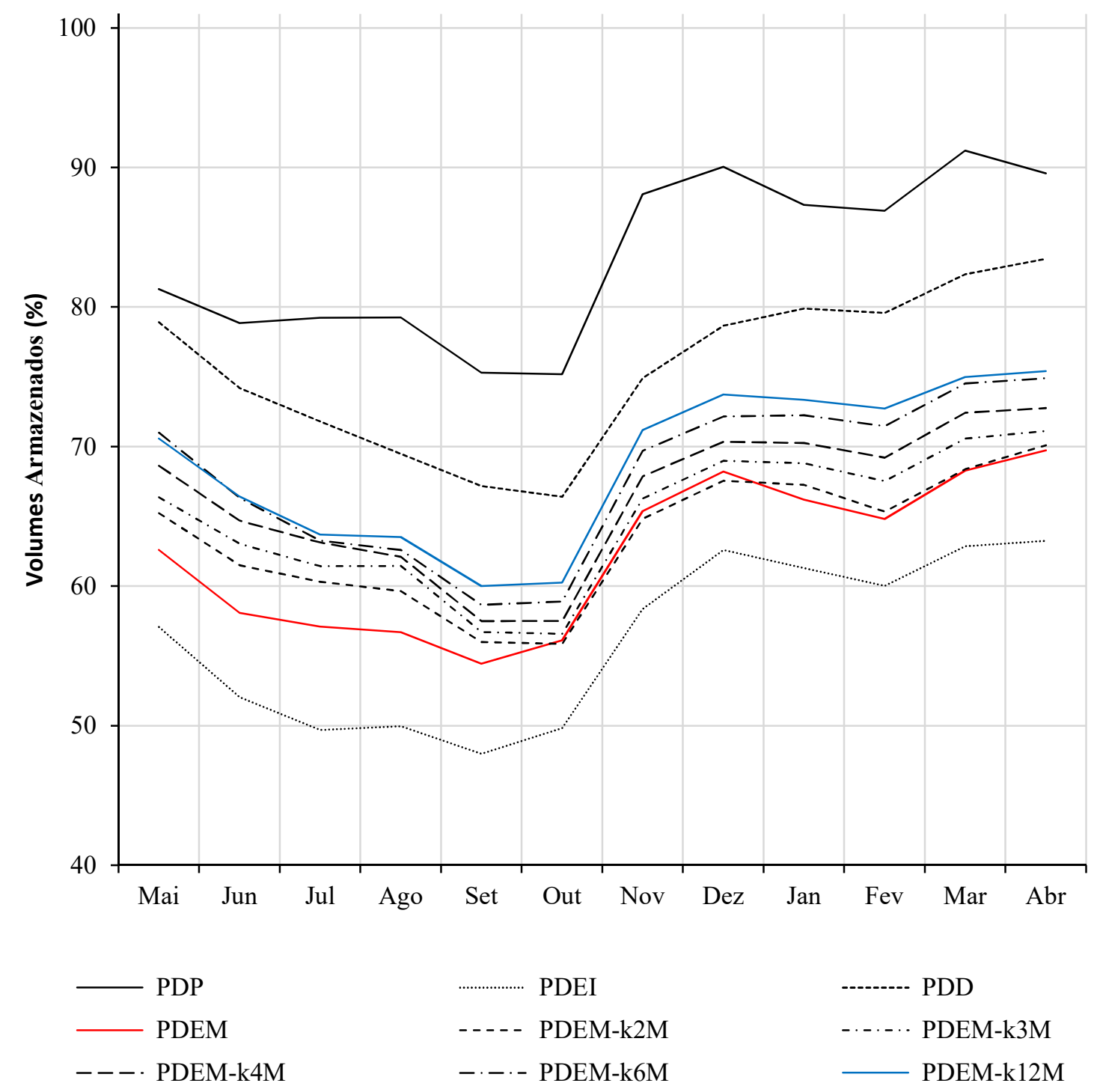

Figura 49 - Volumes armazenados médios mensais da usina hidrelétrica de Foz do Areia. 


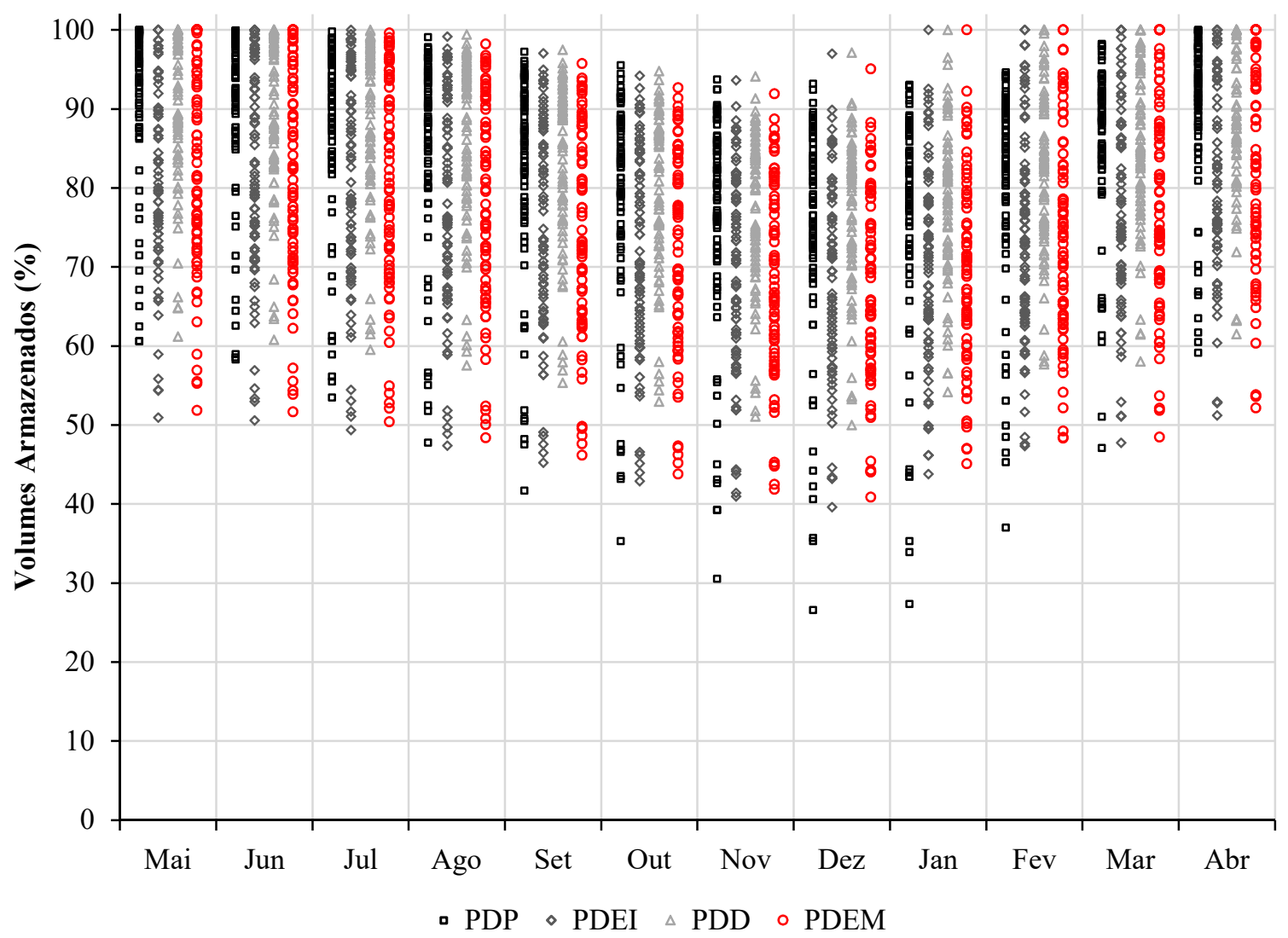

(a)

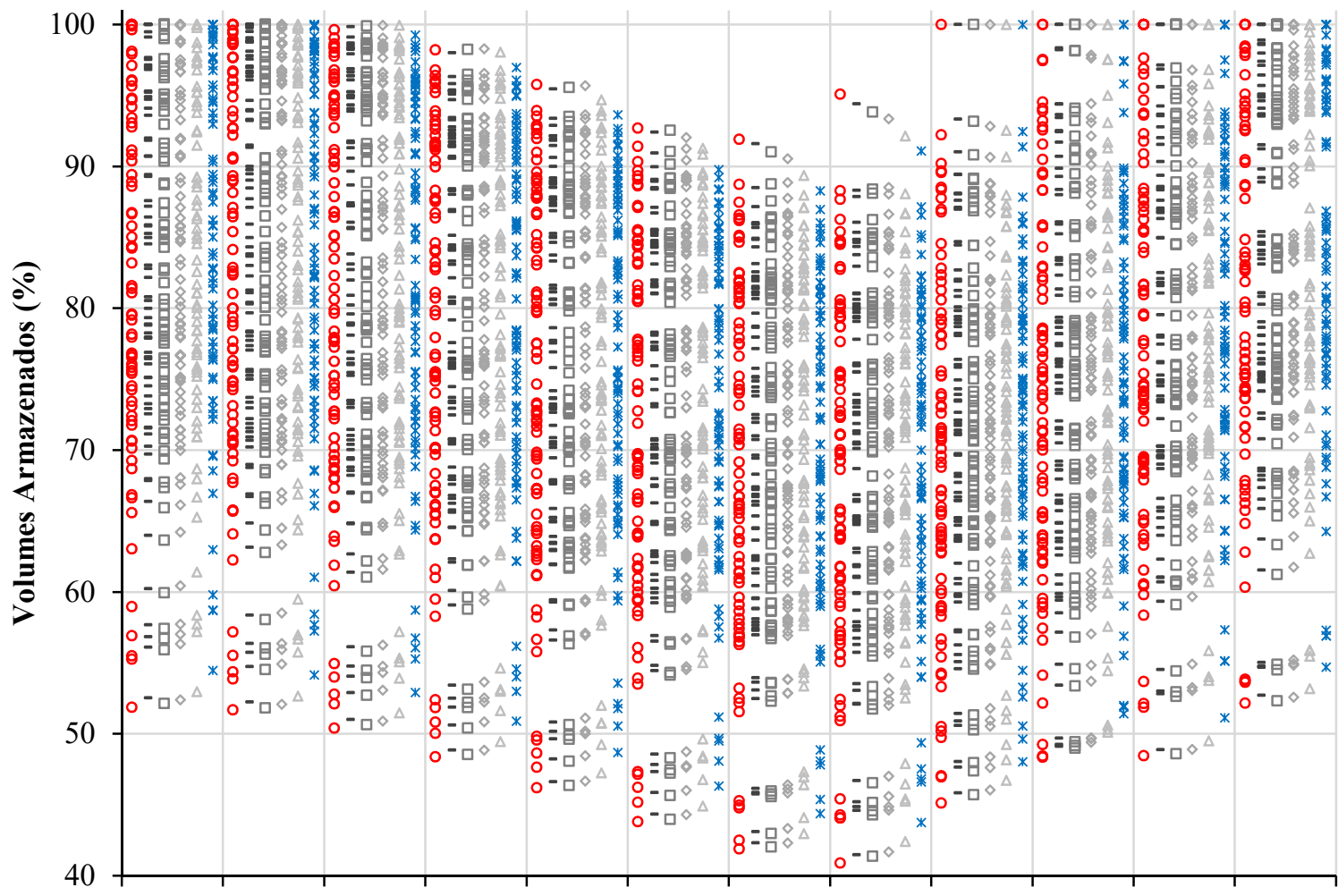

○ PDEM - PDEM-k2M PDEM-k3M 。PDEM-k4M $\triangle$ PDEM-k6M * PDEM-k12M

(b)

Figura 50 - Volumes mensais armazenados na usina hidrelétrica de Serra da Mesa com as técnicas clássicas (a) e com as técnicas propostas (b). 


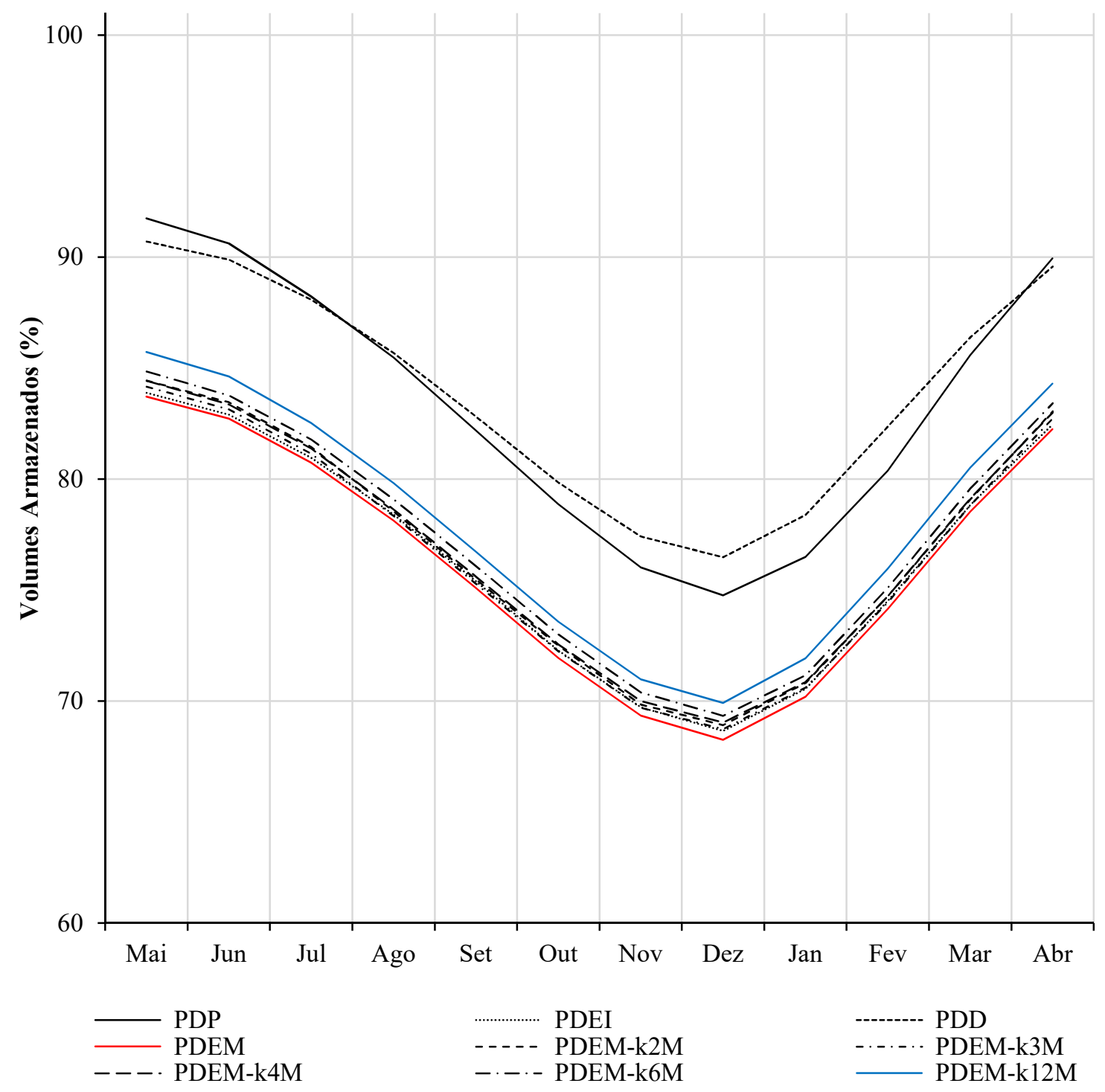

Figura 51 - Volumes armazenados médios mensais da usina hidrelétrica de Serra da Mesa. 


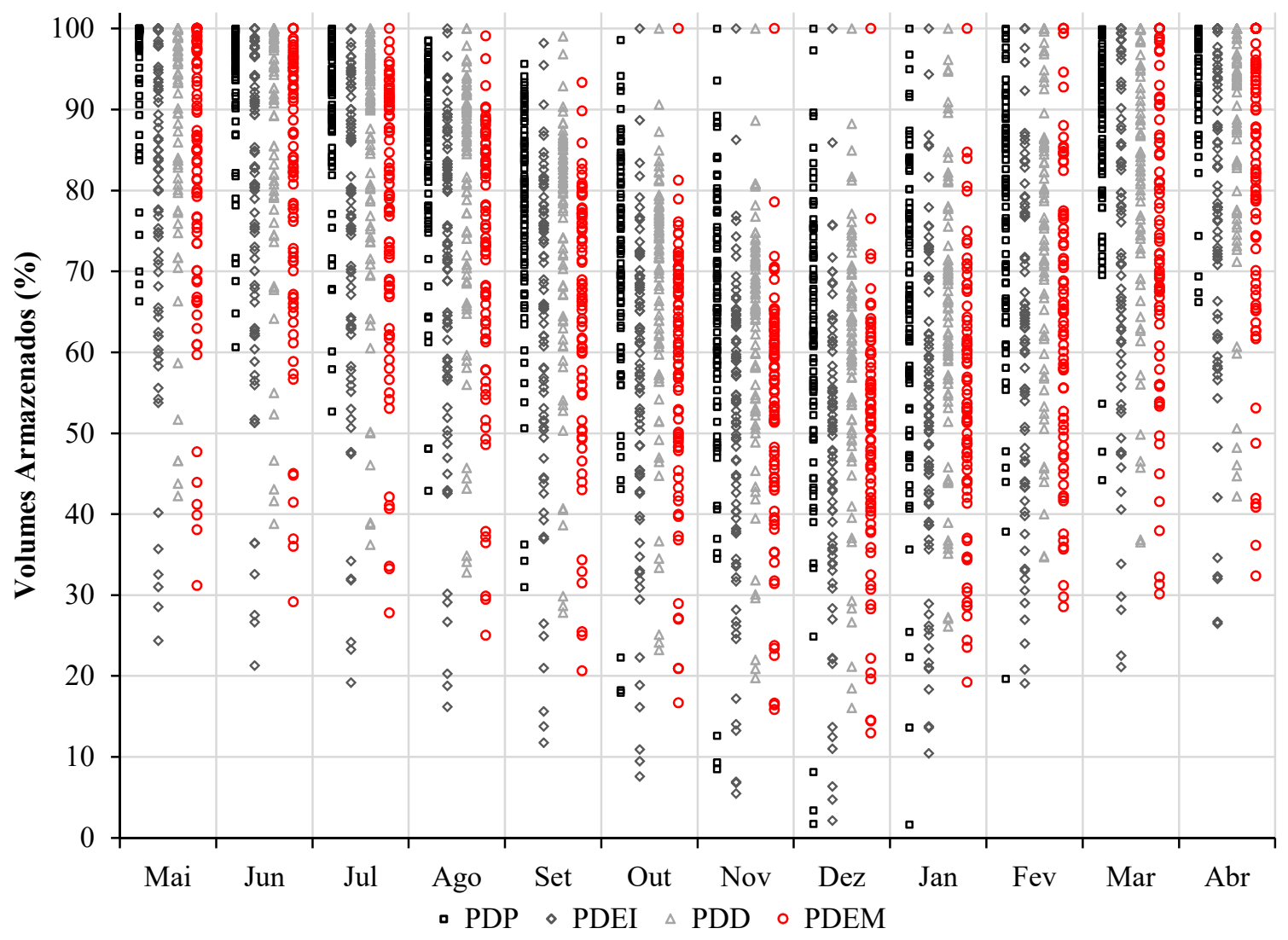

(a)

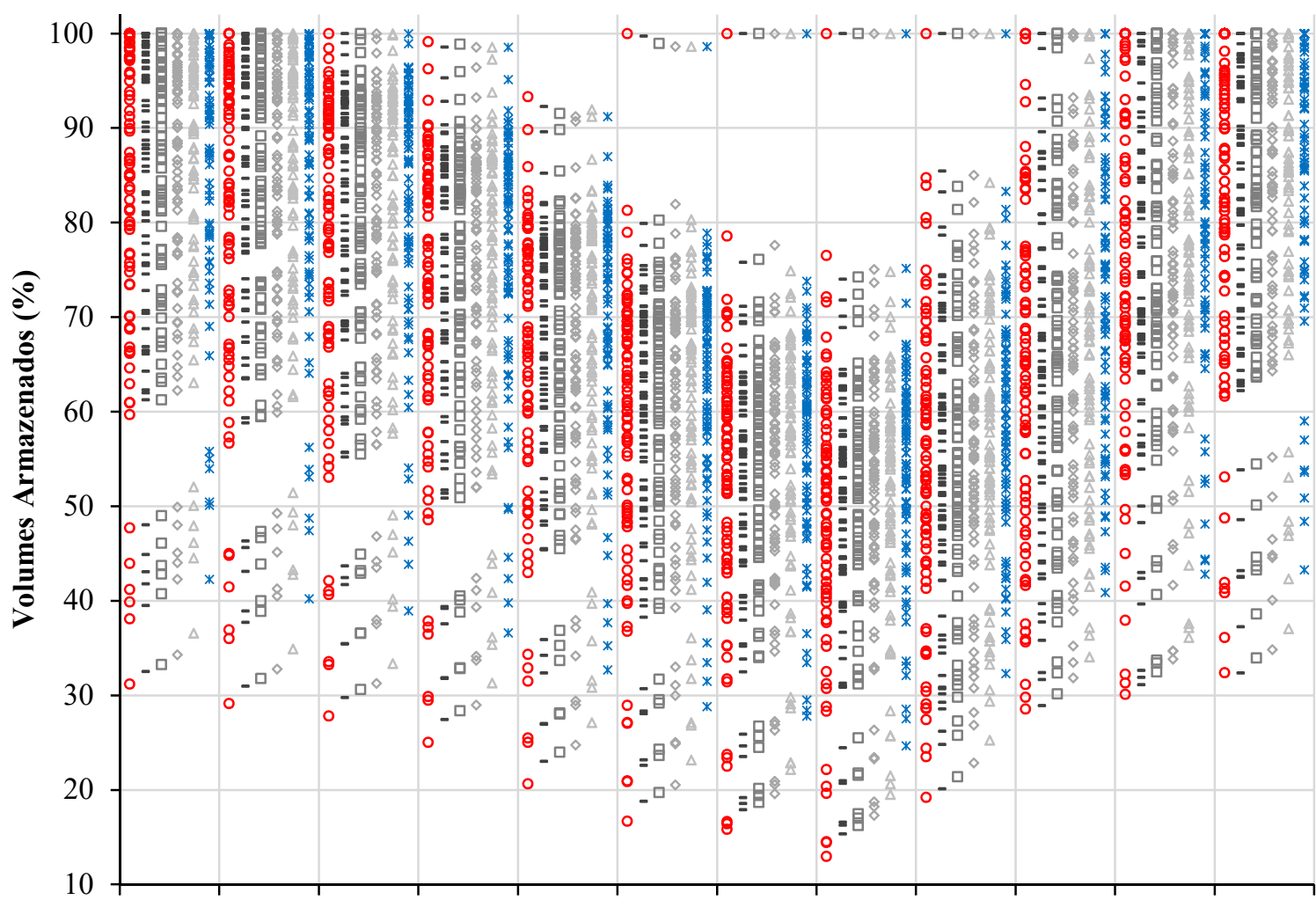

○ PDEM - PDEM-k2M 口PDEM-k3M 。PDEM-k4M $\triangle$ PDEM-k6M * PDEM-k12M

(b)

Figura 52 - Volumes mensais armazenados na usina hidrelétrica de Sobradinho com as técnicas clássicas (a) e com as técnicas propostas (b). 


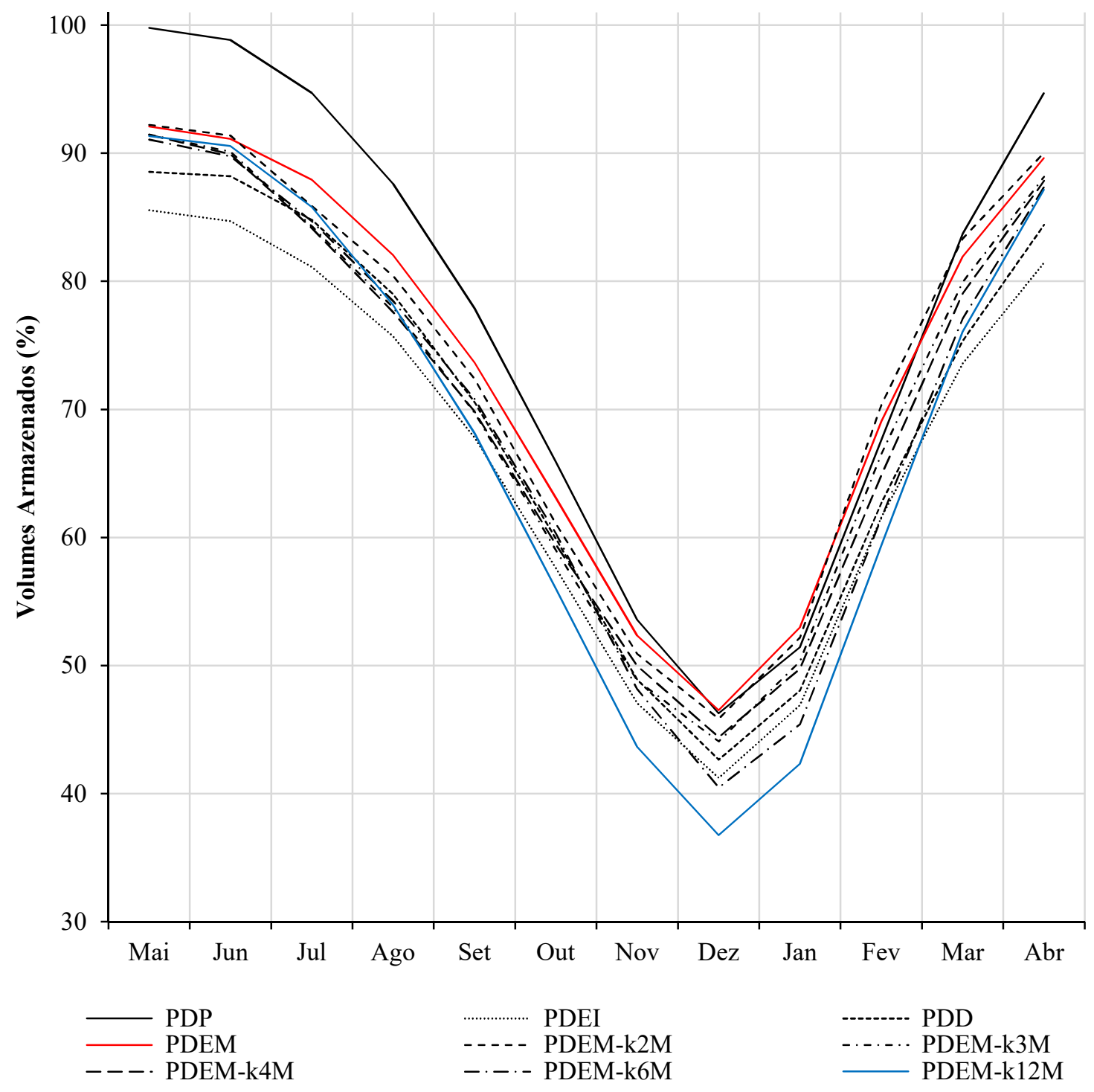

Figura 53 - Volumes armazenados médios mensais da usina hidrelétrica de Sobradinho. 


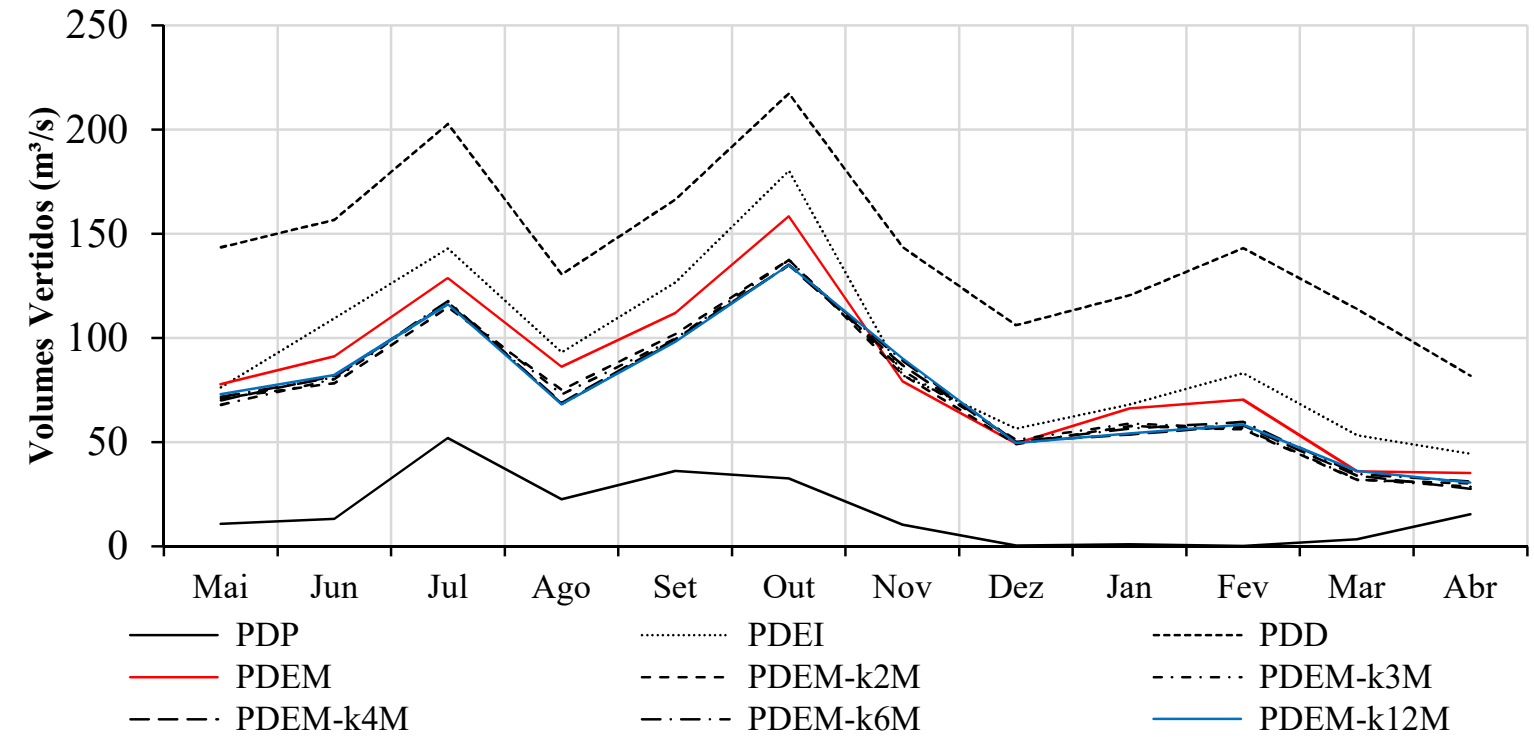

(a)

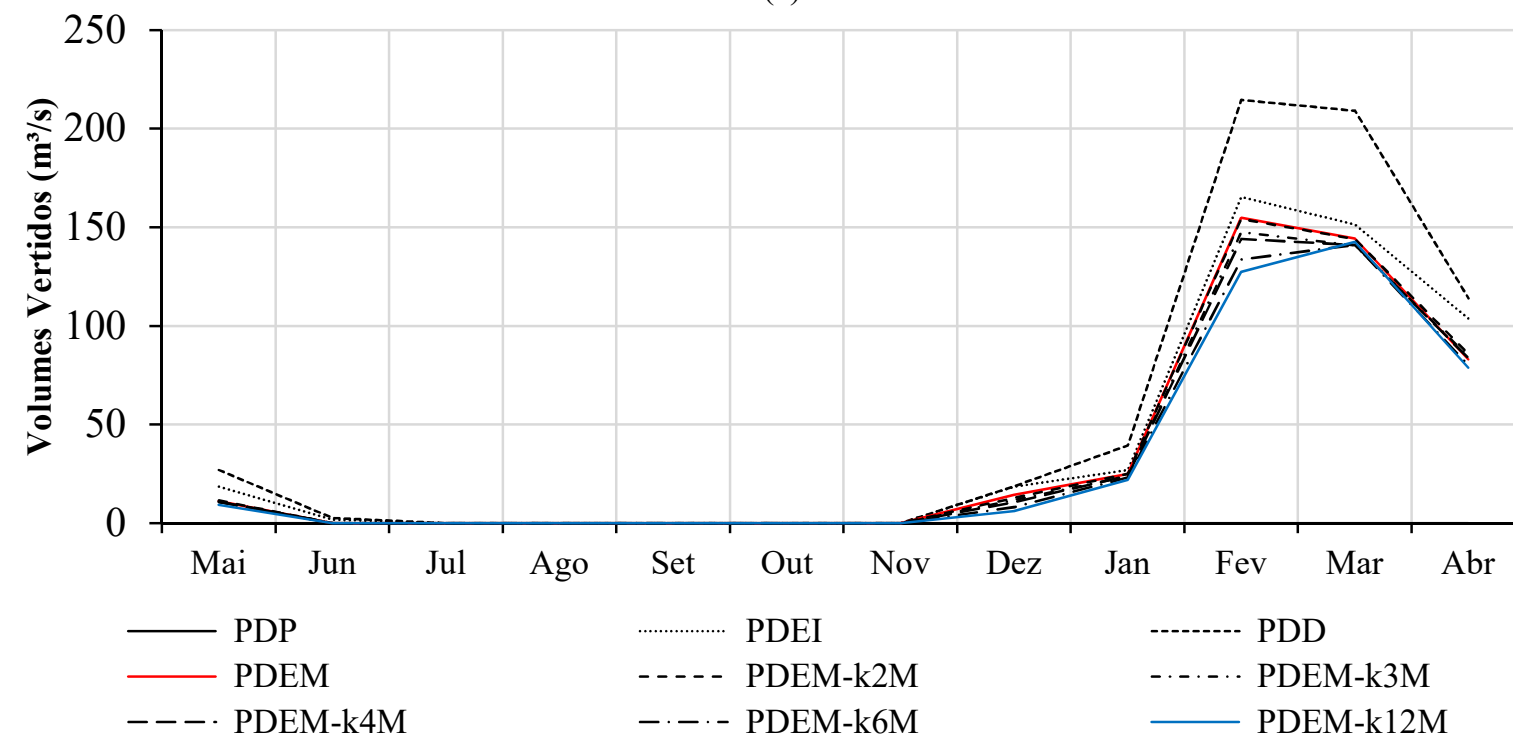

(b)

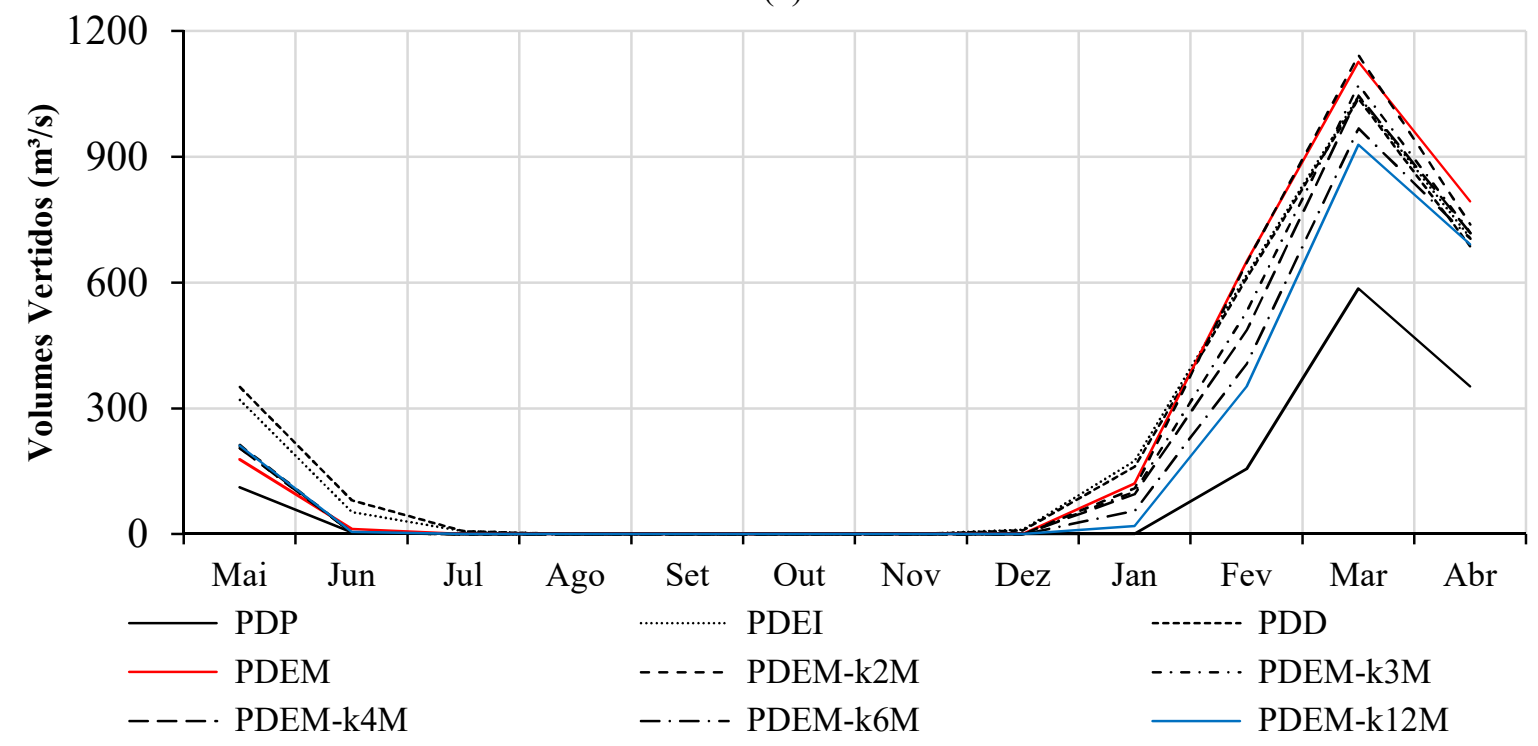

(c)

Figura 54 - Volumes médios mensais vertidos na usina hidrelétrica de Foz do Areia (a), Serra da Mesa (b) e Sobradinho (c). 


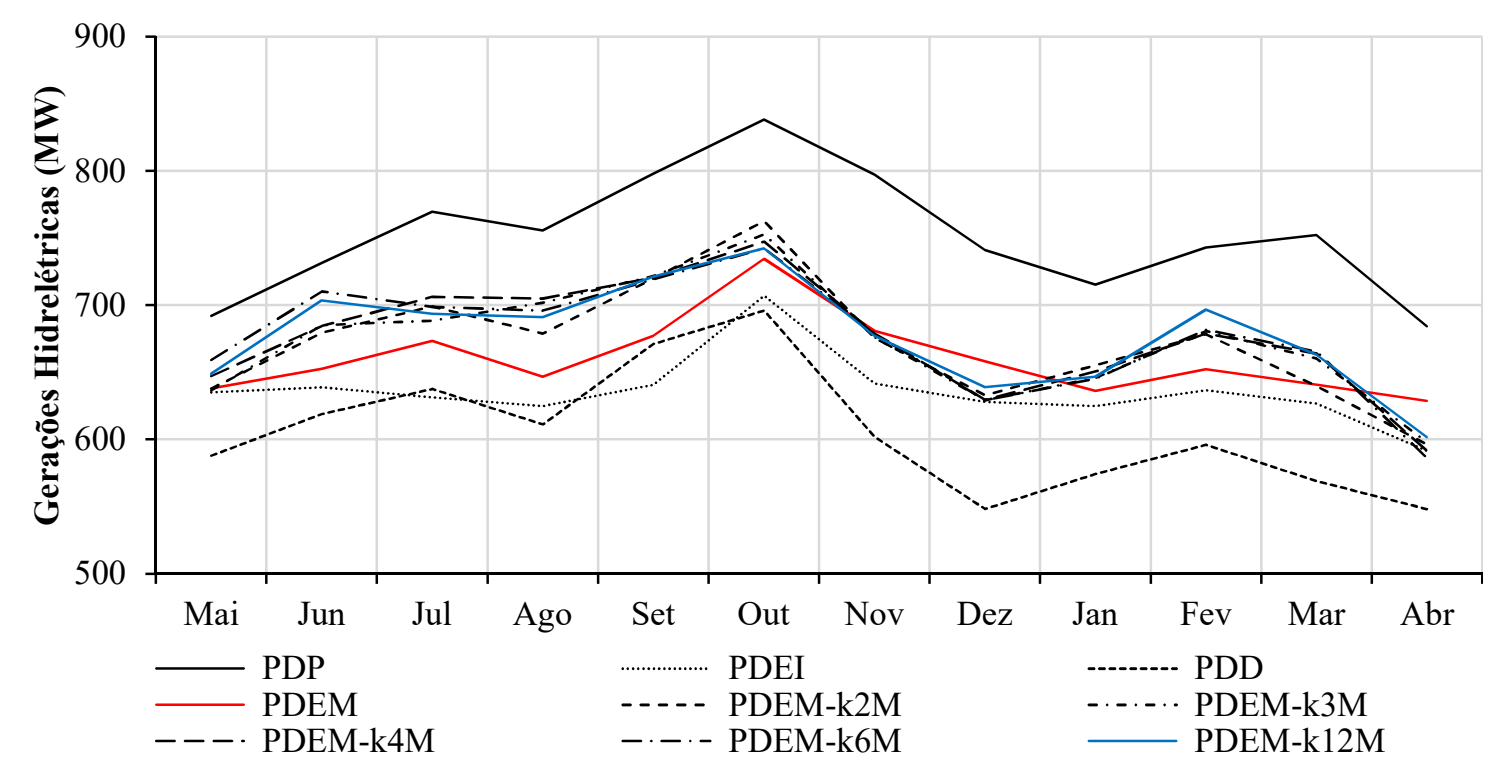

(a)

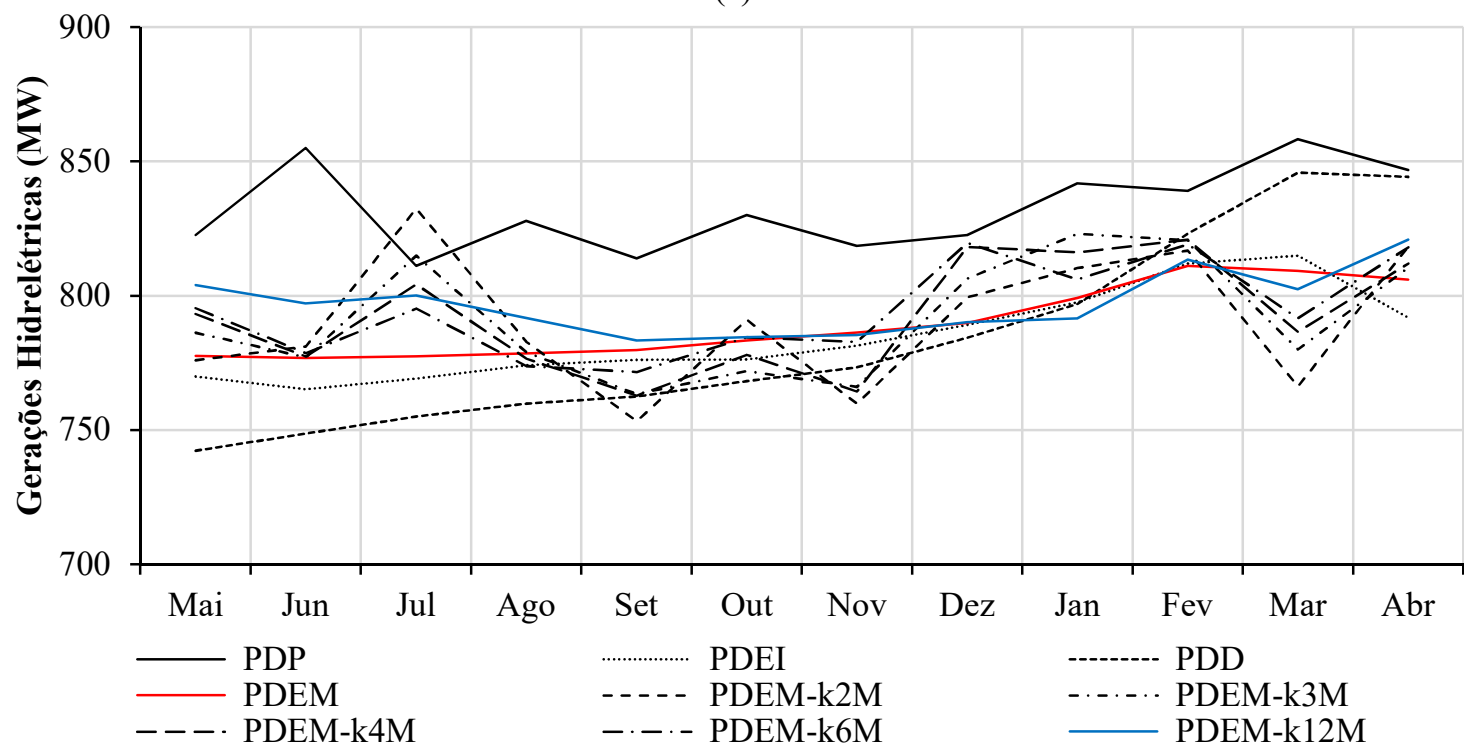

(b)

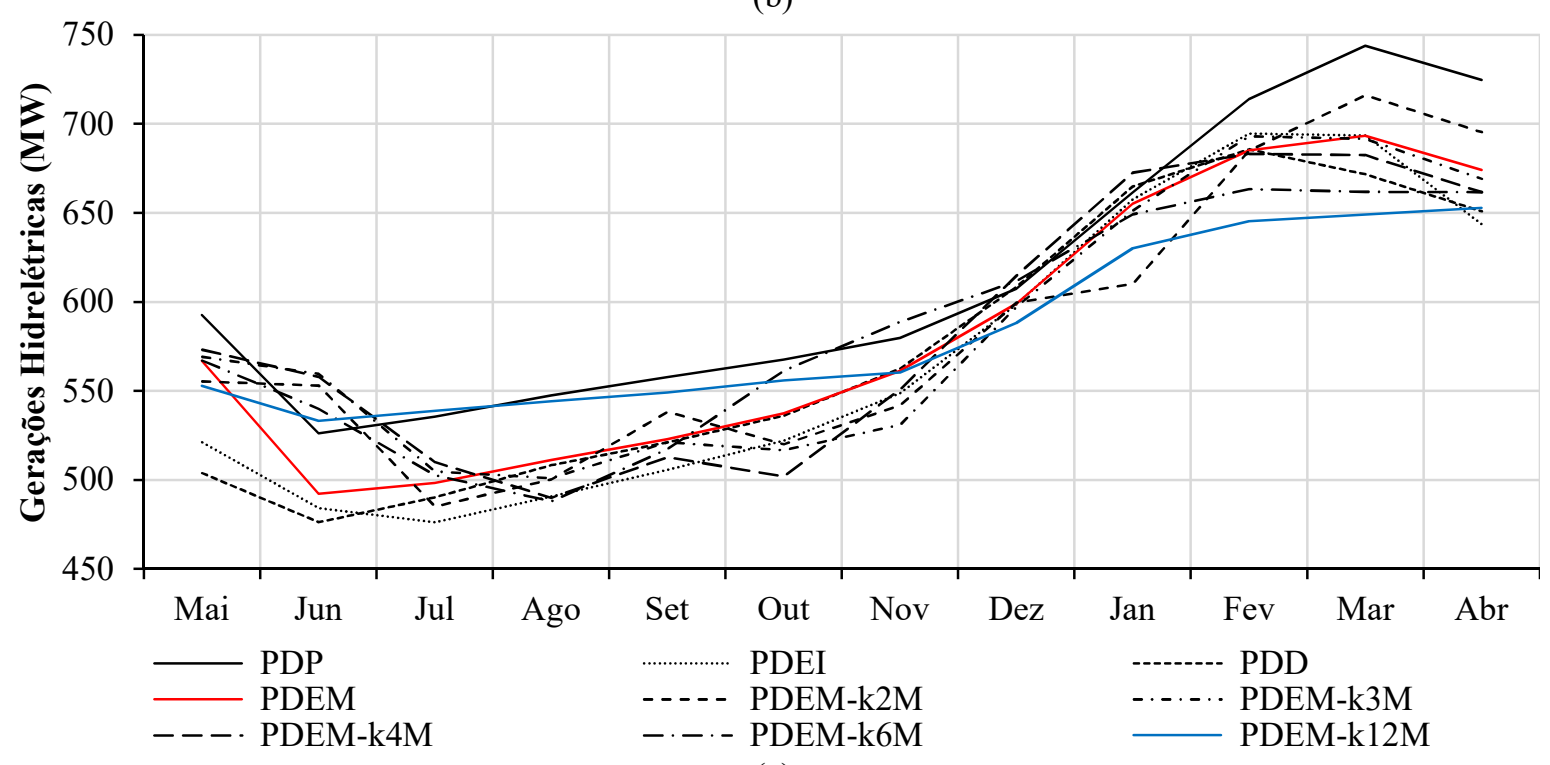

(c)

Figura 55 - Gerações hidrelétricas médias na usina hidrelétrica de Foz do Areia (a), Serra da Mesa (b) e Sobradinho (c). 
Tabela 25 - Resultados médios comparativos para a usina hidrelétrica de Foz do Areia - utilização da água em estatísticas de eficiência e produtividade.

\begin{tabular}{|c|c|c|c|c|}
\hline & $\begin{array}{c}\text { Turbinagem } \\
\qquad\left(\mathrm{m}^{3} / \mathrm{s}\right)\end{array}$ & $\begin{array}{l}\text { Vertimento } \\
\qquad\left(\mathrm{m}^{3} / \mathrm{s}\right)\end{array}$ & $\begin{array}{c}\text { Eficiência } \\
(\%)\end{array}$ & $\begin{array}{l}\text { Produtividade } \\
\left(\mathrm{MW} / \mathrm{m}^{3} / \mathrm{s}\right)\end{array}$ \\
\hline PDP & 637,7 & 16,2 & 97,46 & 1,4482 \\
\hline $\begin{array}{ll}\text { PDEI } & \\
& {[\%]} \\
\end{array}$ & $\begin{array}{rr}562,6 \\
\mathbf{- 1 1 , 7 8} \\
\end{array}$ & $\begin{array}{rr}91,9 & \\
& \mathbf{4 6 6 , 0} \\
\end{array}$ & 83,67 & $\begin{array}{c}1,3027 \\
\mathbf{- 1 0 , 0 4}\end{array}$ \\
\hline $\begin{array}{l}\text { PDD } \\
{[\%]}\end{array}$ & $\begin{array}{rr}511,3 & \\
& \mathbf{- 1 9 , 8 1}\end{array}$ & $\begin{array}{ll}142,5 & \\
& \mathbf{7 7 7 , 6}\end{array}$ & 72,13 & $\begin{array}{r}1,2904 \\
-\mathbf{1 0 , 8 9}\end{array}$ \\
\hline $\begin{array}{ll}\text { PDEM } & \\
& {[\%]} \\
\end{array}$ & $\begin{array}{rr}573,1 & \\
& -10,13 \\
\end{array}$ & $\begin{array}{ll}81,5 & \\
& 401,7 \\
\end{array}$ & 85,78 & $\begin{array}{r}1,3137 \\
\mathbf{- 9 , 2 9} \\
\end{array}$ \\
\hline $\begin{array}{r}\text { PDEM-k2 } \\
{[\%]}\end{array}$ & $\begin{array}{rr}577,5 & \\
& \mathbf{- 9 , 4 4} \\
\end{array}$ & $\begin{array}{ll}77,0 & \\
& \mathbf{3 7 4 , 4} \\
\end{array}$ & 86,67 & $\begin{array}{r}1,3190 \\
\quad \mathbf{8 , 9 2}\end{array}$ \\
\hline $\begin{array}{c}\text { PDEM-k2M } \\
{[\%]}\end{array}$ & $\begin{array}{rr}581,3 & \\
& \mathbf{- 8 , 8 4}\end{array}$ & $\begin{array}{rr}73,0 & \\
\quad \mathbf{3 4 9 , 3} \\
\end{array}$ & 87,44 & $\begin{array}{r}1,3351 \\
-7,81 \\
\end{array}$ \\
\hline $\begin{array}{l}\text { PDEM-k2P } \\
{[\mathbf{\%}]}\end{array}$ & $\begin{array}{ll}626,6 & \\
& \mathbf{- 1 , 7 3}\end{array}$ & 27,9 & 95,55 & $\begin{array}{r}1,3846 \\
-4,39\end{array}$ \\
\hline $\begin{array}{r}\text { PDEM-k3 } \\
{[\mathbf{[ \% ]}]}\end{array}$ & $\begin{array}{rr}574,9 & \\
& \mathbf{- 9 , 8 6}\end{array}$ & $\begin{array}{rr}79,6 & \\
& \mathbf{3 9 0}, 4\end{array}$ & 86,15 & $\begin{array}{r}1,3255 \\
\mathbf{- 8 , 4 7}\end{array}$ \\
\hline $\begin{array}{r}\text { PDEM-k3M } \\
{[\%]}\end{array}$ & $\begin{array}{rr}581,5 & \\
& \mathbf{- 8 , 8 6} \\
\end{array}$ & $\begin{array}{rr}73,0 & \\
& \mathbf{3 4 9 , 8} \\
\end{array}$ & 87,45 & $\begin{array}{r}1,3431 \\
-7,26\end{array}$ \\
\hline $\begin{array}{l}\text { PDEM-k3P } \\
{\left[\begin{array}{l}\% \\
0\end{array}\right.}\end{array}$ & $\begin{array}{ll}634,4 & \\
& \mathbf{- 0 , 5 2} \\
\end{array}$ & 20,0 & 96,85 & $\begin{array}{r}1,4207 \\
\mathbf{- 1 , 9 0} \\
\end{array}$ \\
\hline $\begin{array}{r}\text { PDEM-k4 } \\
{[\mathbf{\%}]}\end{array}$ & $\begin{array}{ll}574,9 & \\
& \mathbf{- 9 , 8 5} \\
\end{array}$ & $\begin{array}{rr}79,5 & \\
& \mathbf{3 8 9 , 6} \\
\end{array}$ & 86,17 & $\begin{array}{r}0,3299 \\
\mathbf{- 8 , 1 7}\end{array}$ \\
\hline $\begin{array}{l}\text { PDEM-k4M } \\
{[\%]}\end{array}$ & $\begin{array}{ll}581,5 & \\
& \mathbf{- 8 , 8 1}\end{array}$ & $\begin{array}{rr}72,7 & \\
& \mathbf{3 4 7 , 5 1}\end{array}$ & 87,50 & $\begin{array}{r}1,3498 \\
-6,79\end{array}$ \\
\hline $\begin{array}{r}\text { PDEM-k4P } \\
{[\%]}\end{array}$ & $\begin{array}{ll}637,2 & \\
& \mathbf{- 0 , 0 8} \\
\end{array}$ & 17,1 & 97,32 & $\begin{array}{r}1,4475 \\
-\mathbf{0 , 0 4} \\
\end{array}$ \\
\hline $\begin{array}{l}\text { PDEM-k6 } \\
{[\%]}\end{array}$ & $\begin{array}{rr}575,4 & \\
& \mathbf{- 9 , 7 7} \\
\end{array}$ & $\begin{array}{rr}79,1 & \\
& \mathbf{3 8 6 , 8} \\
\end{array}$ & 86,25 & $\begin{array}{r}1,3297 \\
\mathbf{- 8 , 1 9}\end{array}$ \\
\hline $\begin{array}{r}\text { PDEM-k6M } \\
{[\%]}\end{array}$ & $\begin{array}{r}580,4 \\
\mathbf{- 8 , 9 8}\end{array}$ & $\begin{array}{rr}73,7 & \\
& \mathbf{3 5 3}, 9\end{array}$ & 87,30 & $\begin{array}{r}1,3573 \\
-6,28 \\
\end{array}$ \\
\hline $\begin{array}{l}\text { PDEM-k6P } \\
{[\%]}\end{array}$ & 638,1 & 16,2 & 97,46 & $\begin{array}{r}1,4710 \\
1,57 \\
\end{array}$ \\
\hline $\begin{array}{r}\text { PDEM-k12 } \\
\text { [\%] }\end{array}$ & $\begin{array}{rr}575,7 & \\
& \mathbf{- 9 , 7 2} \\
\end{array}$ & $\begin{array}{rr}78,8 & \\
& \mathbf{3 8 5 , 3} \\
\end{array}$ & 86,31 & $\begin{array}{r}1,3300 \\
\mathbf{- 8 , 1 6} \\
\end{array}$ \\
\hline $\begin{array}{r}\text { PDEM-k12M } \\
{[\%]}\end{array}$ & $\begin{array}{rr}580,7 & \\
& \mathbf{- 8 , 9 4}\end{array}$ & $\begin{array}{r}73,5 \\
\quad 352,7 \\
\end{array}$ & 87,34 & $\begin{array}{r}1,3605 \\
-6,05\end{array}$ \\
\hline $\begin{array}{r}\text { PDEM-k12P } \\
{[\mathbf{\%}]}\end{array}$ & $\begin{array}{ll}638,4 & \\
& \mathbf{0 , 1 1} \\
\end{array}$ & 16,0 & 97,49 & $\begin{array}{r}1,4737 \\
\mathbf{1 , 7 9} \\
\end{array}$ \\
\hline
\end{tabular}


Tabela 26 - Resultados comparativos para a usina hidrelétrica de Foz do Areia - custos e geração hidrelétrica.

\begin{tabular}{|c|c|c|c|c|c|c|}
\hline & \multicolumn{2}{|c|}{$\begin{array}{c}\text { Geração Hidrelétrica } \\
\text { (MW) }\end{array}$} & \multicolumn{4}{|c|}{$\begin{array}{c}\text { Custos } \\
(\$)\end{array}$} \\
\hline & Média & $\begin{array}{l}\text { Desvio } \\
\text { Padrão }\end{array}$ & $\begin{array}{l}\text { Totais } \\
\left(* 10^{\wedge} 6\right)\end{array}$ & $\begin{array}{c}P D D \\
(\%)\end{array}$ & $\begin{array}{c}P D E M \\
(\%)\end{array}$ & $\begin{array}{c}P D D / P D E M \\
(\%)\end{array}$ \\
\hline PDP & 751,4 & 310,1 & 9,73 & 0,00 & $-15,66$ & $-100,00$ \\
\hline PDEI & $\begin{array}{l}636,9 \\
\mathbf{- 1 5 , 2 5} \\
\end{array}$ & $\begin{array}{l}259,9 \\
\mathbf{- 1 6 , 1 8} \\
\end{array}$ & 11,74 & 20,66 & 1,76 & 11,25 \\
\hline PDD & $\begin{array}{l}605,8 \\
-\mathbf{1 9 , 3 8}\end{array}$ & $\begin{array}{l}214,4 \\
-\mathbf{3 0 , 8 6} \\
\end{array}$ & 12,19 & 25,27 & 5,65 & 36,10 \\
\hline PDEM & $\begin{array}{l}660,8 \\
-\mathbf{1 2 , 0 6}\end{array}$ & $\begin{array}{l}311,4 \\
\mathbf{0 , 4 2}\end{array}$ & 11,54 & 18,57 & 0,00 & 0,00 \\
\hline PDEM-k2 & $\begin{array}{r}669,8 \\
-\mathbf{1 0 , 8 7}\end{array}$ & $\begin{array}{r}334,0 \\
7,69\end{array}$ & 11,50 & 18,19 & $-0,32$ & $-2,02$ \\
\hline $\begin{array}{l}\text { PDEM-k2M } \\
{[\%]}\end{array}$ & $\begin{array}{l}671,7 \\
-\mathbf{- 1 0 , 6 2} \\
\end{array}$ & $\begin{array}{r}333,8 \\
7,63\end{array}$ & 11,46 & 17,78 & $-0,66$ & $-4,23$ \\
\hline PDEM-k2P & $\begin{array}{r}726,9 \\
-\mathbf{3 , 2 7} \\
\end{array}$ & $\begin{array}{r}355,8 \\
\mathbf{1 4 , 7 5} \\
\end{array}$ & 10,51 & 8,04 & $-8,88$ & $-56,72$ \\
\hline PDEM-k3 & $\begin{array}{l}670,5 \\
\mathbf{- 1 0 , 7 7}\end{array}$ & $\begin{array}{r}336,3 \\
\mathbf{8 , 4 4}\end{array}$ & 11,50 & 18,21 & $-0,30$ & $-1,92$ \\
\hline $\begin{array}{l}\text { PDEM-k3M } \\
{[\%]}\end{array}$ & $\begin{array}{l}673,4 \\
-\mathbf{1 0 , 3 9}\end{array}$ & $\begin{array}{r}332,0 \\
\mathbf{7 , 0 4}\end{array}$ & 11,41 & 17,29 & $-1,08$ & $-6,88$ \\
\hline PDEM-k3P & $\begin{array}{r}734,2 \\
-\mathbf{2}, \mathbf{3 0} \\
\end{array}$ & $\begin{array}{r}332,4 \\
7,19 \\
\end{array}$ & 10,20 & 4,89 & $-11,54$ & $-73,66$ \\
\hline PDEM-k4 & $\begin{array}{l}672,7 \\
-\mathbf{1 0 , 4 8}\end{array}$ & $\begin{array}{r}338,6 \\
\mathbf{9 , 1 8}\end{array}$ & 11,47 & 17,91 & $-0,56$ & $-3,55$ \\
\hline $\begin{array}{l}\text { PDEM-k4M }[\%] \\
{[\%]}\end{array}$ & $\begin{array}{l}675,5 \\
-\mathbf{1 0 , 1 0}\end{array}$ & $\begin{array}{r}331,8 \\
\mathbf{7 , 0 1}\end{array}$ & 11,37 & 16,84 & $-1,46$ & $-9,32$ \\
\hline PDEM-k4P & $\begin{array}{r}\text { 737,1 } \\
\mathbf{- 1 , 9 1} \\
\end{array}$ & $\begin{array}{r}311,5 \\
\mathbf{0 , 4 4} \\
\end{array}$ & 10,01 & 2,91 & $-13,21$ & $-84,33$ \\
\hline PDEM-k6 & $\begin{array}{l}674,3 \\
-\mathbf{1 0 , 2 6}\end{array}$ & $\begin{array}{r}338,2 \\
\mathbf{9 , 0 6}\end{array}$ & 11,44 & 17,54 & $-0,87$ & $-5,55$ \\
\hline PDEM-k6M & $\begin{array}{l}676,1 \\
\mathbf{- 1 0 , 0 3}\end{array}$ & $\begin{array}{r}331,0 \\
\mathbf{6 , 7 4}\end{array}$ & 11,35 & 16,66 & $-1,61$ & $-10,25$ \\
\hline PDEM-k6P & $\begin{array}{r}740,0 \\
-\mathbf{1 , 5 3} \\
\end{array}$ & $\begin{array}{l}291,5 \\
-\mathbf{6 , 0 0}\end{array}$ & 9,83 & 1,07 & $-14,76$ & $-94,23$ \\
\hline PDEM-k12 & $\begin{array}{l}675,2 \\
-\mathbf{1 0 , 1 5}\end{array}$ & $\begin{array}{r}339,3 \\
\mathbf{9 , 4 0}\end{array}$ & 11,43 & 17,43 & $-0,96$ & $-6,11$ \\
\hline $\begin{array}{l}\text { PDEM-k12M } \\
{[\%]}\end{array}$ & $\begin{array}{r}677,1 \\
-9,89\end{array}$ & $\begin{array}{r}331,0 \\
\mathbf{6 , 7 5}\end{array}$ & 11,33 & 16,45 & $-1,79$ & $-11,42$ \\
\hline 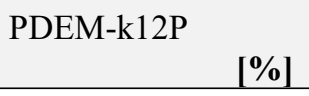 & $\begin{array}{r}741,7 \\
\mathbf{- 1 , 3 0} \\
\end{array}$ & $\begin{array}{r}285,5 \\
-7,94 \\
\end{array}$ & 9,76 & 0,36 & $-15,35$ & $-98,05$ \\
\hline
\end{tabular}


Tabela 27 - Resultados médios comparativos para a usina hidrelétrica de Serra da Mesa - utilização da água em estatísticas de eficiência e produtividade.

\begin{tabular}{|c|c|c|c|c|}
\hline & $\begin{array}{c}\text { Turbinagem } \\
\qquad\left(\mathrm{m}^{3} / \mathrm{s}\right)\end{array}$ & $\begin{array}{l}\text { Vertimento } \\
\left(\mathrm{m}^{3} / \mathrm{s}\right)\end{array}$ & $\begin{array}{c}\text { Eficiência } \\
(\%)\end{array}$ & $\begin{array}{l}\text { Produtividade } \\
\left(\mathrm{MW} / \mathrm{m}^{3} / \mathrm{s}\right)\end{array}$ \\
\hline PDP & 774,4 & 0,0 & 100,00 & 1,9710 \\
\hline $\begin{array}{ll}\text { PDEI } & \\
& {[\%]} \\
\end{array}$ & $\begin{array}{rr}736,4 & \\
& \mathbf{- 4 , 9 0} \\
\end{array}$ & 40,0 & 94,57 & $\begin{array}{r}1,8564 \\
\mathbf{- 5 , 8 2} \\
\end{array}$ \\
\hline $\begin{array}{ll}\text { PDD } & \\
& {[\%]}\end{array}$ & $\begin{array}{ll}723,6 & \\
& \mathbf{- 6 , 5 6} \\
\end{array}$ & 51,5 & 92,88 & $\begin{array}{r}1,8374 \\
-6,78 \\
\end{array}$ \\
\hline $\begin{array}{ll}\text { PDEM } & \\
& {[\%]} \\
\end{array}$ & $\begin{array}{rr}741,1 & \\
& -4,30 \\
\end{array}$ & 35,6 & 95,20 & $\begin{array}{r}1,8579 \\
-\mathbf{5 , 7 4} \\
\end{array}$ \\
\hline $\begin{array}{r}\text { PDEM-k2 } \\
{[\%]}\end{array}$ & $\begin{array}{ll}739,8 & \\
& \mathbf{- 4 , 4 7} \\
\end{array}$ & 36,5 & 95,07 & $\begin{array}{r}1,8631 \\
\quad \mathbf{- 5 , 4 8}\end{array}$ \\
\hline $\begin{array}{c}\text { PDEM-k2M } \\
{[\%]}\end{array}$ & $\begin{array}{ll}740,9 & \\
& \mathbf{- 4 , 3 3}\end{array}$ & 35,7 & 95,18 & $\begin{array}{r}1,8627 \\
\quad \mathbf{5 , 5 0} \\
\end{array}$ \\
\hline $\begin{array}{r}\text { PDEM-k2P } \\
{[\%]}\end{array}$ & $\begin{array}{rr}744,0 & \\
& -3,93 \\
\end{array}$ & 32,3 & 95,66 & $\begin{array}{r}18673 \\
-5,26 \\
\end{array}$ \\
\hline $\begin{array}{r}\text { PDEM-k3 } \\
{[\mathbf{[ \% ]}]}\end{array}$ & $\begin{array}{rr}743,3 & \\
& \mathbf{- 4 , 0 1}\end{array}$ & 33,8 & 95,45 & $\begin{array}{r}1,8186 \\
-7,73\end{array}$ \\
\hline $\begin{array}{r}\text { PDEM-k3M } \\
{[\%]}\end{array}$ & $\begin{array}{rr}742,5 & \\
& \mathbf{- 4 , 1 6}\end{array}$ & 34,5 & 95,35 & $\begin{array}{r}1,8582 \\
\mathbf{- 5 , 7 2}\end{array}$ \\
\hline $\begin{array}{l}\text { PDEM-k3P } \\
{\left[\begin{array}{l}\% \\
0\end{array}\right.}\end{array}$ & $\begin{array}{ll}747,4 & \\
& \mathbf{- 3 , 4 8} \\
\end{array}$ & 29,7 & 96,03 & $\begin{array}{r}1,8231 \\
-7,50 \\
\end{array}$ \\
\hline $\begin{array}{r}\text { PDEM-k4 } \\
{[\mathbf{\%}]}\end{array}$ & $\begin{array}{ll}743,3 & \\
& \mathbf{- 4 , 0 1} \\
\end{array}$ & 33,8 & 95,45 & $\begin{array}{r}0,7937 \\
\mathbf{- 8 , 9 9}\end{array}$ \\
\hline $\begin{array}{l}\text { PDEM-k4M } \\
{[\%]}\end{array}$ & $\begin{array}{ll}742,5 & \\
& -4,11\end{array}$ & 34,1 & 95,41 & $\begin{array}{r}1,8579 \\
-\mathbf{5 , 7 4}\end{array}$ \\
\hline $\begin{array}{l}\text { PDEM-k4P } \\
{[\%]}\end{array}$ & $\begin{array}{ll}748,1 & \\
& \mathbf{- 3 , 3 9}\end{array}$ & 29,0 & 96,12 & $\begin{array}{r}1,8008 \\
-8,64\end{array}$ \\
\hline $\begin{array}{l}\text { PDEM-k6 } \\
{[\%]}\end{array}$ & $\begin{array}{rr}743,9 & \\
& \mathbf{- 3 , 9 4} \\
\end{array}$ & 33,2 & 95,54 & $\begin{array}{r}1,7648 \\
-\mathbf{1 0 , 4 6}\end{array}$ \\
\hline $\begin{array}{r}\text { PDEM-k6M } \\
{[\%]}\end{array}$ & $\begin{array}{rr}743,9 & \\
& \mathbf{- 3 , 9 4}\end{array}$ & 32,7 & 95,60 & $\begin{array}{r}1,8606 \\
-\mathbf{5 , 6 0} \\
\end{array}$ \\
\hline $\begin{array}{l}\text { PDEM-k6P } \\
{[\%]}\end{array}$ & $\begin{array}{ll}752,5 & \\
& -\mathbf{2 , 8 2} \\
\end{array}$ & 24,6 & 96,73 & $\begin{array}{r}1,7870 \\
\mathbf{- 9 , 3 4} \\
\end{array}$ \\
\hline $\begin{array}{r}\text { PDEM-k12 } \\
\text { [\%] }\end{array}$ & $\begin{array}{rr}742,0 & \\
& \mathbf{- 4 , 1 9} \\
\end{array}$ & 34,1 & 95,40 & $\begin{array}{r}1,7913 \\
-\mathbf{9 , 1 2}\end{array}$ \\
\hline $\begin{array}{r}\text { PDEM-k12M } \\
{[\%]}\end{array}$ & $\begin{array}{rr}744,6 & \\
& -\mathbf{3 , 8 5} \\
\end{array}$ & 31,8 & 95,73 & $\begin{array}{r}1,8730 \\
-4,97\end{array}$ \\
\hline $\begin{array}{r}\text { PDEM-k12P } \\
{[\mathbf{\%}]}\end{array}$ & $\begin{array}{ll}762,2 & \\
& \mathbf{- 1 , 5 8} \\
\end{array}$ & 13,9 & 98,18 & $\begin{array}{r}1,8570 \\
-\mathbf{5 , 7 8}\end{array}$ \\
\hline
\end{tabular}


Tabela 28 - Resultados comparativos para a usina hidrelétrica de Serra da Mesa - custos e geração hidrelétrica.

\begin{tabular}{|c|c|c|c|c|c|c|}
\hline & \multicolumn{2}{|c|}{$\begin{array}{c}\text { Geração Hidrelétrica } \\
\text { (MW) }\end{array}$} & \multicolumn{4}{|c|}{$\begin{array}{c}\text { Custos } \\
(\$)\end{array}$} \\
\hline & Média & $\begin{array}{l}\text { Desvio } \\
\text { Padrão }\end{array}$ & $\begin{array}{l}\text { Totais } \\
\left(* 10^{\wedge} 6\right)\end{array}$ & $\begin{array}{c}P D D \\
(\%)\end{array}$ & $\begin{array}{c}P D E M \\
(\%)\end{array}$ & $\begin{array}{c}P D D / P D E M \\
(\%)\end{array}$ \\
\hline PDP & 832,20 & 155,1 & 2,25 & 0,00 & $-14,61$ & $-100,00$ \\
\hline PDEI & $\begin{array}{r}785,95 \\
\mathbf{- 5 , 5 6} \\
\end{array}$ & $\begin{array}{r}143,2 \\
-\mathbf{7 , 6 9} \\
\end{array}$ & 2,66 & 17,97 & 0,73 & 5,01 \\
\hline PDD & $\begin{array}{r}784,86 \\
\mathbf{- 5 , 6 9} \\
\end{array}$ & $\begin{array}{r}153,9 \\
\mathbf{- 0 , 7 9}\end{array}$ & 2,70 & 19,90 & 2,38 & 16,30 \\
\hline PDEM & $\begin{array}{r}790,50 \\
\mathbf{- 5 , 0 1} \\
\end{array}$ & $\begin{array}{r}151,8 \\
-\mathbf{2}, \mathbf{1 4} \\
\end{array}$ & 2,64 & 17,11 & 0,00 & 0,00 \\
\hline PDEM-k2 & $\begin{array}{r}792,16 \\
-\mathbf{4 , 8 1}\end{array}$ & $\begin{array}{r}166,1 \\
7,06\end{array}$ & 2,67 & 18,44 & 1,13 & 7,77 \\
\hline PDEM-k2M & $\begin{array}{r}791,40 \\
-4,90\end{array}$ & $\begin{array}{r}156,0 \\
\mathbf{0 , 5 4}\end{array}$ & 2,64 & 17,29 & 0,16 & 1,07 \\
\hline PDEM-k2P & $\begin{array}{r}796,97 \\
\mathbf{- 4 , 2 3} \\
\end{array}$ & $\begin{array}{r}170,4 \\
\mathbf{9 , 8 2} \\
\end{array}$ & 2,63 & 16,99 & $-0,10$ & $-0,68$ \\
\hline PDEM-k3 & $\begin{array}{r}791,92 \\
-\mathbf{4 , 8 4}\end{array}$ & $\begin{array}{r}162,5 \\
\mathbf{4 , 7 7}\end{array}$ & 2,66 & 18,01 & 0,77 & 5,28 \\
\hline PDEM-k3M & $\begin{array}{r}792,36 \\
-\mathbf{4}, \mathbf{7 9}\end{array}$ & $\begin{array}{r}156,9 \\
\mathbf{1 , 1 0}\end{array}$ & 2,63 & 16,99 & $-0,10$ & $-0,66$ \\
\hline PDEM-k3P & $\begin{array}{r}796,52 \\
\mathbf{- 4 , 2 9} \\
\end{array}$ & $\begin{array}{r}168,0 \\
\mathbf{8 , 3 0} \\
\end{array}$ & 2,63 & 16,83 & $-0,24$ & $-1,65$ \\
\hline PDEM-k4 & $\begin{array}{r}792,51 \\
-4,77\end{array}$ & $\begin{array}{r}169,7 \\
\mathbf{9 , 4 1}\end{array}$ & 2,68 & 18,84 & 1,48 & 10,14 \\
\hline PDEM-k4M & $\begin{array}{r}793,25 \\
-4,68\end{array}$ & $\begin{array}{r}158,4 \\
\mathbf{2}, \mathbf{1 1}\end{array}$ & 2,63 & 16,83 & $-0,24$ & $-1,62$ \\
\hline PDEM-k4P & $\begin{array}{r}797,92 \\
\mathbf{- 4 , 1 2} \\
\end{array}$ & $\begin{array}{r}175,3 \\
\mathbf{1 2 , 9 9} \\
\end{array}$ & 2,64 & 17,35 & 0,21 & 1,42 \\
\hline PDEM-k6 & $\begin{array}{r}793,40 \\
-4,66\end{array}$ & $\begin{array}{r}176,3 \\
\mathbf{1 3 , 6 7}\end{array}$ & 2,69 & 19,49 & 2,03 & 13,91 \\
\hline PDEM-k6M & $\begin{array}{r}795,38 \\
-\mathbf{4 , 4 2}\end{array}$ & $\begin{array}{r}161,7 \\
\mathbf{4 , 2 5}\end{array}$ & 2,62 & 16,38 & $-0,62$ & $-4,26$ \\
\hline PDEM-k6P & $\begin{array}{r}802,97 \\
\mathbf{- 3 , 5 1}\end{array}$ & $\begin{array}{r}183,4 \\
\mathbf{1 8 , 1 9}\end{array}$ & 2,62 & 16,49 & $-0,53$ & $-3,63$ \\
\hline PDEM-k12 & $\begin{array}{r}796,35 \\
\mathbf{- 4 , 3 1}\end{array}$ & $\begin{array}{r}182,8 \\
\mathbf{1 7 , 8 5}\end{array}$ & 2,69 & 19,26 & 1,83 & 12,56 \\
\hline $\begin{array}{l}\text { PDEM-k12M } \\
{[\%]}\end{array}$ & $\begin{array}{r}797,54 \\
-4,16\end{array}$ & $\begin{array}{r}165,3 \\
6,57\end{array}$ & 2,61 & 15,97 & $-0,97$ & $-6,63$ \\
\hline PDEM-k12P & $\begin{array}{r}818,31 \\
\mathbf{- 1 , 6 7} \\
\end{array}$ & $\begin{array}{r}189,5 \\
\mathbf{2 2 , 1 6} \\
\end{array}$ & 2,50 & 11,06 & $-5,17$ & $-35,37$ \\
\hline
\end{tabular}


Tabela 29 - Resultados médios comparativos para a usina hidrelétrica de Sobradinho - utilização da água em estatísticas de eficiência e produtividade.

\begin{tabular}{|c|c|c|c|c|}
\hline & $\begin{array}{l}\text { Turbinagem } \\
\qquad\left(\mathrm{m}^{3} / \mathrm{s}\right)\end{array}$ & $\begin{array}{l}\text { Vertimento } \\
\left(\mathrm{m}^{3} / \mathrm{s}\right)\end{array}$ & $\begin{array}{c}\text { Eficiência } \\
(\%)\end{array}$ & $\begin{array}{l}\text { Produtividade } \\
\left(\mathrm{MW} / \mathrm{m}^{3} / \mathrm{s}\right)\end{array}$ \\
\hline PDP & 2555,6 & 99,5 & 96,11 & 0,3264 \\
\hline $\begin{array}{ll}\text { PDEI } & \\
& {[\%]} \\
\end{array}$ & 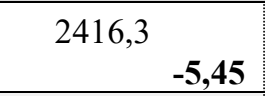 & $\begin{array}{|ll|}241,7 & \\
& \mathbf{1 4 2 , 8} \\
\end{array}$ & 90,00 & $\begin{array}{r}0,2996 \\
\mathbf{- 8 , 2 1} \\
\end{array}$ \\
\hline $\begin{array}{ll}\text { PDD } & \\
& {[\%]} \\
\end{array}$ & 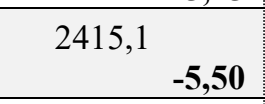 & $\begin{array}{|ll|}242,5 & \\
& \mathbf{1 4 3 , 7} \\
\end{array}$ & 89,96 & $\begin{array}{r}0,3045 \\
-6,71 \\
\end{array}$ \\
\hline $\begin{array}{ll}\text { PDEM } & \\
& {[\%]} \\
\end{array}$ & 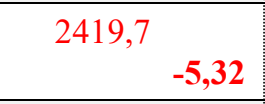 & $\begin{array}{|ll|}237,1 & \\
& \mathbf{1 3 8 , 2} \\
\end{array}$ & 90,20 & $\begin{array}{r}0,3061 \\
-6,23 \\
\end{array}$ \\
\hline $\begin{array}{r}\text { PDEM-k2 } \\
{[\%]}\end{array}$ & \begin{tabular}{|r|}
2435,7 \\
\\
\end{tabular} & 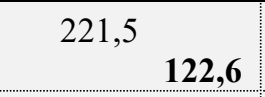 & 90,91 & $\begin{array}{r}0,3045 \\
\quad \mathbf{6 , 7 4}\end{array}$ \\
\hline $\begin{array}{r}\text { PDEM-k2M } \\
{[\%]}\end{array}$ & $\begin{array}{rr}2421,9 \\
\quad-5,23 \\
\end{array}$ & \begin{tabular}{|rr}
235,0 & \\
& $\mathbf{1 3 6 , 2}$ \\
\end{tabular} & 90,30 & $\begin{array}{r}0,3073 \quad \\
\quad \mathbf{5 , 8 6} \\
\end{array}$ \\
\hline $\begin{array}{r}\text { PDEM-k2P } \\
{[\%]} \\
\end{array}$ & $\begin{array}{rr}2462,7 & \\
& \mathbf{- 3 , 6 4} \\
\end{array}$ & $\begin{array}{rr}194,5 & \\
& \mathbf{9 5 , 5} \\
\end{array}$ & 92,10 & $\begin{array}{r}0,3072 \\
-\mathbf{5 , 9 1} \\
\end{array}$ \\
\hline $\begin{array}{cc}\text { PDEM-k3 } & \\
& {[\%]}\end{array}$ & $\begin{array}{rr}2432,8 & \\
& \mathbf{- 4 , 8 1}\end{array}$ & \begin{tabular}{ll|}
224,6 & \\
& $\mathbf{1 2 5 , 7}$
\end{tabular} & 90,77 & $\begin{array}{r}0,3017 \\
\mathbf{- 7 , 5 8}\end{array}$ \\
\hline $\begin{array}{r}\text { PDEM-k3M } \\
{[\%]}\end{array}$ & $\begin{array}{rr}2440,6 & \\
& -4,50\end{array}$ & 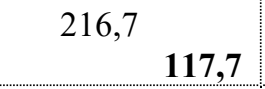 & 91,12 & $\begin{array}{r}0,3069 \\
\mathbf{- 5 , 9 9}\end{array}$ \\
\hline $\begin{array}{r}\text { PDEM-k3P } \\
{[\mathbf{\%}]}\end{array}$ & \begin{tabular}{|r|}
2468,4 \\
\\
$-\mathbf{3 , 4 1}$ \\
\end{tabular} & $\begin{array}{|rr|}189,0 & \\
& \mathbf{8 9 , 9} \\
\end{array}$ & 92,34 & $\begin{array}{r}0,3058 \\
-6,33 \\
\end{array}$ \\
\hline $\begin{array}{r}\text { PDEM-k4 } \\
{[\mathbf{\%}]}\end{array}$ & 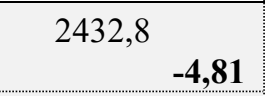 & $\begin{array}{|ll|}224,5 & \\
& \mathbf{1 2 5 , 6} \\
\end{array}$ & 90,77 & $\begin{array}{r}0,3002 \\
\mathbf{- 8 , 0 5}\end{array}$ \\
\hline $\begin{array}{r}\text { PDEM-k4M } \\
{[\%]}\end{array}$ & \begin{tabular}{|ll}
2447,0 & \\
& $-4,25$ \\
\end{tabular} & $\begin{array}{|ll|}210,4 & \\
& \mathbf{1 1 1 , 4} \\
\end{array}$ & 91,40 & $\begin{array}{r}0,3060 \\
-6,28\end{array}$ \\
\hline $\begin{array}{r}\text { PDEM-k4P } \\
{[\%]}\end{array}$ & $\begin{array}{|rr|}2479,8 & \\
& \mathbf{- 2 , 9 7} \\
\end{array}$ & $\begin{array}{|ll|}177,7 & \\
& \mathbf{7 8 , 5} \\
\end{array}$ & 92,83 & $\begin{array}{r}0,3062 \\
-6,19 \\
\end{array}$ \\
\hline $\begin{array}{rr}\text { PDEM-k6 } \\
\\
{[\%]}\end{array}$ & 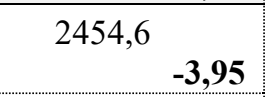 & $\begin{array}{|ll|}202,6 & \\
& \mathbf{1 0 3 , 6} \\
\end{array}$ & 91,75 & $\begin{array}{r}0,3040 \\
-\mathbf{6 , 8 8}\end{array}$ \\
\hline $\begin{array}{r}\text { PDEM-k6M } \\
{[\%]}\end{array}$ & $\begin{array}{rr}2464,4 & \\
& -3,57 \\
\end{array}$ & 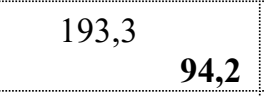 & 92,16 & $\begin{array}{r}0,3091 \\
\quad-5,30 \\
\end{array}$ \\
\hline $\begin{array}{r}\text { PDEM-k6P } \\
{[\%]}\end{array}$ & \begin{tabular}{|rr}
2521,6 & \\
& $\mathbf{- 1 , 3 3}$ \\
\end{tabular} & $\begin{array}{|ll|}135,8 & \\
& \mathbf{3 6 , 5} \\
\end{array}$ & 94,61 & $\begin{array}{r}0,3164 \\
\mathbf{- 3 , 0 8} \\
\end{array}$ \\
\hline $\begin{array}{r}\text { PDEM-k12 } \\
{[\mathbf{\%}]}\end{array}$ & $\begin{array}{rr}2479,7 & \\
& \mathbf{- 2 , 9 7} \\
\end{array}$ & 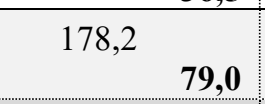 & 92,81 & 0,3113 \\
\hline $\begin{array}{r}\text { PDEM-k12M } \\
{[\%]}\end{array}$ & $\begin{array}{rr}2476,2 & \\
& -3,11\end{array}$ & \begin{tabular}{ll|}
181,7 & \\
& $\mathbf{8 2 , 5}$
\end{tabular} & 92,66 & $\begin{array}{r}0,3137 \\
-\mathbf{3 , 9 1}\end{array}$ \\
\hline $\begin{array}{r}\text { PDEM-k12P } \\
{[\%]}\end{array}$ & $\begin{array}{ll}2556,2 & \\
& \mathbf{0 , 0 2} \\
\end{array}$ & 101,7 & 96,02 & $\begin{array}{r}0,3286 \\
\mathbf{0 , 6 7}\end{array}$ \\
\hline
\end{tabular}


Tabela 30 - Resultados comparativos para a usina hidrelétrica de Sobradinho - custos e geração hidrelétrica.

\begin{tabular}{|c|c|c|c|c|c|c|}
\hline & \multicolumn{2}{|c|}{$\begin{array}{c}\text { Geração Hidrelétrica } \\
\text { (MW) }\end{array}$} & \multicolumn{4}{|c|}{$\begin{array}{c}\text { Custos } \\
(\$)\end{array}$} \\
\hline & Média & $\begin{array}{l}\text { Desvio } \\
\text { Padrão }\end{array}$ & $\begin{array}{l}\text { Totais } \\
\left(* 10^{\wedge} 6\right)\end{array}$ & $\begin{array}{c}P D D \\
(\%)\end{array}$ & $\begin{array}{c}P D E M \\
(\%)\end{array}$ & $\begin{array}{c}P D D / P D E M \\
(\%)\end{array}$ \\
\hline PDP & 612,55 & 133,7 & 2,14 & 0,00 & $-13,71$ & $-100,00$ \\
\hline PDEI & $\begin{array}{r}570,12 \\
-6,93 \\
\end{array}$ & $\begin{array}{r}147,5 \\
\mathbf{1 0 , 2 8} \\
\end{array}$ & 2,58 & 20,45 & 3,93 & 28,68 \\
\hline PDD & $\begin{array}{r}573,64 \\
-6,35\end{array}$ & $\begin{array}{r}153,2 \\
\mathbf{1 4 , 5 4}\end{array}$ & 2,56 & 19,66 & 3,25 & 23,72 \\
\hline PDEM & $\begin{array}{r}583,21 \\
-4,79 \\
\end{array}$ & $\begin{array}{r}156,9 \\
\mathbf{1 7 , 2 8} \\
\end{array}$ & 2,48 & 15,89 & 0,00 & 0,00 \\
\hline PDEM-k2 & $\begin{array}{r}585,63 \\
-4,39\end{array}$ & $\begin{array}{r}166,5 \\
\mathbf{2 4 , 5 2}\end{array}$ & 2,49 & 16,30 & 0,36 & 2,61 \\
\hline $\begin{array}{l}\text { PDEM-k2M } \\
{[\%]}\end{array}$ & $\begin{array}{r}583,62 \\
-4,72\end{array}$ & $\begin{array}{r}157,7 \\
\mathbf{1 7 , 9 3}\end{array}$ & 2,48 & 15,84 & $-0,05$ & $-0,33$ \\
\hline PDEM-k2P & $\begin{array}{r}592,82 \\
-\mathbf{3 , 2 2} \\
\end{array}$ & $\begin{aligned} 166,4 \\
\mathbf{2 4 , 4 2} \\
\end{aligned}$ & 2,42 & 13,12 & $-2,39$ & $-17,44$ \\
\hline PDEM-k3 & $\begin{array}{r}584,81 \\
-\mathbf{4 , 5 3}\end{array}$ & $\begin{array}{r}172,5 \\
\mathbf{2 8 , 9 7}\end{array}$ & 2,52 & 17,63 & 1,51 & 10,98 \\
\hline PDEM-k3M & $\begin{array}{r}584,03 \\
-4,66\end{array}$ & $\begin{array}{r}158,7 \\
\mathbf{1 8 , 6 9}\end{array}$ & 2,48 & 15,80 & $-0,07$ & $-0,53$ \\
\hline PDEM-k3P & $\begin{array}{r}594,13 \\
-\mathbf{3 , 0 1}\end{array}$ & $\begin{array}{l}169,1 \\
\mathbf{2 6 , 4 0}\end{array}$ & 2,42 & 12,97 & $-2,52$ & $-18,39$ \\
\hline PDEM-k4 & $\begin{array}{r}585,35 \\
-4,44\end{array}$ & $\begin{array}{l}179,3 \\
\mathbf{3 4 , 0 2}\end{array}$ & 2,54 & 18,53 & 2,28 & 16,61 \\
\hline $\begin{array}{l}\text { PDEM-k4M } \\
{[\%]}\end{array}$ & $\begin{array}{r}584,62 \\
-4,56\end{array}$ & $\begin{array}{l}159,7 \\
\mathbf{1 9 , 4 0}\end{array}$ & 2,48 & 15,69 & $-0,18$ & $-1,28$ \\
\hline PDEM-k4P & $\begin{array}{r}596,19 \\
-\mathbf{2 , 6 7} \\
\end{array}$ & $\begin{array}{r}172,2 \\
\mathbf{2 8 , 7 6} \\
\end{array}$ & 2,41 & 12,59 & $-2,85$ & $-20,77$ \\
\hline PDEM-k6 & $\begin{array}{r}586,98 \\
-\mathbf{4 , 1 7}\end{array}$ & $\begin{array}{r}181,2 \\
\mathbf{3 5 , 5 0}\end{array}$ & 2,53 & 18,14 & 1,95 & 14,20 \\
\hline PDEM-k6M & $\begin{array}{r}584,74 \\
-4,54\end{array}$ & $\begin{array}{r}158,3 \\
\mathbf{1 8 , 3 3}\end{array}$ & 2,47 & 15,41 & $-0,41$ & $-2,99$ \\
\hline PDEM-k6P & $\begin{array}{r}603,98 \\
\mathbf{- 1 , 4 0}\end{array}$ & $\begin{array}{r}162,9 \\
\mathbf{2 1}, \mathbf{7 7}\end{array}$ & 2,31 & 7,74 & $-7,03$ & $-51,27$ \\
\hline PDEM-k12 & $\begin{array}{r}583,41 \\
-4,76\end{array}$ & $\begin{array}{r}157,5 \\
\mathbf{1 7 , 7 4}\end{array}$ & 2,48 & 15,89 & 0,00 & 0,01 \\
\hline PDEM-k12M & $\begin{array}{r}583,60 \\
-4,73\end{array}$ & $\begin{array}{r}154,8 \\
\mathbf{1 5 , 7 7}\end{array}$ & 2,47 & 15,41 & $-0,41$ & $-3,01$ \\
\hline $\begin{array}{l}\text { PDEM-k12P } \\
{[\%]}\end{array}$ & $\begin{array}{r}607,73 \\
\mathbf{- 0 , 7 9}\end{array}$ & $\begin{array}{l}121,0 \\
\mathbf{- 9 , 5 2}\end{array}$ & 2,15 & 0,48 & $-13,30$ & $-97,00$ \\
\hline
\end{tabular}


